\title{
MASTER
}

\section{Contingency Plans for Chromium Utilization}

National Materials Advisory Board

Commission on Sociotechnical Systems

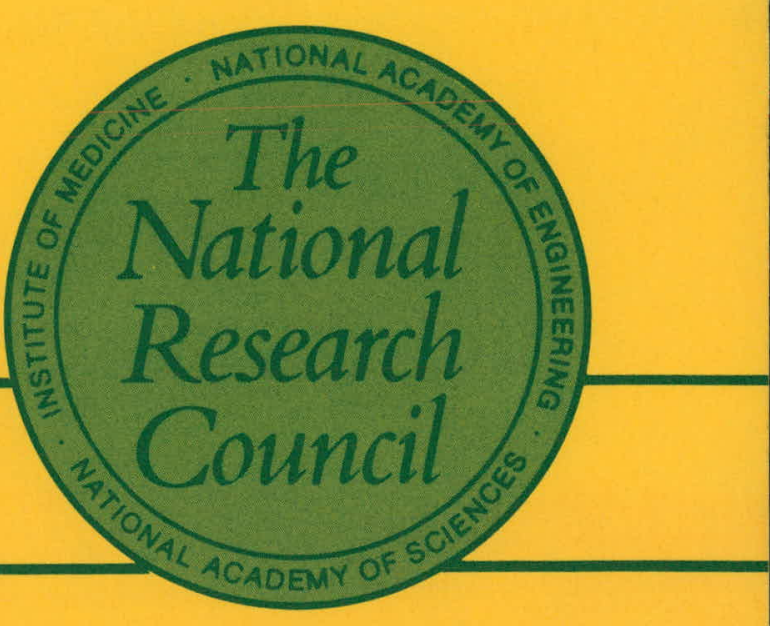




\section{DISCLAIMER}

This report was prepared as an account of work sponsored by an agency of the United States Government. Neither the United States Government nor any agency Thereof, nor any of their employees, makes any warranty, express or implied, or assumes any legal liability or responsibility for the accuracy, completeness, or usefulness of any information, apparatus, product, or process disclosed, or represents that its use would not infringe privately owned rights. Reference herein to any specific commercial product, process, or service by trade name, trademark, manufacturer, or otherwise does not necessarily constitute or imply its endorsement, recommendation, or favoring by the United States Government or any agency thereof. The views and opinions of authors expressed herein do not necessarily state or reflect those of the United States Government or any agency thereof. 


\section{DISCLAIMER}

Portions of this document may be illegible in electronic image products. Images are produced from the best available original document. 


\section{Contingency Plans for Chromium Utilization}

Report of the
Committee on Contingency Plans 9506773
for Chromium Utilization

NATIONAL MATERIALS ADVISORY BOARD

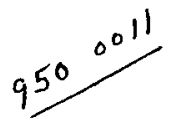

Commission on Sociotechnical Systems

National Research Council

NATIONAL ACADEMY OF SCIENCES

Washington, D.C. 1978

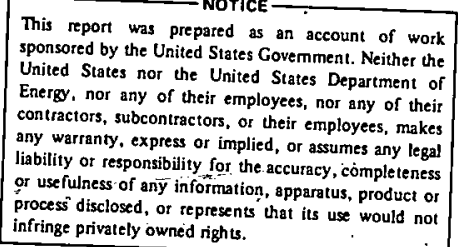




\section{NOTICE}

The project that is the subject of this report was approved by the Governing Board of the National Research Council, whose members are drawn from the councils of the National Academy of Sciences, the National Academy of Engineering, and the Institute of Medicine. The members of the committee responsible for the report were chosen for their special competence ana with regard for appropriate balance.

This report has been reviewed by a group other than the authors according to procedures approved by a Report Review Committee consisting of members of the National Academy of Sciences, the National Academy of Engineering, and the Institute of Medicine.

This study by the National Materials Advisory Board was conducted under Contract No. GS-OO-DS-(D)-94008 with the General Services Administration, the U.S. Bureau of Mines, and the National Aeronautics and space Administration, and Contract No. EY-76-C-02-2746 with the Department of Energy.

This report is available from the printing and Publishing office, National Academy of Sciences, 2101 Constitution Avenuc, N.W., Washington, D.C. 20418.

Publication NMAB-335

Library of Congress Catalog Card Number 77-95193

IInternational Śtanāard Book. Number 0-309-02737-3

Printed in the United States of America. 
THIS PAGE

\section{WAS INTENTIONALLY LEFT BLANK}


COMMITTEE ON CONTINGENC'́ PLANS FOP CHROMIUM UTILILATION

\section{Chaai프므}

EAPI R. PARKEF, Professor, Department of Mincral Technology, University of California, Berkeley

Members

MORTIMER D. APBOTT, Consultant, Buchanan Dam, Texas

HAROLD J. BARNETT, Profiessor, Department of Economics, Washington University, St. Louis, Missouri

JAMES C. BURROWS, Vice President and Senior Research Associate, Charles River Associates, Inc., Cambriăge, Massachusetts

SELWYN ENZER, Associate Director, Center for Futures Research, University of Southern California, Los Angeles

DAVID C. GOLDBERG, Manager, Materials and Engineering Department, Advanced Energy Systems Division, Westinghouse Electric Corporation, Pittsburgn, Pennsylvania

ROBIN I. JONES, Program Manager, Metallurgy, Materials Research Center, Stanforä Research Institute, Menlo Park, California

REMUS A. LULA, Assistant to Vice President-Technical Director, Allegheny Ludlum Corporation Pesearch Center. Brackenridge, Pennsylvania

EDWARD L. PEPPEF, Vice President Resource Consulting Section, Arthur D. Little. Inc., Cambridge, Massachusetts

ROBERT W. SMITH, Consultant, Flint, Michigan

\section{Liaison Pepresentatives}

MICHAEL BOZZELII, Federal Preparedness Agency, General Services Administration, Washington, D.C.

HARRIS BURTE, Acting Chief Scientist, Air Force Materials Laboratory, Wright-Patterson Air Force Base, Ohio

EDWARD J. DYCKMAN, Defense Industrial Resources Support Office, Cameron Station, Alexandria, Virginia

DONALD A. FINK, Federal Energy Aäministration, washington, D. C. 
ROBERT D. FRENCH, Army Materials and Mechanics Research Center, Watertown, Massachusetts

S. J. GIONFRIDDO, Acting Director, Market anō Technical services Division, General Services Aäministration. Washington, D.C.

LOUIS IANNIELLO, Materials Science Program, Division of Physical Research, Department of Energy, Washington, D.C.

WIILIAM J. KAESTNER, Materials Division, Bureau of Domestic Commerce, Department of Commerce, Washington, D.C.

JAMES H. KORDES, Office of Assistánt Secretary of Defense, The Pertagon, Washington, D. C.

JEROME KRUGER, Chief, Corrosion and Electroaeposition Section. National Bureau of Standarás, Department of commerce, Washington, D.C.

JOSEPH MAITZ, Materials and Structures Division, National Aeronautics and space Aäministration, Washington, D. C.

JOHN L: MORNING, U.S. Bureau of Mines, U.S. Department of the Interior, Washington, D.C.

ROBERT J. MPOCZEK, Federal Preparedness Agency, General Services Administration, Washington, D.C.

ANDREW S: PROKOPOVITSH, U.S. Bureau of Mines, U.S. Department of the Interior. Washington, D.C.

JOSEPH . STEPHENS, NASA-Lewis Research Center, Cleveland, Ohio

$\underline{\text { NMAB }}$ Staff

BEN A. KORNHAUSER, Staff Engineer

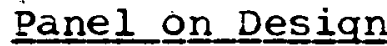

\section{Chairman}

DAVID C. GOLDBERG. Manager. Materials and Engineering Department, Aävancea Energy Systems Division. Westinghouse Electric Corporation, Pittsburgh, Pennsylvania

\section{Secretary}

MORTIMER D. ABEOTT, Consultant, Buchanan Dam, Texas 


\section{Members}

ROBERT T. ANDERSON, Technical Director, American Society for Nondestructive Testing, Columbus, Ohio

JAMES C. BURROWS, Vice President and Senior Research Associate, Charles River Associates, Inc., Cambridge, Massachusetts

JACK E. LaBELLE, Chief Metallurgist, Detroit Diesel Allisor. Division, General Motors Corporation, Detroit, Michigan

MICHAEL A. STREICHER, Research Fellow, DuPont Experimental Station, E. I. DuPont de Nemours $\varepsilon$ Company. Wilmington. Delaware

SETH E. WILSON, Principal Engineer, Materials and Processes, Boeing Aerospace Company, Seattle, Washington

\section{Panel on Processing}

\section{Chairman}

EDWARD I. PEPPER, Vice Presiāent, Resource consulting section, Arthur D. Iittle, Inc.; Cambriage, Massachusetts

\section{secretary}

RENE SCHLATTER, Manager of Research and Development, Latrobe Steel Company, Latrobe, Pennsylvania

\section{Members}

HAROLD N. BOGAFT, Director, Manufacturing Engineering and Quality Office, Ford Motor Company, Dearborn, Michigan

HALIOCK C. CAMPEELI, Manager, Education, American Welōing Society, Miami, Florida

ALBERT L. HOFFMANNER, Associate Manager, Metalworking section, Battelle Memorial Institute, Columbus, Ohio

NORMAN O. KATES, Vice President, Technology, Linäberg Corporation. Chicago, Illinois

HOWARD.W. PICKERING, Chairman, Metallurgy Section, Department of Materials Science, Pennsylvania state Univerșity, University Park, Pennsylvania 
INGO WALTER, Professor of Economics and Finance, Graduate School of Business Aäministration. New York University. New York, New York

\section{Panel on Substitution}

Chairman

ROBERT W. SMITH, Consultant, Flint, Michigan

\section{Vice Chäirmąn}

JACK H. WESTBROOK, Manager, Materials Information Services, Corporate Research and Development Center, General Electric Company. Schenectady. New York

\section{Secretary}

ROBIN L. JONES, Program Manager, Metallurgy, Materials kesearch Center. Stanford Research Institute, Menlo Park. California

\section{Members}

ROBERT BANNER, Manager, Research and Development and Technical Service, Chromium Chemicals Section, Divisional Technical Center. Diamond Shamrock Chemical Company. Painesville, Ohio

HAROLD J. BARNE'IT, professor, Department of Economics, Washington University. St. Louis, Missouri

MICHAEL P. FEDOCK, Assistant Head, Ceramics División, Research Center, Republic Steel Corporation, Clevelana, onio

S. FLOREEN, Research Fellow, International Nickel Company. Suffern, New York

FREDERICK A. LOWENHEIM, Technical. Writer and consultant, Plainfiela. New Jersey

REMUS A. LULA, Assistant to Vice President-Technical Director. Allegheny Ludlum Corporation Research Center. Brackenridge, Pennsylvania

M. SEMCHYSHEN, Manager, Market Development, Climax Molybdenum Corporation of Michigan; Ann Arbor, Michigan 


\section{PREFACE}

Many elements that possess unicue properties or impart unique properties when added to other materials are scarce and expensive ana. consequently, are used sparingly by materlal producers and Labricators. Chromium presents a different and unusual picture: It is an element that imparts unique properties to the material to which it is added, but it is not scarce anō its price has been relatively low until recent years. It plays a vital anā almost irreplaceable role in widely aisparate commoāities (e.g.. stainless steels, tool steels, wrought alloy steels. cast iron and steel, superalloys, refractories, coatings anā cladadings, pigments and paints, leather tanning chemicals. metal finishing chemicals, and árilling muds), and chromiumcontaining materials are used in a variety of hightechnology military and commercial applications.

Chromium, however, is a completely imported element with known commercial deposits concentrated in only a few countries: South Africa, 76.6 percent of deposits; Rhodesia, 20.6 percent; the USSR, 0.8 percent; Turkey, 0.2 percent; other sources. 1:8 percent. Given the global. political situation, the possibility of forming a chromium cartel that coula produce severe economic penalties anä industrial disruptions by interrupting U.S. chromium imports is of serious concern.

Realizing the gravity of the situation, the Department of Energy, U.S. Bureau of IMines, National Ae ronautics and Space Administration, and Federal Preparedness Agency (of the General Services Aaministration) sponsored this study by the National Materials Advisory Board of the National Academy of sciences to identify alternative means for reducing chromium consumption so that contingency programs for substitution, processing, and product design mignt be formulated well in advance of any chromium shortages.

As the Committee sought to identify alternative means for reducing chromium consumption, it concentrated primarily on: (1) the substitution of materials containing less or no chromium for chromium-containing materials (Dr. R. W. Smith, chairman). (2) the use of various production processes, that would eliminate or reduce the amount of chromium used and permit chromium recovery by recycling (Mr. E. I. Pepper, chairman), and (3) changes in component design that would eliminate or reduce the amount of chromium used (Mr. D. C. Golaberg. chairman). In assessing these alternatives, the 
Committee assumed the worst possible supply situation (i.e... a total embargo on all foreign sources of chromium ore and ferrochromium). The activities of the commitee and its Panels are āescribea in detail in chapter 2 of this report and its overview of the chromium supply and demand situation is presented in chapter 3. Chapters 4, 5, and 6 present detailed information on the design. processing, and substitution alternatives.

When the Panel drafts were completed, an overview group consisting of Dr. Earl R. Parker, Mr. Selwyn Enzer, Dr. Robin L. Jones, and the three panel chairmen met to discuss the overlap of ?anel material. to evaluate the results, and to discuss the summary of general conclusions and recommenaations, in adadition to principal consiajerations that emerged in the overview. The analyses and inputs of Mr. Enzer and Dr. Jones were particularly valuable in this phase.

In summary, this report is the product of the cooperation and expertise of all the individuals and companies cited in the Acknowledgments and is based on data collected through November 1976. 
The committee is indebted to the following individuals for their special contributions:

- Mr. Harvey E. Atkinson, Engineering Department, E. I. DuPont de Nemours and Company. for his presentation on the application of plastics in the chemical process plant of DuPont

- Dr. Henry. E. Frankel and Mr. S. J. Dapkunas of the Department of Energy for their presentations on the material requirements of coall gasification ana iquefaction systems

- Dr. Serge Gratch, Scientific Research Staff, Ford Motor Company. for his many contributions on present and potential applications of polymers for industrial uses

- Professor G. I. Kulcinski, Department of Nuclear Engineering. University of wisconsin, for his contribution on chromium consumption in the possible materials for fusion reactors

- Mr. Kenneth B. Higbie, Division of Solid Wastes, U.S. Bureau of Mines, for his presentation on the recycling of urban solid waste and Mr. P. Needham. U.S. Bureau of Mines, College Park, for his presentation on ion implantation

- Dr. Edward Hucke of the University of Michigan for his help on the chapter on substitution

- Mr. George Robinson of the General Motors Research Laboratories for his assistance on the chapter on substitution

- Dr. Gerald Scinneberger of the General Motors Institute for his help on the chapter on substitution

- Mr. Ralph M. Smailer of Lukens Steel Company for his presentation on, ana contributions concerning. clad steel manufacture and applications with respect to chromium utilization

- Mr. Albert J. wein of Steelmet, Inc.. for his general information on the scrap recycling of stainless steels and heat-resisting alloys 
- Beech Aircraft Corporation, Wichita, Kansas: Boeing Vertol Compary. Philadelphia, Pennsyivania; Cessna Aircraft Company, Wichita, Kansas; McDonnel1-Douglas Corporation, St. Louis. Missouri; Northrop Corporation, Los Angeles. California; Pratt $\&$ Whitney Aircraft Division, United Technologies Corporation, East Hartford, Connecticut; Sikorsky Aircraft Division, United Technologies Corporation, Stratford, Connecticut; and The Boeing Company, Seattle, Washington, for information on 1975 chromium consumption and estimated consumption through 1980

- Dr. William J. Harris, Jr., of the Association of American Railroads for his survey on the use of chromium in railroad passenger cars

- Allis-Chalmers, Milwaukee, Wisconsin; American Shipbuilding Company. Lorain, Onio; Engineering Works Division. Dravo Corporation, Pittsburgh, Pennsylvania: Marathon LeTourneau offshore Company, Houston, Texas; Sun Shipbuilding $\&$ Dry Dock Company. Chester, Pennsylvania; The Boeing Company, Seattle, Washington; and Todá Shipyards Corporation, New York, New York, for information on 1975 chromium consumption and estimated consumption through 1980

- The Technical Aãvisory Committee of The Refractories Institute, chaired by Dr. J. A. crookston. for the survey of its members regarding the production and shipment of chrome-bearing refractories to various industries, substitution possibilities, material recycling, anà future technological requirements 


\section{Chairman}

JULIUS J. HARWOOD, Director, Materials Science Laboratory. Englneering duã Research stuff, Ford Motor Company. Dearborn. Michigan

\section{Past Chairman}

SEYMOUR I. BLUM, Director, Energy and Resources Management, The MITRE Corporation, Bedford, Massachusetts

\section{Members}

JAMES BOYD, Consultant, Materials Associates, Washington, D. C.

ALAN G. CHYNOWETH, Executive Director. Electronic Device, Process and Materials Division. Bell Laboratories, Murray Hill, New Jersey

ARTHUR C. DAMASK, Professor, Pnysics Department, Queens College of New York City; Flushing

SELWYN ENZER, ASSOciate Director, Center for Futures Research, University of Southern California, Los Angeles

HERBERT I. FUSFELD, Director of Research Kennecott Copper Corporation, New York, New York

JOHN B. GOODENOUGH, Professor of Inorganic Chemistry. Inorganic Chemistry Laboratory. University of Oxford, Oxford England

JAMES R. JOHNSON, Executive Scientist and Director. Advanced Research Programs Laboratory, 3M Company. St. Paul. Minnesota

LAWRENCE LEVY, President, Northern Energy Corporation. Cambridge, Massachusetts

WILLIAM D. MANLY, Senior Vice President, Cabot corporation. Kokomo, Indiana

FREDERICK T. MOORE, Economist Advisor, Industrial Project, World Bank, Washington, D.C.

WALTER S. OWEN, Head̄, Materials science Department, Massachusetts Institute of Technology. Cambridge. Massachusetts 
HAROLD W. PAXTON, Vice President-Research, U.S. Steel Corporation, Pittsburgh, Pennsylvania

ELI M. PEARCE, Head; Department of Chemistry, Professor of Polymer Chemistry $\&$ Engineering, Polytechnic Institute of New York, Brooklyn

NATHAN. E. PROMISEL, Consultant, Silver spring, Maryland DAVID V. RAGONE, Dean, College of Engineering, University of Michigan, Ann Arbor

JASON M. SALSBURY, Director, Chemical Research Division, American Cyanamid Company, Wayne, New Jersey

RAYMOND I. SMITH, President, Michigan Technological University, Hougition

MORRIS A. STEINBERG, Director, Technology Applications, Lockheed Aircraft Corporation, Burbank, California

GIULIANA C. TESORO, Adjunct Professor, Massachusetts Institute of Technology. Dobbs Ferry. New York

JOHN E. TILTON, Commodities Division, United Nations Conference on Trade and Development. Geneva, Switzerland

JOHN B. WACHTMAN, JR., Division Chief, Inorganic Materials Division. National Bureau of Standards, Washington, I. C.

MAX I. WILIIAMS, Dean, School of Engineering, University of Pittsburgh, Pittsburgh, Pennsylvania

NMAB_STAFF:

W. R. PRINDLE, Executive Director

R. V. HEMM, Acting Executive Secretary 
Chapteri 1 SUMMARY, CONCLUSIONS, AND RECOMMENDÄTIONS I

1.1 Generai conclusions anä Recommendations

1. 1. 1 Conclusions

1.1.2 Recoommenátions

1.2 Specific Conclusions änd Recommendations

1.2.1 Conclusions

1.2.2 Recommendations 13

Chapter. 2 INT'RODUCTION 16

2.1 Background 16

2. 2 Charge and scope is

$2: 3$ Stuāy Approach 20

References : 22

Chapter 3 ALTERNATIVES FOR REDUCING THE VULNERABIIITY OF THE UNITED STATES TO FUTUKE SHORTAGES OF CHROMIUM SUPPLY

3.2 The Extent of U.S. Vulnerability 24

3.2.1 U.S. Chromium Consumption 24

3.2.2 Sources of U.S. Supply 31

3.2.3 World supply and Demand 34

3.2.4 Discussion and Conclusions 37

3.3 Chromium Conservation 39

3.3.1 Quantification of Opportunities to
Reduce Chromium Consumption

3.3:2 Consumption Projections at Two 47

3.3.3 Impacts of Conservation 53

3.3.4 Discussion and Conclusions.. 55

3.4 Alternatives and Supplements to
Conservation

3.4.1 Stockpiling 57

3.4.2 Exploration 60

3.4.3 Combined Approaches 61

$3: 5$ Conclusions and Recommenäation 64

$\begin{array}{ll}\text { References } & 67\end{array}$

Chapter 4 DESIGN

4.1 Introāuction 68

4.2 Design Consideration 68

4.2.1 Bias 68

4.2.2 Available Resources 68

4.2.3 Reliability and Iife Expectancy 69

4.2.4 Weight 70

4.2.5 Ease of Recycling 70

4.2.6 Aesthetics 70 
4.3 Design Criteria 71

4.3.1 Corrosion 71

4.3.1.1 Sulfidic Corrosion in

Hydrogen-Free Environment

4.3.1.2 Operating Iimits for steel

in Hyārogen Service

4.3.2 Oxidation

4.3.3 Stress

4. 3.3. 1 Stress Reduction

4.3.3.2 Uncinanged

4.3.3.3 Stress Increase 85

4.3.4 Decreasing Cinromium Consumption 91

4.3.5 Standards, Specifications, and Quality Assurance Considerations 93

4.3.5.1 NDE Design Considerations 94

4.3.5.2 Requirements for specifications and Standarās that Minimize waste and Over-Design

4.3.5.3 The Role of In-Process Inspection in Achieving Conservation

4.3.5.4 Relationship of Quality Assurance and Design in Conservation

4.3.5.5 Potential of Technical societies in Conservation Strategies

4.3.6 Design for Recycling

4. 4 Product Trends

4.4.1 Energy and Process Equipment

4.4.1.1 Oil and Gas Exploration and

Production

101

4.4.1.2 Oil Refineries

101

4.4.1.3 Gas Processing

103

4.4.1.4 Shale Oil

$4.4 \cdot 1 \cdot 5$

Synthetic Fuels from coal

103

4.4.1.6 Nuclear Power

$4 \cdot 4 \cdot 1.7$

Coal-Fired Electric Utilities

106

4.4.1.8 Energy Ināustries Excluded

4.4.1.9 Summary of Chromium Neeās in

the Energy Industry

4.4.2 Automotive Industry

106

111

115

4.4.3 Aircraft Industry

4.4.4 The Marine Industry

4.5 Summary, Conclusions, and Recommendations

4.5.1 Summary

4.5.2 Conclusions

119

4.5.3 Recommendations

121

References

123

Bibliography 
5.2.1 Primary Melting and Refining Methods

5.2.2. Finvi rnnmental considerations

5.2.3 Energy Considerations

5.2.4 Ferrochromium in the Stockpile 136

5.3 Casting Processes

137

5.3.1 Casting Processes for Wrought products

5.3.2 Casting Processes for Shape Castings

5.4 Mill-Product Fabrication

5.4.1 Processes and Design Developments 139

5.4.2 Consumption of Chromium

141

5.5 Manufacturing Processing

141

5.5. 1 Machining and Grinding

142

5.5.2 Forming and Deep Drawing

142

5.5.3 Part Forging

5.5.4 Chipless Machining

143

5.5.5 Isothermal Working

144

5.6 Joining

5.6.1 Welding and Weld Repair

145

147

5.6.2 Brazing and Soldering

147

5.6.3 Mechanical Joining

150

150

5.6.4 Aāhesive Bonding

151

5.7 Surface Coatings

151

5.7.1 Clad Stainless steel 152

5.7.2 Weld Overlay 153

5.7.3 Chromized sheet steel 155

5.7.4 The Dilex Chromizing Process 157

5.7.5 Electroplating 158

5.7.6 Ion Implantation 160

5.8 Economic and Technical Dimensions of
Chromium Recycling

5.8.1 Economics and the Materials Cycle 161

5.8.2 Chromium Recovery and Reuse 164

5.8.3 Stainless Steel anā Heat-Resisting
Alloy Scrap

$\begin{array}{lll} & \text { Alloy Scrap } & 165 \\ 5.8 .4 & \text { Metallurgical Inaustry wastes } & 166\end{array}$

5.8.5 Refractory Industry wastes. 169

5.8.6 Chemical Industry Wastes 169

5.9 Summary, Conclusions, and Recommendations 170

5.9.1 Summary

5.9.2 Conclusions

170

5.9.3 Recommendations 178

References

181

Bibliography 182

$\begin{array}{lll}\text { Chapter } 6 & \text { SUBSTITUTION } & 185\end{array}$

6.1 Introauction 185

6.2 Substitutability 189

6.2.1 Ferrous Materials 189 
6.2.1.1 Chromium Demand and

Substitutability in stainless and

Heat Resisting steels

6.2.1.2 Substitutability of Chromium in Tool steels

189

6.2.1.3 Substitutability of chromium in

Wrought Alloy steels and Iron and Stee 1 Castings

6.2 .1 .3 .1

Wrought Alloy steels

6.2.1.3.2 Alloy Steel Cástings

6.2.1.3.3 Alloy Cast Irons

6.2.1.3.4 Substitute Materials

6.2.2 Substitutability of Chromium in Nonferrous Alloys

6.2.2.1 Iron-Nickel-Base Alloys Including Nickel-Base Alloys other than Superalloys

6.2.2.2 Nickel-Base Superalloys

$6.2 \cdot 2 \cdot 3$

Cobalt-Base Alloys

218

6.2 .2 .4

Aluminum-Base Alloys

220

6.2 .2 .5

Titanium-Base Alloys

220

6.2 .2 .6

Copper-Base Alloys

221

222

6.2.2.7 Substitute Materials

222

6.2.3 Ceramic Products

6.2.3.1 Chromite Uses (Brick, Gunning, and

222

6.2 .3 .2

Ramming Mixes and Chromite sands)

222

$6.2 \cdot 3.3$

Chromium Carbides and Borides

Chromite and chromium oxide Grains

229

6.2.3.4 Material Substitutes

230

230

6.2 .4 Plated coatings

6.2.5 Chemicals Containing Chromium

232

237

6.2 .5 .1

Pigments and Paints

237

6.2.5.2 Leather Tanning

239

$6.2 \cdot 5.3$

Metal Finishing and Treatment

239

$6.2 \cdot 5 \cdot 4$

Drilling Mud Aăditives

239

6.2 .5 .5

Water Treatment Compounds

$6.2 \cdot 5 \cdot 6$

Wood Treatment compounds

$6.2 \cdot 5 \cdot 7$

Chemical Manufacture and other

$6.2 \cdot 5.8$

Uses

Material substitution

Considerations

240

240

240

6.2.6 Chromium-Free Coatings

6.2.6.1 Aluminum, Zinc and Aluminum-zinc

Alloy Coatings

6.2.6.2 Plated Coatings as Substitutes

for Chromium-Containing Alloys

6.2.6.3 Coated Plastics and Polymer-Coated Steel

6.2.6.4 Ceramic Coatings as Replacement

for Stainless Steel 
6.2.6.5 Titanium and Titanium-Clad Metals 248

6.2.6.6 Tantalum and Tantalum-Clad Metals 250

6.3 Evaluation 2.51

6.3.1 Effects on Industry and Technology 252

6.3.2 Effects on the Economy 254

6.3.3 Effects on the Environment 255

6.4 Summary, Conclusions, and
Recommendations

6.4 .1 Summary 256

6.4.2 Conclusions 256

6.4.3 Recommendations . 261

References $\quad 262$

Bibliography 266

$\begin{array}{lll}\text { Appendix A STEEL SELECTION BY HAP.DENABILITY AND } & 267 \\ \text { ALLOY ELEMENTS } & \end{array}$

$\begin{array}{ll}\text { References } & 270\end{array}$

$\begin{array}{lll}\text { Appendix B CHROMIUM CONTENT IN CARS, TRUCKS, BUSES, } & 271 \\ \text { AND TRUCK TRAILERS } & \end{array}$

References $\quad 289$

Notes $\quad 289$

Appendix C CHROMIUM UTILIZATION IN THE AIRCPAFT

References $\quad 300$

Appendix D CHROMIUM USAGE IN THE MARINE INDUSTRY 301

Reference $\quad 303$

Appendix E CONSUMPTION OF CHROMIUM AND FERROCHROMIUM 304

$\begin{array}{ll}\text { References } & 313\end{array}$

Appendix F JOINING $\quad 314$

F. 1 Welding 314

F. 2 Brazing and soldering 323

F.3 Mechanical Joining 326

F. 4 Adhesive Bonding 326

F.5 Weld overlay . . 326

Appendix G CALCULATIONS AND ASSUMPTIONS FOR DETERMINING THE CHROMIUM USED FOR STAINLESS STEEL PFODUCTION

Appendix H SUBSTITUTES FOR STAINLESS STEEI. 333

Appendix I ALTERNATIVES FOR STAINLESS STEEL IN
AUTOMOBILES 
Appendix $J$ COATINGS FOR PLASTICS

343

J. 1 Electroplating

J. 2 Vacuum Metallizing

343

J. 3 Chemical Vapor Depos

J.4 Painting

J.5 Adhesively Bonded Metallic Films

343

344

344

References

344

344

Appendix $K$ ELIMINATION OF CHROMIUM FRCM BRIGHT TRIM

K. 1 Bumpers

K. 2 Grilles, Bezels, and Outside Rear-View

345 Mirrors

K. 3 Wheelcovers

K. 4 Winäshield wiper Arms

K. 5 Door Handles

K. 6 Lettering and Emblems

K.7 Window Surround Moldings, Rocker Panel Molāings. Body siāe Molạings

K. 8 Interior Bright Trim

References

\section{TABLES}

Table 1 Potential Savings of Chromium-Containing Materials

Table 2 Relative Importance of Metals utili.zing Chromium in 1964 and 1976

Table 3 Chromium Consumption in the United states by Physical Form in 1964 and 1976

Table 4 U.S. Chromium Imports from Various sources. 1963-1976

Table 5 World Chromium Ore Resources

Table 6 Depletion Times for known Chromium ore Resources

Table 7 Trend Forecast of U.S. Chromium Consumption Pattern in 1977

Table 8 Prospects for Chromium Savings by Recycling of Industrial Wastes

Table 9 Prospects for Chromium Savings by Processing Improvements 
Page

Table 10 Prospects for Chromium Savings by Materials Substitution and Redesign

Table 11 overall Summary of potential for Chromium Savings

Table 12 overall Impact of Potential Conservation opportunities on Chromium Consumption Forecast for 1977

Table 13 U.S. Government Stockpile of Chromium-Based Materials

Table 14 Maximum Metal Temperatures for Low Oxidation Rates of Chromium Alloys in Air

Table 15 Maximum Metal Temperatures for Low Scaling of Chromium Alloys in Steam Service

Table 16 Chromium Needs for Oil and Gas Exploration and Production

Table 17 Chromium Needs for Oil, Refineries...

Table 18 Chromium Needs for Gas Processing Plants

Table 19 Chromium Needs for shale Oil Production

Table 20 Chromium Needs for synthetic Fuels From coal

Table 21 Chromium Requirements of Different Nuclear Power Reactors

Table 22 Chromium content of 1.475-MW TOKAMAK Nuclear Island

Table 23 Chromium Needs for Nuclear Power

Table 24 Chromium Needs for Coal-Fired Electric utilities

Table 25 Summary of Chromium Needs of the Process and. Energy Industry

Table 26 . Key Uses of Chromium in Alloys

Table 27 Estimates of Potential Chromium Recoverable from Industrial process wastes

Table 28 Potential Chromium Savings through Processing Modifications 
Page

Table 29 Typical Applications of Chromium-Containing Materials

Table 30 Stainless Steel Production

190

Table 31 Alternate Materials for Stainless Steels

194

Table 32 Example of Possible chromium Savings in Stainless stee 1

198

Table 33 Chromium Demand and Substitutability in Tool Steels

Table 34 Consumption of Chromium in Alloy wrought and Cast steel by Market Category. 1972

203

Table 35 Chromium Consumption in Wrought Alloy steels in 1974

204

Table 36 Chromium Consumption Forecast for Wrought Alloy Steel

205

Table 37 Nominal Chemical Analysis of Standard and EX Steels Referenced in Report

207

Table 38 Chromium Demand and Substitutability in Wrought Alloy steel

Table 39 Chromium Consumption in Alloy Steel Castings

Table 40 Chromium Consumption in Alloy Cast Iruns

Table 41 Chromium Demand and Substitutability in Cast Alloy Iron and Steel

Table 42. Chromium Demand and Substitutability

in Nonferrous Alloys

224

Table 43 Iron and Steel Industry Consumption of Chromium-Bearing Refractories, 1969 and 1974

Table 44 Summary of Replies to The Refractories Institute Questionnaire on Chrome-Bearing Refractories, April 1976

Table 45 World Total Chromium Production Cumulated through 1974

Table 46 Alternatives for Ceramic Products 
Table 48 U.S. Consumption of Chromium Chemicals

Table 49 Chromium Demand and Substitutability in Chemicals containing Chromium

Table 50 Potential Savings of Chromium-Containing Materials by substitution

Table B-1 Chromium Usage in U.S.-Built Passenger Cars Powered by Conventional otto Cycle Piston Engines

Table B-2 U.S. Production of Passenger Cars; Euses, anã Trucks; 1972-1975

Table B-3 Chromium Balance for Automotive Vehicles

Table B-4 Vehicle Parts Requiring Chromium in an Emergency until Alternates Are Developed.

Table B-5 Emergency Chromium Reductions in Vehicles

Table B-6 Total Chromium Content in Various Engines

Table C-1 Estimated Aircraft Industry Chromium Consumption

Táble C-2 Aircraft Industry Chromium Consumption by Material Form for 1975

Table C-3 Ratio of Chromium Contained in Completed Airframe versus that Purchased by Manufacturer

Table C-4 Chromium Usage for a Iarge Commercial Transport Airframe by Raw Material

Table C-5 Chromium Usage for a Iarge Commercial Transport Airframe by Functional Area

Table D-1 Estimated Marine Industry Chromium Consumption

Table E-1 Production and Allocations of Ferrochromium Alloys for Stainless Steels and Chromium-Containing steels 
Table E-2 Stainless Steel Production and Losses

Table E-3 Breakdown of Stainless steel Shipments. 1968-1974

Table E-4 Chromium-Containing Alloy steel production and Losses

Table E-5 Breakajown of Chromium-Containing Alloy steel Shipments, 1968-1974

Table E-6 Major Stainless Steel Grades, 1970 Production

Table E-7 Major Alloy Steel Grades. 1970

Table F-1 Nominal Compositions of Low-Alloy Steel Chromium-Bearing welding Electrodes

Table F-2 Nominal Compositions of stainless steel welding Electrodes

Table F-3 Nominal Compositions of Nickel Alloy Welding Electrodes Containing Chromium

Table F-4 Nominal Compositions of Surfacing Electrodes Containing Chromium

Table F-5 Nominal Compositions of Titanium Alloy Electrodes containing chromium

Table F-6 Nominal Compositions of Chromium-Free Nickel-Base welding Electrodes

Table F-7 Nominal Compositions of Chromium-Free Surfacing Electrodes

Table F-8 Nominal Compositions of Brazing Filler Metals without Chromium, Suitable for Brazing Chromium-Bearing Alloys

Table F-9 Nominal Composition of Brazing Fillex Metals Containing Chromium

Table G-1 Chromium Use in Stainless Steel

Table H-1 substitutes for Stainless steels 
List B-1 Characteristics of the Piston Ctto Engine 276

Iist B-2 Characteristics of the Rotary Otto Engine 277

List B-3 Characteristics of the Piston Diesel Engine $2 / 8$

List B-4 Characteristics of the Battery Electric Engine 279

List B-5 Characteristics of the Brayton (Gas Turbine) Engine

List B-6 Characteristics of the Rankine (Steam) Engine 281

List B-7 Characteristics of the Stirling Engine 282

FIGURES

Figure 1 Historical Data on U.S. Chromium Consumption

Figure 2 Historical Trends in the Relative Importance of Chromium Usage in Metallurgical, Chemical, and Refractory Applications

Figure 3 Projections of U.S. Chromium Demand 30

Figure 4 Sources of U.S. Chromium Imports 32

Figure 5 Historical and Projected world Chromium Consumption

Figure 6 Projections of U.S. Chromium Consumption Showing the Impact of Implementing Conservation Measures Based on Currently Available Technology

Figure 7 Projection of U.S. Chromium Consumption Showing the Impact of Maximum Technically Feasible Conservation

Figure 8 The Protection offered by the U.S. Chromium Stockpile on a Business-As-Usual Basis 
Figure 9 Depletion of the Present Chromium Stockpile Following a Hypotheticäl Cessation of Supply in Early 1987

Figure 10 Depletion of an Enlarged Chromium stockpile Following a Hypothetical cessation of supply in Early 1987

Figure 11 Average Corrosion Rates for High-Temperature Sulfur corrosion in a Hyạrogen-Free Environment

Figure 12 Operating Limits for Steels in Hydrogen service

Figure 13 Fatigue strength Curve for 15-5 PH Precipitation Hardening Stainless steel

Figure 14 Effect of Hardness on Fatigue Iimit of Through-Hardened and Tempered steel

Figure 15 Effect of Inclusiogns on Fatigue

Figure 16 Effect of Alloy Composition on Threshhold stress

Figure 17 Fracture Toughness as a Function of Yield Strength for AISI 4340 steel

Figure 18 Effect of steel composition and Hardness on Wear and tife in Abrasive Applications

Figure 19 Effect of shot Peening on the Iife of Helical Compression Springs of 1095" and $8655 \mathrm{H}$ steel Made by Hot Winding

Figure 20 Effect of Nitriding on Fatigue Iife of 4340 Steel in Ful1-scale Bending Fatigue Tests of Individual "Throws" on Crankshafts 90

Figure 21 Summary of Design and Inspection Requirements

Figure 22 Forecast of Automotive Industry Usage of Chromium in Cars. Trucks, and Buses. 1975-2000

Figure 23 Overview of Principal Decarburization processes Used in Stäinless steelmaking 
Figure 24 . Typical Manufacturing Sequence for High Rate Production of Alloy and Stainless Steel or Billets

Figure 25. Master Chart of Welding and Allied

Processes

Figure 26 Network of Materials Flows and Recovery

Figure A-1 History of Alloy Steel Usage

Figure B-l Forecast of Automotive Industry Usage of Chromium in Cars, Trucks, and Buses, 1975-2000

Figure F-1 Master Chart of Welding and Allied.

Processes 
The United States depends entirely on foreign sources for the critical material, chromium, making it very vulnerable to supply disruptions. This vulnerability results because chromium is essential for the fabrication of corrosion-resisting steels and high-temperature, oxidationresisting alloys in applications that are vital to the nation's technological well-being; because no substitutes are known for these materials in those applications; and because the known, substantial deposits of chromite ore are only in a few geographical locations that could become inaccessible to the United States as a result of political actions. The effectiveness of programs such as stockpiling. conservation, and research and development for substitutes to reduce the impact of disruption of imports of chromite and ferrochromium are discussed. Alternatives for decreasing chromium consumption also are identified for chromium-containing materials in the areas of design. processing, and substitution. 


\section{Contingency Plans for Chromium Utilization}


Chapter 1

SUMMARY, CONCLUSIONS, AND RECOMMENDATIONS

Chromium is an element that imparts unique properties to the material to which it is added. While it is an important ingredient in many commoaities, it is irreplaceable in stainiess steels and high-temperatureresisting superalloys, two classes of materials that are vital to the technological well-being of the nation. currently. there are no chromium-free substitutes that can be used in these critical applications nor are any such substitutes likely to be developed in the forcseeable future.

The Uniteō States is completely dependent on imported chromium and known commercial deposits are located in only a few countries. The committee could not identify any technological responses that would eliminate completely U.S. vulnerability to a long-term disruption of chromium imports. Accorāingly. contigency plans for chromium utilization are assessed, assuming the worst possible supply situation, that is, a total embargo on all foreign sources of chromium ore and ferrochromium. These contingency plans stem from a technical perspective and the study does not propose measures for coping with chromium contingencies by legal, political, or financial means.

\section{1 GENERAI CONCLUSIONS AND RECOMMENDATIONS}

\section{1.1 conclusions}

These general conclusions anā recommendations present the Committee's findings regarding the degree to which the United states can reduce its dependence on imported chromium and recommended programs that might lead to reduction of that dependency.

1. Although important segments of U.S. industry are vitally dependent on chromium, insufficient effort has been made to develop substitutes for or to conserve, reclaim, or recycle chromium-containing materials. Consequently, a drastic curtailment of chromium supply would have serious short- and long-term effects.

2. Known chromium reserves are estimated at about 5 billion short tons and are expected to last for several centuries: On the basis of the currently known information, the quantity ana location of prover and potential reserves are such that, at 
the current rate of consumption, the geographic concentration of chromium deposits will increase; within 25 to 75 years, the world will depend completely upon South African and Rhodesian deposits.

3. U.S. chromium deposits are small and virtually no prospects exist for the discovery of any significant new U.S. deposits. There is little evidence to suggest the existence of significant chromium deposits outside of those geographic areas presently known. The discovery of aaditional deposits in producing regions with limited known reserves (e.g., the USSR and Turkey or elsewhere) would be beneficial in maintaining the few alternate sources of supply that currently exist, even if the new deposits were not developed initially.

4. No substitutes exist or are likely to be developed for chromium in the high-strength steels, hightemperature metals, and corrosion-resisting alloys that are essential in the manufacture of jet engines, petrochemical and power plant equipment, and various other critical products. It is highly unlikely that corrosion-resisting or high-strength alloy steels without chromium will be developed for such critical applications, although chromiumfree substitutes could be used for decorative stainless steels, automotive trim, flatware, refractories, and some chemicals.

5. Current U.S. chromium consumption could be reduced potentially up to one-third within about five years without creating major economic dislocations by using available technology to substitute alternative materials or processes, to recover and recycle waste chromium, and to deșign for greater chromium efficiency.

6. A major chromium-conserving research program has the potential of reducing U.S. chromium consumption an additional one-third within 10 years but could involve economic perialties (or disruptions) in some areas.

7. Even if the above measures are taken, however, essential or unsubstitutable U.S. chromium consumption is expected to be at least 180,000 short tons per year (approximately 6 percent of 19.75 worla chromium production), on the average, in the foreseeable future. 
8. Sudden manáatory chromium conservation programs woula result in severe economic dislocations even if all needed development work were completed in advance.

9. Chromium conservation is an ineffective response to short-term (about five years) shortages. Moreover, unilateral changes in U.S. consumption will have very little impact on long-term world conditions but would create severe economic penalties for the nation.

10. Conventional stuekpiling can provide short-term protection (five years) against chromium shortages; however, the continued use of chromium in easily collected functional products (e.g... hub caps, flatware, ana coins) may provide a more cost-effective stockpile for the types of shortages the United states is likely to encounter during the remainder of this century.

11. The criticality of chromium to U.s. industry generally is not appreciated, and this lack of awareness works against the development of long lead-time technologies, stockpiles, or international agreements necessary to avoid supply
interruptions.

12. The optimum response to the nation's increasing vulnerability to a disruption of the chromium supply probably would involve a combination of three approaches: some form of stockpiling to proviae short-term (about five years) protection. conservation measures to provide medium-term (five to ten years) protection by reducing the consumption rate and thereby extending the life of the stockpile, and exploration for new deposits to provide long-term (more than ten years) protection against a total disruption of supply from existing
sources.

\subsubsection{Recommendations}

1. The criticality of U.S. dependence on foreign chromium shoula be publicized widely in conjunction with the intention to institute a program to decrease U.S. vulnerability to chromium requirements.

2. A basic research program aimed at developing substitutes for chromium in stainless steels and high-temperature, oxidation-resisting alloys 
should be initiated. Although this is a long-term program with little chance for early success, it is the only technical possibility for eliminating U.S. vulnerability to a long-term chromium embargo.

3. The search for new chromium deposits outside of current producing areas should be supported with adequate incentives, particularly on the North American continent.

4. Research into chromium conservation and recycling technology should be pursued vigorously, but only price and the marketplace should be used to control consumption. Detailed examination of this interaction will require further study.

5. A study should be initiated to develop innovative methods for stockpiling chromium to provide up to five years protection against a cessation of supply and improved methods for ensuring that the content of the stockpile is matched properly to changing U.S. needs.

6. The combination of approaches -- stockpiling, conservation, and exploration -- should be explored as a strategy in addressing the chromium problem.

7. A thorough technoeconomic follow-on study (i.ncluding cost-benefit analyses) should be undertaken to assess the substitution potential of chromium-containing alloys.

\section{2 SPECIFIC CONCLUSIONS AND RECOMMENDATIONS}

These specific conclusions anā recommendations represent the committee's most attractive approaches for reducing U.S. chromium consumption. However, as indicated earlier, these recommendations will not eliminate U.S. dependence on imported chromium but could reduce by two thirds the quantity of chromium that otherwise would have been consumed. It should be noted that implementing the recommenaations below would involve considerable time. . money, and effort from development of the alloys through various aspects of metallurgical processing such as heat treatment, fabrication, and testing.

\section{2.1 Conclusions}

1. The design team (consisting of a aesigner, materials engineer. processing engineer. 
nondestructive evaluation engineer, and maintenance entineer) is the most effective technical approach for using and conserving materials.

2. Bias, available resources, reliability and life expectancy, weight, ease of recycling, aesthetics, corrosion, stress, and alternative materials must be considered in the design process.

3. Significant increases in chromium consumption are anticipated only in three product areas during the next 20 to 30 years: nuclear reactors, synthetic fuel plants, and high-temperature batteries. Decreases in the chromium content of materials used in key components of the petrochemical. nuclear, and aviation industries would drastically affect total life, cost, and performance reliability. However, design innovation and changes in purchasing attitudes in other areas could offset this added demand readily (e.g.. automotive components such as hub caps, catalytic converters, and other accessories).

4. Conservative design factors of safety, selected arbitrarily and imposed by design specification. can result in excessive product weight. inefficient design, and increased chromium consumption. Nondestructive testing and evaluation can play an important role in chromium conservation by permitting less conservative design factors of safety.

5. Universities and technical societies have a major role to play in creating an awareness of the proper utilization of chromium in products tinrough curricula:changes, handbook revisions, seminars, and publications.

6. Various process changes can result in a total chromium savings of appproximately 100,000 tons per year (see Table 28, chàpter 5, Processing, for details).

7. Duplex melting and refining systems minimize the chromium loss in slags during melting and refining, and their use in producing tool steels and high-chromium alloy steels coula result in substantial chromium savings. (Major stainless steel producers are practicing duplexing now.) 
8. Surface coating of materials offers a good opportunity for chromium conservation; applicable processes include stainless clad plate, surface chromium diffusion (sheet and parts). weld overlays. chemical deposition, and ion implantation. Where economic incentive exists. surface coatings already have been utilized. Further extension is limited by economic barriers. e.g.. coated and clad products in thin sections. protecting the edge and joining thin sections in a manner that will preserve the corrosion resistance of the surface and edge presents technical problems that must be solved.

9. Continuous-strand casting to produce tonnage quantities of semi-finished forms (slabs and billets) of chromium-bearing stainless and alloy steels that subsequently are rolled or forged results in significantly higher yields from molten steel to semi-finished product (about 95 percent as contrasted with 85 percent via conventional ingot pouring practicel.

Ceramic mold and precision investment casting can provide products that require minimal machining and that therefore are materialefficient. Opportunities for chromium conservation in technically proven casting processes include near-net-shape cast preforms and cast hollow preforms for pipe and tube production.

New processes, such as hot isostatic pressing (HIP) to heal casting defects and to improve mechanical properties of precision cast parts, rheocasting, slush-casting and squeeze casting, require evaluation before their technical and economic feasibility and potential chromium conservation possibilities can be established.

10. More than 95 percent of the raw stainless steel melted and converted into steel mill products either is shipped to customers or is recycled as home scrap indicating that limited opportunity exists for further savings in chromium processing of raw stainless steel to mill products. In chromium-bearing alloy and low-alloy steels, the potential for chromium conservation is greater through better alloy identification, separation. and segregation of recyclable home scrap within the steel mills. 
11. Steel and alloy processing operations, normaliy used to achieve the most economical manufacturing. must be reassessed to minimize generated scrap and to ensure that the generated scrap is in recyclable form.

Powder metal preforms are promising. particularly for parts requiring a minimum of metal removal. To increase the use of this process, lower-cost metal powders and less expensive sintering operations must be available. Also, the interaction between forging and powder metallurgy must be better to achieve a part finished to precise tolerances and high physical properties.

Chipless machining (e.g.. Gesselschaft fur Fertigungstechnik und Maschinenbau Aktiengesellschaft [GFM] machines) could be developed and applied to manufacturing tubes from hollow cylinder shell castings of specialty and alloy steels -- particularly if it were better demonstrateō and if published data on its applicability and production capabilities 'were made available.

Isothermal forging, especially for chromiumcontaining nickel-base superalloys, is well suited to the production of near-net-shaped aircraft engine components and structural forms and should improve and increase in use. The needs for advancing this process are improved die materials, new or improved high-temperature lubricants, improved die heating practices, and better design and preparation of die and preform.

12. Today's methods of joining chromium-containing alloys include welding, brazing, soldering, mechanical fastening, and adhesive bonding. Welding is the most efficient methoa since no other technique equals it for joint efficiency and strength. Brazing and soldering are commercially significant but few brazed joints match the strength of the chromium-containing alloys being joined. Mechanical fastening using high-strength bolts, rivets, lock-seams, sheet-metal screws and keys results in weight and strength penalties; nevertheless, items that must be disassembled later usually are keyed or bolted. Adhesive bonding is far behind other joining techniques in strength and development. 
The use of welding and brazing to replace joints mechanically fastened by bolts, rivets. etc.. saves material by eliminating double plates, overlap, rivets and bolts. Autageneous (no filler metal) welding techniques such as electron beam, electron resistance and friction welding, minimize chromium use and wastage. Narrow-gap welds, made by several semi-automatic and automatic processes. are new, important and emerging chromiumconservation techniques.

The use of new lower-chromium-content alloys may require welding for certain applications. The development of lower chromium electrodes, at least matching the chromium content of the proposed new alloys, is preferred over currently available high-chromium-containing welding electrodes.

13. The U.S. stockpile contains over 750,000 tons of various grades of ferrochromium that contain sulfur exceeding the specification of currently commercial ferrochromium grades. Because duplex melting and refining technology can produce stainless steels economically with a lower sulfur content than conventional electric furnace practice, most of the stockpile could be used with little cost penalty. without duplexing, this ferrochromium would be too expensive to use for stainless steels ana might be unusable for chromium-containing alloy steels, tool steels, and high-performance alloys.

14. Recycling conserves material resources, redúces waste and waste materials, and creates economic and social tenefits by better handling and disposition of the waste stream. The lowest lifecycle cost -- initial purchase price plus maintenance and repair costs plus longevity -should be the motivating force in product selection to achieve maximum conservation of materials, energy, labor, and capital. The amount of generated waste can be reduced by promoting product durability, repairability, and maintainability.

15. Technically, approximately 60,000 tons of chromium can be recovered annually from process wastes in the ferroalloy, stainless steel, refractory and chemical industries but, for economic reasons, very little of this waste is recovered now. An opportunity also exists for increased recycling in user industries where its prompt industrial scrap 
TABLE 1 Potential Savings of Chromium-Containing Materials (in million pounds)

\begin{tabular}{|c|c|c|c|c|c|c|c|}
\hline \multirow{2}{*}{ Material Designation } & \multirow{2}{*}{$\begin{array}{l}\text { Total } \\
\text { Chromium } \\
\text { Used } \\
\end{array}$} & \multirow{2}{*}{$\begin{array}{l}\text { Total } \\
\text { Chromium } \\
\text { Saved } \\
\end{array}$} & \multicolumn{4}{|c|}{ Time Required for Substit ution } & \multirow{2}{*}{$\begin{array}{l}\text { Irreplaceable } \\
\text { Chromium } \\
\end{array}$} \\
\hline & & & $\begin{array}{l}\text { Immedi- } \\
\text { ately } \stackrel{\text { a }}{ }\end{array}$ & $\begin{array}{l}\text { Within } \\
5 \text { Yrs. }\end{array}$ & $\begin{array}{l}5 \text { to } 10 \\
\text { Yrs. } \frac{c}{}\end{array}$ & $\begin{array}{l}\text { At Least } \\
10 \text { Yrs. } \\
\end{array}$ & \\
\hline Stainless Steel & 569 & 332 & 203 & -- & .129 & -- & 237 \\
\hline Tool Steel & 7 & -- & -- & -- & -- & -- & 7 \\
\hline Wrought Alloy Steel & 123 & 103 & 22 & 35 & 46 & - & 20 \\
\hline Cast Iron and Steel & 82 & 54 & 5 & 10 & 35 & 4 & 28 \\
\hline Non-Ferrous Alloys & 29 & 2 & -- & -- & 2 & -- & 27 \\
\hline Chromium Electroplate & 21 & 17 & 14 & 3 & - & -- & 4 \\
\hline Refractories & $249^{f}$ & 225 & 110 & - & .115 & -- & 24 \\
\hline Chromium Chemicals & 68 & 11 & 6 & -- & 5 & -- & 57 \\
\hline Total & 1,148 & 744 & 360 & 48 & 332 & 4 & 404 \\
\hline
\end{tabular}

NOTE: The assigned development times imply a reasonably well-funded and well-staffed investigation -- a crash program supported by government and industry might achieve desired results in much less time. while a poorly funded and under-staffed program might drag indefinitely with no tangible results. The development times estimate only the time required to arrive at a viable technological solution to the substitutability problem. involved. The time required to implement the technology depends on economic, political and social factors that are too complex to evaluate in any quantitative way and are beyond the scope of this study.

a Amount saved by functionally acceptable chromium-free substitutes currently available. Direct or indirect cost penalties are incurred.

b Amount saved by functionally acceptable chromium-free substitutes provided after short development (less than $\mathbf{5}$ years) with a high probability of success. Direct or indirect cost penalties are incurred.

c Amount saved by functionally acceptable chromium-free substitutes provided after intermediate-term (5 to 10 years) research with a high probability of success. Direct or indirect cost penalties are incurred.

d Amount saved by functionally acceptable chromium-free substitutes provided after $:$ long-term (more than 10 years) research with a high probability of success. Direct or indirect cost penalties are incurred.

e Amount considered irreplaceable. No functionally acceptable chromium-free substitutes are identifiable. Basic research and new technology are needed.

$\underline{f}$ Includes refractory types not reported by the U.S. Bureau of Mines 
is sold via dealers or directly to steel and alloy producers. Much the same is true for obsolete scrap when the cost of collection and separation is high and recovery is low.

The key problems in recycling today are that primary or virgin chromium is relatively inexpensive and secondary metals in general, and chromium in particular, have a low economic value compared to primary metal. However, increasing energy and disposal costs are expected to foster recycling.

16. Substituting other materials for chromiumcontaining stainless steel, tool steel, wrought alloy steel. cast iron anà steel, nonferrous alloys, electroplate, refractories, ana chemicals can result in a total chromium savings of 744 million pounds per year (see Tabie 1, for details) without seriously affecting quality.

17. An assessment of the end-use requirements of major stainless steel categories indicates that:

- 10 percent (about 32 million pounds of chromium) could be replaced by existing chromium-free materials without serious degradation of service performance.

- 50 percent labout 160 million pounds of chromium) might be replaced with a high probability of success after a short-term research and development effort.

- 40 percent (about 125 million pounds of chromium) cannot be replaced without design or process improvements because an unacceptable degradation of service performance would result.

Economical chromium-free substitutes are unavailable for use in chemical processing when corrosion or elevated temperature resistance is required. In a chromium cut-off, these applications must be supplied by allocation or abandoned until new technology is developed.

Alternative copper- and nickel-kase alloys also are subject to serious scarcities anci are produced in limited quantities. Titanium and titanium-clad steels might be viable substitutes for chromium-containing materials in chemical 
tanks and piping where service temperatures are relatively low. Coatings, clad materials, aluminum alloys, anà plastics neeà more research and evaluation before qualifying as substitutes in many applications.

18. The primary contribution of chromium to wrought and cast steel is its influence on hardenability. Several other elements that influence hardenability can eliminate or reduce chromium usage but at a significant economic penalty. An assessment of the ena-use requirements of wrought alloy steels indicatẹ that:

- 50 percent (about 64 million pounds of chromium) of the chromium now used probably could be replaced with little difficulty.

- 30 percent (about 39 million pounds of chromium) more might be replaced after a

- 20 percent (about 20 million pounds of chromium) is considerea irreplaceable.

opportunities for substitution are substantial in iron and steel castings and an estimated 50 million pounds of chromium could be saved. Chromium is essential in high-alloy steel castings and the 32 million pounds of chromium used in this application are irreplaceable.

19. Chromium in tool steels is considered irreplaceable in view of the relatively small amount of chromium used (less than 1 percent of total U.S. consumption), the importance of tool steels to the national economy, and the high cost of replacement materials.

20. Although the number of non-ferrous alloy compositions containing chromium is large, the amount of chromium consumed represents only about 2 to 3 percent of total U.S. consumption.

In aluminum-base, titanium-base and copperbase alloys, chromium primarily alters phase relationships to produce specific and preferred microstructures. Although lead times of several years might be required to qualify a substitute alloy for a critical application, reducing or 
eliminating chromium consumption in aluminum-. titanium-, and copper-base alloys would not cause major difficulties.

The chromium content of nickel-base, ironnickel-base, and cobalt-base alloys ranges from 10 to 25 percent, and no other alloying elements confer the same degree of oxidation and corrosion resistance. Although further research anā development, especially in the areas of coatings and engineering ceramics, eventually may decrease chromium dependence, it is not now possible to reduce chromium consumption significantly in these alloys by material substitution. For the foreseeable future, it will be necessary to ensure the availability of chromium for these alloys.

21. The largest use of chromium in ceramic products is as chromite refractories in basic steel plants anā as facing sands in steel foundries, and to a great extent. non-critical materials may be substituted at some cost/performance penalty. About 50 percent of the chromite could be replaced with little trouble by using magnesite-chrome refractories instead of chrome or chrome magnesite. The refractory industry is not geared to producing promising chromium-free substitutes such as spinel, fosterite, and dolomite in suitable form and quantity. Considerable research. development, and evaluation of these materials is warranted. With favorable cost incentive and chrome scarcity, the potential for salvage and reuse of chrome-bearing refractories is considerable in all consuming industries.

22. Electroplating uses about 4 percent of total U.S. chromium consumption, and the chromium chemicals used are made from chemical-grade chromite ore that generally has been unacceptable for metallurgical processing.

About 60 percent of the chromium used in electroplating is for decorative applications; about 30 percent is for engineering (hard) chromium plate; and the remainder is for other metal finishing. painted steel, aluminum, or plastic could be used to replace decorative chromium plate resulting in an annual savings of about 14 million pounds of chromium.

A promising available substitute for hard chromium plate is electroless nickel deposition. 
and about 3 million pounds of chromium could be saved annually if this process were used; however. considerable development would be necessary to provide the needed productive capacity.

More chromic acid is lost or wasted in processing than actually is deposited as chromium metal on the plated parts, and total consumption of chromium could be reduced substantially by successful recycling.

23. Annual U.S. consumption of chromium chemicals is about 10 million pounds of chromium. The primary chemical, sodium dichromate, is made from chemical-grade chromite ore.

Considerable research has been done in all areas of chemical application to find acceptable substitutes. Except for the wood treatment area in which known substitutes for the small amount of chromium chemicals used could result in an annual saving of 6 million pounds of chromium; all major applications would suffer severe cost and performance penalties if known and proven substitutes replaced chromium chemicals. In an emergency, pigments could be eliminated in about half their uses with a drastic limitation of produceable colors and about 14 million pounds of chromium could be saved annually.' No practical substitute exists for the chromium usea in tanning leather, the chromium lignosulfates used in dxilling mud additives, or the chromium compounds used in water treatment additives. At present. economics favors chromium as corrosion inhibitors in aqueous systems. It is expected that federal regulations will eliminate these compounds in open systems because of their hazard to health.

\subsubsection{Recommendations}

1. The design team approach should be implemented by the highest operating decision makers of both industry and government. To promote chromium conservation. design teams should be encouraged to ensure that:

- Materials are specified with actual required composition and properties.

- Data compilations are available that are current, comprehensive and precise concerning 
chromium-bearing materials and their potential substitutes.

- Combinations of materials are used that are compatible with current recycle systems.

- Materials consistently have the required quality.

- Processing is adjusted to accommodate material variations as determined by nondestructive testing, evaluation, and feedback during processing.

- Finished products have the highest quality and reliability possible through in-process control and have reduced reliance on final inspection.

- Products in service can be inspected to determine their remaining useful life and safety, and can be disassembled and repaired easily at relatively low cost.

2. Incentives or penalties should be considered by government to stimulate changes in the design of high-chromium-content products so that they may be readily identified, disassembled, and recycled.

3. Research should be accelerated to develop surface coatings with better high-temperature corrosion and oxidation resistance, including very thin coatings high in chromium.

4. Programs for nondestructive evaluation (NDE) should be specified and funds allocated specifically for NDE implementation in order to improve material and product reliability. to reduce in-process waste and labor, and to permit designing to higher limits.

5. Further development should be encouraged in the duplex melting and refining of alloy steels with substantial chromium content.

6. Research and development efforts on coated thin sections should bé increased and emphasis placed on providing adequate edge and surface corrosion protection. Particular attention should be given to the fabrication and joining of coated products to ensure cont inuity of corrosion-resisting surfaces and joint strength at reasonable costs. 
7. Research and development in electroless alloy deposition (such as nickel-phosphorus alloy) should be accelerated to make the process competitive with hard-chromium plating on a cost and performance basis.

8. Research on the ion implantation process should continue on a moderate scale.

9. Research and development in the various casting areas should be accelerated since castings potentially can provide high-strength, near-netshape products at savings in energy; processing. and cost if they are sound and consistently reliable.

10. Welding electrodes containing less chromium or filler metals matching proposed new alloys should be developed concurrent with the alloys.

11. The sulfur content of ferrochromium purchased for the U.S. stockpile should not exceed the limits of current commercial grades.

12. Programs should be expedited to develop stainless steels (alloyed with aluminum, titanium; and silicon) that might be substituted in many current stainless steel applications.

13. Low-alloy: chromium-free steel compositions should be developed and tested to replace those steels in which chromium is used mainly for its hardenability characteristic.

14. Economic incentives should be created to stimulate the development and use of lower chromium or chromium-free refractories.

15. Further research is recommended to develop economic chromium-free water treatment compounds. 
Chapter 2

INTRODUCTION

\section{1 BACKGROUND}

The United States is entering a period of increasing materials scarcities and the potential for the formation of material cartels is growing as materials become concentrated in relatively few countries. While this situation has resulted primarily because the world is consuming its raw materials at an ever-increasing rate, inefficiency and waste contribute significantly, possibly critically, to creating an environment in which competition for materials is intense.

Many studies in recent years have emphasized growing U.S. dependence upon imported materials (National Commission on Materials Policy, 1973; National Commission on Supplies and Shortages, 1976; Takeuchi and Varon; 1975). Although chromium, as a 100 percent imported critical material, has been included, the fact that the United states is strategically more vulnerable to a long-term chromium embargo than to an embargo of any other natural resource. including petroleum, has not been recognized. This critical vulnerability results because:

1. Chromium is essential for the fabrication of certain materials (e.g.. corrosion-resisting steels and hiyh-temperature, oxidation-resisting alloys) used in applications (including jet engines, aircraft, and chemical equipment) that are vital to the nation's technological wellbeing.

2. There are no known substitutes for chromium in the fabrication of the alloys mentioned above and no other chromium-free materials can be used in these applications without enormous performance and cost penalties.

3. Virtually all of the known substantial deposits of chromite ore are in South Africa. Rhodesia, the USSP, and Turkey.

The strategic nature of this situation was not detected by the materials studies mentioned above primarily because the five indicators generally used as tests of material criticality do not reveal the true nature of the chromium situation. These five indicators are: (1) criticality of applications, (2) U.S. supplies, (3) alternative 
(substitute) materials, (4) size of reserves, and (5) geographic distribution of foreign sources of supply. While the first three of these indicators reveal that chromium is highly critical, the last two deceptively reduce its strategic nature. Chromium is not in short supply in an absolute sense, and it will take several conturies to deplete. current deposits at projected world consumption rates. Even more misleading is the signal that comes from the last indicator, a proxy measure intended to include insight into the geographic distribution of remaining deposits. The proxy indicator of statistical data on which foreign sources have supplied the United States previously with chromium disguises the situation likely to evolve in the future.

In the past, the United states imported chromium from more than six sources in wiojely separated geographic regions. Within the next 20 to 75 years, however, all remaining known chromium deposits of substantial quantity will be in two geographically close regions -- Rhodesia anā South Africa. The chromium deposits in other regions (e.g. the USSR, Turkey, the Philippines, and India) that traditionally supplied the U.S. with chromium either will be exhausted or insignificant.

Unfortunately, the unique role that chromium plays in a technological society and the geographic concentration of remaining reserves are not widely appreciated facts among the economists and market specialists who contribute to most reports on materials. For example, in 1973 it was reported to the president and the congress that the United states depended completely on foreign chromium sources and that few, if any, alternates to chromium exist for many applications (National Commission on Materials Policy. 1973). However, the Commission failed to note that many chromium-containing materials (that have no substitutes) are absolutely critical to the nation's industry and that the geographic concentration of remaining world chromium resources sets the stage for a natural monopoly. In 1975. two World Bank economists assessing prospective market conditions from 1975 to 1985 for some 27 "strategic" commodities did not include chromium in their list (Takeuchi and Varon 1975 ).

The strategic nature of chromium also was not stressed adequately by the National Commission on supplies and shortages (1976): however, the Commission did highlight two other aspects related to mineral supply and demand situations that are important to the formulation of alternative chromium policies. The first is that the quantity of "known resources" can change drastically in a relatively brief time. Particularly relevant is the 
Commission's observation that world chromite reserves have increased 675 percent from 1950 to 1970 despite interim consumption. Discoveries of chromium deposits in regions (including under the oceans) geographically separated from those now being exploited would defuse the criticality of the U.S. vulnerability to a chromium embargo. secondly, the Commission report includes an excellent discussion of mineral embargoes and identifies the key factors that should be considered in evaluating the possibility of these conditions occurring. Unfortunately (because the commission failed to recognize that there are no substitutes for chromium in the fabrication of corrosion-resisting steels and high-temperature alloys and that remaining chromium reserves are highly concentrated). the Commisision concluded that "the likelihood of a total embargo by exporters of any of the nonfuel minerals is very remote," a conclusion unjustified by the known information concerning chromium.

If the exporters of another material like tin (for which the nation completely depends on imports) were to form a cartel and if that cartel were to cease all shipments to the United States. significant cost and performance penalties would result. Many processes would have to change or less effective materials would have to be substituted and costs would be higher. The United States might even do without some of the products that it currently enjoys. If. on the other hand, the United States had to survive without chromium, the impact would be enormously greater. The rate at which remaining chromium reserves are becoming concentrated in Rhodesia and South Africa makes this a possibility that cannot be dismissed casually.

Experts on international trade frequently state that ultimately economic forces prevail and that as long as deposits are plentiful, dislocations tend to be short-lived since the economic needs of the exporters and importers eventually are brought into balance. However, during the period that extends from the perception of a change in the marketplace to the time by which the new balance is realized, many severe problems can, and often do, occur. Failure to appreciate the unique strategic characteristics of chromium to U.S. industry only intensifies the criticality of the situation and works against developing long lead̄time technologies, stockpiles, or international agreements that may avoid economic dislocations.

\section{2 CHARGE AND SCOPE}

It was in recognition of this situation that the Department of Energy. U.S. Bureau of Mines. National. Aeronautics and Space Administration, and Federal Preparedness Agency of the General Services Administration 
requested the National Academy of sciences to undertake a study to identify alternative technical responses to reducing U.S. vulnerability to a chromium shortage if one were to materialize. To be included in these responses were means for reducing chromium consumption and waste and the development of guideliues fur contingency programs for substitution and processing and product design changes that might be initiated either in response to a chromium shortage or in an attempt to reduce the nation's vulnerability to a possible chromium shortage. The Academy undertook this effort and assigned responsibility for the project to the National Materials Advisory Board, which appointed a highly qualified Committee on Contingency plang for Chromium Utilization to conduct the study.

The study's sponsors agreed that the committee should assume a worst-case situation in its deliberations. This worst case is. of course, a total embargo against the United states by all foreign sources of chromite ore and

ferrochromium. The committee also explored some of the economic and political responses to such an embargo when such responses involved technical considerations.

In considering such options, a distinction must be made between two alternative forms in which such an embargo may occur. One form would involve only the United states (such an embargo may even be self-imposed -- i.e., the nation may refuse to buy chromium from all producers). The other form could involve not only the United States but all of our major trading partners as well -- Western Europe and Japan. The responses that would be effective under each of these forms are different, and these differences are noted, where appropriate, throughout this report.

In conducting its study, the committee particularly sought to determine:

1. The extent to which technical innovation, material substitution, conservation, and recycling and a combination of these technical responses can reduce U.S. vulnerability to a total embargo by all foreign sources of chromium.

2. How long it would take to implement these technical responses.

3. How likely it is that these responses will produce the desired reduction in chromium consumption.

4. Who should initiate or provide the incentive for these programs. 
5. The extent to which U.S. reliance on stockpiling as a response to a chromium embargo would be affected by technical considerations:

Technical alternatives in design; recovery and recycling, and substitution all have cost and performance considerations, and cost and performance were important factors in the committee's study. However, the committee was not charged with evaluating these factors in detail and its evaluation was concerned with alternatives that appeared likely to result in "acceptable" options in both performance and cost. When possible, changes in costs were estimated, but only on a relative basis. In addition, the committee did not evaluate the secondary consequences of changes in costs so it was not possible to determine how they. in turn, might affect consumption patterns. Instead, only conditional judgments were made and generally are reflected in this report in the following form: If chromium were to increase in price by a factor of $K$, then process $Y$ would be more economical and would result in a saving of $z$ tons of chromium per year. These conditional statements assume that only the price of chromium rises and that there is no concurrent increase in the cost of other materials or processes.

This study addresses aspects of contingency planning other than policy, which is outsiae the scope of this Committee. The implementation of many of the approaches discussed herein also may depend on legislative and regulatory actions whose aspects or interactions are outside the Committee's charge, 1976.

This report is based on data collected through November

\subsection{STUDY APPROACH}

To compile much of the data it needed to make its overall assessment, the committee organized into three panels to focus on design, processing, and substitution. Each of these panels was concerned hoth with current consumption patterns and with expected changes in chromium consumption in the future. These future changes included prospects for both reductions and increases in the demand for chromium.

Even though the panel approach separated the major issues involved in chromium fabrication and use, many areas of overlap were encountered. These areas of overlap were resolved to a great degree by arbitrarily placing overlapping considerations in one area (e.g.. all recycling aspects were assigned to the panel on Processing); however. 
this did not eliminate the overlaps entirely (i.e.. recycling still was treated by the panel on Design from the perspective of what might be done to "design for recyclability." to collect waste products, etc.). Thus, the division was not as crisp as was desired.

The lack of definitive data concerning the breakdown of chromium usage by application presented a significant difficulty that the committee attempted to circumvent in part by adopting one set of figures for current and projected consumption. It was recognized that the accuracy of forecasted consumption is uncertain and that recordkeeping variations make historical data uncertain; however, the committee did not deem this to be an important problem since the major issue is relative changes in consumption that may occur in the future and. for this purpose, any reasonable data base would suffice. It was not possible to deal in the same manner with the lack of consumption data concerning the specific alloys and their applications. Such breakdowns are important if the possibilities for substitutions are to be evaluated accurately and double countingl is to be avoided. Thus, the Committee's panels were forced to estimate such quantities.

The committee believed that it was important to indicate the probability of success associated with each of the technical alternatives that they identified. These are presented throughout this report, with the usual caveats regarding estimates of uncertain outcomes such as technical developments. However, even greater uncertainty surrounds the ability to implement these developments in processes where failure can result in catastrophic losses. Industry is typically reluctant to abandon tried and true materials; thus, the ability to realize the potential savings contained in the committee's recommendations may depend more on convincing test data and a vigorously implemented information dissemination program than on the technical developments themselves.

1 Double counting could occur if, for example, processing changes could reduce the chromium needed to produce a certain alloy by $k$ percent and design changes permitted a reduction in the use of that same alloy by. say $m$ percent: In such a case, the actual amount of chromium saved is $\mathrm{k}+\mathrm{m}-\mathrm{km}$. However, these quantities cannot be identified accurately without detailed data describing consumption patterns by both alloy and application. 
In order to identify alternative technical responses to a potential shortage of chromium, the Committee developed an overview of worldwide trends in the supply and demand for chromium. This overview served to evaluate: (1) the impact of a change in consumption on available chromium supplies. (2) the rate at which such supplies are being concentrated, and (3) the effectiveness of a stockpile as a means of protection against short-term shortages of chromium. The overview was not concerned with short-run details, such as the modifications that might be required by a particular process to permit one ore to be substituted for another or the economic consequences associated with such a transition. While these latter considerations are of critical importance in actual operations, they mask the macro aspects of how much ore is left in each region, the importance of possible technical substitutions, etc. However, the committee was concerned with the details involved in the high payoff technical options for reducing chromium consumption including their economic considerations, performance penalties. and time delays. Descriptions of these technical opportunities comprise the bulk of this report.

The accuracy of the macro results depends heavily on the committee's ability to anticipate possible technological developments and changes in patterns of consumption. This is a very difficult task even when such analyses are confined to U.S. consumption as this study is. However, it is necessary to extend this information to worldwide conditions in order to appreciate the rate at which chromium in certain geographic regions is being exhausted. While this extrapolation of results may be more uncertain than the impact of the specific technical changes identified in the body of this report, it is believed that greater quantitative precision would not alter the basic conclusions and recommended actions. As will be seen, even if the actual amount of chromium reserves is considerably different than currently believed, the time to realize the consequences presented below would vary only slightly.

REFERENCES

National Commission on Materials Policy. Material Needs and the Environment Today and Tomorrow. Washington. D.C.: Government Printing office. June 1973.

National Commission on Supplies and Shortages. Government and the Nation's Resources. Washington, D.C.: Government Printing office, December 1976. 
Takeuchi, K., and Varon. B. "Commodities shortages and Changes in World Trade." Annals of the American Academy of Politicical and Social Sccience 420 (July 1975) : $46-59$. 
Chapter 3

ALTERNATIVES FOR REDUCING THE VULNERABILITY OF THE UNITED STATES TO FUTURE SHORTAGES OF CHROMIUM SUPPLY

\section{1. INTRODUCTION}

In view of the present total dependence of the United states upon chromium imports, an assessment of its current and future vulnerability to chromium supply shortages should permit comparison of the effectiveness of several approaches that might reduce this vulnerability. To this end, the past and projected future supply and demand trends are analyzed in this chapter for the United states alone and the entire world. U.S. vulnerability to shortages depends on:

- Changing domestic and world demand that is in competition for the supply controlled by the few producing countries

- Changes in global supply as determined by the composition of the ore deposits of the supplying countries, and the quantity and grade of chromium produced.

The Committee was charged with the task of examining contingency plans for the use of chromium in the event of a drastic future shortage. The detailed deliberations of its Panels on Design. Processing, and Substitution (presented in chapters 4-6 of this report) focus primarily on methods of conserving chromium. In this chapter, conservation opportunities identified by the panels are quantified using a consistent framework of assumptions so that the overall effectiveness of conservation as a response to shortages of chromium supply may be judged. Conservation is not. of course, the only approach that could be used to reduce the vulnerability of the United States to chromium shortages. Two other possibilities, stockpiling and exploration for additional ore deposits, are discussed briefly together with some combined approaches.

\section{2 THE EXTENT OF U.S. VULNERABILITY}

\subsection{U.S. Chromium Consumption}

Data showing the apparent U.S. consumption of chromium from 1950 to 1976 are plotted in Figure 1 (U.S. Bureau of Mines. 1950-1976). The chromium metal content of the chromium ore consumed by each of the three major demand segments (metallurgical, refractory, and chemical) are plotted separately in addition to total U.S. consumption. 


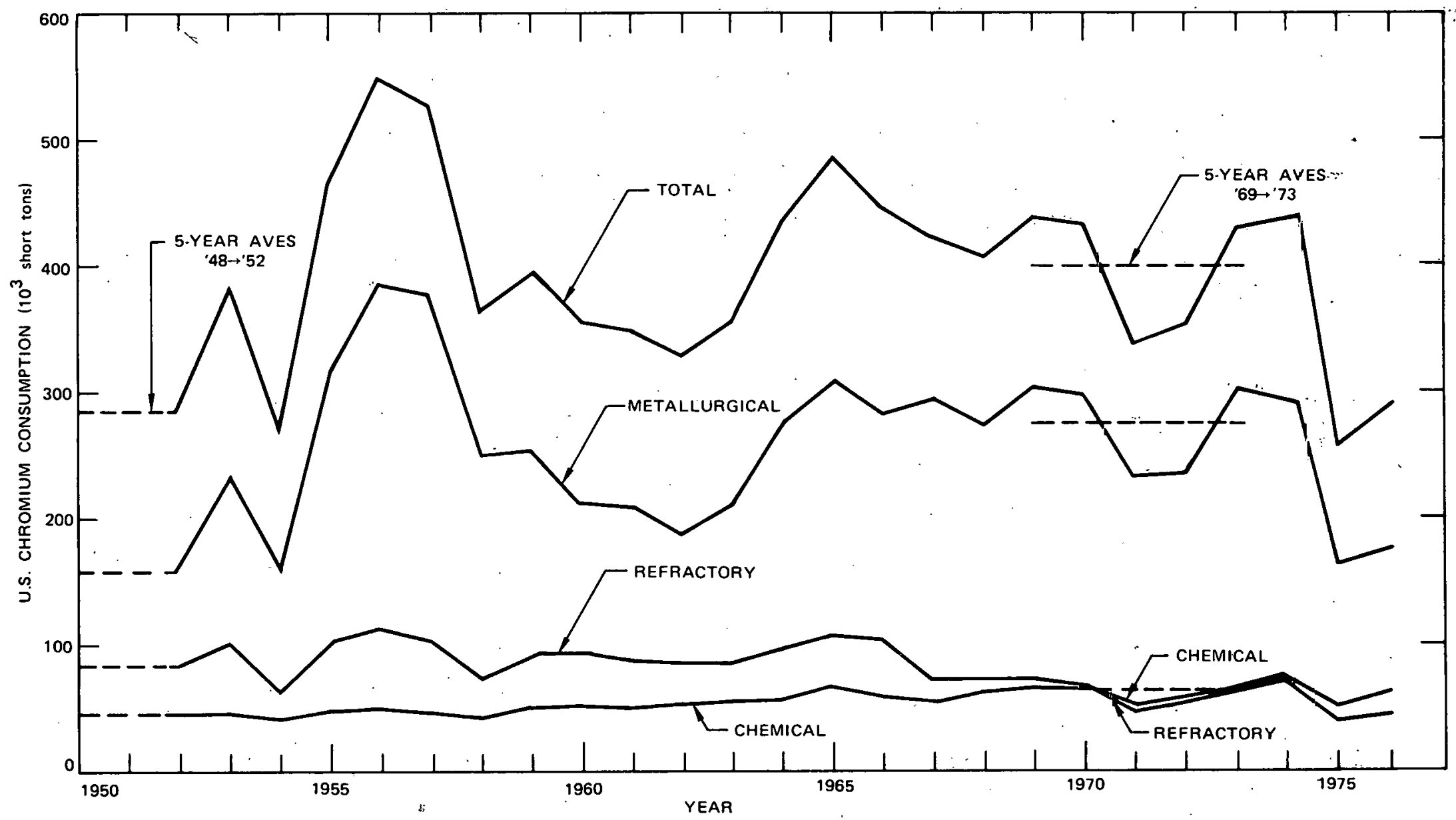

FIGURE 1 Historical Data on U.S. Chromium Consumption (based on data from the U.S. Bureau of Mines 1950-1974, 1975, 1976) 
The same aata were used for Figure 2, which illustrates the relative consumption by the three major demand segments over the same time period.

Although the absolute U.S. consumption data are fairly erratic, the trend indicated by Figure 1 is generally one of modest growth. The exception to this behavior is the use of chromium in refractories, which has declined slowly. Comparisons of the average consumptions during the 1948-1952 and 1969-1973 periods indicate the following average rates of growth in U.S. demand over the 21 year period:

$\begin{array}{lr}\text { Consumption } & \text { Percent per } \\ \text { Total } & +1.6 \\ \text { Metallurgical } & +2.7 \\ \text { Chemical } & +1.6 \\ \text { Refractory } & -1.5\end{array}$

Figure 2 confirms that the relative consumption for refractory applications has declined whereas that for metallurgical applications has increased. Chemicals accounted for an almost constant 15 percent of U.S. consumption throughout the period studied.

The use of chromium by type of metal produced has not changed much in the United states during the past decade as indicated by Table 2. The contained chromium consumed in steelmaking as a proportion of contained chromium consumed in all metals utilizing chromium declined modestly between 1964 and 1976, but the absolute amount consumed in steelmaking remained almost constant.

The relative proportions of the major physical forms in which chromium is consumed in the production of metals. refractories, and chemicals in the United States are compared in Table 3 for 1964 and 1976. The table indicates the shift from low-carbon ferrochrome to the more economical high-carbon ferrochrome and the declining absolute and relative use of chromium in refractories.

Figure 3 projects U.S. chromium demand to the year 2000. Metallurgical uses are projected to continue to grow at the historical rate of 2.7 percent per year from a hypothetical 1971 consumption of 275,000 short tons (the average consumption for 1969 through 1973) . Similarly. chemical uses are' projectea to continue to grow at 1.6 percent per year from a hypothetical 1971 consumption of 62,000 short tons. (This projection did not consider changes that may result from pending government regulations restricting the use of toxic chromium compounds, e.g.. for water treatment and pigments.) A survey of the refractories 


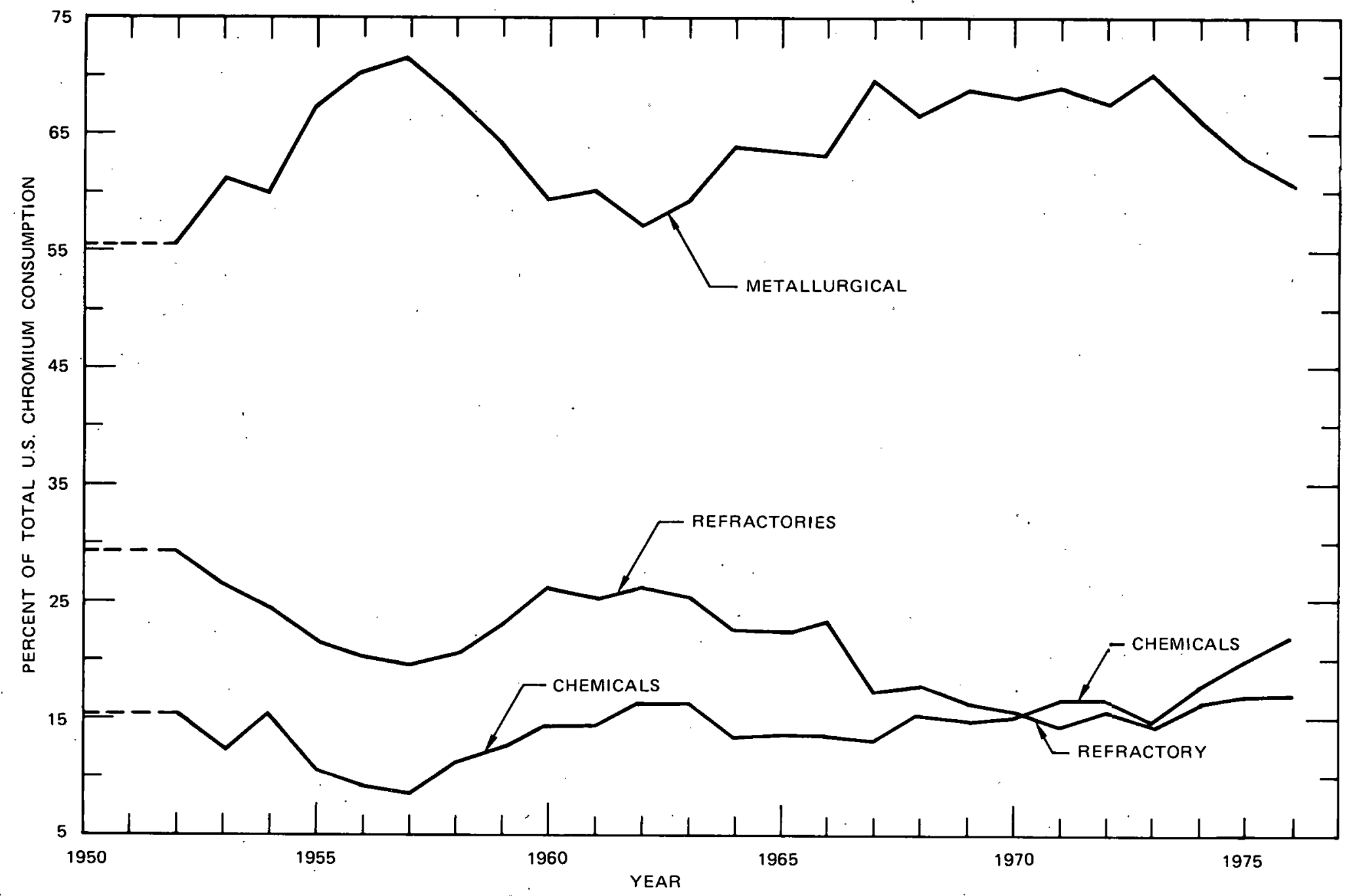

FIGURE 2 Historical Trends in the Relative Importance of Chromium Usage in Metallurgical, Chemical, and Refractory Applications (based on data from the U.S. Bureau of Mines 1950-1974, 1975, 1976) 
TABLE 2 Relative Importance of Metals Utilizing Chromium in 1964 and 1976

\begin{tabular}{|c|c|c|c|c|}
\hline \multirow{2}{*}{$\begin{array}{l}1964 \\
\text { Metal }\end{array}$} & & & \multicolumn{2}{|l|}{1976} \\
\hline & Percent $\underline{\underline{I}}$ & & Metal & Percent $\underline{\mathrm{a}}$ \\
\hline Steel 1 & & & Steel & \\
\hline Stainless & 70.9 & & Stainless & $6: 9.8$ \\
\hline Other alloys & 24.2 & & Tool & 1.2 \\
\hline Subtotal & 95.1 & & $\begin{array}{l}\text { High-strength low- } \\
\text { alloy and electric }\end{array}$ & 3.7 \\
\hline & & & other alloy & 16.2 \\
\hline & & $\therefore$ & Carbon & 1.4 \\
\hline & & & Subtotal & 92.3 \\
\hline . & & & Iron castings & $2 . .6$ \\
\hline Iron castings & 1.7 & & Superalloys & 2.5 \\
\hline High-temperature alloys & 2.2 & & other alloys & 1.7 \\
\hline Nickel and other alloys & 1.0 & & Miscellaneous & 0.9 \\
\hline Total & 100.0 & & Total & 100.0 \\
\hline
\end{tabular}

NOTE: Data from U.S. Bureau of Mines, 1964 and 1976.

a Contained chromium as a percentage of U.S. metallurgical consumption. 
TABLE 3 Chromium Consumption in the United States by Physical Form in 1964 and 1976 (1,000 short tons contained chromium)

\begin{tabular}{|c|c|c|c|c|}
\hline & \multicolumn{2}{|c|}{1964} & \multicolumn{2}{|c|}{1976} \\
\hline \multicolumn{5}{|l|}{ Metal Production } \\
\hline High-carbon ferrochrome & 83 & $(21 \%) \cdot \underline{a}$ & 159 & $(44 \%)$ \\
\hline Low-carbon ferrochrome & 104 & $(27 \%)$ & 54 & $(15 \%)$ \\
\hline F'errochrome silicon & 32 & $(8 \%)$ & 26 & $(7 \%)$ \\
\hline Other & 10 & $(3 \%)$ & $\underline{9}$ & $(3 \%)$ \\
\hline Subtotal. & $\overline{229}$ & $(59 \%)$ & $\overline{248}$ & $(69 \%)$ \\
\hline Refractories & 11.4 & $(29 \%)$ & 46 & $(13 \%)$ \\
\hline Chemicals & $\underline{45}$ & $(12 \%)$ & 64 & $(18 \%)$ \\
\hline Total & 388 & $(100 \%)$ & 358 & $(100 \%)$ \\
\hline
\end{tabular}

NOTE: Data from U.S. Bureau of Mines 1964 and 1976.

a The figure in parentheses indicated the percentage of total U.S. chromium consumption. 


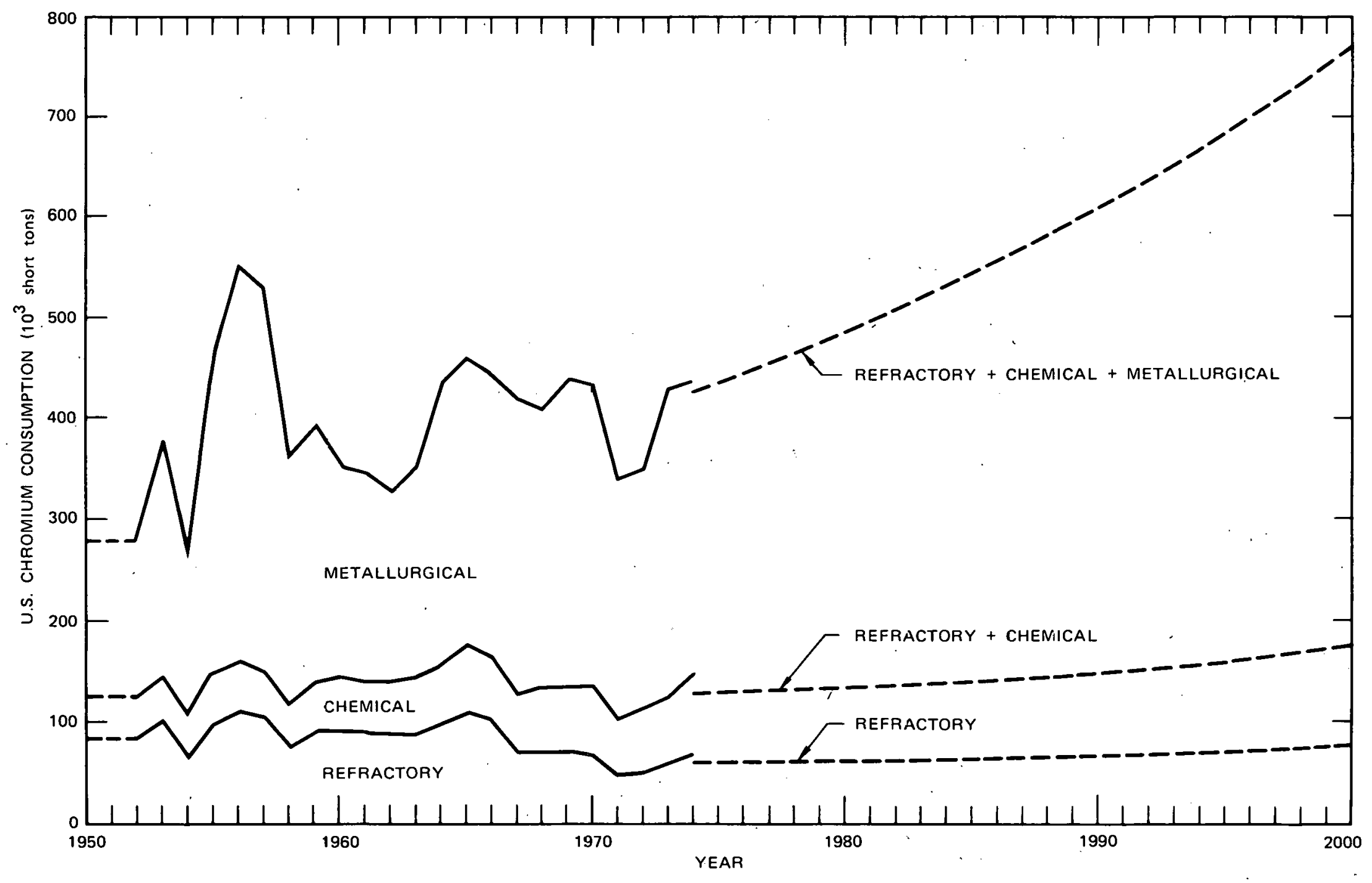

FIGURE 3 Projections of U.S. Chromium Demand (based on data from the U.S. Bureau of Mines 1950-1974, 1975, 1976, and the Committee). 
industry undertaken by the panel on substitution indicated that chromium consumption in refractories is unlikely to fall much below present levels and may in fact recover somewhat. Therefore, it is projected that refractories consumption will remain static at the average 1969-1973 level through 1982 and will grow at 1 percent per year thereafter. Together, these projections lead to the prediction of a growth in U.S. chromium demand of about 2.3 percent per year through 2000. As shown in Figure 3. annual U.S. chromium consumption is expected to reach about 770,000 short tons by the end of the century.

$3=2.2$ Snurres of U.S. Supgegly

The United States depends completely on foreign sources of supply to satisfy its demand for chromium. As shown by historical U.S. Bureau of Mines data in Figure 4, and Table 4, the United States has obtained chromium (in the form of chromite and ferrochromium) mainly from five countries: the USSR, Turkey, South Africa, Rhodesia, and the Philippines. Apart from the perturbation in the late 1960 s and early 1970 s due to the boycott of Rhodesia, the pattern of supply has been fairly stable in the past decade. The largest sources of supply have been south Africa and the USSR, and the remaining imports have been split roughly equally between Turkey. Rhodesia, the Philippines, and other sources.

Chromite ores have been classified into several grades. The definition currently acceptable to the U.S. Geological Survey and the Bureau of Mines is:

"Chromite consists of varying percentages of chromium, iron, aluminum, and mangnesium oxides. Historically, chromite has been classed into three general grades associated with end use; namely. metallurgical, chemical, and refractory. During the past decade, technological advances have allowed considerable interchangeability among the various grades, particularly for the so-called chemical grade, which can be utilized.in all three consuming industries. A more definitive classification is high-chromium (metallurgical grade) for chromite' containing a minimum of 46 percent chromic oxide $\left(\mathrm{Cr}_{2} \mathrm{O}_{3}\right)$ and with a chromiumto-iron ( $\mathrm{Cr}: \mathrm{Fe}$ ) ratio greater than 2:1; high-iron (chemical-grade) chromite containing 40 to 46 percent $\mathrm{Cr}_{2} \mathrm{O}_{3}$ and with a chromium-to-iron ratio of 1.5:1 to 2:1: and high-aluminum (refractory-grade) chromite containing more than 20 percent aluminum oxide $\left(\mathrm{Al}_{2} \mathrm{O}_{3}\right)$ and more than 60 percent $\mathrm{Al}_{2} \mathrm{O}_{3}$ plus $\mathrm{Cr}_{2} \mathrm{O}_{3}$." (U.S. Bureau of Mines 1975). 


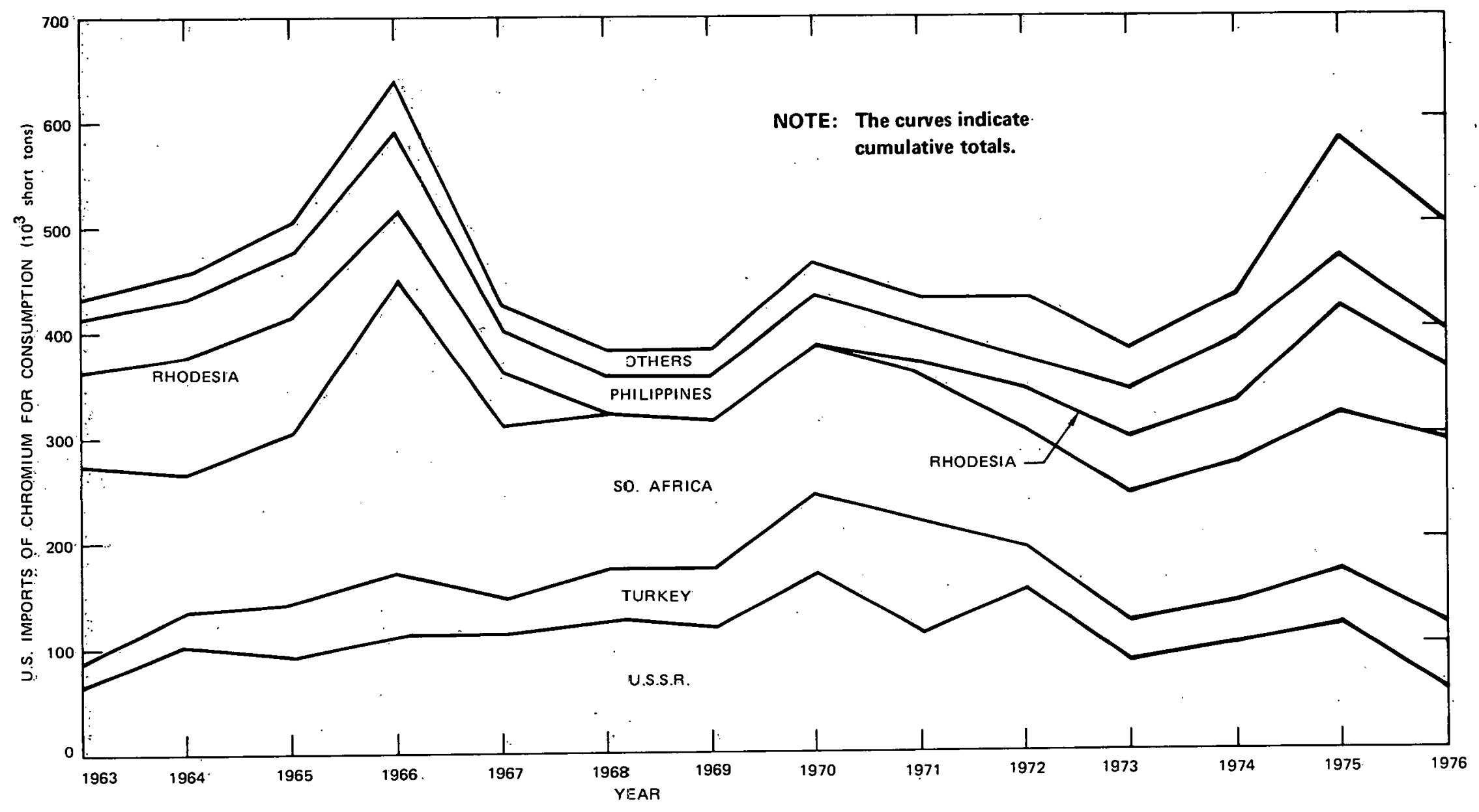

FIGURE 4 Sources of U.S. Chromium Imports (based on data from the U.S. Bureau of Mines. 1950-1.974, 1975, 1976) 
TABLE 4 U.S. Chromium Imports from Various Sources, 1963-1976 (1,000 short tons)

\begin{tabular}{|c|c|c|c|c|c|c|c|c|}
\hline Year & USSR & Turkey & South & Africa & Rhodesia & Philippines & Other & "Total \\
\hline 1963 & .64 & 25 & 186 & & 89 & 47 & 23 & 434 \\
\hline 1964 & .103 & 32 & 134 & & 110 & 51 & 29 & 459 \\
\hline 1965 & .91 & 5.1 & 163 & & 110 & 61 & 29 & 505 \\
\hline 1966 & 112 & 59 . & 280 & & 65 & 77 & .48 & 641 \\
\hline 1.967 & 113 & 35 & 164 & & 49 & 43 & 2.3 & 427 \\
\hline 1968 & 125 & 49 & 14.7 & & -- & 38 & 23 & $\equiv 82$ \\
\hline $1.96 \cdot 9$ & 118 & 56 & 141 & & -- & 44 & 24 & 383 \\
\hline 19.70 & 170 & 79 & 137 & & -- & 48 & 35 & 4.69 \\
\hline 1.97 .1 & $1: 12$ & 107 & .141 & & 8 & 36 & 27 & 431 \\
\hline $.197: 2$ & 154 & 40 & 109 & & $: 40$ & 29 & $5 \cdot 9$ & $4: 31$ \\
\hline 19973 & 82 & .41 & 126 & & $5: 1$ & 44 & $\because 44$ & 388 \\
\hline 1974 & $10: 3$ & 40 & 142 & & 4.7 & 58 & .42 & 432 \\
\hline 1975 & 120 & 53 & 147 & & 101 & 48 & $1: 1$ & 580 \\
\hline 197.6 & 61 & $: 61$ & 172 & & 67 & 37 & 101 & $499^{\circ}$ \\
\hline
\end{tabular}

NOTE: . Based on data from U..S. Bureau of Mines 1963-1975 and 1976. 


\section{2. 3 World Supply and Demand}

Figure 5 shows past and projected world production (apparent consumption) of chromium. Historical data suggested the 3 percent annual rate of growth that is used for the projection, and on this basis, world chromium consumption is expected to reach about $3.8 \mathrm{million}$ short tons by 2000 - roughly double present demand (the Institute of Geological Sciences, 1955-1975). Thus, U.S. consumption as a percentage of the world total should decline slightly from its present level of about 24 percent to about 20 percent in 2000 .

Chromium is the twenty-first element in the earth's crust in order of abundance, ranking with zirconium. vanadium, zinc, nickel, copper, and tungsten as being moderately abundant. Chromite is the only commercial mineral of chromium and varies compositionally within wide limits permitted by the formula:

$$
\text { (Mg, } \left.\mathrm{Fe}^{2+}\right)\left(\mathrm{Cr}, \mathrm{Al}, \mathrm{Fe}^{3+}\right)_{2} \mathrm{O}_{4}
$$

The $\mathrm{Cr}_{2} \mathrm{O}_{3}$ content of chromite ranges from about 15 percent to 64 percent, but directly usable ores that are mixtures of chromite and silicate minerals range from about 33 percent to 55 percent $\mathrm{Cr}_{2} \mathrm{O}_{3}$.

of the three variations of chromite ore recognized. high-chromium ores are used mostly for metallurgical

purposes, principally for making ferrochromium. High-iron ores are used in the production of chromium-based chemicals and are finding increased use in the manufacture of lower quality ferrochromium. High-iron ores also are used for refractory purposes and foundry sands. High-aluminum ores are used mostly for refractory purposes, principally in the manufacture of magnesite-chrome and chrome-magnesite bricks.

In the following discussion, chromium ore deposits are classified in two broad categories: reserves (ores considered exploitable under existing economic and technological conditions) and potential ores (deposits that demand more favorable conditions for exploitation). The term "resources" is used to designate the total of reserves plus potential ores.

Known world chromium ore resources are summarized in Table 5 (U.S. Bureau of Mines and other sources). Known ore resources total about 5 billion short tons and are estimated to contain about 1.2 bilion short tons of chromium, more than a 500-year supply at present demand levels. Thus, the physical limitations of world primary chromium resources will not be a consideration by 2000. However, Table 5. 


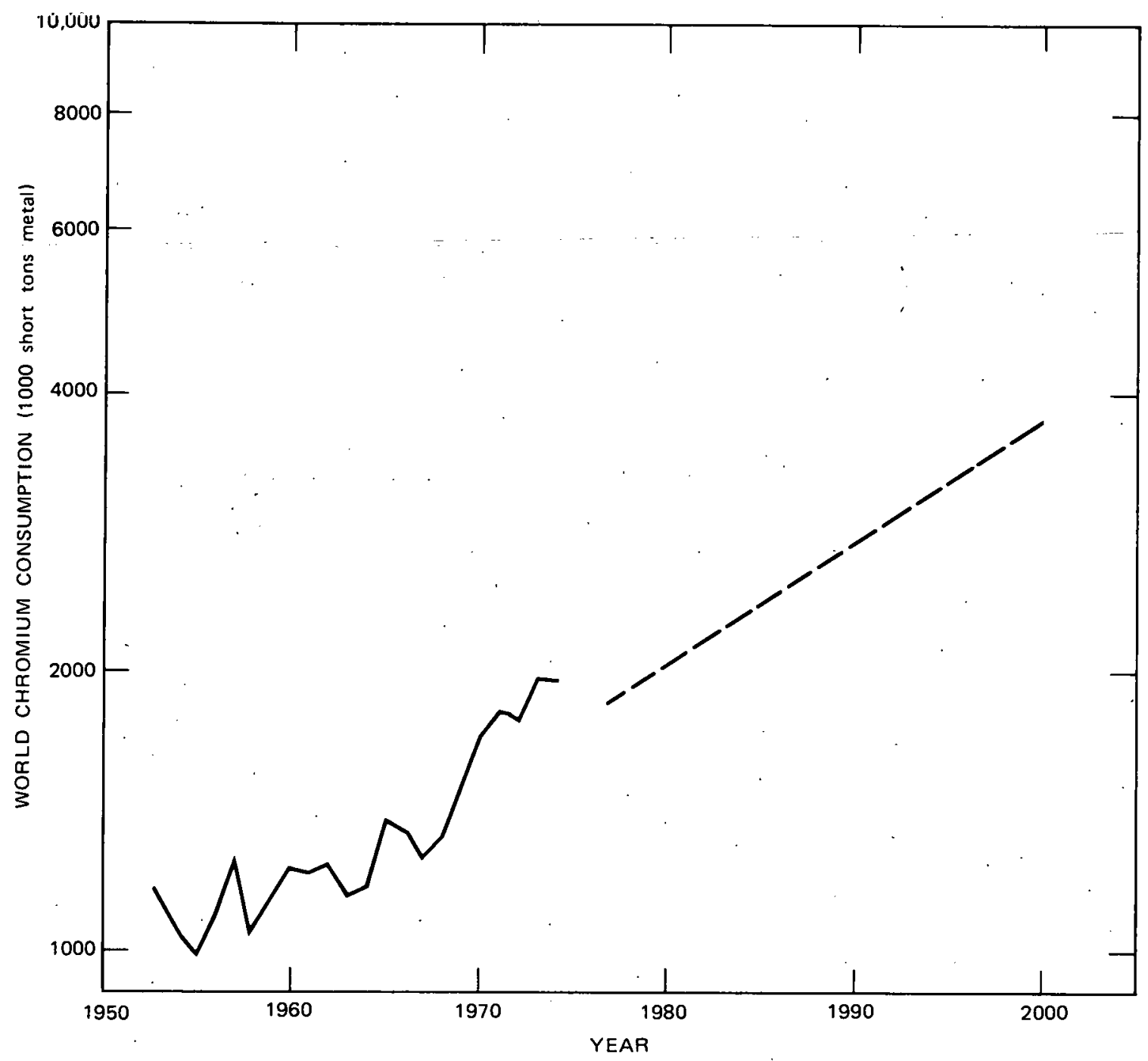

FIGURE 5 Historical and Projected World Chromium Consumption (based on data from the Institute of Geological Sciences 197) 
Table 5 World Chromium Ore Resources

\begin{tabular}{|c|c|c|c|c|}
\hline \multirow[b]{3}{*}{ Country } & \multicolumn{2}{|c|}{ Known Ore Reserves } & \multicolumn{2}{|c|}{ Known Potential Ore } \\
\hline & \multicolumn{2}{|c|}{ Million Short } & \multicolumn{2}{|c|}{ Million Short } \\
\hline & Tons Ore & $\%$ world & & $\%$ World \\
\hline South Africa & 1,194 & 62.4 & 2,333 & 76.5 \\
\hline Rhodesia & 626 & 32.7 & 626 & 20.5 \\
\hline USSR & 24 & 1.2 & 25 & 0.8 \\
\hline Philippines & 5 & 0.3 & $<1$ & $<0.05$ \\
\hline Turkey & 2 & 0.1 & 6 & 0.2 \\
\hline All other & 63 & 3.3 & .58 & 2.0 \\
\hline Total & 1,914 & 100.0 & 3,049 & 100.0 \\
\hline
\end{tabular}


reveals a remarkable geographical concentration of the world's chromium ore resources. Two countries, South Africa and Rhodesia, together have nearly 95 percent of the known world reserves and about 97 percent of the known potential ore.

\subsection{Discussion and_Conclusions}

Any country that depends entirely on foreign sources for the supply of a strategically important raw material is potentially vulnerable to economically or politically motivatea shortages. In the past, the United States reduced its chromium vulnerability by obtaining its supplies from sources that differed widely in both geographical location and political ideology (see Table 4 and Figure 4); however. it seems clear from Table 5 that this approach will become increasingly difficult in the future. Because south Africa and Rhodesia completely dominate known chromium ore resources, they eventually also must dominate world chromium supply. It might be argued that additional ore discoveries in other parts of the world would tend to reduce the future dominance of southern Africa; however, the known ore resources in South Africa and Rhodesia are so vast that there is little incentive for additional exploration in other areas. Thus, it is probable that a natural chromium supply monopoly will evolve and that the United States will depend increasingly on South Africa and Rhodesia for its future chromium requirements. As a consequence, U.S. vulnerability to chromium shortages will increase greatly.

It is important to examine the time scale over which this conclusion is likely to become reality. A crude method of quantifying the period involved is shown in Table 6 which compares the longevities of the major known deposits of chromium ore (assuming continuing ore production at 1973 levels). Although depletion time estimates of natural resources are notoriously unreliable, the data suggest that South Africa and Rhodesia will reach a monopolistic situation within 25 to 75 years. Clearly, the projected increase in world consumption (Figure 5) will tend to decrease this period, and any major new ore discoveries, in other parts of the world will tend to increase it.

Another way to state this. situation is to treat world chromium resources as if they consisted of just two sources of supply: South African and Rhodesian, and the rest of the world. If the South African and Rhodesian sources were disrupted and the rest of the world provided the entire demand for chromium, the depletion time at the 1975 level of 8.74 million short tons of ore would be 21 years. Furthermore, even if the United states reduced its consumption level to zero during this disruption period, the 
TABLE 6 Depletion Times for Krown Chromium Ore Resources

\begin{tabular}{lclc}
\hline Country & $\begin{array}{l}\text { Known Chromium Ore } \\
\text { Resources } \\
\text { (million short tons) }\end{array}$ & $\begin{array}{l}1973 \text { Chromium Ore } \\
\text { Production } \\
\text { (million short tons) }\end{array}$ & $\begin{array}{l}\text { Depletion Time at } \\
\text { 1973 Production } \\
\text { (years) }\end{array}$ \\
\hline South Africa & 3,527 & 1.85 & 1,906 \\
Rhodesia & 1,252 & 0.61 & 2.052 \\
USSR & 49 & 2.13 & 23 \\
Philippines & 6 & 0.65 & 9 \\
Turkey & 8 & 0.63 & 13 \\
All Other & 121 & 1.58 & 77 \\
\multicolumn{1}{c}{ Total } & 4,963 & 7.45 & 666 \\
\hline
\end{tabular}

NOTE: Based on data from the Institute of Geological Sciences, 1975. 
time to depletion would increase only to 27 years. These data indicate not only the limited longevity of known chromium deposits outside of Africa but also their relative insensitivity to U.S. consumption. Indeed, concentration of world chromium reserves is not exclusively a. U.S. problem and the problem cannot be solved by reduced U.S. consumption alone.

\subsection{CHROMIUM CONSERVATION}

One response to a shortage of chromium supply would be to attempt to reduce consumption, and identification of the opportunities that exist to do so was the major topic addressed by the committee. This section presents quantititive estimates (based on the detailed considerations presented in chapters 4-6) of the reductions in chromium consumption that could be achieved by conservation programs in the areas of substitution. recycling and improved processing practice, and design. Two types of conservation opportunities are distinguished and are considered separately: - Category $1--$ Technically feasible with currently

- Category 2 -- Dotentially feasible with future technology but requiring up to 10 years research and development

Using these definitions, chromium uses may be viewed as being of three types:

(1) Those that could be eliminated by using existing substitutes or by making other state-of-the-art technological adjustments

(2) Those that could be eliminated if a conservation research program were initiated and proved to be successful

(3) Those that could not be eliminated using either of the above approaches

Before the amounts of chromium that fall in each of these three classes can be calculated, a forecast of the U.S. consumption pattern must be made. Projections of chromium consumption in metallurgical, refractory, and chemical uses were presented earlier (Figure 3); however, a more detailed breakdown of U.S. consumption is required to quantify specific conservation opportunities. A breakdown of the amounts of chromium expected to be used during 1977 in 21 end-use areas is presented in Table 7. This forecast, which 
TABLE 7 Trend Forecast of U.S. Chromium Consumption Pattern in 1977

\begin{tabular}{|c|c|c|}
\hline Use & $\begin{array}{l}\text { Quantity Consumed a } \\
(1,000 \text { short tons })\end{array}$ & $\begin{array}{l}\text { Percer } \\
\text { Consur }\end{array}$ \\
\hline \multicolumn{3}{|l|}{ Metallurgical } \\
\hline $\begin{array}{l}\text { Wrought stainless an } \\
\text { resisting steels }\end{array}$ & 232 & 51.3 \\
\hline Tool steels & 6 & 1.3 \\
\hline Wrought alloy steels & 43 & 9.5 \\
\hline Cast alloy steels & 14 & 3.1 \\
\hline Alloy cast irons & 8 & 1.8 \\
\hline Nonferrous alloys & 14 & 3.1 \\
\hline Other & 6 & 1.3 \\
\hline Subtotal & $\overline{323}$ & 71.4 \\
\hline
\end{tabular}

\section{Refractories}

Chrome and chrome-magnesite 10

Magnesite-chrome brick

Granular chrome-bearing

Granular chromite

Subtotal
14

27

10

61
2.2

3.1

6.0

$\frac{2.2}{13.5}$

Chemicals

Pigments

Metal finishing

Leather tanning

Drilling muds

Wood treatment

Water treatment

Chemical manufacturë

Textiles

Catalysts

Other

Subtotal

Total
18

15

11

3

4

4

5

2

$<1$

$\frac{5}{68}$

$\overline{452}$
4.0

3.3

2.4

0.7

0.9

0.9

1.1

0.4

$<0.3$

$\frac{1.1}{15.1}$

100.0

a

Exclusive of scrap. 
is based on data obtained by the panel on Substitution, has been scaled to match the 1977 trend projections for metallurgical consumption (323,000 short tons), refractories consumption $(61,000$ short tons). and chemical consumption $(68,000$ short tons) shown in Figure 3 .

3.3. 1 Quantification of opportunities to Reduce chromium Consumption

Opportunities for chromium conservation by improved recycling of industrial wastes are discussed in detail in Chapter 5. Combining the chromium recovery opportunities identified by the Panel on Processing with the projected 1977 chromium consumption pattern presented in Table 7 allows the potential chromium savings to be estimated as shown in Table 8. All the potential chromium savings fall into Category 2 (considered potentially feasible with future technology but requiring up to 10 years of research and development). By far. the most important recycling opportunities are in the refractory uses of chromium where recycling of about 40,000 short tons of chromium per year (6.5 percent of the projected 1977 consumption of chromium in refractories) is considered potentially feasible. Pecycling of metallurgical and chemical wastes does not offer any very exciting opportunities for chromium conservation. It is estimated that only 4.5 percent of the projected 1977 consumption of chromium in metallurgical end uses and only about 6 percent of the chemical consumption potentially could be recovered from industrial wastes. Moreover, a consiäerable number of recycling technologies would have to be developed to achieve even these modest recoveries because of the diversity of wastes involved.

The Panel on Processing also considered the prospects for chromium conservation by improving the metallurgical processing of chromium-containing alloys. Four processing steps were identified in which the potential exists for significant chromium savings. Table 9 presents estimates of the potential chromium savings scaled to the 1977 metallurgical consumption pattern shown in Table 7 . About 21.000 short tons of chromium per year (6.8 percent of 1977 metallurgical consumption) could be saved by employing existing advanced technology for melting, refining, and casting operations. It is estimated that an additional annual savings of about 16,000 short tons of chromium would become technically feasible if research and development directed toward processing improvements were undertaken and proved to be as successful as expected.

Chromium conservation opportunities associated with materials substitution are considered in detail in chapter 6. In most cases, the effective use of a substitute 
TABLE 8 Prospects for Chromium Savings by Recycling of Industrial Wastes

\begin{tabular}{lll}
\hline & \multicolumn{2}{l}{ Potential Chromium Savings a } \\
\cline { 2 - 3 } Source of Waste & 1,000 Short & Percent of 1977 \\
Tons per Year & Segment Consumption
\end{tabular}

\section{Metallurgical}

Ferroalloy slags

Stainless steel furnace dusts

$$
1.0
$$

2.5

Stainless steel grinding swarfs

2.0

3.6

Stainless steel mill scale

Stainless pickel liquor

Ferroalloy flue dusts

ECM and EDM sludges

$$
\text { subtotal }
$$

0.8

3.5

$\frac{1.3}{14.7}$

$$
\begin{aligned}
& 0.3 \\
& 0.8 \\
& 0.6 \\
& 1.1 \\
& 0.2 \\
& 1.1 \\
& 0.4 \\
& \hline 4.5
\end{aligned}
$$

\section{Refractories}

Foundry sand

21
$\frac{34}{40}$
$\frac{31}{65}$

\section{$\frac{31}{65}$}

$\begin{array}{ll}1.0 \mathrm{~b} & 1.5 \\ 2.0-1 & 2.9 \\ 0.7 & 1.0\end{array}$

\section{Chemicals}

Etching wastes

Plating wastes

Catalysts

Chromate and dichromate, leather

tanning, paint pigments, and textiles

$$
\text { Subtotal }
$$

Total

$\frac{0.4}{4.1}$
$\overline{58.8}$
$\underline{\underline{6.0}}$
13.0

a All the potential chromium savings fall into Category 2 (considered potentially feasible with future technology but requiring up to 10 years of research and development).

$\underline{b}$ At present, 1,000 short tons are recovered from plating wastes. 
TABLE 9 Prospects for Chromium Savings by Processing Improvements

\begin{tabular}{|c|c|c|c|c|}
\hline Processing Step & $\begin{array}{l}\text { Potential Savi } \\
1,000 \text { Short } \\
\text { Tons Chromium } \\
\text { Per Year }\end{array}$ & $\begin{array}{l}\text { s- Category 1a } \\
\% \text { of } 1977 \\
\text { Metallurgical } \\
\text { Consumption }\end{array}$ & $\begin{array}{l}\text { Potential Sav } \\
\text { l,000 Short } \\
\text { Tons Chromium } \\
\text { Per Year }\end{array}$ & $\begin{array}{l}5 \text { - Category } 2 \\
\% \text { of } 19-77 \\
\text { Metallurgical } \\
\text { Consumption }\end{array}$ \\
\hline Melting and refining & 19 & 5.9 & 0 & 0 \\
\hline Casting & 3 & 0.9 & 6 & 1.9 \\
\hline $\begin{array}{l}\text { Mill product fabricaiion and } \\
\text { manufacturing processing }\end{array}$ & 0 & 0 & 9 & 2.8 \\
\hline Joining & $\underline{0}$ & $\underline{0}$ & 1.4 & $\underline{0.4}$ \\
\hline Total & 22 & 6.8 & 16.4 & 5.1 \\
\hline
\end{tabular}

a Technically feasiblí now.

$\underline{b}$ Potentially feasible after 10 years of research and development. 
material containing less or no chromium would require some redesign of the product, as discussed in chapters 6 and 4 .

By combining the conservation opportunities identified in chapter 6 with the projected pattern of U.S. consumption in 1977 (Table 7), the estimates of potential chromium savings shown in Table 10 have been obtained. It is estimated that potentially one-quarter of the metallurgical and chemical consumptions of chromium and one-third of the refractory consumption can be substituted using existing technology. If suitably directed research and development programs are undertaken, it is estimated that substitution of an additional one-third of metallurgical consumption and one-half of refractory and chemical consumption would become technically feasible.

The estimates of chromium savings presented in Tables 8 through 10 all refer to the same projected 1977 consumption pattern. It is valid, therefore, to combine them to obtain estimates of the total potential impact of technically feasible conservation measures on the U.S. consumption of chromium. Table 11 presents the summary of estimates of the percentages of metallurgical, refractory, and chemical consumption that could be saved by taking advantage of Category 1 and Category 2 conservation opportunities in the areas of substitution, processing, recycling, and design. The table also lists the sum of the Category 1 and 2 percentages that represent the maximum savings considered technically feasible for each combination of conservation approach and chromium consumption segment. For example. substitution using existing technology (Category 1) is estimated to be capable of saving 25 percent of the metallurgical consumption of chromium. As a result of research and development, it is anticipated that substitution of an additional 36 percent of the same metallurgical consumption base would become technically feasible. Therefore, the maximum technically feasible savings of metallurgical consumption that can be achieved by substitution is $61(25+36)$ percent.

The percentages in Table 11 can be added horizontally but not vertically (because of the problem of double counting). Thus, in Table 11, the total Category 1 plus Category 2 savings that can be achieved in metallurgical consumption is not $78(=61+12+5)$ percent but rather is more closely approximated by:

$$
67=100-\frac{39 \times 88 \times 95}{10,000} \text { percent }
$$

This results because the application of recycling to obtain a 5 percent savings would permit conservation by processing 
TABLE 10 Prospects for Chromium Savings by Materials Substitution and Redesign (1,000 short tons)

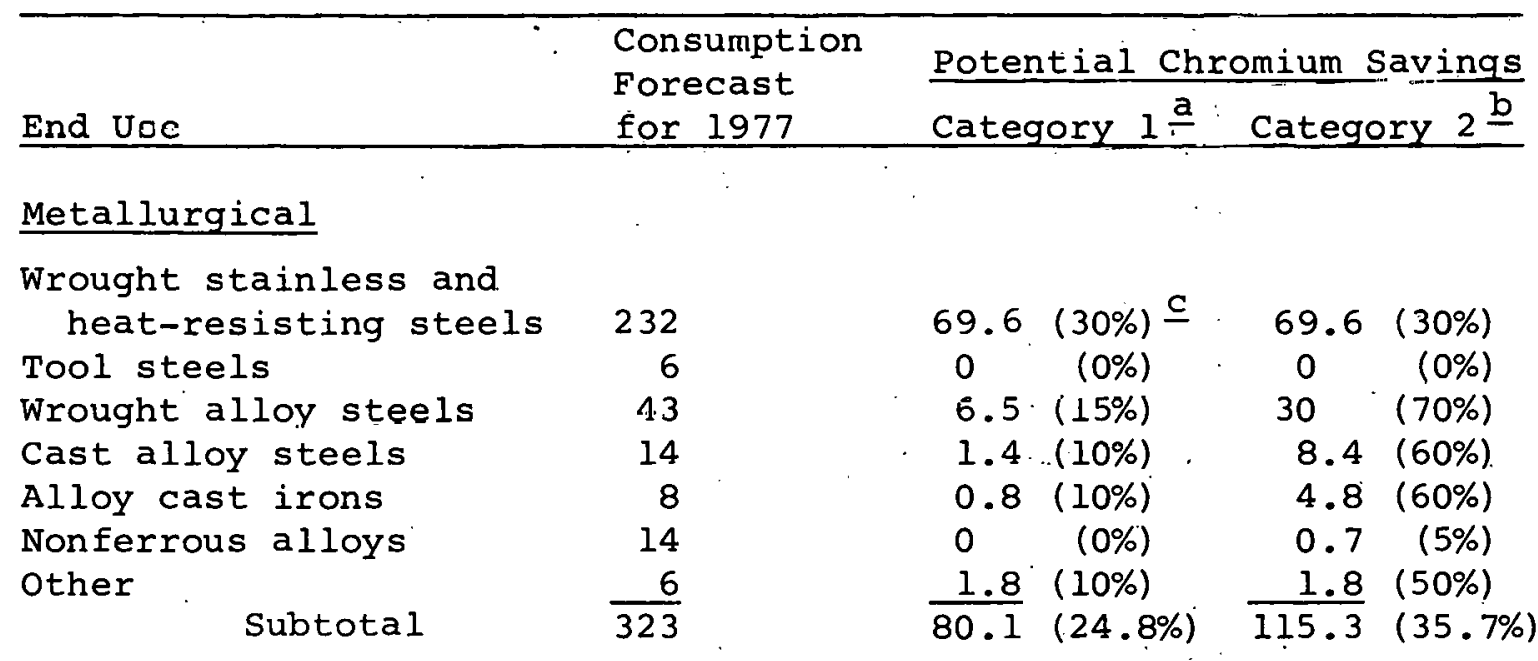

Refractories

Chrome and chromemagnesite brick

Magnesite-chrome brick materials

Granular chromite

Subtotal

$\begin{array}{lllll}10 & 7.5 & (75 \%) & 2.5 & (25 \%) \\ 14 & 4.0 & (28 \%) & 8.0 & (56 \%) \\ 27 & & & & \\ 10 & 5.0 & (18.5 \%) & 20.0 & (74 \%) \\ 61 & \frac{4.0}{20.5}(40 \%) & 4.0 & (40 \%) \\ & & & \end{array}$

Chemicals

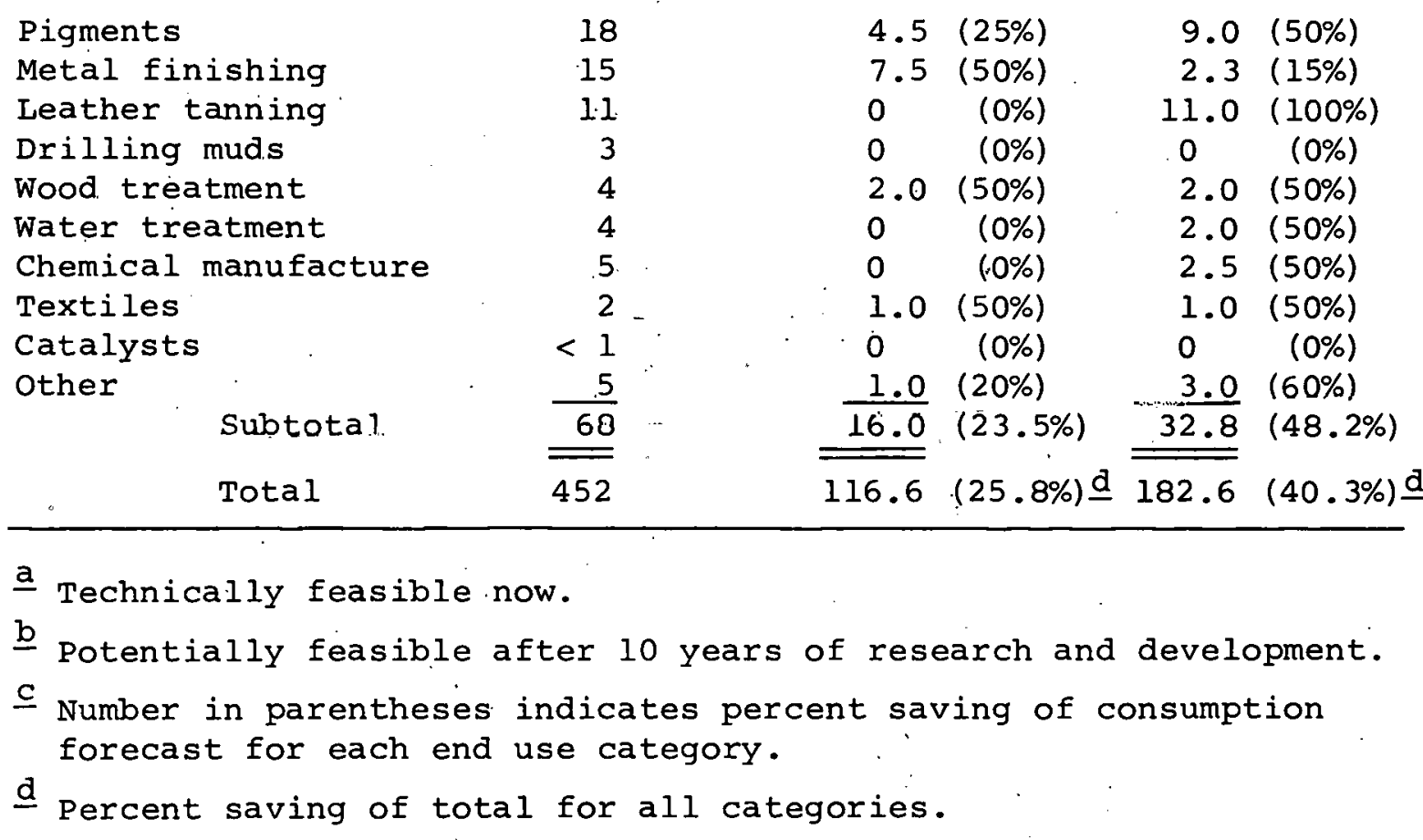


TABLE 11 Overall Summary of Potential for Chromium Savings

\begin{tabular}{|c|c|c|c|c|}
\hline \multirow[b]{2}{*}{ Conservation Approach } & \multirow[b]{2}{*}{$\begin{array}{l}\text { Consumption } \\
\text { Segment }\end{array}$} & \multicolumn{3}{|c|}{$\begin{array}{l}\text { Percent of Segment Consumption That } \\
\text { Can Be Saved. }\end{array}$} \\
\hline & & $\begin{array}{l}\text { By Cate- } \\
\text { gory } 1 \text { a }\end{array}$ & $\begin{array}{l}\text { By cate- } \\
\text { gory } 2 \underline{\mathrm{b}}\end{array}$ & $\begin{array}{l}\text { By Categories } \\
1 \text { and } 2\end{array}$ \\
\hline $\begin{array}{l}\text { Substitution with materials } \\
\text { containing no (or less) } \\
\text { chromium coupled with } \\
\text { redesign as necessary }\end{array}$ & $\begin{array}{l}\text { Metallurgical } \\
\text { Refractories } \\
\text { Chemicals }\end{array}$ & $\begin{array}{l}25 \\
34 \\
24\end{array}$ & $\begin{array}{l}36 \\
57 \\
48\end{array}$ & $\begin{array}{l}61 \\
91 \\
72\end{array}$ \\
\hline $\begin{array}{l}\text { Use of improved processing } \\
\text { methods for alloys containing } \\
\text { chromium }\end{array}$ & Metallurgical & 7 & 5 & 12 \\
\hline $\begin{array}{l}\text { Recycling of wastes containing } \\
\text { chromium }\end{array}$ & $\begin{array}{l}\text { Metallurgical } \\
\text { Refractories } \\
\text { Chemicals }\end{array}$ & $\begin{array}{l}0 \\
0 \\
0\end{array}$ & $\begin{array}{r}5 \\
65 \\
6\end{array}$ & $\begin{array}{r}5 \\
65 \\
6\end{array}$ \\
\hline $\begin{array}{l}\underline{a} \text { Technically feasible now. } \\
\underline{b} \text { Potentially feasible after } 10\end{array}$ & years of resea & and & 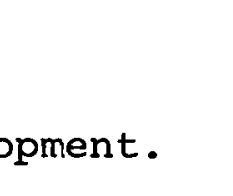 & . \\
\hline
\end{tabular}


improvements, and substitution would only be applied to the remaining 95 percent of the original metallurgical

consumption. Similarly, if the 12 percent processing saving is taken on the remaining 95 percent, only $95 \times 88 / 100$ percent of the original metallurgical consumption will be available for substitution savings. When the 61 percent substitution savings are taken, the remaining consumption will be reduced to:

$$
\frac{95 \times 88 \times 39}{10,000} \text { percent }
$$

of the original metallurgical consumption, which leads to the 67 percent overall savings quoted abuve.

With the above approach, the 1977 chromium consumption was estimated for metallurgical, chemical, and refractory uses for three cases:

- Business as usual (BAU). i.e.. the trend forecasts from Figure 3 and Table 7

- Business as usual less the savings from Category 1 conservation opportunities

- Business as usual less the savings from Category 1 and Category 2 conservation opportunities

The consumption estimates are tabulated in Table 12 and suggest that U.S. chromium consumption potentially could be reduced by 30 percent by conservation based on existing technology. An additional 40 percent reduction in consumption could become technically feasible if research and development related to chromium conservation were púrsued vigorously. The remaining 30 percent of current U.S. chromium consumption cannot be eliminated by the conservation measures identified by the committee.

\subsubsection{Consumption Projections at Two Conservation Levels}

The impact that conservation could have on the future consumption of chromium in the United states now can be projected. Two cases will be considered: The first examines the impact of technically feasible conservation measures based on existing technology (i.e.. Category 1 ). The second case shows the impact of the maximum level of conservation considered technically feasible (i.e.. Category 1 + Category 2).

Because the metallurgical, chemical, and refractory consumption segments are projected to grow at different rates in a business-as-usual situation (Figure 3), they were 
TABLE 12 Overall Impact of Potential Conservation Opportunities on Chromium Consumption Forecast for 1977 (1,000 short tons)

\begin{tabular}{|c|c|c|c|}
\hline \multirow[b]{2}{*}{$\begin{array}{l}\text { Consumption } \\
\text { Segment }\end{array}$} & \multirow{2}{*}{$\begin{array}{l}\text { Present } \\
\text { Consumption } \\
\text { (BAU } \underline{a} \text { ) }\end{array}$} & \multicolumn{2}{|c|}{ Projected Net Consumption } \\
\hline & & BAU - Category $1 \underline{b}$ & $\begin{array}{l}\text { BAU - Categories } \\
1 \text { and } 2 \subseteq\end{array}$ \\
\hline Metallurgical & 323 & 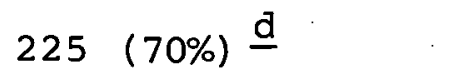 & $105(33 \%)$ \\
\hline Chemical & 68 & $(76 \%)$ & $(26 \%)$ \\
\hline Refractories & 61 & $(66 \%)$ & $(3 \%)$ \\
\hline Total & 452 & $(70 \%)$ & $125(28 \%)$ \\
\hline
\end{tabular}

a Business as usual.

$\underline{b}$ Business as usual less the savings from Category 1 conservation opportunities (technically feasible now).

$\subseteq$ Business as usual less the savings from the conservation opportunities from Category 1 (technically feasible now) and Category 2 (potentially feasible after 10 years of research and development).

d Numbers in parentheses indicate percent of 1977 segment consumption. 
treated separately in preparing the projections that follow. However, it was assumed that the pattern of chromium use within each of the three segments would change little during the remainder of this century. This assumption permits use of the percent business-as-usual datä listed in Table 12 for the three segments to estimâte the impact of conservation on futurê U.S: consumption.

Figure 6 summarizes the trends in chromium consumption that would result if the United states reduced its chromium consumption by implementing conservation measures based on currently available technology. The several scenarios included in Figure 6 assume that no supply constraints exist. Curve $A B C$ is the business-as-usual projection from Figure 3. Curves $A D H$ and $A E H$ are projections of consumption following initiation of Category 1 conservation programs in 1977: The consensus off the Committee was that $d$ period of five years might be needed to implement category 1 conservation measures: in añ orderly manner but that implementation probabiy coula be accomplished in about half that time in a national emergency. The 5-year and 2.5-year implementation periods result in curves $A E H$ and $A D H$. respectively. (For converience, it has been assumed that consumption falls linearly as the Category 1 conservation meașures are implemented:) curves $B G H$ and $B F H$ depict the effect of initiating an equivalent conservation program in 1987 for 5-year and 2.5-year implementation periods. respectively.

Fiğure 6 shows that implementation of the Category 1 conservation measures leads to a transition from the business-as-usual consumption growth curve to a second growth curve at about a 30 percent lower level of consumption. However. because implementation of the conservation measures requires a significant amount of time, the minimum consumptions reached when the conservation program has been fully implemented are always greater than 70 percent of the consumption at the time the program was initiated. For example, the consumption at $\mathrm{E}$, the low point on curve $A E H$, is about 78 percent of that at $A$ because of the anticipated continuing growth during the implementation period in those end uses not affected by the conservation measures.

If Figure 6 is considered in the context of a chromium supply shortage. it is apparent that the effectiveness of conservation as a response increases as the implementation time decreases. Thus, the shaded triangles ADE and BFG in Figure 6 represent chromium consumption that is eliminated by implementing the Category 1 conservation measures over a 2.5-year period rather than a 5-year period. 


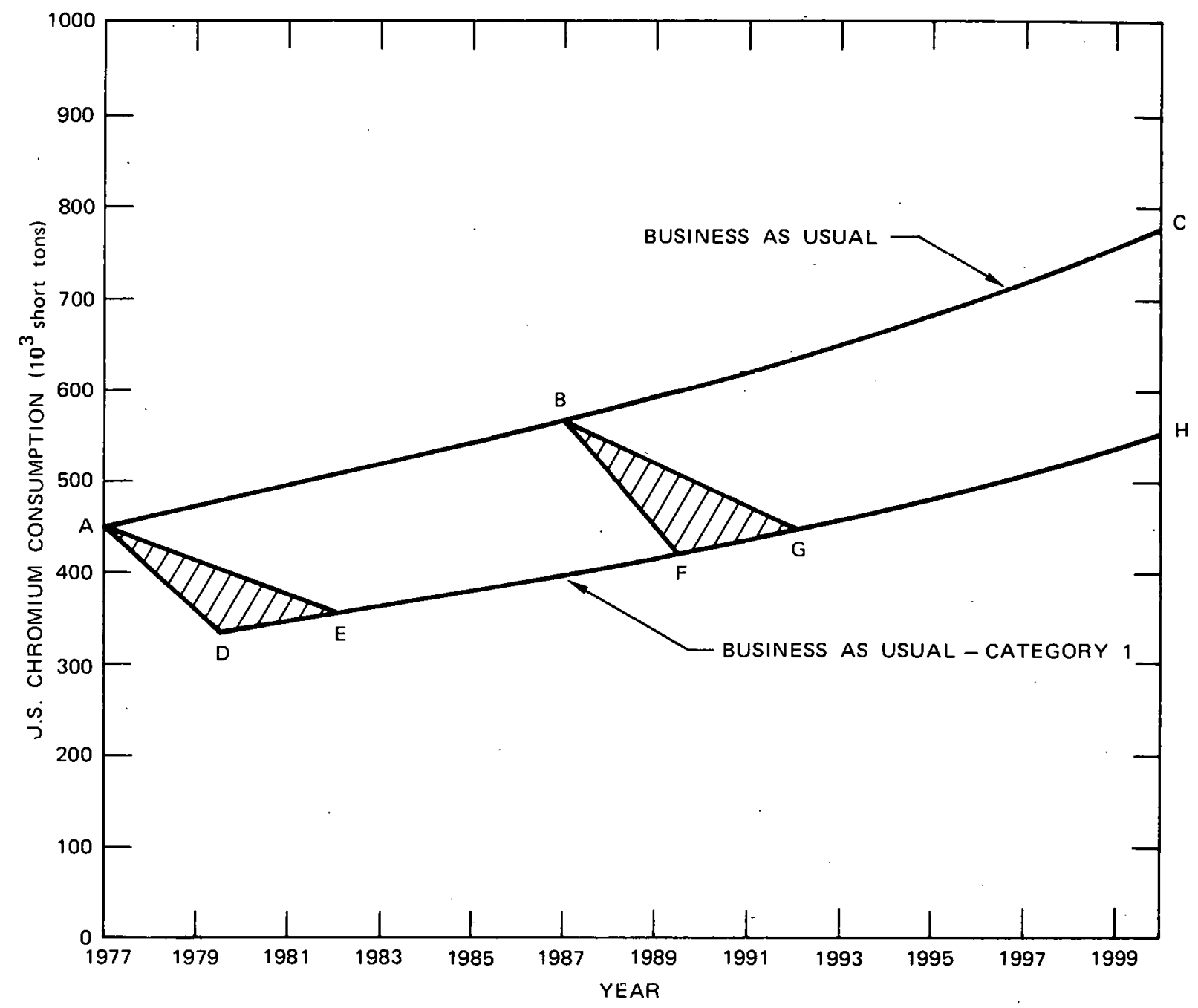

FIGURE 6 Projections of U.S. Chromium Consumption Showing the Impact of Implementing Conservation Measures Based on Currently Available Technology 
Figure 7 summarizes the expected trends in chromium consumption if the United States were to implement all the conservation measures considered by the committee to be potentially technically feasible. Curve ABC again shows the business-as-usual consumption projection from Figure 3. As before, implementation of the conservation measures results in a transition from the business-as-usual curve to a lower consumption growth curve that, in the present case, is at about 30 percent of the business as usual consumption level. Curve ADEH projects the consumption expected if the U.S. were to implement Category 1 and Category 2 conservation measures over a 12.5-year period lconsidered the minimum practicable in view of the 10-year research and development period required before implementation of some of the Category 2 measures could begin) beginning in 1977 . segment $A D$, replotted from Figure 6 , reflects the impact (assumed linear) on consumption of implementing the Category 1 conservation measures as quickly as possible. segment $D E$, (again assumed linear) is attributable to implementation of the Category 2 measures as they become available. At $E$, the low point on the curve, the consumption is about 170.000 short tons per year or about 37 percent of the consumption level at which the conservation program was initiated. However, a long lead time of 12.5 years is required to fully implement the conservation measures.

Curve $A B I G H$ is based on the same assumptions as curve ADEH except that program initiation is assumed to occur in 1987 rather than in 1977. Here again. implementation of the category 1 and category 2 conservation measures drives consumption down to about 37 percent of the level at which the program was initiated but only over a long period of time. In contrast. curve $A B F H$ shows the projected consumption if the research and development needed for the category 2 conservation measures had been completed in advance (i.e.. if the required 10 -year research and development program had been initiated in 1977 and had been brought to a successful conclusion before the initiation of the conservation program). It is estimated that implementation of the Category 1 and Category 2 conservation schemes then could be completed within five years. The consumption at the end of this period would be about 180,000 short tons or about 32 percent of the consumption at the initiation of the program. If the conservation program was undertaken in response to a supply shortage, curve ABFH would represent a much stronger response than curve ABIGH because it would allow reducing the cumulative U.S. chromium consumption to be decreased by an amount equivalent to the shaded area in Figure 7. 


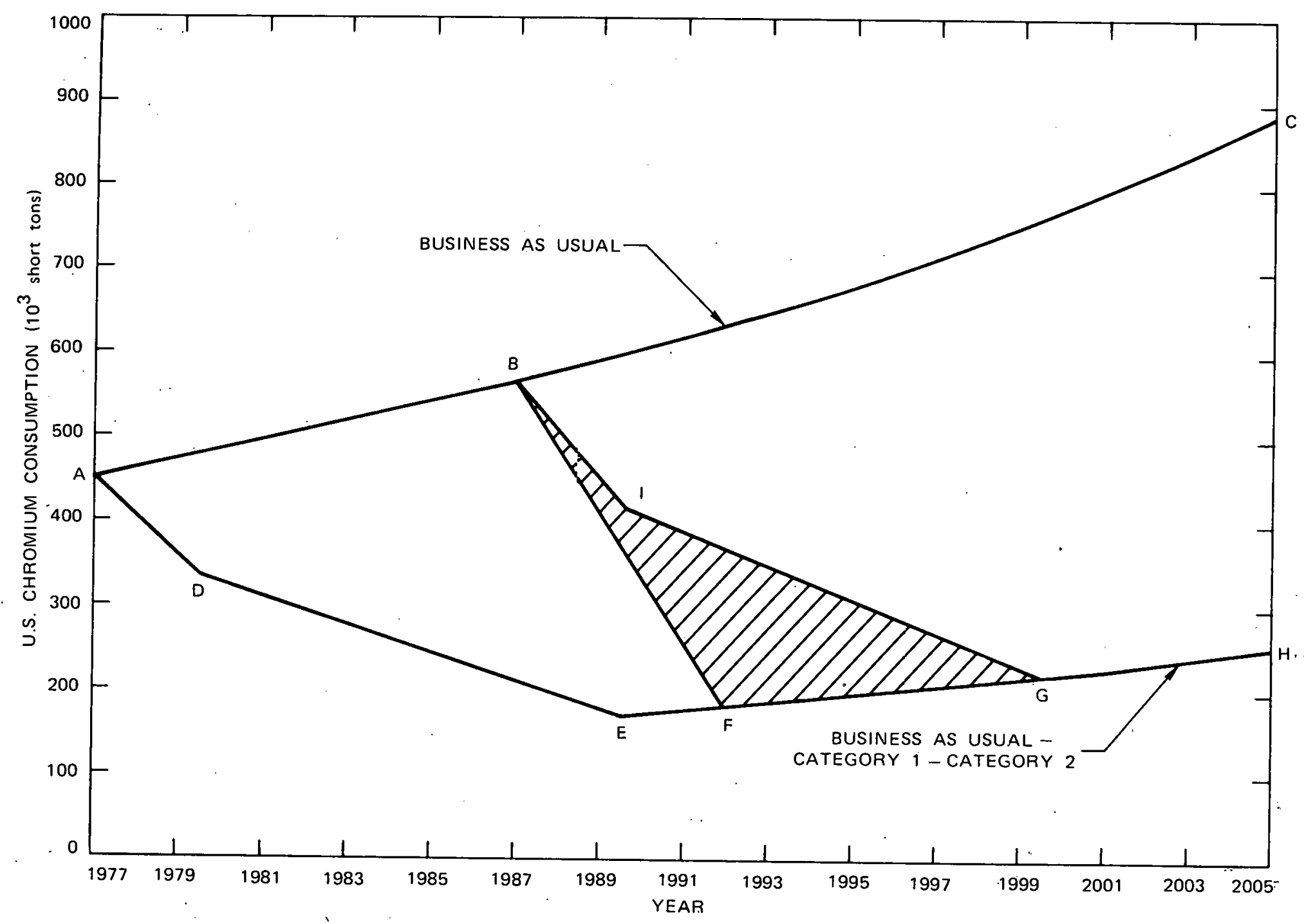
$\begin{array}{cl}\text { FIGURE } 7 & \text { Projection of U.S. Chromium Consumption Showing the: Impact of } \\ & \text { Maximum Technically. Feasible Conservation }\end{array}$ 
The quantitative estimates of chromium savings and lead tines embodied in Figures 6 and 7 are subject to cunsiderable uncertainty and very few accurate data exist for improving the present estimates. Moreover. further refinement of the quantitative data probably would not have much effect on the conclusions reacned since the consumption rate is offset only temporarily.

\subsubsection{Impacts of Conservation}

In this section, the following question is considered: If an intensive program of chromium conservation is implemented by the United states in response to a chromium supply shortage, what would be the foreseeable impacts. other than the desired decrease in consumption? Chromium is irreplaceable for some applications and the amounts used for them are small compared to total U.S. consumption. Hence. the available chromium would be allocated preferentially to these end uses. Examples of industries that would be affected little by drastically reduced chromium availability and strong efforts to conserve it are:

- Tool steels, which use chromium for metal cutting and forming

- Superalloys, which use it for jet engines and gas turbines

- Chromium chemicals, which are used in closed systems for water treatment additives and in leather tanning.

Some industries would benefit by drastically reduced availability of chromium and by strong efforts to conserve it. Examples are manufacturers of substitute materials such as titanium, tantalum, aluminum, zinc, plastics, porcelain enamel, coatings, and metal paints. A lack of chromium because of high prices or government taxes to restrain its use and enforce its recycling would strongly encourage substitute materials. Many industries would benefit by recapturing old markets previously lost to chromiumcontaining materials or by creating new markets. As no one material could substitute across-the-board, the impact on any given material would be modest but always positive.

other industries, likely to benefit, are associated with recycling efforts. Examples are: 
Industry

Scrap sorting

Crushing and grinding

Chemical processing

Beneficiation
Application

Metals

Refractories and foundry sands Chemical waste and effluents

Stockpiled material and

low-grade ore

An immediate demand by chromium-consuming industries to use state-of-the-art recycling equipment and technology in the above applications would be expected as well as incentives to develop more efficient and less costly new processes.

Still other industries likely to benefit are associated with the production of clad and coated materials and their subsequent testing and processing. In the event of a requirement to reduce chromium demand substantially, the use of stainless clads and coatings on less corrosion- and oxidation-resisting materials would increase and would require new technology and increased production capacity. More importantly, demand would arise for equipment to form, join, and edge-seal such composite materials. New nondestructive testing procedures and equipment also would be required to ensure the integrity of the protective surface layer when initially formed and after subsequent inplant processing.

Many industries would be affected unfavorably by drastically reduced availability of chromium and strong efforts to conserve it. Examples are:

\section{Industry}

Refractories Nonferrous alloys stainless steels

Alloy steels

\section{Use}

Steel producers and foundries Broad spectrum of users Fabricated metals, machinery other than electrical, transportation primary metals, machinery other than electrical, fabricated metals

The greatest impact would be on stainless steel producers and users because the opportunity to apply or develop lowchromium stainless alloys is limited. In a truly drastic supply situation, it would be necessary to live with less stainless steel. The consequences for some user industries would be modest or only economic in nature, but the effects would devastate others, such as the nuclear power industry.

very few of the chromium conservation opportunities identified in chapters 4 through 6 are cost-effective at present; therefore, implementing an intensive program of 
chromium conservation would involve substantial costs as well as sacrifices in service performance. These added costs may arise from more complex designs, additional processing steps, additional testing or from the use of more expensive substitute materials. As a consequence, the overall impact of a chromium conservation program on the U.S. industry and economy is certain to be negative. Just how negative would depend critically on the extent to which conservation was implemented. Although the committee was unable to generate any meaningful quantitative estimates, it is considered likely that achievement of a 70 percent reduction in consumption, while technically feasible, might be potentially crippling to the economy but that a 30 percent reduction might be attainable without serious economic consequences or industrial dislocations.

\section{3. 4 Discussion and Conclusions}

It would be technicaliy feasible to reduce U.S. chromium consumption by about one-third by implementing existing conservation technology and by about two-thirds by supplementing existing technology with the new developments expected to result from a 10-year program of research and development related to chromium conservation. The effectiveness of conservation as a response to a chromium shortage depends strongly on the time required to implement the chromium conservation programs -- a much stronger response to a hypothetical supply shortage in 1987 would be possible if, in the interim, the 10-year research and development program, mentioned above, had been completed successfully. Even so, the lead times required to fully implement chromium conservation programs are so long that conservation would not become effective as a response to a shortage of supply unless the shortage were to last for several years.

The committee ajoes not believe that the reductions in. chromium consumption discussed in this section will be selfinitiating in the U.S. market-oriented economy. Rather, the reductions represent what could be expected from a planned program. In the Committee's view, if the United States were faced with a shortage of chromium supply, the need for a planned program would be imperative. If the marketplace were the sole determinant for allocating limited supplies of chromium, automobile bumpers might win out over chemical tanks.

The industrial dislocations and economic penalties associated with an intense national effort to conserve as much chromium as is technically feasible would be severe but might be acceptable in a national emergency. However, if the United states attempted to pursue chromium conservation 
unilaterally in anticipation of a possible supply shortage rather than in response to a real situation, the substantial penalties involved would not be justifiable. In fact. unilateral conservation by the United states as: a hedge against a possible future shortage makes very little sense except for the relatively few conservation opportunities. that do not entail cost-performance penalties." Since most of the conservation measures are not currently costeffective, they would not be implemented voluntarily but would have to be legislated. The effect of such legislation would be poorer quality and more expensive products than could be produced with the normal use of chromium. Aside from the reduction in societal benefits, these legislated changes would have a substantial economic impact on the competitive position of these U.S. products relative to foreign products that would be made using the normal chromium practice. For example, if the United states decided unilaterally to substitute silver plate for stainless steel in domestically produced flatware, foreign suppliers of stainless steel flatware would attempt to satisfy the U.S. market with their less expensive products. If the United States truly wanted to conserve the chromium used in stainless steel flatware, it woula be necessary to embargo imports. This solution is not very practical considering the vast number of products for which a comparable situation would exist.

On the other hand, a reduction in chromium consumption on a worldwide basis (if such an agreement could be reached) might be justifiable if it provided the time necessary to develop durable agreements regarding the management of remaining chromium resources. This aspect is part of a. much larger issue concerning world mineral resources in general and is beyond the scope of this committee's deliberations.

Although in the United States it is difficult to justify initiating any chromium conservation programs that are likely to produce adverse economic consequences. research aimed at the development of alternative materials, process improvements, design efficiencies, and recovery and recycling of spent chromium should be accelerated. As seen in Figure 7, the developments that result from this research would be of considerable value if a shortage of chromium supply occurred in the future. This research also may proauce new methods for reducing chromium consumption that are economically attractive, particularly if chromium prices rise. However, under present economic conditions, the required research is not likely to be undertaken by industry without government incentives.

Finally, although conservation may reduce the vulnerability of the Unitea States to chromium shortages, it 
cannot eliminate it. About one-third of U.S. chromium demand cannot be saved by conservation measures based on present or projected future technology. Much of this chromium is consumed in uses that are absolutely vital to U.S. inaustry. Approaches other than conservation. theretore, are required to assure that enough chromium is availatle to satisfy these needs. Moreover, because of the long implementation times required, conservation alone would be of little value in the event of an abrupt disruption of chromium supply. To respond effectively to this situation. stockpiles could make up larger deficits while conservation measures are being implemented, in addition to providing the substantial amounts still required on a continuing basis.

\section{4 ALTERNATIVES AND SUPPLEMENTS TO CONSERVATION}

\subsection{Stockpiling}

One of the traditional approaches to the problem of providing protection against potential cartelization of raw materials has been the use of stockpiles and, indeed, the U.S. Government has a stockpile of chromium. A summary of the content of the stockpile is presented in Table 13.

The time to deplete this stockpile depends on the rate at which the United States is consuming chromium and the makeup of the stockpile. Figure 8 shows a projection of the approximate number of years to use up the entire stockpile as a function of time, assuming that all of the material in the stockpile inventory at present could be used and that U.S. consumption follows the business-as-usual growth curve depicted in Figure 3. (The question of whether the present content of the stockpile is optimum is adaressed in

chapter 5.) As can be seen, the stockpile offers more than three years of protection at present consumption rates; however, this protection would dwindle to less than two years by 2000 if no conservation programs are initiated and the stockpile itself is unchanged.

The key issue regarding stockpiling of chromium concerns the type of protection sought. If protection is sought aydinst a cartel trying to maximize its economic returns and if that cartel has the resources to hold out long enough, no feasible stockpile can suffice. If, on the other hand, the United States is seeking protection against temporary supply dislocations, such as might occur due to short-term instabilities, it is necessary to define an appropriate protective time period. For any such decision. Figure 8 indicates the protection that would be realized from the current stockpile. Changes in the stockpile would produce proportionate shifts in crotective times. 
TABLE 13 U.S. Government Stockpile of Chromium-Based Materials (1,000 short tons) a

\begin{tabular}{|c|c|c|}
\hline Description & Inventory & $\begin{array}{l}\text { Estimated } \\
\text { Contained. } \\
\text { Chromium }\end{array}$ \\
\hline \multicolumn{3}{|l|}{ Ores } \\
\hline Metallurgical & 1,984 & 651 \\
\hline Chemical & 254 & 76 \\
\hline Refractory & 406 & 86 \\
\hline Nonstockpile grade & 561 & 172 \\
\hline \multicolumn{3}{|l|}{ Ferroalloys } \\
\hline High-carbon & 409 & 266 \\
\hline Low-carbon & 304 & 198 \\
\hline Silicon & 57 & 23 \\
\hline Nonstockpile grade & 25 & 13 \\
\hline \multirow[t]{2}{*}{ Chromium metal } & 4.5 & 4.5 \\
\hline & & $1,489.5$ \\
\hline
\end{tabular}

NOTE: Based on data from U.S. Bureau of Mines 1975.

a As of September 30, 1975 . 


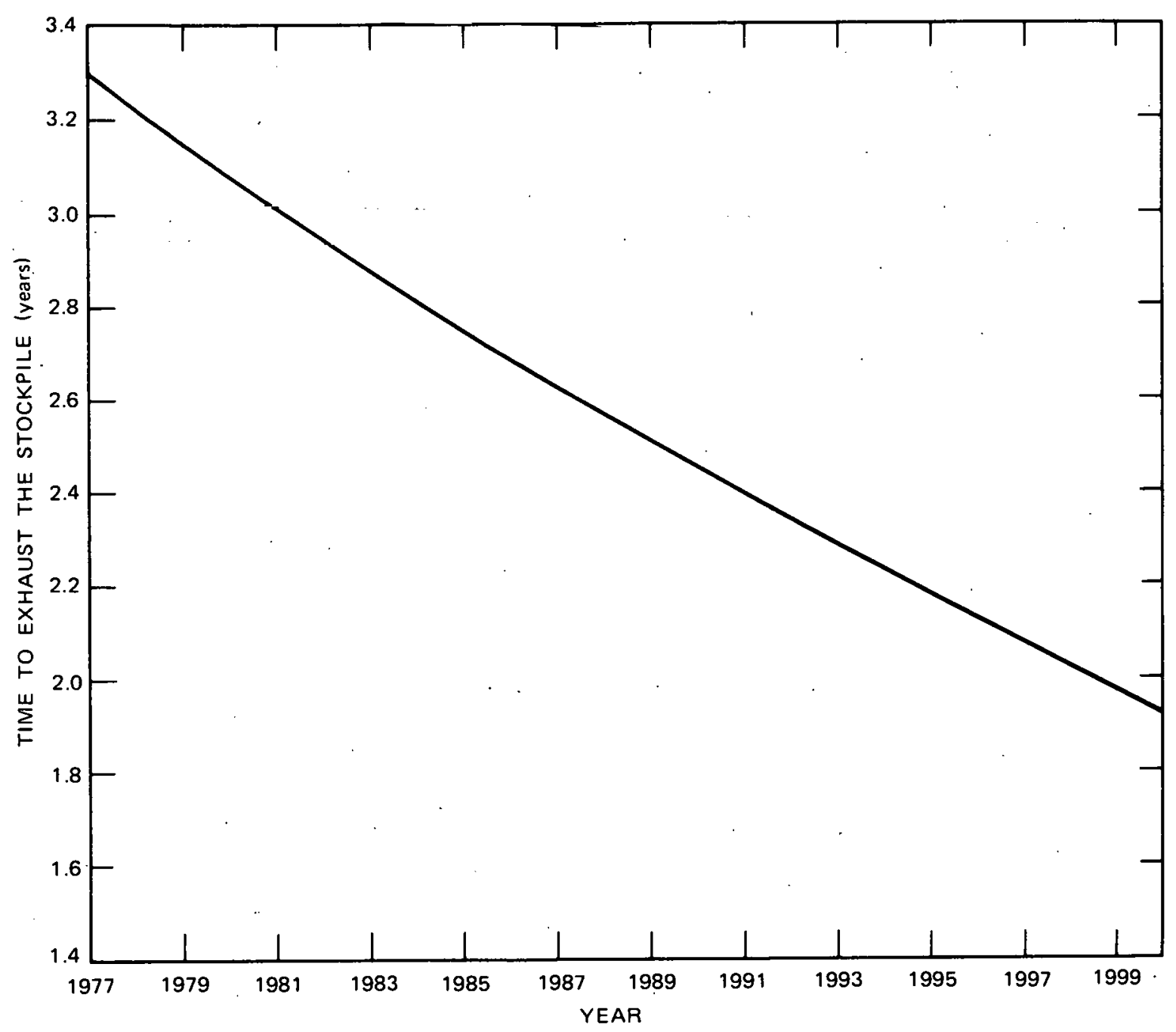

FIGURE 8 The Protection offered by the U.S. Chromium Stockpile on a Business-As-Usual Basis 
The U.S. strategic stockpile of chromium is part of a program concerned primarily with wartime protection. During such emergencies, the causes of shortages and the natural demand patterns are considerably different from those normally encountered. Should the United States wish to increase its stockpile as assurance against "economic warfare," politically induced embargoes, etc.. innovative approaches to stockpiling may be appropriate. For example. if all the new automobiles sold in the united states containea 10 pounas of chromium in an easily recoverable form (e.g.. hub caps made from a standard high-chromium alloy). within about 10 years, a "stockpile" of about 500,000 short tons would have been established -- enough to satisfy the demand for about one year. This suggestion would require study by government and a government policy decision, and would have to be implemented by the end-use industry involved.

Although the maintenance of a strategic stockpile of chromium-containing materials generally is accepted as a necessary and effective strategy, the desirability of a separate economic stockpile is a controversial subject being debated in and out of congress. An economic stockpile might benefit from the cyclical nature of world industry by accumulating excess stocks of minerals and metals when times are slack, providing a buffer from severe economic dislocations in an emergency and a little more time for research and development on alternative responses to minerals shortages.

\subsubsection{Exploration}

Another method of reducing the vulnerability of the United States to future shortages of chromium would be to attack directly the developing problem of increasing geographic concentration of chromium ore resources. As mentioned earlier, the United states has reduced its vulnerability in the past by obtaining its chromium needs from a diverse group of suppliers. This policy could be continued if additional exploration resulted in the discovery of new, high-quality ore deposits in areas of the world remote from southern Africa. It would not be necessary to develop these deposits. The mere fact of their existence would provide excellent protection against a longterm supply embargo (but not against a short-term supply disruption) .

However, as mentioned earlier, the size of the Rhodesian and South African reserves essentially eliminates any incentive for additional exploration on the part of private industry. Thus, any additional exploration probably must be financed by the $U . S$. government, either directly or 
indirectly. The involved exploration costs could be considerable, and high capital costs would be incurred if the new deposits had to be developed hurriedly in an emergency. Moreover, there is absolutely no assurance that additional exploration would uncover new, economically exploitable ore deposits. Thus, although additional exploration might aid in reducing U.S. vulnerability. exploration alone would not provide a solution to the problem.

\subsubsection{Combined Approaches}

Up to this point, the Committee considered the separate use of conservation, stockpiling. and exploration to reduce U.S. vulnerability to future shortages of chromium. However, an optimum solution to this situation probably would be to combine two or, possibly, all three of these approaches.

For example, if exploration were undertaken and proved successful, these new sources could reduce the vulnerability of the United States. However, in the interim, the stockpile must provide adequate supplies for the time needed to develop the newly discovered ore deposits. An alternative approach (that would avoid the element of uncertainty involved in exploration and might also prove to be less expensive) would be to combine conservation and stockpiling. Figure 9 shows the way in which the stockpile would be depleted following a hypothetical complete cessation of chromium imports at the beginning of 1987. If the present stockpile were used to supply the entire U.S. consumption anā consumption continued unchecked (i.e.. consumption followed the business-as-usual curve in Figures 6 and 7), the stockpile would be exhausted by mid1989 (curve 1). Implementation of the Category 1 conservation measures over a 2.5-year period (curve $A B F H$ in Figure 6) would increase the depletion time only by about 7 months. Even if the maximum technologically feasible conservation response was implemented (curve $A B F H$ in Figure 7), the stockpile would still be exhausted by mid-1990.

The ineffectiveness of the conservation measures in the case illustrated in Figure 9 is due to the comparatively long lead times required to implement the conservation programs. Obviously, protection can be improved by adjusting the stockpile size to obtain a better match between the stockpile depletion time and the time required to implement the conservation measures. Figure 10 illustrates what happens if the available stockpile is doubled to $3 \mathrm{million}$ short tons of contained chromium and if chromium imports cease in 1987. In this case, unchecked consumption (curve 1) would exhaust the stockpile in five 


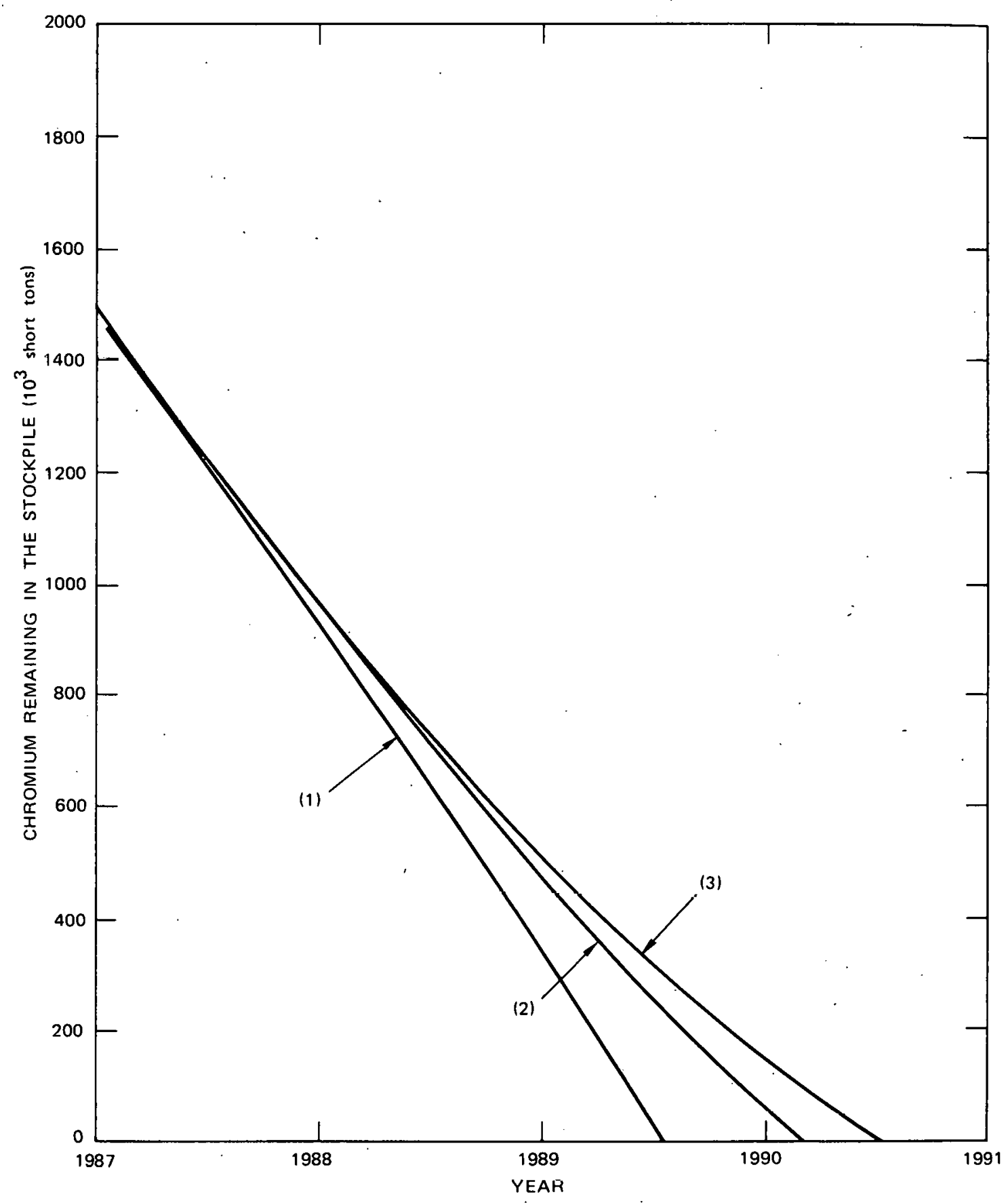

\section{Depletion Curves}

1 - Business as usual.

2 - Using currently available conservation methods.

3 - Using maximum technologically feasible conservation.

FIGURE 9 Depletion of the Present Chromium Stockpile Following a Hypothetical Cessation of supply in Early 1987 


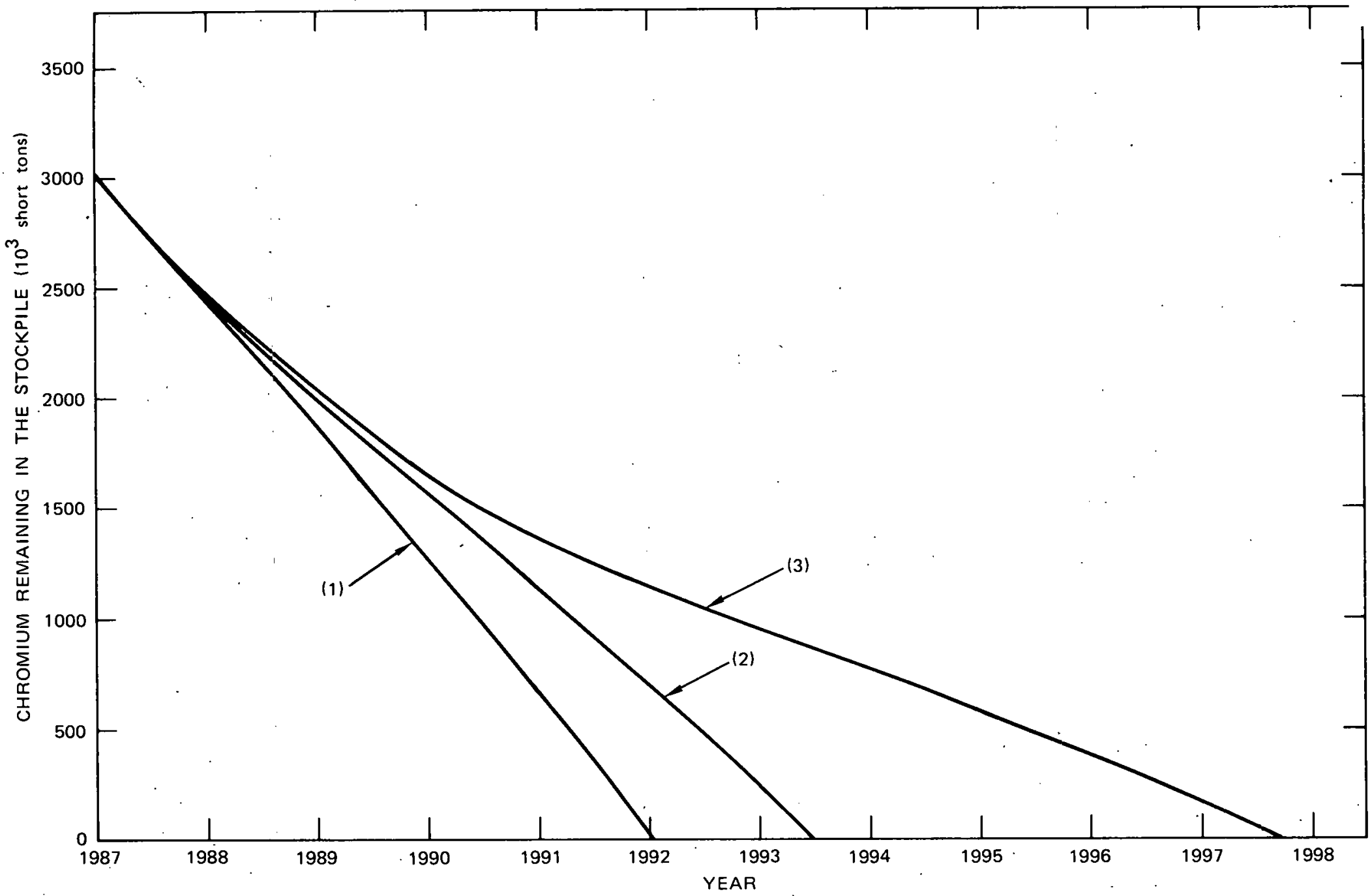

\section{Depletion Curves}

1 - Business as usual.

2 - Using currently available conservation measures.

3 - Using maxinum technologically feasible conservation.

FIGURE 10 Deplezion of an Enlarged Chromium Stockpile Following a Hypothetical Cessation of Supply in Early 1987 
years; implementation of Category 1 conservation measures is again relatively ineffective (curve 2), but implementation of Category 1 plus Category 2 conservation measures would more than double the effective life of the stockpile (curve 3). However, curve 3 is based on the assumption that the research and development required for the Category 2 conservation measures had been completed prior to the cessation of imports in 1987.

A final possibility is to develop a three-pronged approach to reducing U.S. vulnerability. Consider the situation if over the next 10 years the United States: increased its chromium stockpile to $3 \mathrm{million}$ short tons contained chromium, (2) undertook a successful program of research and development aimed at chromium conservation, and (3) undertook a successful program of exploration to locate additional ore deposits. The United states then would be in an excellent position to respond to any subsequent supply interruption. As shown in Figure 10, the combination of the larger stockpile and an intensive conservation program could satisfy the chromium requirements of the country for more than 10 years, providing ample time to bring ore production from the new deposits up to the required level.

\subsection{CONCLUSIONS AND RECOMMENDATION}

1. Over the years, the unique properties, low cost, and plentiful supply of chromium-containing materials have made important segments of U.S. industry vitally dependent on chromium. These same factors have inhibited, almost entirely. research on possible substitutes for chromium and serious efforts to conserve, reclaim, or recycle chromium-containing materials. Now, a drastic curtailment of the availability of chromium would have serious consequences in both the short and long term.

2. The present situation regarding worldwide chromium ore resources appears to favor the development of a Rhodesian/South African supply monopoly over the next 25 to 75 years. Thus, the United states. which is completely dependent on imports for its substantial chromium requirements. will become increasingly vulnerable to politically or economically motivated interruptions of supply as alternative ore resources dwindle in the future.

3. The strategic role that chromium plays in U.S. society and the unique geographic concentration of known ore resources are not widely known or appreciated even among many materials experts, and 
failure to appreciate this role only can work against developing the long lead-time technologies, stockpiles, or international agreements necessary to avoid economic dislocations.

4. None of the three approaches considered here (conservation, stockpiling, and exploration) can protect the United States completely against the possibility of a future disruption (or drastic shortage) of chromium supply. Although conservation technically may be capable of reducing U.S. consumption hy as much as 70 percent, the lead time to implement the program needed to achieve this level of savings is substantial, probably as mucr as 12.5 years at present. While this lead time could be reduced to perhaps 5 years following completion of a suitably directed 10-year research and development program. conservation will remain an ineffective response to short-term (< 5 years) supply interruptions. Moreover. chromium conservation involves economic penalties that, although difficult to quantify. would be severe if attempted reductions of consumption approach the limits of technical feasibility. Because of these costs and because the rate at which the world's ore resources are expected to concentrate are not likely to be very sensitive to changes in U.S. consumption. conservation is only appropriate as a response to an actual shortage of supply (i.e., nothing will be gained by unilaterally implementing a policy of chromium conservation in the United States in anticipation of a possible future shortage of supply) .

5. Stockpiling can provide the United States with effective protection against short-term interruptions of supply but its protection is finite and could be overcome by sufficiently determined action by the suppliers. obviously, if a supply monopoly develops. Rhodesia and south Africa will be in a position to wait out any conceivable stockpile should they choose to do so. The general issue of stockpiling policy lies outside the charge of this committee. However, it is apparent that for stockpiling to be most effective, the material in the stockpile must be optimally matched to U.S. needs. Thus, the content of the stockpile must be adjusted at fairly frequent intervals to compensate for trends, such as the decreasing domestic 
ferrochrome productive capacity. A further observation pertinent to the present study is that a substantial builaup of the size of the U.S. stockpile is unlikely to be viewed with much enthusiasm by the chromium suppliers and might actually trigger a reaction such as the formation of a cartel.

6. Exploration, if successful in finaing exploitable new chromium reserves, would provide protection against a long-term interruption of supply even if the new deposits were not developed initially. However, there is no current incentive for exploration so the costs (which might prove to be considerable) would have to be borne by the U.S. government. Furthermore, the probability of success is unknown and, even if success were achieved, little protection against short-term supply shortages or disruptions would be provided because of the long lead time required for the development of the deposits. This lead time could be reduced if the deposits were developed as, and when, they were found but the costs involved would be very high and probably are not justifiable in view of the known size of the deposits that are already in production.

7. An optimum response to reducing the vulnerability of the United States. probably would be to combine all three approaches. stockpiling in one form or another could be used to provide short-term protection (< 5 years). Medium-tcrm protection (5-10 years) would be achieved by using conservation to extend the life of the stockpile. while exploration would provide insurance against a truly long-term interruption of supply $(>10$ years).

The committee recommends that the U.S. government consider the following three actions:

plan and fund a 10-year research and development program aimed at the development of advanced chromium conservation technology and focused on the specific opportunities for chromium conservation by recycling. substitution, and processing improvements identified in chapters 4 through 6 of this report.

- Develop and implement a program of incentives to encourage exploration for additional nigh-quality 
chromium ore deposits in nearby parts of the world such as South America and Canada.

Fund studies on innovative methods of stockpiling chromium to provide up to 5 years of protection against a cessation of imports and on improved methods of ensuring that the content of the strategic stockpile is matched properly to the changing needs of the United states.

P.EFERENCES

Institute of Geological sciences. Statistical Summary of the Mineral Industry. London. England: Her Majesty's Stationery Office, 1955, 1960, 1965, 1970, 1975.

U.S. Bureau of Mines. Chromium-- 1977. USBM Mineral Commodity profiles report no. MCP-1. Washington, D.C.: U.S. Bureau of Mines, May 1977.

U.S. Bureau of Mines. Minerals Yearbook: Vol. 1. Metals, Minerals and Fuels. Washington, D.C.: U.S. Bureau of Mines. 1950-1974. 1975 (preprint).

U.S. Bureau of Mines. Mineral Facts and Problems. USBM Bulletin 667. Washington, D.C.: U.S. Bureau of Mines, 1975.

U. S. Bureau of Mines. Mineral Industry Surveys: Chromium, Monthly: Washington, D.C.: U.S. Bureau of Mines. 1976 (monthly). 


\section{Chapter 4}

DESIGN

\section{1 INTRODUCTION}

The present raw material cost of chromium will not spur the designer to substitute alternate materials or to "design around" chromium; therefore, he must be educated to use the minimum amount of chromium consistent with conservation and recycling philosophies. Thus, a design philosophy for chromium conservation is presented in this chapter to make availatle to the designer some of the information that he needs to perform his function efficiently. Also presented are initial systems design criteria that can minimize the nation's dependence on chromium imports. Examples from the energy, transportation, marine, and process industries are used to illustrate barriers and incentives to change and innovation.

\subsection{DESIGN CONSIDERATIONS}

During the recent industrial growth era, the designer has been the arbiter in establishing customer preference with respect to shape, aesthetics, and style as well as materials of construction. The major impact for future chromium conservation may be initiated by his using tradeoff studies that weigh operating efficiency and life-cycle cost against the amount of chromium incorporated. To perform effectively in the future, the product designer must consider the facturs discussed below.

\subsection{Bias}

The designer often selects a particular material or mill form basea on his prior experience. Since this experience was gained when first cost and aesthetics rather than chromium conservation were the design motivators, specific guidelines, indoctrination, training, and a unified policy must be developed to tell the designer which processes have the greatest potential for using chromium efficiently (e.g.. least losses in melting and recycle). which forms (casting, forging, or weldment) are most effective, and which materials can meet the requirements of the product. These points are discussed in greater detail below.

\subsubsection{Available Resources}

A basic guideline of the designer is the short-term and long-term availability of mineral resources. If major 
elements of an alloy are considered critical, unavailable or not stockpiled, the designer normally will not use them in a product. Because of its geopolitical sensitivity. chromium falls into the critical category.

\section{2.3 Reliability and Life Expeclangy}

When the function or performance of a product is defined, the product must be analyzed in sufficient detail to establish minimum design criteria to ensure that it functions properly and achieves desired goals of reliability, maintainability, cost, and aesthetics. The selection of candidate construction materials, another key aspect of the design process, involves effecting the best compromise and considering such design factors as product life, initial and total cost, and efficiency of operation as well as environment (corrosion, oxidation). temperature. requisite strength properties, weight, and form. For example, if the operating temperature of a nuclear reactor were reduced, stainless steel would not be needed and a significant chromium saving would be achievea but efficiency would be sacrificed. The customary questions in design practice are: Is this desirable? Is it economical? Can performance objectives be met?

Another major design consideration that affects chromium conservation is selecting criteria for life and maintainability. Generally, the designer must choose between finite and long life design (i.e.. should he aim for

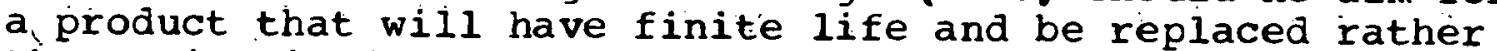
than maintained by using minimal critical materials and lowcost processes or should he strive for infinite product life by using the most corrosion- and wear-resisting materials and the highest quality form and process needed to achieve good maintainability -- commensurate with reasonable cost). There probably always will be a middle ground in which material and energy can be conserved by selectively applying wear-resisting coatings to key wear areas, using design techniques that minimize corrosion (coatings, drain holes. galvanic couplings), relying on careful corrosion and stress analyses that permit use of the lowest chromium alloy content material for the job, and permitting ease of replacement or repair of the failure-sensitive critical components.

To achieve full and responsible chromium conservation, the full range of quality assurance techniques -- including specifications, standards, in-process inspection, inspectability, and feedback from these inspections to the designer -- must be used. Defective hardware found during inspection can be accepted as deviant material and repaired and used or recyclea. However, once a defective component 
is integrated into the finished system, recalling for recycling, repair, or replacement becomes more difficult. Thus, the initial design should facilitate nondestructive testing and evaluation. Juäicious use of quality assurance can be a powerful tool for chromium conservation since excessive application of too high a standard for the intended product can be wasteful.

Examples of application of each of these design considerations exist in most industries. The aerospace industry provides convenient examples for each of the extremes and the compromise conditions -- the expendable drone airplane, the Apollo space vehicle, and the costconscious commercial airplane, respectively.

\subsubsection{Weight}

A reduction or increase in product weight can be another design tool to conserve chromium. Reduction in total weight obviously introduces less chromium into a product particularly if the reduction can be traced back to the mill. Not only is less chromium present in the finished hardware (and therefore not available for ready recycling) but less energy is consumed in the process and possibly less energy will be used in moving the product during its life.

On the other hand, increasing product weight could mean operating at a lower stress, using lower chromium-containing alloys that have a longer oxidation and corrosion life-time, and permitting the use of coatings or claddings on carbon steels. Once again, the designer must decide winich route is the best for a particular appiication.

\section{2.5 Ease of P.ecycling}

The designer should provide for the recycling of chromium-containing products by designing to permit ready disassembly for recall. repair, or replacement and by using a marking system and part numbers that would permit ready identification and location of chromium-containing parts.

\section{2.6 Aesthetics}

Aesthetic considerations enter into the design of many chromium-plated and stainless steel components ranging from automobile bumpers to kitchen sinks and building exteriors. The aesthetic appeal of these parts may be associated with the impression of newness, cleanliness, and durability created although some chromium-plated parts may have been introduced as inexpensive substitutes for traditional brass parts. 
Because of these considerations, pullic acceptance of various possible substitutes is impossible to predict except in instances where past marketing experience exists (presentation by S. Gratch to the Panel on substitution. June 7, 1976). For example, the public generally has not noticcd the replacement of most interior automotive chromium-plated die-cast $z$ inc parts by vacuum metalized plastics, and color keyed, painted bumpers on many small sportly cars have been accepted readily in place of the conventional chromium-plated bumpers. Thus, aesthetics may not represent any real. long-term barrier to chromium and stainless steel substitution; however it may become one if poor judgment is used in effecting substitution.

\section{3 DESIGN CRITERIA}

\subsection{Corrosion}

\subsubsection{Sulfidic Corrosion in Hydrogen-Free Environment}

Chromium-containing steels have been used extensively by the petroleum industry and others to control corrosion in equipment used to process sulfur-containing oil at elevated temperatures. Below approximately $500^{\circ} \mathrm{F}$, carbon steel is normally adequate. At higher temperatures, chromium steels are usually more economical because the added first cost is offset easily by the extended life. The results of an American Petroleum Institute (API) survey (McConomy 1963). reproduced in Figure 11, show that, in the absence of hydrogen, sulfidic corrosion approximately doubles when operating temperature is increased from 50 to 100 o F. On the other hand. the corrosion rate decreases by a factor of 2 for each 2.5 to 3 percent increment of chromium in the stee1.

Unfortunately. no satisfactory substitute for chromium is known to reduce sulfidic corrosion in steel at high temperature although several partially successful attempts during the past 20 years provided sulfur resistance by "diffusing" aluminum into the outer layer of steel exposed to a sulfurous environment. In the absence of a hyarogen environment, however, rorrosion is a surface phenomenon and the corrosion-resisting material may be applied as a surface coating by using corrosion-resisting linings that are bonded, loose or spot welded, or weld deposited. While these techniques can increase the cost of fabrication. they conserve chromium by eliminating its use in the backing plate.

In general: it is neither beneficial nor chromiumconserving to reduce the normal concentration of chromium in the corrosion-resisting lining (Figure 11). If a vessel is 


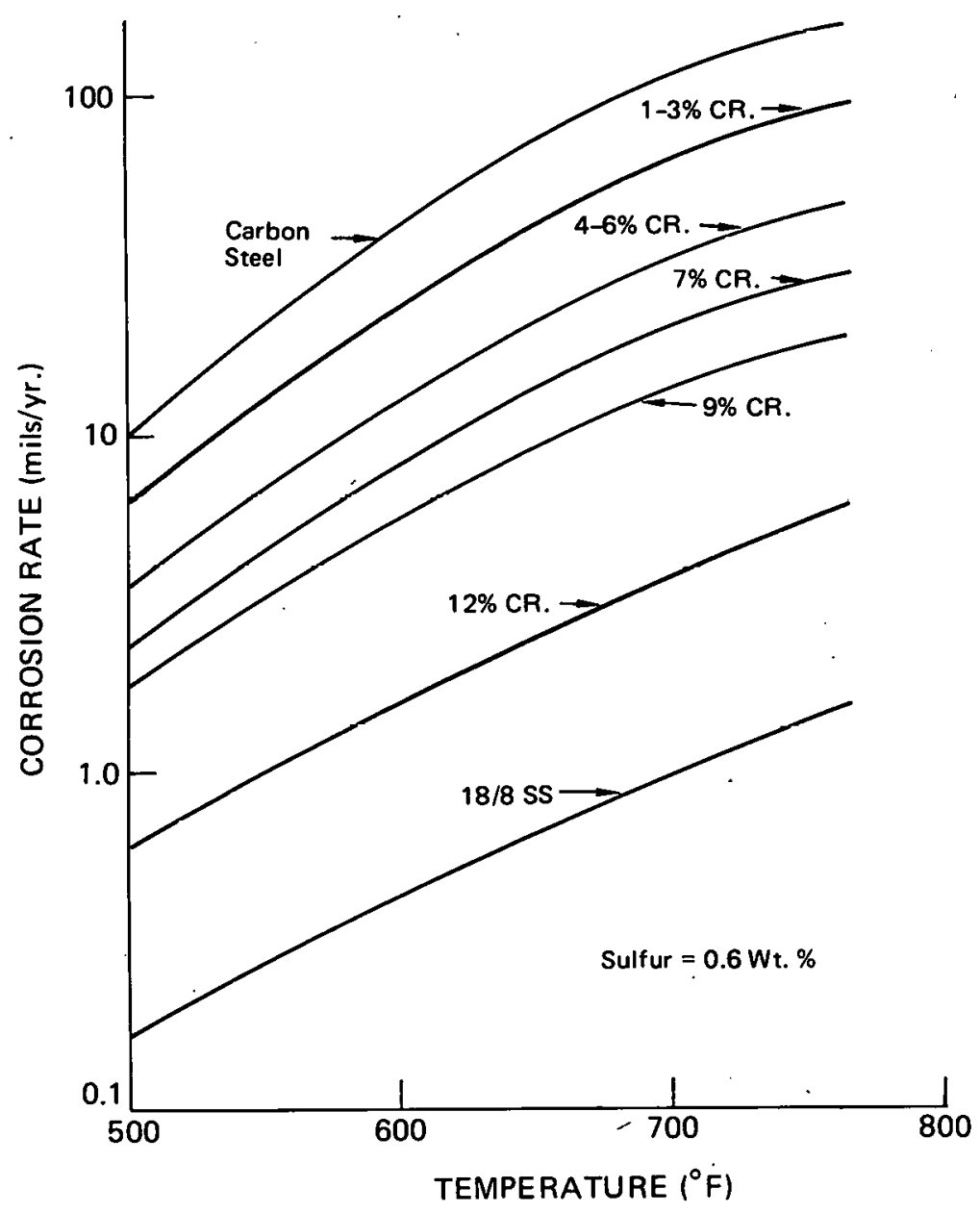

NOTE:

High-temperature sulfur corrosion Hydrogen-free environment

Average sulfur $=0.6$ weight percent

FIGURE 11 Average Corrosion Rates for High-Temperature Sulfur Corrosion in a Hydrogen-Free Environment (McConomy 1963)

NOTE: From H. R. McConomy, "High-Temperature Sulfidic Corrosion in Hydrogen-Free Environment," Proceedings of the American Petroleum Institute 43, III (1963): 78-96; reprinted by courtesy of the American Petroleum Institute. Compiled from 1961 A.P.I. questionnaire data from industry desulfurizing processes and published or reported data on nondesulfurizing processes. Average sulfur is 0.6 weight percent. 
designed with a 1/8-inch-thick, 12 percent chromium liner and is operated at $750{ }^{\circ} \mathrm{F}$, the corrosion rate is about 6 mils per year and the expected service life is about 20 years. If the chromium content of the liner is reduced to 9 percent, the corrosion rate increases to about $19 \mathrm{mils}$ per year and the expected vessel life is reduced to about 6.6 years using the 1/8-inch-thick liner. For 20 years of service, a 0.4-inch-thick liner (or equivalent) would be required, and the total amount of chromium used over the 20year period would be 2.4 times as much as would have been needed if the preferred 12 percent chromium liner were used. Thus, reducing the chromium content of liners designed to resist sulfidic corrosion normally leads to a longuterm increase -- not a decrease -- in chromium consumption. This example suggests that chromium would be conserved by using thin linings of high-chromium steel rather than by using thick linings of low-chromium steel. However, minimum thickness is constrained by the fabrication problems.

\subsubsection{Operating Limits for Steel in Hydrogen Service}

Hydrodesulfurization and hydrogenation operations have increased dramatically in petroleum refining operations during the past 20 years and have introduced an additional problem in the design of processing equipment. At high temperature and high pressure, molecular hydrogen dissociates into atomic hydrogen, penetrates into the steel, and reacts with carbon to form methane. This reaction creates high internal pressure that causes the metal to fail by intergranular cracking. With vessels designed to operate at internal pressures of several hundred or thousand pounds per square inch, such failure can be catastrophic and must be avoided at all costs.

Hydrogen attack on steel is decreased by the addition of carbide-forming alloying elements such as chromium, molybdenum, tungsten, vanadium, titanium, and columbium. safe working guidelines for the design of equipment for use in high-temperature, high-pressure hydrogen service have been developed and published by the API and are reproduced here as Figure 12 (Nelson 1949; American Petroleum Institute 1977). The curves in this figure are based on using chromium and molybdenum as carbide-stabilizing materials and are the largest single collection of reliable data on this subject. In time, guidelines for using other (nonchromium, molybdenum) carbide stabiliziers may be developed. but care must be taken to develop reliable alternatives and to avoid substituting one critical material for another. Reliability in any alternative is a primary requirement because of the catastrophic consequences of failure. 


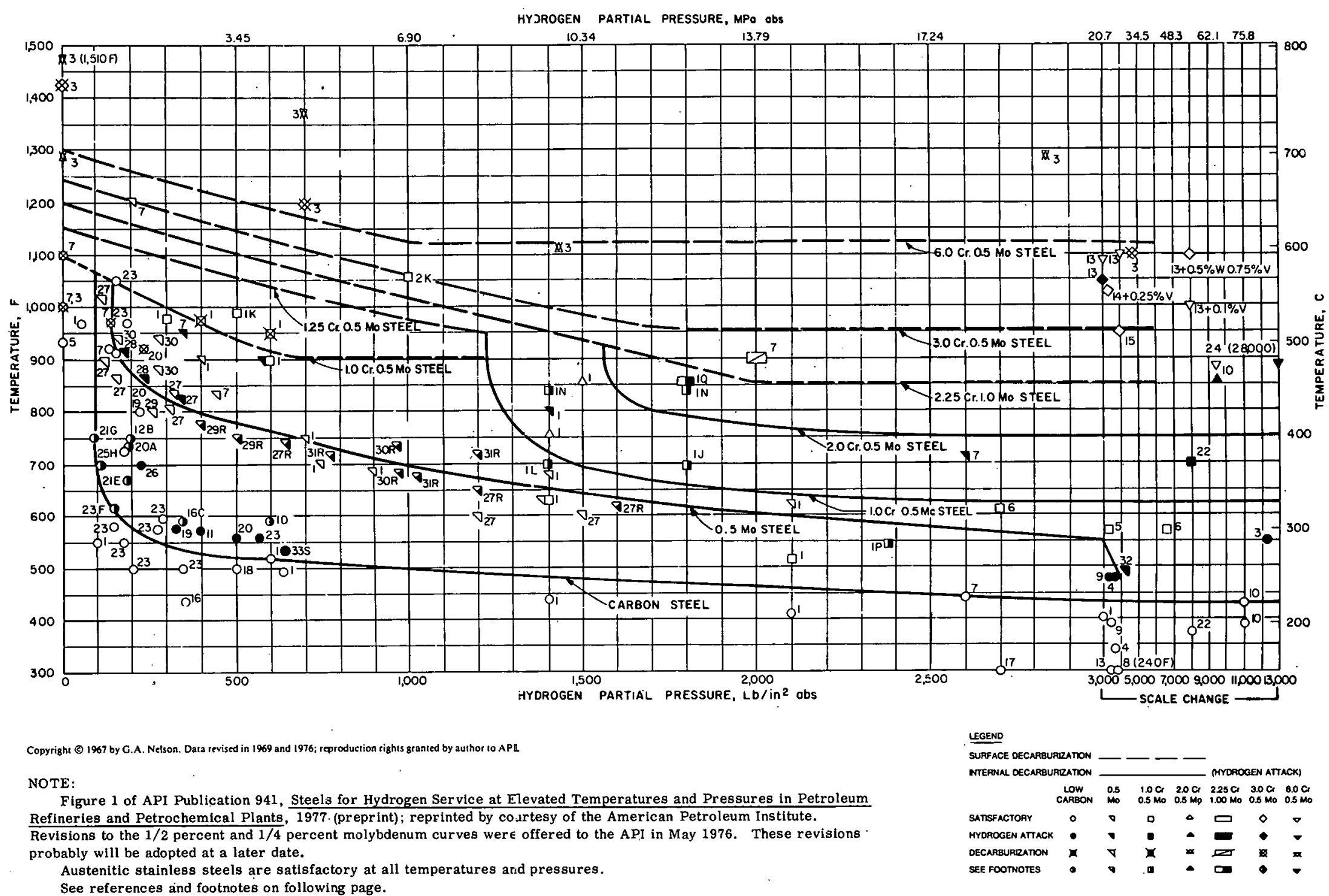

FIGURE 12 Operating limits for steels in hydrogen service

(American Petroleum Institute 1977) 


\section{References and Footnotes for Figure 12}

\section{References:}

1. Shell Oil Cu.*

2. Timken Roller Bearing Co.*

3. F.K. Naumann, "Influence of Alloy Additions to Steel upon Resistance to Hydrogen Under High Pressure," Tech. Mitt. Krupp, 1 [12], pp. 223-34, 1938.

4. N.P. Inglis and W. Andrews, "The Effect on Various Steels of Hydrogen at High Pressure and Temperature," J. Iron Steel Inst., 128 [2], pp. 383-97, 1933.

5. J.L. Cox, "What Steel" to Use at High Pressures and Temperatures," Chem. Met. Eng., 40, pp. 405-9, 1933.

6. R.J. Sarjant and T.H. Middleham, "Steels for Autoclaves," World Power Conf., Chem. Eng. Cong. Trans., London, I, pp. 66-110, June, 1936.

7. Standard Oil Co. of California.*

8. E.I. du.Pont de Nemours and Co., Inc."

9. Ammoniawerk Merseberg, 1938."

10. Hercules Powder Co.*

11. C.A. Zapffe, "Boiler Embrittlement," Trans. ASME, 66, pp. 81-126, Feb., 1944.

12. The M.W. Kellogg Co.*

13. German operating experience, 1946.

14. Vanadium Corp. of America. *

15. Imperial Chemical Industries, Billingham, England."

16. T.C. Evans, "Hydrogen Attack on Carbon Steels," Mech. Eng., 70, pp. 414-16, 1948.

17. Norweg. Hydroelectric, Oslo, Norway.*

18. J.J. Hur, J.K. Deichler, and G.R. Worrell, "Building a Catalytic Reformer?" Oil Gas J., 54 [78], pp. 103-7, Oct. 29, 1956.

19. A.R: Ciuffreda and W.D. Rowland, "Hydrogen Attack of Steel in Reformer Service, Proc. API, 37 [III], pp. 116-28, 1957.

20. API Refinery Corrosion Comm. survey, 1957.

21. Air Products, Inc., Mar. 1960.*

22. G.D. Gardner and J.T. Donavan, "Corrosion and Erosion in the Synthetic-Fuels Demonstration Plants," Trans ASME, pp. 525-33, 1953.

23. AMOCO Oil Co., 1960 .

24. E.W. Comings, High Pressure Technology, McGraw-Hill Book Co., Inc., New York, 1956.

25. M. Hasegawa and S. Fujinaga, "Attack of Hydrogen on Oil Refinery Steels," Tetsu To Hagane, 46 [10], pp. 1349-52, 1960.

26. K.L. Moore and D.B. Bird, "How to Reduce Hydrogen Plant Corrosion," Hydrocarbon Process, 44 [5], pp. 179-84, May, 1965.

27. Union Oil Co. of California, 1976 data."
28. AMOCO Oil Co., 1976 data.*

29. Standard Oil Co. of California, 1976 data.*

30. Exxon Corp., 1976 data.*

31. Shell Oil Co., 1976-data.*

32. Cities Service Oil Co., 1976 data.*

33. Gulf Oil Corp., 1976 data.*

Footnotes:

A. A section made of A106 pipe was found to be attacked to 27 percent of its thickness after 5,745 hours. Other pieces of pipe in the same line where unaffected.

B. The attack was concentrated in the overheated section of a hot bent steel elbow. The unheated straight portions of the elbow were not attacked.

C. In a series of 29 steel samples, 12 were attacked while 17 were not. D. After 2-years exposure, 5 out of 6 pieces of carbon steel pipe were attacked. One piece of pipe was unaffected.

E. Attack was concentrated in the weld and heat-affected sections of A 106 pipe. Metal on each side of this zone was unaffected.

F. After 11-years service, attack was found in the hot bend section of A106 pipe. Unheated straight sections were not affected.

G. After 2-years service, all parts of carbon steel pipe, including weld and heat-affected zones, were satisfactory.

H. After 4-years service, weld and heat-affected zones of A106 pipe showed cracks.

J. After 31 -years service, a steel forging containing 0.3 percent $C, 1.3$ percent $\mathrm{Cr}$, and 0.25 percent Mo showed cracks 0.007 inch deep.

K. 1.25 percent $\mathrm{Cr}-0.5$ percent Mo steel pipes.

L. After 4-years service, a steel forging containing 0.3 percent $C, 1.3$ percent $\mathrm{Cr}, 0.25$ percent $\mathrm{Mo}$ was unaffected.

$M$. After 4-years servicè, a steel forging containing 0.2 percent $C, 1.2$ percent $\mathrm{Cr}_{\mathrm{r}}, 0.35$ percent Mo showed cracks 0.032 inch deep.

N. After 7-years service, a steel forging containing 0.3 percent $C, 1.52$ percent $\mathrm{Cr}, 0.50$ percent Mo showed cracks 0.050 inch deep.

P. After 30 -years service, a steel forging containing 0.30 percent $C$, 0.74 percent $\mathrm{Cr}, 0.43$ percent $\mathrm{Ni}$ was unaffected.

$\mathrm{Q}$. After 15 -years in ammonia service, a pipe containing 0.15 percent C, 2.25 percent $\mathrm{Cr}, 1.00$ percent Mo showed no hydrogen cracks but was nitrided to a depth of 0.012 inch.

R. Stainless steel cladding on 0.5 Mo steel. No known hydrogen attack.

S. After 8 years carbon steel cracked.

*Private communication to Subcommittee on Corrosion 
The broken linès at the top of Figure 12 illustrate the tendency of steels to decarburize by the migration of carbon to the surface and its reaction there with hydrogen. This phenomenon creates a nearly pure iron layer the surface that has lower tensile strength, hardness, and fatigue strength: Minor surface decarburization is not usually of great conceern in refinery equipment design.

The solid lines at the bottom of Figure 12 illustrate the tendency of steels to decarburize internally with resulting cracking caused by methane formation. This phenomenon is of great concern in refinery equipment design. In high-pressure hydrotreaters or hydrocrackers, the practice is to use 2.25 percent chromium/1 percent molybdenum steel, designated by the American society for Testing and Materials (ASTM) as A-387. Grade 22. As shown, this material is not expected to fail by internal cracking under design conditions in present refinery hydroprocessing. steels containing less chromium could fail under some service cond́litions.

Because of the potential for catastrophic failure, chromium and molybdenum currently are considered practically indispensible for use in hot high-pressure hydrogen service. As mentioned above, other suitable alloying materials eventually might be found but; thus far, none have proven satisfactory.

Since about 1940. Other designs have been tried or considered with less than phenomenal success. Some designs used either a multilayer or a solid outer shell of carbon steel that was designed to withstand the internal design pressure. A loose-fitting pressure-tight liner of alloy steel is fabricated inside the outer shell. The outer shell has holes drilled through the entire thickness so that any hydrogen. which diffuses through the inner alloy shell, will leak to the atmosphere and not accumulate to build hydrogen pressure against the inside of the carbon steel outer shell. A satisfactory method for installing leak-proof nozzles in the vessel. without providing a diffusion path for hydrogen to penetrate into the carbon steel shell, has not yet been developed.

\subsection{Oxidation}

In petroleum refining and petrochemical plant designs, alloy selections for high-temperature furnace tubes are dictated by the alloy's resistance to air oxidation. Limiting temperatures for low air oxidation rates have been assembled and are presented in Table 14 (American Petroleum Institute 1973). At temperatures above the reported values, oxidation rates become appreciable. 
TABLE 14 Maximum Metal Temperatures for Low Oxidation Rates of Chromium Alloys in Air

\begin{tabular}{ll}
\hline Material & $\begin{array}{l}\text { Temperature } \\
\left({ }^{\circ} \mathrm{F}\right)\end{array}$ \\
\hline Carbon steel & 1,050 \\
C-Mo steel & 1,050 \\
$\frac{1}{2} \%$ chromium steel & 1,075 \\
$1 \frac{1}{4} \%$ chromium steel & 1,100 \\
$2 \%$ chromium steel & 1,150 \\
$2 \frac{1}{4} \%$ chromium steel & 1,175 \\
$3 \%$ chromium steel & 1,175 \\
$5 \%$ chromium steel & 1,200 \\
$7 \%$ chromium steel & 1,250 \\
$9 \%$ chromium steel & 1,500 \\
$12 \%$ chromium steel & 1,500 \\
18 Cr-8 Ni steel & 1,600 \\
25 Cr-12 Ni steel & 2,000 \\
25 Cr-20 Ni steel & 2,100 \\
\hline
\end{tabular}

NOTE: Data from American Petroleum Institute 1973, chapter 2. 
When a tube is selected to resist high-temperature sulfidic corrosion on the inside, it usually resists air oxidation adequately on the outside, but when it does not, a higher chromium alloy is selected. If the chromium supply were restrictea severely, an attempt probably would be made to diffuse alumi num into the outer surface of a lower chromium alloy or a carbon steel tube.

High-temperature steam also causes severe scaling of carbon-steel and low-chromium alloys because an oxidation process results from the decomposition of steam into hydrogen and oxygen. Table 15 presents the limiting temperatures for the use of chromium steels in steam service which are about 50 to 100 of lower than those for air oxidation. No satisfactory alternatives are known for the use of the chromium steels in this service.

\subsection{3 stress}

The life of many components is controlled by the stress placed on them in service. Design stresses are calculated on the basis of anticipated loads and environment plus the expected life of the product, and stress criteria are available from a variety of sources such as MII-Handbook 5 (NAVSHIPS 250-008-5) and the American Society of Mechanical Engineers ( $A S M E$ ) Boiler Code. The most reliable stress criteria are those developed on the hasis of similar service experience or through statistical treatment of results from a relatively large number of tests and should result in the conservation of chromium as well as other materials and energy by permitting efficient product design. Further conservation of chromium through selectiun ü malerials containing less chromium often is hindered because stress criteria are not correlated with chromium content. In the long run. chromium conservation also can be achieved by designing for longer life.

\subsubsection{Stress Reduction}

A reduction in the applied stress generally results in longer service life and may be accomplished by decreasing the stress producing factor (i.e.. speed, pressure, load. etc.) or by increasing the section thickness. The increase in service life that will result from a given stress reduction depends to some extent on the original stress. The service life of components such as propeller shafts. axles, crank shafts, and aircraft lower wing skins may be limited by fatigue (i.e.: the initiation and growth of cracks caused by repetitive application of tensile stress significantily below the material's ultimate tensile strength). 
TABLE 15 Maximum Metal Temperatures for Low Scaling of Chromium Alloys in Steam Service.

\begin{tabular}{lc}
\hline Material & $\begin{array}{c}\text { Temperature } \\
\left({ }^{\circ} \mathrm{F}\right)\end{array}$ \\
\hline Carbon steel & 950 \\
C-Mo steel & 975 \\
$\frac{1}{2} \%$ chromium steel & 1,000 \\
$1 \frac{1}{4} \%$ chromium steel & 1,050 \\
$2 \%$ chromium steel & 1,080 \\
$2 \frac{1}{4} \%$ chromium steel & 1,100 \\
$3 \%$ chromium steel & 1,125 \\
$5 \%$ chromium steel & 1,150 \\
$7 \%$ chromium steel & 1,175 \\
$9 \%$ chromium steel & 1,200 \\
\hline
\end{tabular}

NOTE: Data from American Petroleum Institute 1973, chapter 2 . 
Data on cycles-to-failure versus stress level for 15-5 $\mathrm{PH}$ (15 percent chromium) steel are presented in Figure 13 (Armco 1976). A reduction in maximum stress level from 150,000 to 140,000 psi approximately doubles the life for the H1025 condition while a similar reduction in stress from 135,000 to 130,000 psi increases the life by more than 50 times. Fatigue 1 ife at $10 \mathrm{million}$ cycles (fatigue limit) for low-alloy steels varies with strength level or hardness as shown in Figure 14 (American Metals Society 1961) but is not influenced appreciably by composition.

A chromium content of approximately 1 percent will be found in the $41 \times x, 43 x x, 51 \times x$, and $86 x \times$ alloys. Since fatigue properties are unaffected by chromium content. reducea consumption of chromium could be achieved on fatigue-life-controlled designs without reducing performance by selecting material from chromium-free alloys when corrosion and heat resistance are not critical. Other material characteristics, such as hardenability, also must meet design requirements and could preclude selection of a substitute alloy in some cases. (section 4.4 presents a methodology for alternate alloy selection.)

Stress concentrations (e.g.. changes in geometry. holes, and fillets; surface roughness produced by fabrication operations or corrosion; and material defects such as inclusions) will: reduce fatigue life. Figure 15 (American Society. for Metals 1961) shows the effect of inclusion size on fatigue life and emphasizes the need for quality assurance throughout the processing of the alloy to ensure optimum usage of the contained chromium.

Shorter-than-expected service life can result when corrosive action of the environment reduces fatigue life. Due to variables between specimen tests and operational hardware, design changes or material substitutions should be verified whenever possible by tests using actual operational components and a real or simulated service environment.

Reduction of operating stress can increase the life of components (e.g.. high-strength bolts, actuator bottles, and helical springs) subjected to sustained tensile stress in applications where failure is caused by stress-corrosion cracking or hydrogen-induced cracking. Applied stress versus time to failure data are illustrated in Figure 16 (Fontana and Greene 1967) for four different stainless steels that are grouped into two performance ranges. Greater chromium content is associated with the improved performance, and the effect of reduced stress on increase in life is a function of the original stress for each material. 

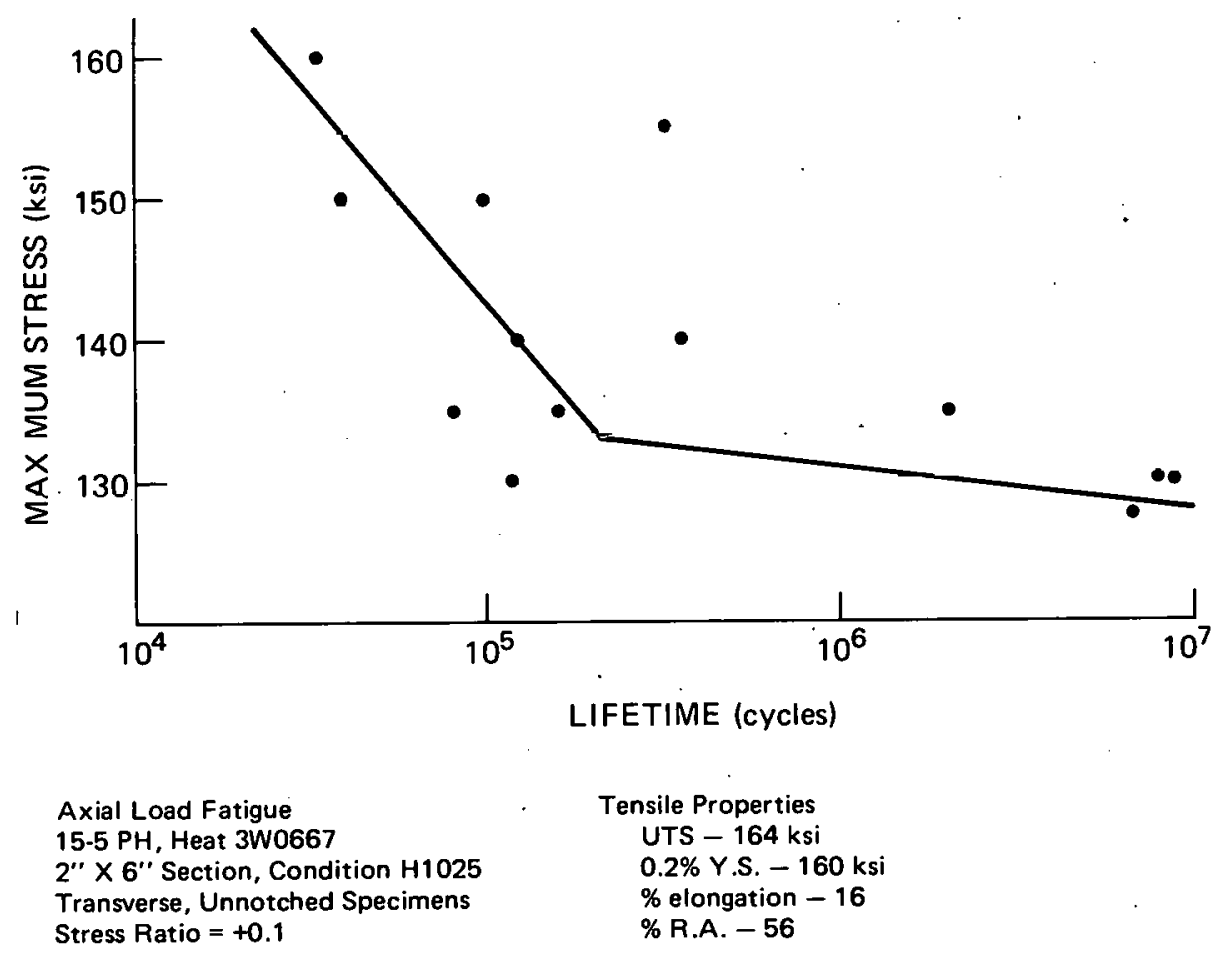

\% R.A. -56

FIGURE 13 Fatigue Strength Curve for 15-5 PH Precipitation Hardening Stainless Steel (Armco Steel Corporation 1977) 


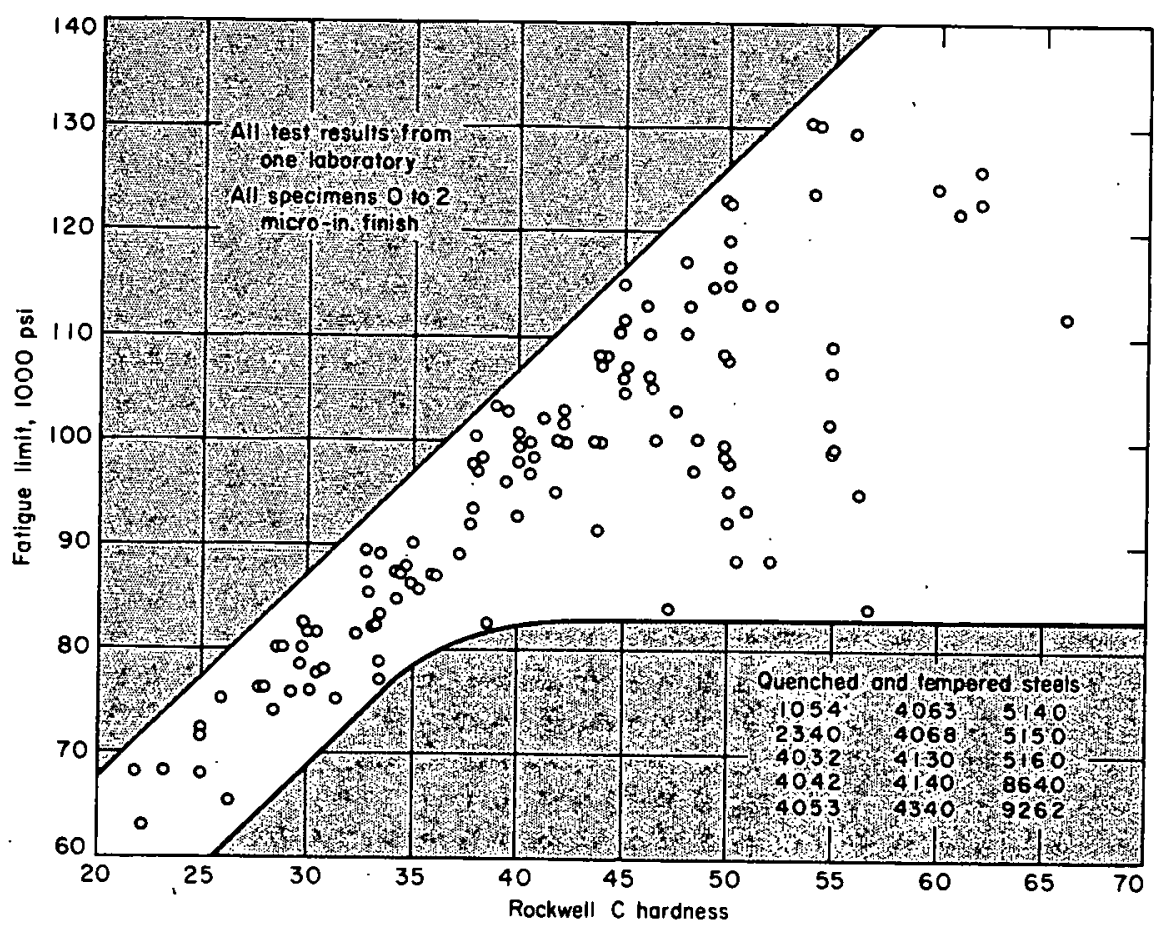

FIGURE 14 Effeet of Hardness on Fatigue Limit of Through-Hardened and Tempered Steel

(American Society for Metals 1961)

NOTE: Bỳ permission from Metals Handbook, Volume 1, p. 217, (c) American Society for Metals, 1961. Standard 0.250-in. diameter. R. R. Moore rotating-beam fatigue specimens were tested. 


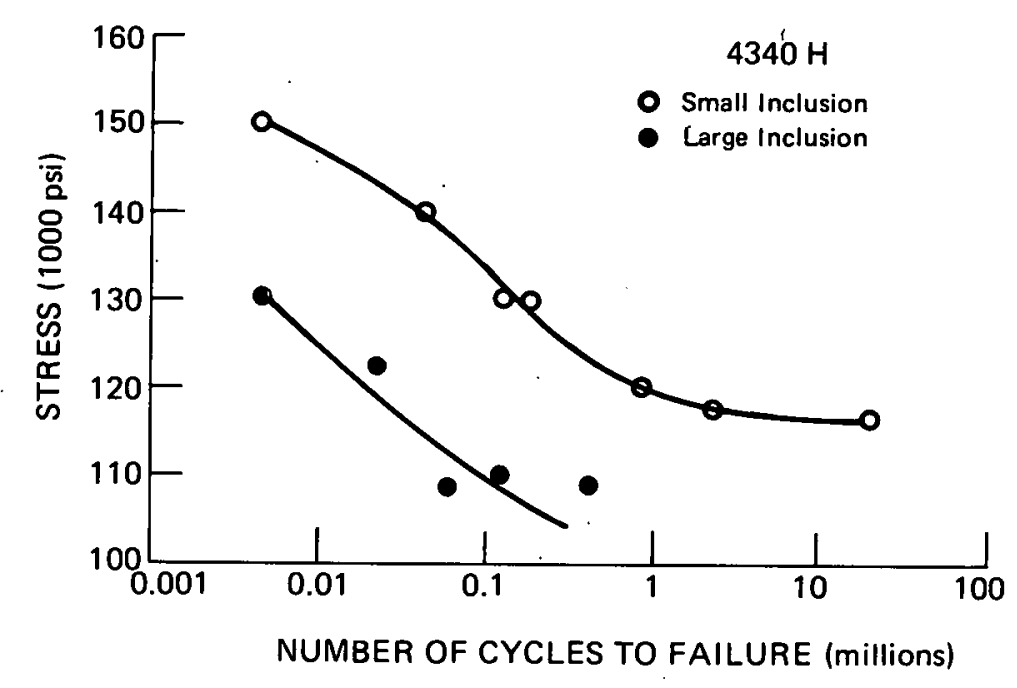

-FIGURE 15 Effect of Inclusions on Fatigue

(American Society for Metals 1961)

NOTE: By permission from Metals Handbook, Volume 1, p. 224, (c) American Society for Metals, 1961. 


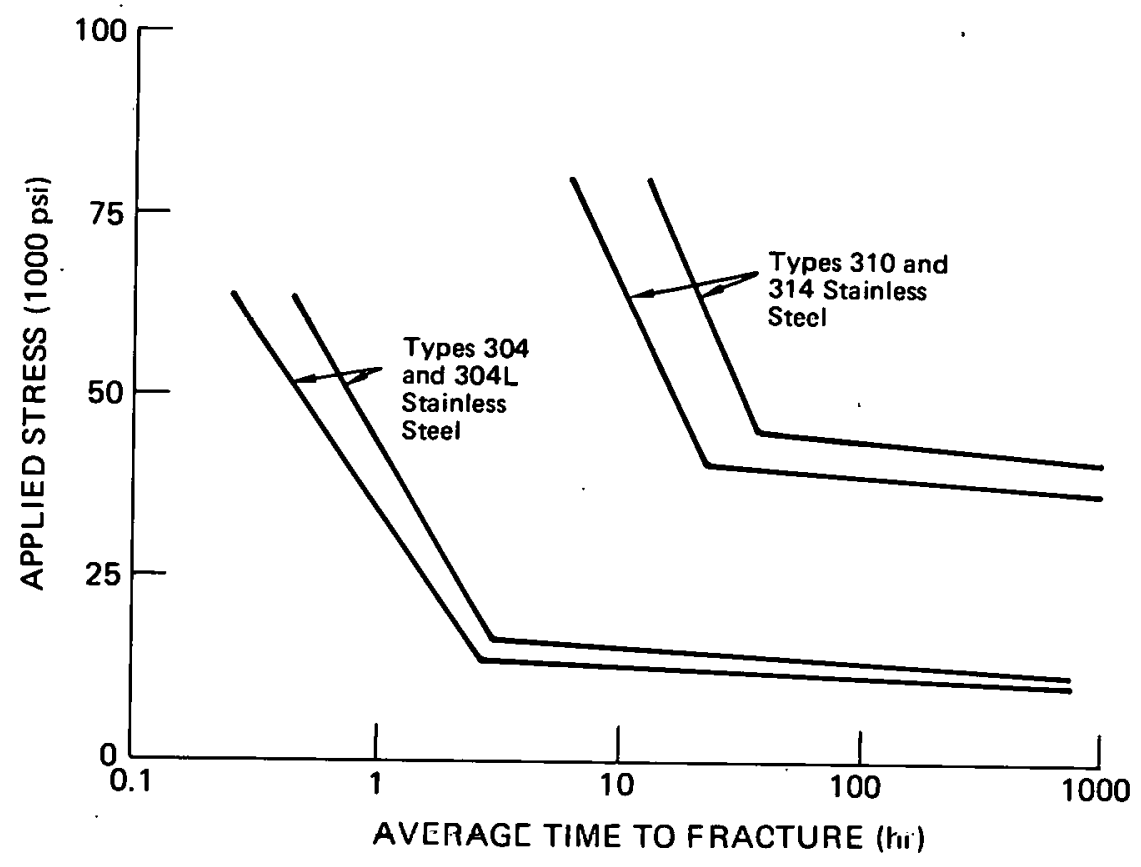

FIGURE 16 Effect of Alloy Composition on Threshhold Stress (Fontana and Greene 1967)

NOTE: From Corrosion Engineering, Fontana and Greene, copyright (c) 1967 by McGraw-Hill, Inc. Used with permission of McGraw-Hill book Company. 
The data of Figure 16 are not converted readily to design criteria and are of limited value to the designer even though screening of materials is accomplished. Consequently, in recent years many investigators have been developing data applicable to fracture mechanics concepts (Metals Handbook 1975) that permit the reliability of a design to be evaluated in terms of applied stress and the size of defects. Figure 17 (Peterson and Brown 1967) is an example of such data. The lower curve represents conditions above which stress-corrosion cracking will occur. Increased susceptibility with increasing strength, as shown by the data, is a potential hazard to designs enduring sustained tensile stress and should be considered when stress levels are raised in chromium conservation efforts.

Some designs (e.g.. lifting equipment and high-pressure gas bottles) are life-limited by the stress level at which rupture occurs from overloading. In these cases, a reduction in design stress criteria would result in longer life, if the component were inadvertently overloaded in service or if a general degradation mechanism (e.g.. corrosion, oxidation, creep, and wear) reduced load-bearing sections to thicknesses susceptible to failure at normal working stresses. Section thicknesses generally are increased to reduce the average working stresses for cases involving overloads. Average life improvement is proportional to the increase in degradation allowance, but design changes would be determined on the basis of experience for inadvertent overloads.

Design actions that reduce stress levels by increasing section thickness would increase initial requirements for chromium and product weight when chromium's properties are essential. Adāed weight also would be undesirable for moving components or mobile products since wear and the energy required for operating the equipment would be increasea, and in designing for longer life of such equipment, weight should not be increased.

\subsubsection{Unchanged Stress}

Longer life may be designed into a produrt without changing applieā working stresses by using alloys more resistant to the service environment, by improving control of the service environment, and by inducing favorable residual stresses into selected components. Research and development are required, particularly in the first area, to provide materials with improved environmental resistance. Increases in chromium content are expected for alloys having improved resistance to corrosion and oxidation but, as will be discussed below, are not expected for alloys having improved elevated temperature rupture strength. Figure 16 


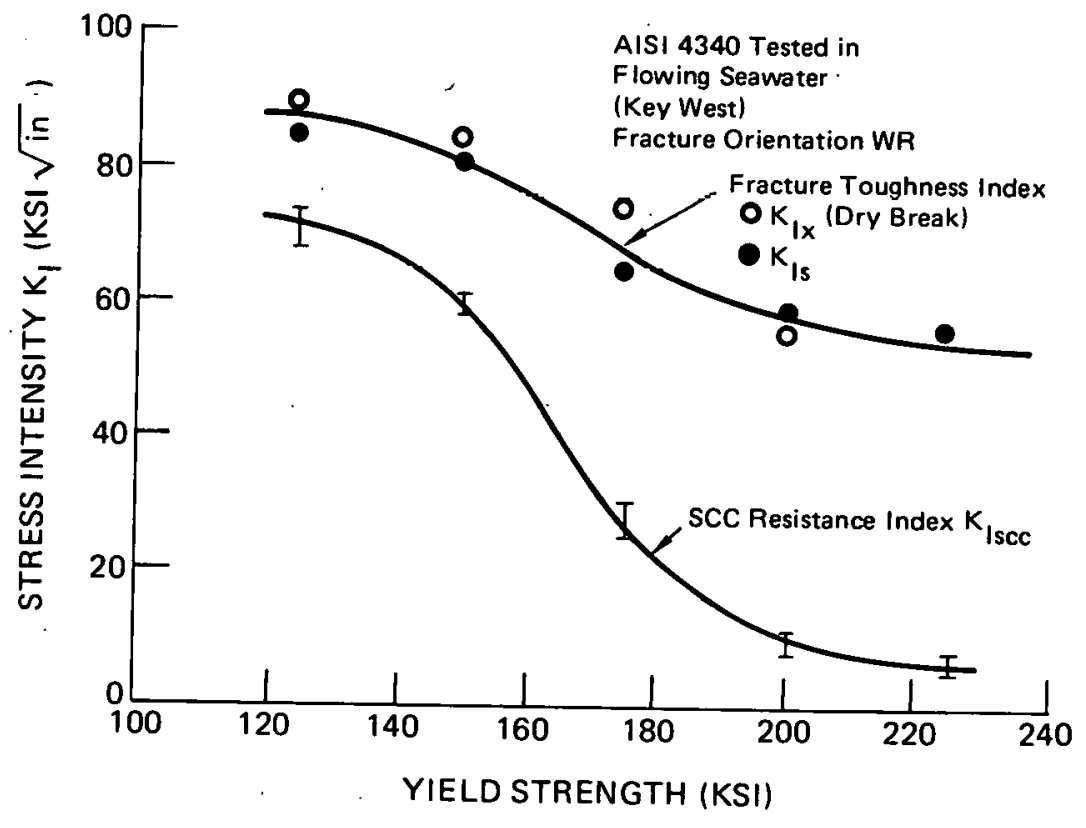

FIGURE 17 Fracture Toughness as a Function of Yield Strength for AISI 4340 Steel (Peterson and Brown 1967)

NOTE: The fracture toughness indices $\mathrm{K}_{\mathrm{IX}}, \mathrm{K}_{\mathrm{IS}}$, and $\mathrm{K}_{\mathrm{ISCC}}$ for AISI 4340 steel plotted as a function of yield strength show that resistance to stress corrosion cracking (SCC) is degraded more severely with increasing yield strength than is the fracture toughness. 
illustrates the effect of chromium content on corrosion resistance and Figure 18 (American Society for Metals 1961) shows improvements in wear resistance for chromiumcontaining steels for two different applications.

Advanlageous use of residual stresses effectively increases the life of components subject to failure by fatigue or stress-corrosion cracking without changing the applied stresses. Processes such as shot peening, cold rolling, prestressing, and surface hardening are employed to induce favorable residual stresses in a part. The increase in fatigue life resulting from shot peening of carbon and alloy steel springs is shown in Figure 19 (American society for Metals 1961). For a maximum stress of 90,000 psi. minimum fatigue life increased approximately 10 times. At lower stresses, the increase is even greater.

Surface hardening processes such as carburizing. nitriding, anā induction hardening produce residual compressive stresses in the surface layers. Increases in service life from these processes probably are due to the combined effects of residual stress and high surface hardness. The effect of nitriding on fatigue life is shown in Figure 20 (Gadd and Ochiltree 1945). The engineering benefits from these processes are improved fatigue life and wear resistance. One advantage of carburizing and nitriding is their applicability to low-alloy-content steels to improve their engineering capability.

Although the above discussion has been directed to extending service life without changing design stress levels, the magnitude of benefits derived from favorable residual stress and surface hardness permits an increase in design stress and service life in some cases. Use of higher design stresses is expected to occur primarily in new design.

\subsubsection{Stress Increase}

Increasing design stress criteria above current practice involves one or more of the following: (1) the development of improved or new materiale, (2) greatcr reliance on the integrity of supplemental processing such as shot peening and surface hardening, and (3) more efficient nondestructive inspection of components.

Design working stress is often a factored value of the static tensile strength of the material and raising the tensile strength seems to be a logical method of achieving higher design stress criteria. This approach is frequently attempted but has obvious limitations (Figures 14 and 17) when fatigue life and stress-corrosion cracking are the 

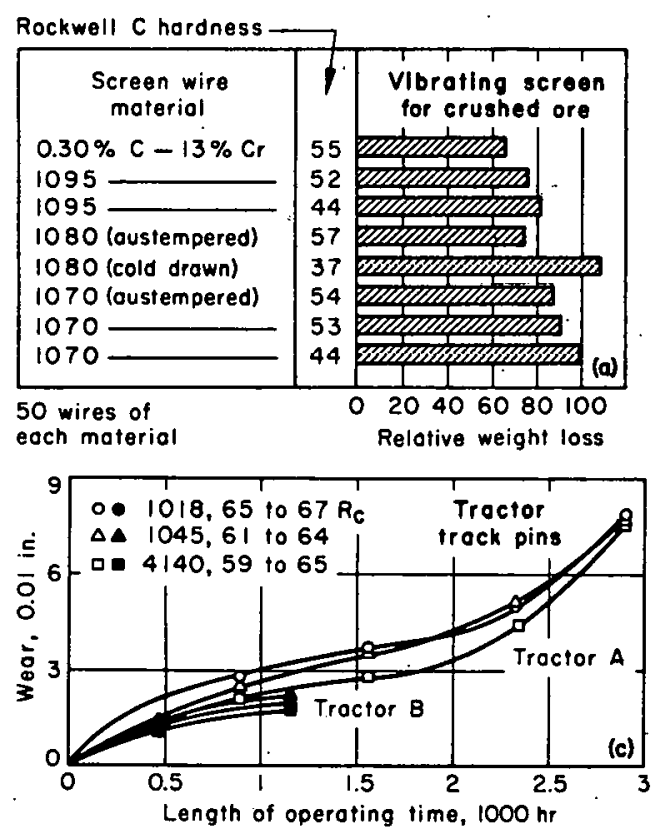

NOTE: By permission from Metals Handbook, Volume 1 , p. 248, (๑) American Society for Metals, 1961. The loxx alloys contain no chromium and the 4140 has a chromium content of approximately 1 percent. Only moderate improvement in wear resistance results from chromium additions to the steel. Chromium-free steels for these applications could reduce performance approximately 15 to 30 percent.

FIGURE 18 Effect of Steel Composition and Hardness on Wear and Life in Abrasive Applications (American Society for Metals 1961) 


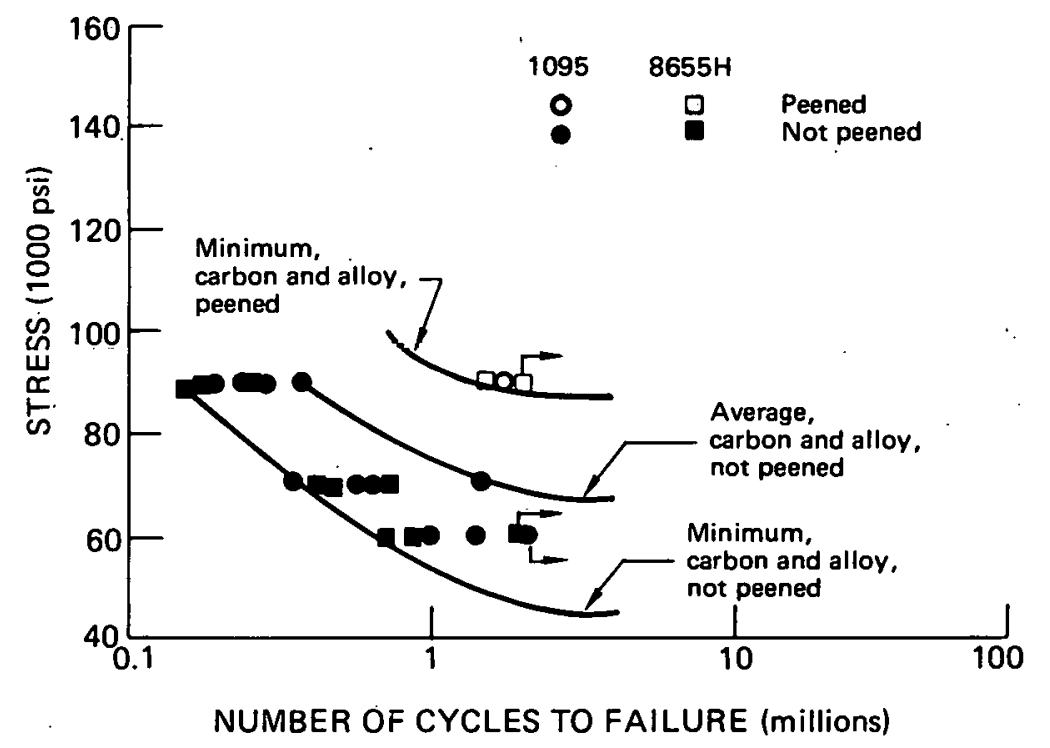

NOTE:

Effect of shot peening on the life of helical compression springs of 1095 and $8655 \mathrm{H}$ steel made by hot winding. Bar diameter was $19 / 32$ to $1-1 / 16$ in. Springs were oil quenched and tempered to $444 \mathrm{Bhn}$. Tests were discontinued at 2 million cycles. All springs were preset and tested at a mean stress of 60,000.psi. Each point indicated on the chart represents a group of no fewer than eight springs.

FíguRE 19 Effect of Shot Peening on the Life of Helical Compression Springs of 1095 and $8655 \mathrm{H}$ Steel Made by Hot Winding (American Society for Metals 1961) 


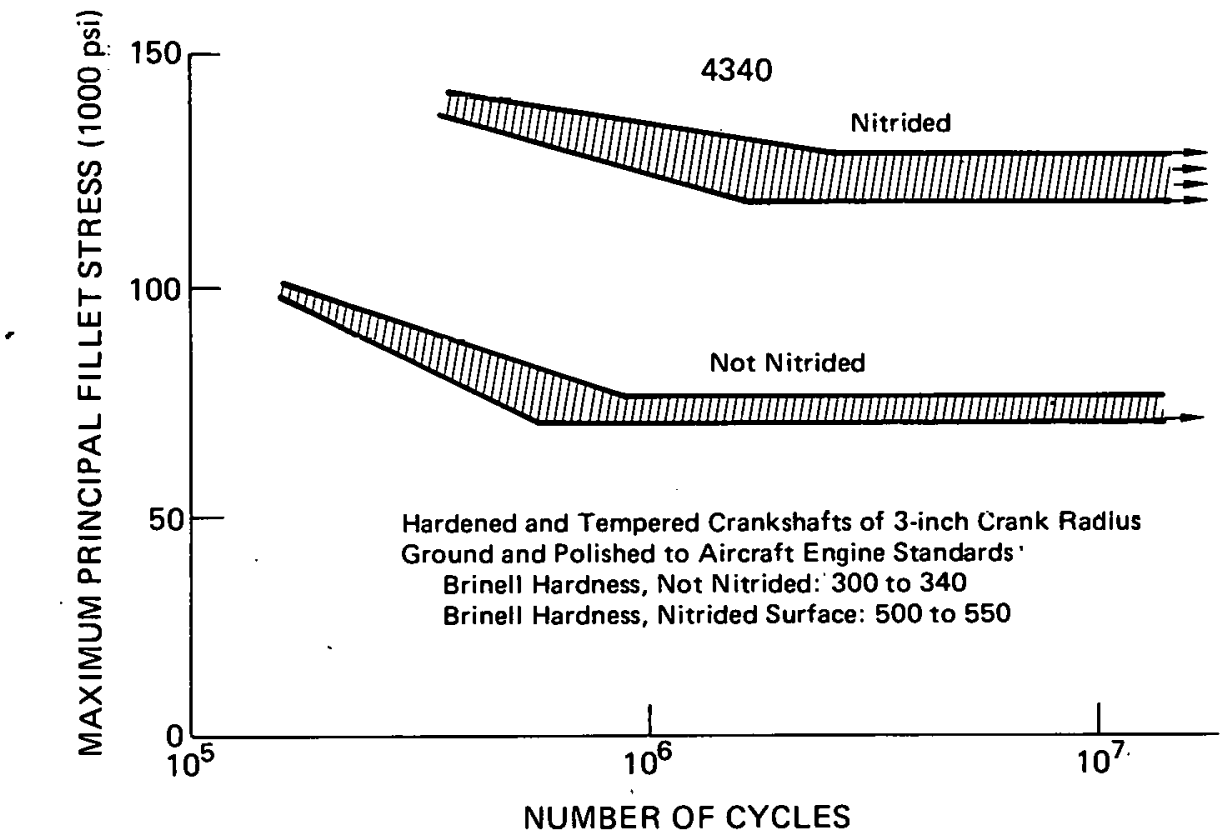

FIGURE 20 Effect of Nitriding on Fatigue Life of 4340 Steel in Full-scale Bending Fatigue Tests of Individual "Throws" of Crankshafts (Gadul and Ochiltree 1945) 
design limiting factors involved. In toth instances, at tensile strengths above approximately 180,000 psi, there is a marked degradation for stress corrosion and no significant improvement. in minimum capability for fatigue life. Raising tensile strength to obtain higher design stress criteria in such a situation could increase chromium consumption as a result of earlier failures.

The effect of chromium content on the stress capability of stainless steel in a severe corrosion environment was illustrated in Figure 16. An increase in chromium content of approximately 30 percent raises the stress capability of the 310 stainless over 304 by a factor of 3 for a 1,000-hour life. An improvement in performance of this magnitude could result in chromium conservation since the use of higher operating stresses could reduce product weight and the total amount of chromium consumed.

Working stresses are a major design consideration in the planned service life of a product. Efficient successful design allows for degradation mechanisms and utilizes supplemental processing, as appropriate, while minimizing cost. Effective material utilization is the result of efficient design and is achieved most readily on mature products, but it requires comprehensive design study as well as development effort on new products.

\subsection{Decreasing Chromium Consumption}

An overall decrease in chromium consumption while retaining equal life and performance of a component may be accomplished by reducing the weight of the product, using materials containing less (content) chromium, or combining these approaches. As noted above, reducing the weight of a product while employing the same materials of construction results in higher working stresses and increased design complexity and requires that more attention be given to product maintenance. Design complexity could result from supplemental processing to enhance engineering capability. new requirements for application of coatings, use of greater precision, and planned repairability.

Efficient material utilization also may be viewed as a general product weight reauction when the ratio of raw material to finished product weight is reduced. Extrusions, rolled shapes, die forgings, castings, and powder metal compacts are more efficient uses of material than components machined from bar. Castings are considered less efficient because significantly more metal is melted and poured into the mold than is delivered as a finished casting and because the homogeneity of castings is much less than that of wrought material. 
Fusion welding is used as a repair process and joining method to improve material utilization. Components may be joined edge to edge rather than requiring an overlap to accommodate mechanical fasteners. Design efficiency factors often are applied to the weld joint, thereby reducing apparent benefits.

The selection of alloy materials with a lower chromium content is constrained by a number of factors. Iess effective performance of alternative materials may preclude their use for critical applications (e.g., where corrosion or oxidation is a major consideration). Hardenability requirements for heat-treating also enter into the alloy selection process, and since nonchromium alloying elements also increase the hardenability of steel, they could be used to decrease chromium consumption. In the competitive economic environment, cost also influences alloy selection.

Nonmetallic materials may serve as a replacement for chromium-containing alloys for nonstructural and structural applications. For some applications, structural components are being fabricated from advanced composite materials (e.g.. the high strength and modulus properties of advanced composites are attractive for aerospace applications where minimum weight is a prime design goal).

Design efficiency may be achieved through extensive development testing of components and representative specimens or realistic structural analysis. Availability of accurate design data on loads, flaw size, environment, and materials is a prerequisite for detailed structural analysis, and inadequate design data retention and retrieval procedures are considered a major deterrent to efficient design.

The inability to characterize materials often precludes efficient design. Preliminary data often are obtained by laboratory testing and are adjusted as service data become available. Historically, over 10 years have elapsed between the introduction of a new material and its acceptance by the design community.

Design criteria. such as conservative factors of safety, increase product weight and may result in additional chromium consumption. As design analysis becomes better and more comprehensive and as in-process nondestructive testing and evaluation and feedback improve material and product reliability, factors of safety can be reduced and applied more realistically.

Although the costs of alloying elements and their effects on hardenability have been linked qualitatively 
almost since steelmaking began, it was not until the $1940 \mathrm{~s}$ that one of the first quantitative attempts to use this information to devise an optimum steel composition was published (Grossman 1942). At that time, the relative costs of the alloying elements chromium, nickel, and molybdenum were about 1:2:5, respectively. Today, this ratio is about $1: 5: 9$.

A careful and continuing survey of the cost and availability of the various alloying elements used in steelmaking is essential for their efficient and costeffective utilization in steel design. ouantitative knowledge of the influence of individual alloying elements on properties, such as case and base hardenability. permits the cost of an alloying element to be compared with its effect on properties. This comparison permits the chemical composition of a steel to be optimized. Ideally. hardenability efficiency should reflect the hardenability contribution of an alloying element with respect to the cost of the element. Because the contributions to base and case hardenability $\left(D_{I b}\right.$ and $\left.D_{I C}\right)$ are koth important in designing a case-hardening steel, the two efficiencies must be considered for each element; for a through-hardening steel, only base hardenability efficiency is important.

Recently, the International Harvester Company introduced a steel selection and alloy design system known as the computer harmonized application tailored (CHAT) system (Metal Proqress 1972-73). The CHAT concept minimized the consumption of critical alloying elements during the 1969 nickel shortage when the Equalloy steels (IH SAE EX grades) enabled International harvester to reduce its consumption of nickel. The CHAT procedure could be used to maintain steel production efficiency in the face of potential chromium shortages by permitting increased flexibility in alloy substitution based on available elements and by broadening the standard chemical analysis range limits (while maintaining hardenability within the required.range) to new range. limits established by CHAT analysis. More details on such steel selection and design are given in appendix $A$.

\subsubsection{Standards, Specifications, and guality Assurance} Considerations

Certain high technology, high safety, and high reliability products emphasize the interaction of quality assurance methodology with the design process. While the design engineering function imposes the standards, specifications, and performance criteria for specific products, the quality assurance procedures monitor and often enforce the criteria, particularly for nondestructive 
testing (NDT) or evaluation (NDE). NDT methods are tools to evaluate material properties, structural integrity, and product reliability without destroying the material or items being evaluated, and, by its very nature. NDT plays an important role in conserving materials, equipment and capital resources. NDE saves materials by permitting their use under higher stress conditions. It increases reliability and makes property measurement easier by providing for the screening of materials for flaws before commitment to processing and the sorting of mixed or salvageable materials; it also provides a means for inprocess control and for determining when useful life is questionable or safety is compromised (Federation of Materials societies 1973). Furthermore, materials conservation is extended through the capabilities of NDT (or NDE) to substitute for destructive testing and possibly extend a product's useful life through in-service testing or maintenance. These conservation opportunities are applicable not only to chromium but to all engineering materials. To reap fully the benefits of properly used quality assurance technology. all aspects of quality assurance must be planned from the earliest design stages of a product and sufficient money must be allocated specifically for the necessary testing and evaluation.

\subsubsection{NDE Design Considerations}

Nondestructive evaluation is a phrase used to describe noninjurious methods for testing and evaluating properties and for detecting and measuring discontinuities and defects in materials or parts. Quantitative values are obtained for the properties and defects measured by these tests when they are correlated by destructive testing and service

experience. NDE generally has been applied qualitatively as a mechanism for acceptance or rejection of finished parts.

Testing per se generates raw data that must be translatea into the language of the materials and design engineers before the data can be useful (National Materials Advisory Board 1969). However, the design engineer also must be aware of the appropriate applications and limitations of NDT if it is to be used effectively to conserve materials and lower life-cycle costs. He must learn about NDT and its potential for conserving materials through all stages of the product's life cycle including the manufacturing process and the in-service phase (NATO 1976. Federation of Materials Societies 1973, National Materials Advisory Board 1969).

Since 1969, much has been done to popularize the fracture control approach in structural design. This approach has caused many design engineers to focus upon the 
applications and limitations of NDE methods. Prior to the imposition of fracture control structural design criteria in recent military aircraft and NASA spacecraft programs, the design approach to NDE results asked: How small a flaw can be detected? Now the question is: How large a flaw is likely to go undetected? In evaluation programs aimed at answering the latter question, much attention has been drawn to the aspects of inspectability as is illustrated by the following excerpts from recently published papers on the subject:

For a structure of short life operated under adverse conditions or for a long life structure justifiably operated under "kid glove" conditions, reduction in initial flaw size and consequent reliance on sophisticated nondestructive inspection procedures may be a legitimate alternative. Available inspection procedures and estimates of detectable flaw sizes and types are summarized in Table II [not included in this report]. It should be emphasized that flaw detection capability is not absolute, varying with product form, accessibility, test conditions and human factors. The designer is thus well advised to ask guidance from an inspection expert for aid in the parametric studies. (Krupp and walker 1974).

The interface between structural analysis and quality and reliability assurance (QERA) starts with the determination of initial crack length, continues with determinations as to which structures are inspectable and which are not, and how to change the latter into the former and thereby gain weight reduction. (Tupper 1974).

The relationship between design and inspection requirements is summarized in Figure 21 (Wood 1974), which further illustrates the intertwined roles of design and inspection in producing lighter and more reliable structures and, thus, in conserving chromium: While these examples relate mainly to aircraft structure in which the payoff in chromium conservation is slight, the design philosophies exemplified have been extended beyond aircraft, and many nuclear power components currently are being designed using similar practices. Among the advantages of fracture control design are opportunities for developing lighter, more reliable components. If such components are developed; substantial amounts of chromium will be conserved since many nuclear power components currently contain steel alloys with a high chromium content.

Further interdisciplinary interaction among design, materials, processing. maintenance, quality assurance, and 

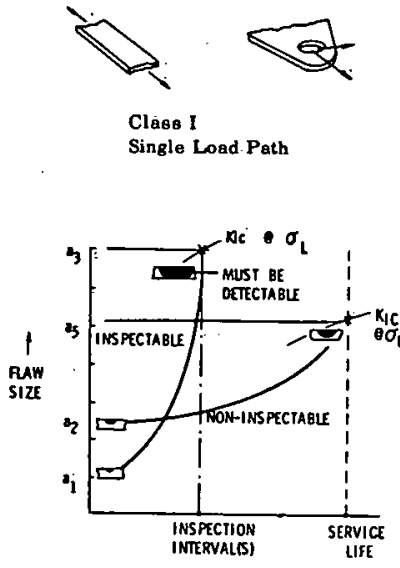

Safe Crack Growth Life Requirement Claas I'Structure
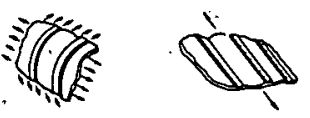

Clase II

Path

Damage Arreat Capability
Class I (monolithic, inspectable)-structure which is classified as single load path, the failure of which could cause loss of aircraft and which is accessible and easily inspectable in service shall be de:igned so that initial flaws of size $a_{1}$ will not grow to critical size (at limit design stress) during one inspection interval. To qualify as inspectable, howeves, it shall be demonstrated that the critical crack size at design limit stress shall be a through the thickness crack of dimension large enough to insure positive detection without major disassembly.

Class I (monolithic; non-inspectable)-structsre which is classified as single load pa th, the failure of which would cause loss of aircraft, and which is neither accessible nor easily inspectable in service $c \pi$ which will not receive periodic inspection, shall be designed so that initial flaws of size $a_{2}$ will not grow to critical size (at limit design stress) in one lifetime.

Class II-shall have sufficient residual strength and-life to complete' $m$ ission following the incurrence of damage.

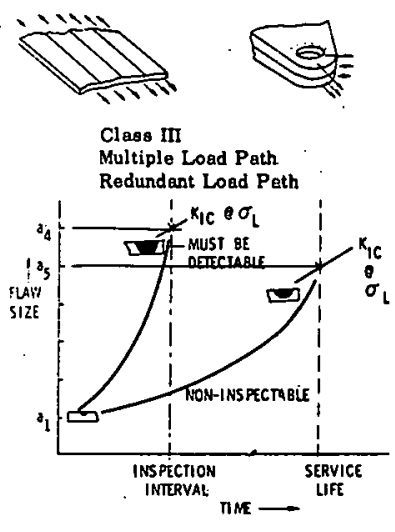

Safe Crack Growth Life Requirement Clase III Structure (Any Member)

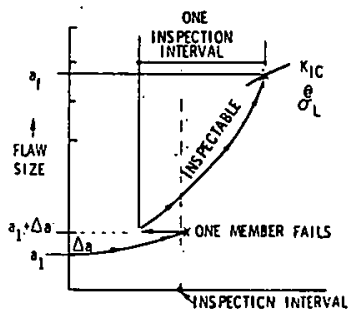

TIMK

Safe Life Requirement For Remaining Structure After Failure Or Sinaio Principal Element Requirement Clase III-Inspectable

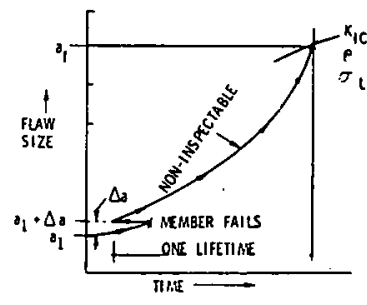

Safe Life Requirement For Remainin Structure ARer Failure Of Singlo Principal Element Requirement
Class III (inspectable)-structure which consists of multiple load paths, which is easily accessible for inspection and for which periodic in service inspections are planned shall be designed so that initial flaws of size $a_{1}$ in any member will not grow to critical size (at design limit stress) in one inspection period and cause failure of the element. In addition, one principal member shall be assumed to fail at any time during the service life. The remaining structure (assumed to be flawed initially) shall be capable of carrying design limit stress at the end of one inspection interval. The safe crack growth analysis for the remaining structure shall be performed by assuming that each member is flawed initially and that growth in each member has continued at the assumed time of failure of the principal element. The most critical time of member failure shall be determined and safe crack growth allowable stress based on this criteria.

Class III (non -inspectable)-structure which consists of multiple load paths and fulfills the residual strength requirements of $\mathrm{C}$, but is neither easily accessible or inspectable in service shall be designed so that initial flaws in any member of size a shall not grow to critical size (at limit design stress) in one lifetime. One principal element failure shall be assumed to occur at any point in the design life. The remaining structure (assumed flawed initially) shall be capable of carrying design limit stress at the end of one lifetime. The safe crack growth analysis for the remaining structure shall be performed by assuming that each member is flawed initially and that growth on each mem ber has continued at the assumed time of failure of the principal element. The most critical time of member failure shall be determined and the safe crack growth allowable stress based on this criteris.

NOTE: From Fracture Prevention and Control, ( ) 1974 by American Society for Metals. reproduced by permission. 
NDE engineers is essential to the successful propagation of this potentially powerful structural analysis concept. In view of the opportunities to conserve chromium and other strategically significant materials, all practicable resources should be focused on developing the engineering aspects of fracture control desiyns.

\subsubsection{Reguirements for Specifications and standards that Minimize Waste and Over-Design}

In manufacturing products, industry operates in accordance with technical contract documents (e.g.. drawings, specifications, or codes) that are international, national, industry, or proprietary standards. These standards should be kept current; however, the state of the art is so fluid that national or industry standards generally do not reflect the latest technology. Since standards represent specific agreements on quality between buyer and selier. standards that are useful to large segments of industry and government normaliy are developed.

The U.S. government differs from most nations in that no single agency is empowered to set standards. Several specific government agencies have statutory responsibilities for standards where health and safety are involved, but other U.S. standards generally äre sẹt through a voluntary consensus process. Although the nation's materials standards and specifications system operates reasonably. well, some serious problems such as the following remain:

1. A proliferation of standards exists in a number of material and product areas due to overlapping interests and has resulted in a large number of different identification systems and formats.

2. Product specifications and standards generally have not kept pace with rapidly advancing materials technology although some code-writing organizations in various product areas are. beginning to revise their procedures.

3. Standards and specifications traditionally are based on material compositions rather than end performance and, therefore, tend to restrict the use of new or improved materials.

4. The nation!s participation in the activities of the International standards organization (Iso) has not kept pace with its mounting interests in international trade (Federation of Materials Societies 1973). 
The cry against proliferation has been heard and most standard-, specification-. and code-generating. bodies are attempting to consolidate and reduce the number of standards. However, the consensus system under which U.S. industry operates inherently reacts slowly to rapid changes in the state of the art. It is believed that most existing documents were developed without regard for conservation of chromium and other strategic materials. Recommendations for increasing awareness of the need for conservation are presented elsewhere in this chapter.

Another effective means of stretching available material supplies is to simplify and reduce the many grades, and during world war II, sizable savings in materials were realized in this way. By reducing the excessive number of sizes, types, grades ana models of products available, fewer items could be manufactured and stocked and those items making the most economical use of scarce materials could be retained. For example, the domestic steel industry currently produces about $13.5 \mathrm{million}$ tons per year of about 330 different grades of structural steel valued at about $\$ 4.2$ billion. This multiplicity of grades severely impairs structural steel productivity because of such problems as small heat-lot sizes, more home scrap, and off-specification naterial. In addition, the proliferation of steel grades complicates material selection and fosters conservatism in design and overgrading of material for many applications (Federation of Materials Societies 1973).

At a chromium workshop, one participant stated that users must determine more accurately the metal requirements for a given application before specifying or overspecifying particular grades. Overspecification for stainless steel applications, which use two-thirds of domestic chromium. increases chromium consumption appreciably (Air Force Materials Laboratory 1975). Cited examples weŗe: 
Stainless

Steel Type

AISI 400

Series

AISI 430

Series

AISI 304

Series
Specification Change

Lowering carbon from 0.05

to 0.02 percent reduccs

chromium about $1 / 2$ percent

Change to AISI 429 series with 2 percent less chromium or to AISI 405 series with 5 percent less chromium and a lumi num

Change to AISI 200 series with 2 percent less chromium or to AISI 301 and 302 series with 1 to 2 percent less chromium
Approximate

Chromi um

Savings $(\%)$

8 to 10

12

10

4.3.5.3 The Role of In-Process Inspection in Achieving Conservation

In section 4.3.4, the roles of quality assurance and NDE in design and in-service phases of the product life cycle were emphasized. Those roles are relatively modern extensions of the traditional inspection used in the manufacturing or processing phases. A natural outcome of in-process inspection, NDE, ana feedback is materials conservation. Today's trends in automated inspection and NDE could yield further opportunities for conservation since automated NDE is only in its infancy (Federation of Materials Societies 1973).

\subsubsection{Relationship of Quality Assurance and Design in} Conservation

Given the complexities of design, the multitude of available materials and the need to prolong the availability of materials that are being sought by the industrialized countries, a more rational approach to design is the design team. This team should be composed of individuals from the involved technologies with the expertise needed to develop a viable product and should be convened when an idea originally is conceived. By careful analysis of a product's function and total life cycle (i.e.. design, materials selection, initial manufacture, quality control and evaluation, service life, and recycle), a fine looking. efficiently operating, durable, easily maintained product can be made that conserves materials and energy, is recyclable, and is produced at the lowest total (procurement, maintenance, and operating energy) cost (NATO 1976) . 
4.3.5.5 Potential of Technical societies in Conservation Strategies

The basic purpose of most professional and technical societies in the design, materials, quality assurance and NDE disciplines is the advancement of their respective technologies through education and dissemination of information. Without exception. these organizations willingly cooperate with government and industry on projects in the national interest. Individually and collectively (e.g.. Federation of Materials societies). these societies stage forums, workshops, symposia, conferences, etc.. that focus on such topics as conservation. Their publications also are media for information dissemination (e.g.. summaries of reports such as this are sought by technical society editors for inclusion in their publications).

\subsubsection{Design for Recycling}

As noted above, the designer should be alert to and, when possible, should provide for the recycling of chromiumcontaining components from obsolescent proaucts into usabie alloys. With proper incentives and motivation, industry and government could establish computerized part numbering and location systems for major chromium-containing hardware so that rapid and systematic recall could be made.

In a system of this type, the design should permit ready retrieval and replacement of the components involved. At present, this approach has sufficient economic value only in those cases where (e.g.; the food industry) the bulk of the involved hardware is stainless steel and the entire unit is considered recyclable and replaceable with an equivalent material.

Present procedure for scrapping of a car exemplifies the economic and technical factors working together.

\section{4 PRODUCT TRENDS}

\section{4. 1 Energy and Process Equipment}

Duxing and following the Arab oil embargo, it became apparent that the United States depended significantly on foreign oil and would become increasingly dependent as energy demand increased and domestic production of oil and natural gas decreased. Accordingly. project Independence (PI) a massive interagency effort involving over 500 professionals. was initiated in March 1974 to evaluate the nation's energy problems. The study team did not assess the chromium needs of alternate energy programs; however, it did assemble and publish sufficient information (Federal Energy 
Aāministration 1974) to indicate that chromium requirements for several segments of the energy industry could be estimated with a small additional input.

In general, each task force that worked on the Project Independence Blueprint (PIB) chose several alternatives for study in assessing the potential for energy production. Two of these. Business as Usual (BAU) and Accelerated Development (AD) , were selected for assessing chromium needs in this section. Where possible, the level of activity or energy production will be identified for these cases. For identifying the chromium needs of the energy industries, no allowance was made for lead time to deliver the materials required for plant construction which could be two to three years prior to the needed operating date.

\subsubsection{Oil and Gas Exploration and Production}

The PI Oil Resource Task Force estimated drilling activity for two cases. The BAU alternative assumed that only price changes would have an impact on potential production levels and that no new government policies would be promulgated to affect the development of energy resources. The $\mathrm{AD}$ alternative assumed that certain policy constraints on increasing production would be relaxed and that positive steps would be taken to encourage domestic oil production.

The estimated number of drilling rigs and platforms operating for production of oil in certain target years (Federal Energy Administration 1974. Exhibit VI-2) is shown in Table 16. The chromium needed for oil was assumed to be 500 pounds per $r i g$ and platform per year, and the chromium needed for gas was assumed to be 79 percent of that for oil (Albers and Bawiec 1975). The total annual chromium requirement by this segment of the energy industry was indicated to be 1,700 or 3,330 tons per year for the BAU and $A D$ alternatives, respectively.

\subsubsection{Oil Refineries}

The PI Task Force on Facilitiec developed materids and equipment breakdowns for two typical 200,000-barrel-percalendar-day (BPCD) oil refineries -- a gasoline refinery and a fuel oil refinery. To estimate chromium needs, the low-alloy steel and the stainless steel requirements reported by the Task Force (Federal Energy Administration 1974. Table III-5). were assumed to contain 2 percent and 18 percent chromium, respectively. The calculated totals were 616 tons of contained chromium for the gasoline refinery and 5.47 tons of contained chromium for the fuel oil refinery. In this study. 600 tons of contained chromium were used for 
TABLE 16 Chromium Needs for Oil and Gas Exploration and Production (tons)

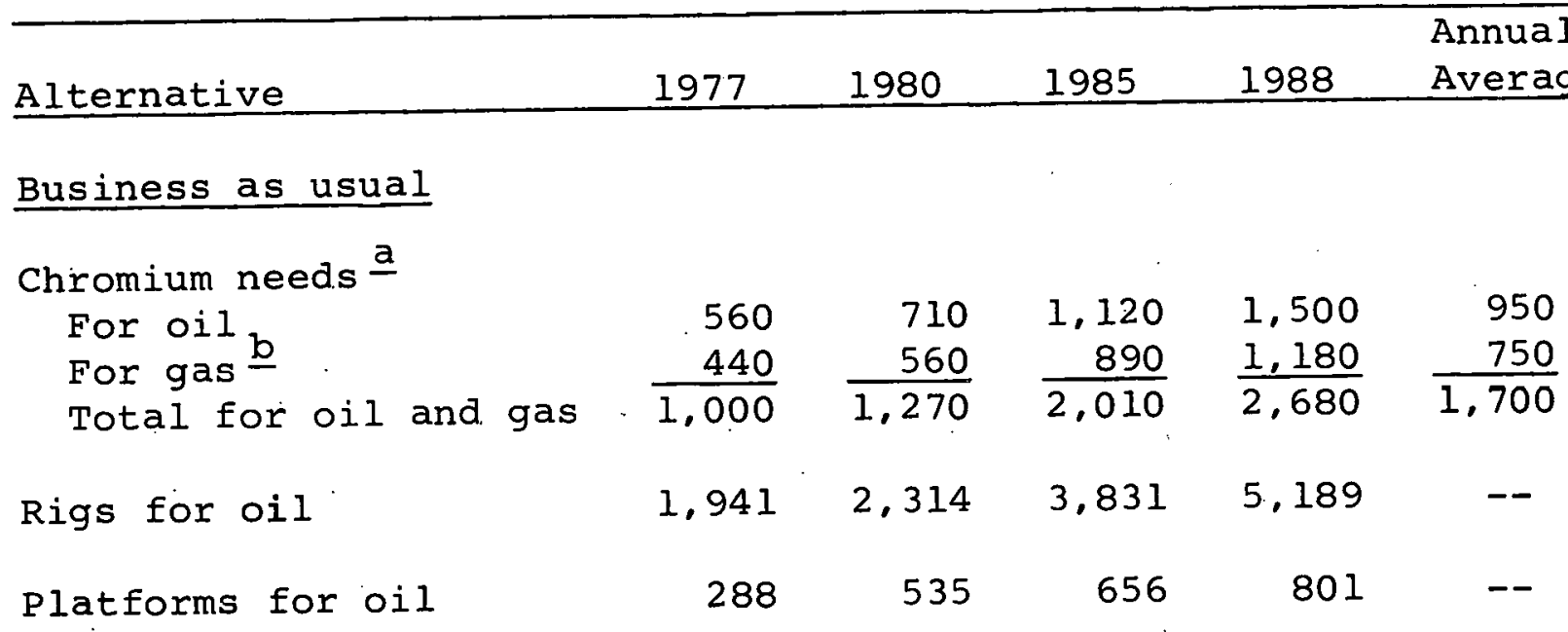

\section{Accelerated development}

Chromium needs a

\begin{tabular}{|c|c|c|c|c|c|}
\hline $\begin{array}{l}\text { For oil } \\
\text { For gas } \\
\text { Total for oil and gas }\end{array}$ & $\begin{array}{r}690 \\
550 \\
1,240\end{array}$ & $\begin{array}{r}1,070 \\
850 \\
1,920\end{array}$ & $\begin{array}{l}2,460 \\
1,950 \\
4,410\end{array}$ & $\begin{array}{l}3,390 \\
\frac{2,680}{6,070}\end{array}$ & $\begin{array}{l}1,860 \\
1,470 \\
3,330\end{array}$ \\
\hline for oil & 2,194 & 3,360 & 8,569 & 12,068 & -- \\
\hline forms for oil & 573 & 923 & 1,284 & 1,508 & - \\
\hline
\end{tabular}

a Based on 500 pounds of chromium per rig and platform per year (Albers and Bawiec 1975).

$\underline{b}$ Ratio to oil is about 0.79 (Albers and Bawiec 1975). 
a typical 200,000-BPCD refinery. The Facilities Task Force also estimated the additional crude capacity and number of new refineries required for the $B A U$ and $A D$ alternatives to be as shown in Table 17. The total annual chromium requirement for this segment of the energy industry was indicated to be only 1,150 and 1,880 tons per year for the $B A U$ and $A D$ alternatives, respectively.

\subsubsection{Gas_Processing}

The number and type of gas processing plants was reported (Federal Energy Administration 1974, Table 7.6) for the $B A U$ and $A D$ conditions, and this information is summarized in Table 18. Alloy and stainless steel plant processing requirements -- $150 \mathrm{million}$ standard cubic feet (SCf) of gas per day -- also were published earlier (Federal Energy Administration 1974, Table 4.1). Assuming 5 percent chromium in the alloy steel and 18 percent in the stainless steel, total chromium needs for construction were calculated as 5 and 62 tons for refrigeratea absorption and cryogenic plants, respectively. The total annual chromium requirement was indicated to be only 1,170 and 1,300 tons per year for the $B A U$ and $A D$ alternatives, respectively.

4. 4. 1.4 shale 0 il

Shale oil production rates of 450,000 barrels per day (BPD) and 1,600,000 BPD by the end of 1990 were projected for the $B A U$ and $A D$ alternatives, respectively (Federal Energy Administration 1974, Tabie II-2). Three types of plants were foreseen: in the first (underground), oil shale will be recovered from underground mines with retorting and processing above ground; in the second (strip), surface mining procedures will be used when the overburden is sufficiently thin with retorting and processing above ground; and in the third (in-situ processing). the oil shale is retorted in its original location below ground after suitable preparations with processing above ground. While in-situ processing has not yet been performed on a production scale, it is of interest because it could eliminate many materials handling and spent-shale disposal problems. These plants may be of different sizes, and capacities of from 50,000 BPD to 200,000 BPD were specified in the PI study.

Chromium usage was estimated from the total steel requirement reported by the PI Facilities Task Force (Federal Energy Administration 1974. Table G-1) that quoted a U.S. Bureau of Mines' estimate of 15 percent of the steel being either alloy or stainless. In high-hydrogen pressure processing (e.g., hydrocracking), the ratio of chromiumcontaining steels was estimated at 80 percent of 2 percent 
TABLE 17. Chromium Needs for Oil Refineries

\begin{tabular}{lcccc}
\hline Alternative & $1977-1980$ & $1980-1985$ & $1985-1990$ & $\begin{array}{c}\text { Annual } \\
\text { Average }\end{array}$ \\
\hline $\begin{array}{l}\text { Business as usual } \\
\text { New crude capacity. } \\
(1,000 \text { BPD a ) }\end{array}$ & 1,251 & $2,3.35$ & 1,564 & -- \\
$\begin{array}{l}\text { Number of new refineries } \\
\text { Chromium needs } \\
\text { (tons/year) }\end{array}$ & 6.2 & 11.2 & 7.5 & 1.9 \\
$\begin{array}{l}\text { Accelerated Development } \\
\text { New crude capacity }\end{array}$ & 1,240 & 1,350 & 900 & 1,150 \\
(1,000 BPD ) & & & & \\
Number of new. refineries & 7,468 & 2,966 & 3,982 & -- \\
$\begin{array}{l}\text { Chromium needs } \\
\text { (tons/year) }\end{array}$ & 7.3 & 14.3 & 19.1 & 3.1 \\
\hline
\end{tabular}

a Barrels per day.

b. At 600 tons of chromium per 200,000 BPD refinery. 
TABLE 13 Chromium: Needs for Gas Prczessing Plants

\begin{tabular}{|c|c|c|c|c|}
\hline Alternative & $1977-1980$ & $1980-1985$ & $1985-1990$ & $\begin{array}{l}\text { Annual } \\
\text { Average }\end{array}$ \\
\hline \multicolumn{5}{|l|}{ Business as usual } \\
\hline \multirow{3}{*}{$\begin{array}{l}\text { Number of new plants } a \\
\text { Refrigerated absorption } \\
\text { Cryogenic }\end{array}$} & & & & \\
\hline & 14 & 0 & 0 & -- \\
\hline & 154 & 35 & 56 & -- \\
\hline $\begin{array}{l}\text { Chromiun neèds } \\
\text { (tons/year) } \underline{b}\end{array}$ & 3,210 & 430 & 6.90 & 1,170 \\
\hline \multicolumn{5}{|l|}{ Accelerated development } \\
\hline Number of new plants $\stackrel{a}{-}$ & & & ' & \\
\hline Refrigerated absorption & 14 & 2 & 23 & -- \\
\hline Cryoçenic & 114 & 52 & 104 & -- \\
\hline $\begin{array}{l}\text { Chromium needs } \\
\text { (tons/year) } \underline{b}\end{array}$ & 2,380 & 650 & $1,3 \cdot 10$ & 1,300 \\
\hline
\end{tabular}

a Based on a 150 million standard cubic feet (scf) per day average plant.

be Based on 5 and 62 tons of chromium for one refrigerated absoprtion: or
one cryogenic plant, respectively. 
chromium steels for thick-walled vessels and 20 percent of 18 percent chromium stainless steels; the chromium usage then calculated to the 0.78 percent basis for the total steel. The chromium needs for shale oil production are summarized in Table 19 at 680 and 2,310 tons per year for the $B A U$ and $A D$ alternatives respectively.

\subsubsection{Synthetic Fuels from Coal}

Conversion of coal to synthetic fuels does not provide a new supply of energy but merely converts the energy in coal into a more convenient gaseous or liquid form that is less likely to pollute. Several processes have been commercialized over the years and many more are under development by the Department of Energy, the U.S. Bureau of Mines, and private industry. The PI Synthetic Fuels Task Force (Federal Energy Administration 1974, pp. 9-13, 19, 101) selected five processes: the liquid fuel FischerTropsch and the Lurgi high-Btu pipeline gas processes (which are representative of current technology) and three others that are representative of developing or advanced technology.

Table 20 provides a summary of estimated materials requirements, the number of plants projected under the BAU and $A D$ construction programs, and chromium requirements. The latter was estimated on the basis of 2 percent chromium in the heavy plate plus 5 percent in pipe. As is shown, potential chromium demand varied from 1,900 to nearly 13,000 tons per year of contained chromium depending upon the time period and the rate at which synthetic fuel plants were to. be developed.

\section{4.1.6 Nuclear Power}

Nuclear power is projected to expand at a rapid rate between 1977 and 1990, when expected nuclear generating capacities for the $B A U$ and $A D$ alternatives are estimated to be 500,000 a nā 730,000 megawatts (MW). respectively (Federal Energy Administration 1974. p. 3.1-5). The 500,000 MW of installed capacity projected for the BAU case is equivalent to 7 million BPD (of plant operation) on a heat equivalent basis. Alternatively. when allowance is made for a 37 percent heat efficiency. in an oil-fired steam boilergenerator. the oil replaced by this power is about 19 million BPD, approximately, the expected total U.S. oil consumption (domestic plus imports) in 1977.

Chromium requirements for various kinds of nuclear power plants have been reported (presentation to the Committee by K. E. Horton, Department of Energy, September 1975). When these numbers are reduced to tons of chromium 
TABLE 19 Chromium Needs for Shale oil Production

\begin{tabular}{|c|c|c|c|}
\hline Type of Plant & $\begin{array}{l}\text { Tons of } \\
\text { Chromium } \\
\text { Per Plant } \underline{\mathrm{b}}\end{array}$ & $\begin{array}{l}\text { Number of } \\
\text { Business } \\
\text { As Usual } \\
1980-1991 \\
\end{array}$ & $\begin{array}{l}\text { Plants } \\
\text { Accelerated } \\
\text { Development } \\
1978-1991 \\
\end{array}$ \\
\hline $50,000 \mathrm{BPD}$ a underground. & 554 & 6 & 10 \\
\hline $100,000 \mathrm{BPD}$ underground. & 1,014 & -- & 2 \\
\hline 100,000 BPD surface & 1,030 & 1 & 3 \\
\hline 150,000 BPD surface & 1,500 & -- & 1 \\
\hline 200,000 BPD surface & 2,000 & -- & 1 \\
\hline $50,000 \mathrm{BPD}$ in-situ & 3,175 & 1 & 5 \\
\hline $\begin{array}{l}\text { Average chromium } \\
\text { (tons/year) }\end{array}$ & & 680 & 2,310 \\
\hline
\end{tabular}

a Barrels per day.

$\underline{b}$ Chromium estimated at 0.78 percent of total steel. 
TABLE 20 Chromium Needs for Synthetic Fuels from Coal

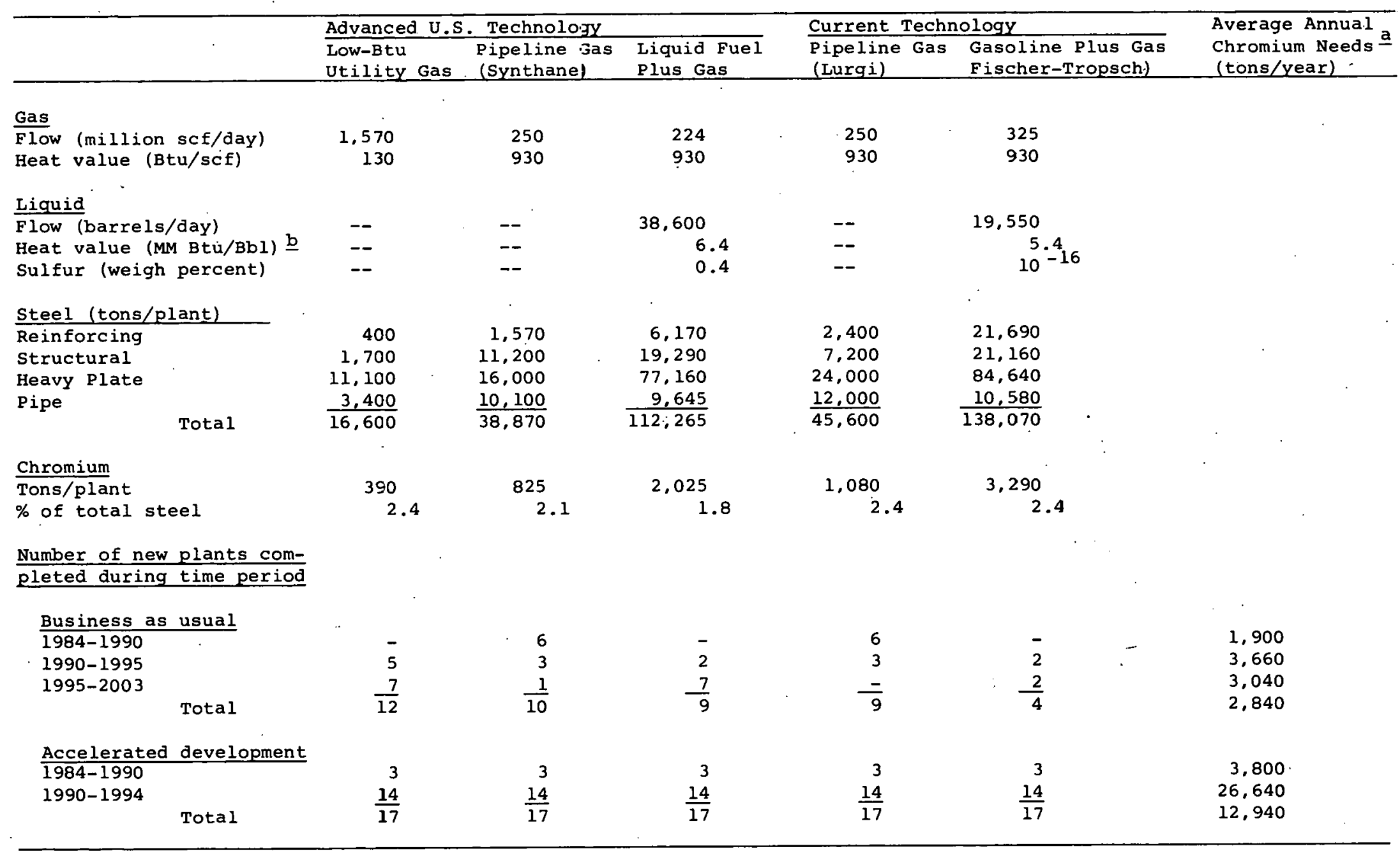

a Basis: 2 percent chromium in heavy plate plus 5 percent in pipe.

$\underline{b}$ Million Btu/barrel. 
per gigawatt ( 1 Gwe = $1000 \mathrm{MW}$ ) of generating capacity and an allowance is made for the chromium requirements of the turbine system, the values shown in Table 21 are obtained. It is worth noting that the liquid metal fast breeder reactor (IMFBR) requires $f i v e$ to seven times as much chromium as the other types. This reactor is not expected to be widely used prior to 1990; however. it may be necessary to develop and use it sooner if the fission reactor is to be a long-term viable option for energy production. All other reactors consume uranium at a rapid rate and will deplete the supply shortly.

The LMFBR, as currently conceived in its prototypes (fast flux test reactor and the clinch River demonstration breeder reactor), is highly dependent upon the availability of certain raw materials (e.g. . chromium, manganese, nickel, and aluminum), and shortages of any of these raw materials can affect commercialization of the IMFBR. more seriously than competitive energy sources because: early impacts of any shortages most likely will occur in the mid-1980s. coinciding with the introduction of the LMFBR; the IMFBR is higher in capital cost per megawatt of capacity and. therefore, more sensitive to increases in material prices than competitive energy sources; and the time required to qualify a substitute material exceeds the time needed for most other types of power generating equipment, because of current licensing requirements.

While the LMFBR is expected to use more than twice the chromium per megawatt generated than the light water reactor, the amount actually involved is only 1 to 2 percent of current annual U.S. chromium consumption. A true assessment of the impact of potential chromium shortages depends on factors such as clarification of the development schedule for the demonstration plants, the social and political environment regarding acceptance of nuclear power, the growth rate of electrical energy demand; and the development of alternate energy-producing methods and their associated total life costs.

In any event, chromium for the LMFBR, has a highpriority rating that is applicable to all the candidate energy systems. The discussion below therefore pertains to the design aspects of all candidate high-technology energy systems.

The first question is how to ensure a chromium supply to serve the needs of our energy-producing industries. As indicated above (see also Table 24), the entire chromium consumption for all energy industries is 3 to 5 percent of the total chromium consumed with nuclear reactors using about one-half of this amount. Introduction of IMFBR will 
TABLE 21 Chromium Requirements of Different Nuclear Power Reactors (tons/ $1,000 \mathrm{MW}$ )

\begin{tabular}{ll}
\hline & Chromium \\
Reactor Type & Requirements $a$ \\
\hline
\end{tabular}

Boiling water reactor (BWR) 275

High-temperature gas-cooled reactor (HTGR) 350

Liquid metal fast breeder reactor (LMFBR) 2,030

$\begin{array}{ll}\text { Pressurized water reactor (PWR) } & 455\end{array}$

a Including turbine system. 
increase chromium usage slightly, but the amount of chromium involved, although vital to the process, is relatively insignificant. Thus, availability of chromium for the LMFBR should not be a problem.

The nuclear industry has initiated design and substitutability efforts aimed at reducing the industry's dependence on chromium. The high visibility of this industry to the government regulatory agencies, code certification groups, public pressure groups, and public itself has resulted in extreme design conservatism. Chromium design and substitution considerations thus far have forused principally on nonsafety-sensitive systems (e.g.. the feedwater supply, auxiliary liquid metal, cover gas, electrical, and plant services) because their qualification and coding time period is relatively short in relation to that of those primary systems that are exposed. to irradiation. stress, and sodium.

Looking keyond the year 1990 and assuming successful development and construction of large-scale TOKAMAK (toroidal confinement device) fusion power plants. more severe demands on chromium will be incurred (private communication from G. L. Kulcinski. Department of Nuclear Engineering, University of Wisconsin, 1976). This assumption stems from the basic features of TOKAMAK fusion power plants (e.g... the low power density of $1 \mathrm{MW} / \mathrm{m}^{2}$ vs 10 to $100 \mathrm{MW} / \mathrm{m}^{2}$ for fission reactors). A $1.475-\mathrm{MW}$ TOKAMAK nuclear island is estimated to require 9.363 tons of chromium with an additional 6.200 for the remaining plant for a total of 15,563 tons or 10.5 tons per megawatt. a demand five times higher than that of breeder reactors (Table 22).

The chromium requirements for the $B A U$ and $A D$ alternatives are tabulated in Table 23. Chromium demands vary from 4.875 tons to 24,000 tons per year depending on the time period and the growth rate of nuclear power.

\section{4.1.7 Coa1-Fired Electric Utilities}

No oil- or gas-fircd electric ulilities dre planned during the period under study (1977-1990). Coal-fired electric utilities, however, are expected to expand as shown in Table 24 for the $B A U$ and $A D$ scheaules (Federal Energy Administration 1974 , p. III-14). The chromium requirement for the new construction is based on using. 135 tons of chromium per 1,000 MW (Federal Energy Administration 1974, Table VIA-XI). Total needs are estimated at 1,600 and 3,840 tons per year for the $B A U$ and $A D$ alternatives, respectively. 
TABLE 22 Chromium Content of 1,475-MW TOKAMAK Nuclear Is land

Component Chromium Demand (\%)

Nuclear island.

Initial structure

First wall replacement

Blanket replacement

Shield.

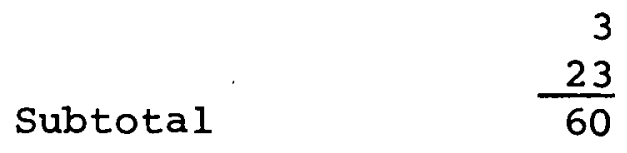

Magnets

Subtotal

\section{9}

8

17

3

$\frac{23}{60}$

TOKAMAK componants

Energy storage unit

Thermal fly wheel

3

Liner

Subtotal

$\frac{3}{16}$

Balance of plant

24

Total

100

NOTE: Based on data from Kulcinski 1976. 
TABLE 23 Chromium Needs for Nuclear Power

1977-1980a 1980-1985a 1985-1990aㅡ. Annual Average

Business as usual

New generating capacity

$(1,000 \mathrm{MW}) \underline{\mathrm{b}}$

39

147

205

Chromium needs

(tons/year) c

4,875

11,025

15,375

11,280

Accelerated development

New generating capacity

$(1,000 \mathrm{MW}) \underline{b}$

225

320

Chromium needs

(tons/year) $\subseteq$

6,625

16,875

24,000

17,250

a January 1 of each year.

$\underline{b}$ Completed in the time period.

C At 375 tons of chromium per 1;000 MW. This is based on a mix of 45 percent boiling water reactor and 55 percent pressurized water reactor with chromium requirements of 275 tons and 455 tons per 1,000 MW, respectively, including 210 tons for the turbine system. 
TABLE 24 Chromium Needs for Coal-Fired Electric Utilities

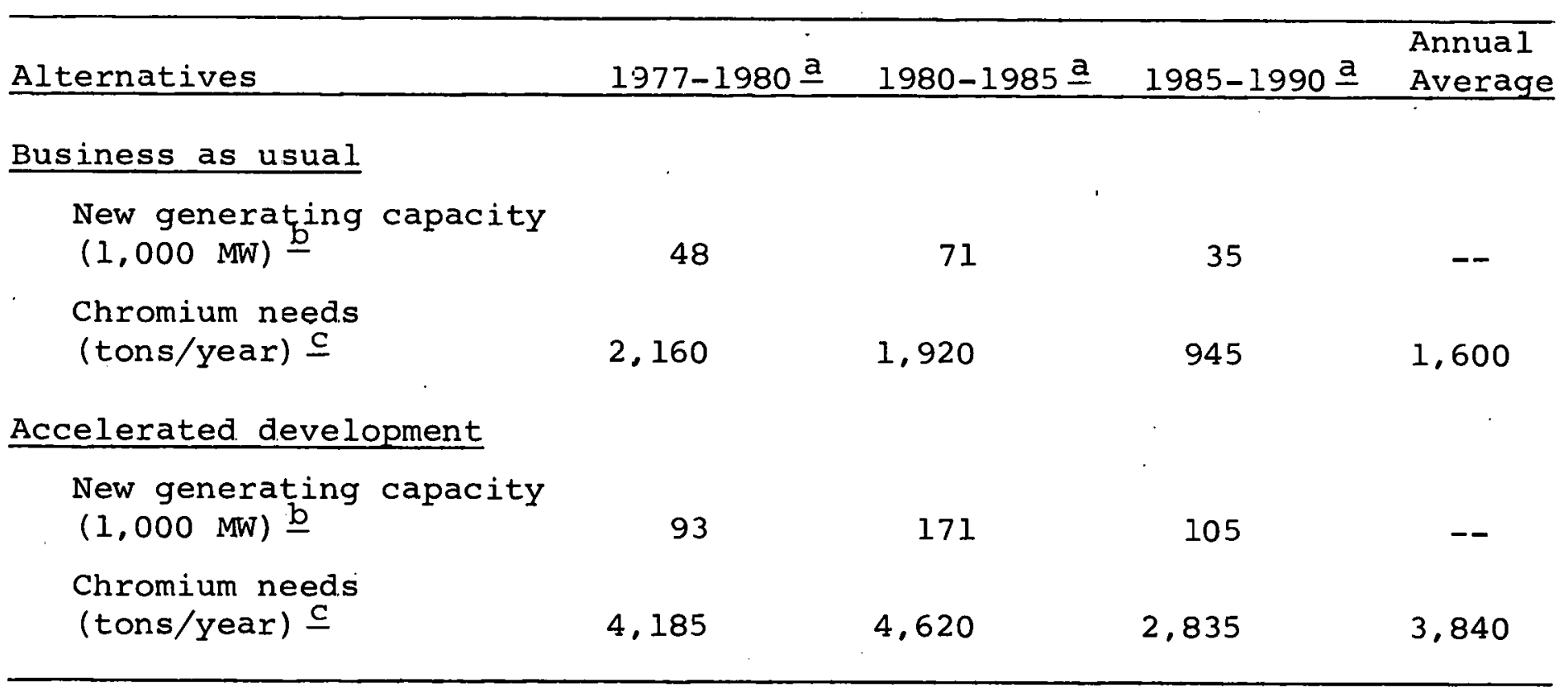

a January 1 of each year.

$\underline{b}$ Completed in the time period.

C At 135 tons chromium per 1,000 MW. 


\subsubsection{Energy Industries Excluded.}

Some sections of the energy industry are not included in this report because chromium usage is expected to be trivial, available data are not sufficient to permit a reasonable estimate of chromium needs to be made, the technology is not advanced sufficiently to permit a reasonable estimate of chromium requirements to be made, or the probable application time is beyond the time frame used in this study. The segments not covered in this report include: coal mining. hydroelectric power, oil and gas pipelines, railroad equipment, deep water ports, geothermal, solar, wind, ocean thermal, bioconversion, new oil tankers, and new liquefied natural gas terminals, and vessels.

\subsubsection{Summary of Chromium Needs in the Energy Industry}

A summary of the chromium needs of the energy industry for new construction to be completed between approximately January 1, 1977, and January 1, 1990, is displayed in Table 25. The annual variation within this 13-year time period indicates a difference less than that between the requirements for the BAU and the AD expansion cases.

The average annual consumption of chromium for new construction by the energy industry is shown as 19.480 and 33,710 tons per year for the BAU and $A D$ alternatives. respectively. These requirements are substantially less than the average of 650,000 tons of chromium expected to be consumed annually in the United states during this same time period. The energy sector's usage, therefore, corresponds to about 3 to 5 percent of total U.S. demand.

The summary table also highlights the fact that the chromium needs of the oil and gas segments are a small part of the chromium requirements of the entire energy industry. Even shale oil production is not expected to be a major consumer of chromium because the economically recoverable reserves are fairly modest and the rate of exploitation probably will be restricted by the supply of water and environmental considerations.

The conversion of coal to gas and clean liquids is not expected to be large during the selected time frame. As noted, the figures shown for the "range of annual chromium needs" are for time periods extending to 199.4 and 2003 . If the average chromium demand for the time period 1984-1994 (12.940 tons per year) had been employed in the $\mathrm{AD}$ "average annual value" column, the synthetic fuel program would have required not 11 percent but about 30 percent of the total chromium required by the energy industry. Thus, the synthetic fuels program could become a major chromium 
TABLE 25 Summary of Chromium Needs of the Process and Energy Industry

\begin{tabular}{|c|c|c|c|c|c|c|}
\hline \multirow[b]{2}{*}{ Industry Segment } & \multicolumn{3}{|c|}{ Business As Usual } & \multicolumn{3}{|c|}{ Accelerated Development } \\
\hline & $\begin{array}{l}\text { Range of } \\
\text { Annual Needs } \\
\text { (tons/year) }\end{array}$ & $\begin{array}{l}\text { Average Ann } \\
\text { Value } \\
\text { (tons/year) }\end{array}$ & (\%) & $\begin{array}{l}\text { Range of } \\
\text { Annual Needs } \\
\text { (tons/year) }\end{array}$ & $\begin{array}{l}\text { Average Annu } \\
\text { Value } \\
\text { (tons/year) }\end{array}$ & $(\%)$ \\
\hline $\begin{array}{l}\text { Oil and gas explora- } \\
\text { tion and production } \underline{b}\end{array}$ & $1,000-2,680$ & 1,700 & 9 & $1,240-6,070$ & 3,330 & 10. \\
\hline Oil refineries & $900-1,240$ & 1,150 & 6 & $1,460-2,300$ & 1,880 & 6 \\
\hline Gas processing & $430-3,210$ & 1,170 & 6 & $650-2,380$ & 1,300 & 4 \\
\hline Shale oil & $680^{c}$ & $680 \subseteq$ & 3 & $2,310^{\mathrm{d}}$ & $2,310^{\mathrm{d}}$ & 7 \\
\hline $\begin{array}{l}\text { Synthetic fuels from } \\
\text { coal }\end{array}$ & $1,900-3,660^{\mathrm{e}}$ & $1,900 \stackrel{\mathrm{f}}{-}$ & 10 & $3 ; 800-26,640^{9}$ & $3,800 \stackrel{h}{-}$ & 11 \\
\hline Nuclear power & $4,875-15,375$ & 11,280 & 58 & $6,625-24,000$ & 17.250 & 51 \\
\hline $\begin{array}{l}\text { Coal-fired electric } \\
\text { utilities }\end{array}$ & $945-2,160$ & 1,600 & 8 & $2,835-4,620$ & 3,840 & 11 \\
\hline Total & $10,730-29,005$ & 19,480 & 100 & $18,920-68,320$ & 33,710 & 100 \\
\hline
\end{tabular}

a January 1, 1977 to January 1, 1990, except as noted.

b January 1, 1977 to January 1; 1989.

C January 1, 1980 to January 1, 1991. Approximately uniform through the whole period.

d January 1, 1978 to January 1, 1991. Approximately uniform through the whole period.

e January 1, 1984 to January 1, 2003. Average for the whole period is 2,840 tons/year.

f January 1, 1984 to January 1, 1990 .

9 January 1, 1984 to January 1, 1994. Average for the whole period is 12,940 tons/year. At this.rate, the usage is about 30 percent of the energy industry total.

h January 1, 1984 to January 1, 1990. 
consumer if the new construction expands as projected for the $A D$ case in the 1990s.

At this time, electric power generation appears to be the industrial segment that will consume the largest share of the industry's chromium, with nuclear power projected to consume the most. Furthermore, if the breeder reactor is developed and commercialized, the chromium need per megawatt of generating capacity could increase by a factor of five or more. Owing to the overriding importance of nuclear energy in the demand for chromium, this subject will be explored in greater detail in the next section of this report.

\section{4.2 Automotive Industry}

The total amount of chromium used by the automotive industry includes that in cars, trucks, buses, and the after-market service parts as well as production scrap if its chromium content is not used beneficially in the recycled form. To arrive at the industry net usage figure. chromium recovered from junk cars, trucks, and buses and used beneficially after recycling must be subtracted from total usage. A forecast of normal and emergency chromium requirements to the year 2000 is shown in Figure 22. Details regarding the chromium content in cars, trucks. buses and truck trailers are presented in appendix $B$.

\section{4. 3 Aircraft Industry}

Chromium utilization trenās in the aircraft industry have been surveyed using two different approaches. First, actual and estimated total chromium consumption figures were requested from major U.S. aircraft companies. second. chromium usage was studied for a large commercial transport aircraft. Accurate and complete data in both cases are lacking because of the greater time and effort needed for the data retrieval method used and because many of the data provided by the contributors were identified as proprietary. However, the details for these approaches are presented in appendix $C$.

Annual chromium consumption by the aircraft industry is minor compared to the national total and represents approximately 6 percent based on U.S. Census statistics for 1972 consumption of chrome products. An estimated 90 percent of the aircraft industry consumption is considered essential. Elimination or even reduction of the chromium content in the alloys used would severely degrade aircraft performance unless a technological breakthrough is achieved in materials development programs. 


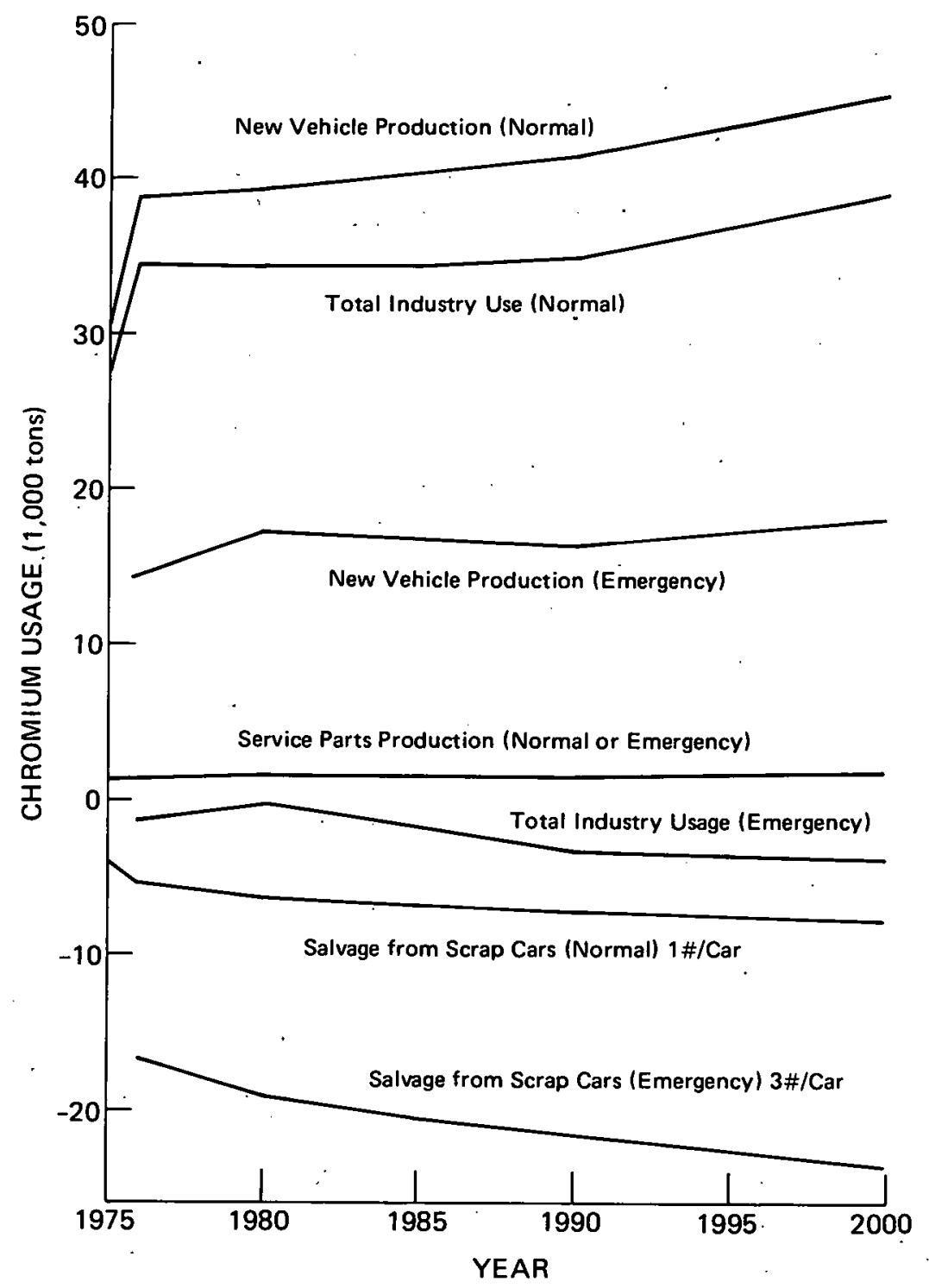

FIGURE 22 Forecast of Automotive Industry Usage of Chromium in Cars, Trucks, and Buses, 1975-2000 (based on data from Jet Propulsion Laboratory 1975, and 1976 presentation to the Committee by J. E. LaBelle, Detroit Diesel Allison, General Motors, Detroit) 


\subsubsection{The Marine Industry}

Chromium usage in the marine industry, was surveyed by (a) personal correspondence with 22 shipbuilders and ship equipment companies requesting information on annual chromium cunsumption and (b) a search for data on the quantity of chromium consumed to fabricate a typical vessel. Seven of the 22 companies contacted responded and 4 of these provided chromium consumption data. Data on chromium consumed for a typical vessel was not available in a form usabie for this survey, although it was determined that the U.S. Navy is in the process of collecting data which will permit computation of chromium weight for specific craft. Results of this Committee's survey (presented in appendix D) reveal the need for a comprehensive study, if accurate chromium utilization data are to be developed for the marine industry.

Chromium consumption by the marine industry is a very small portion of the national total. U.S. Census statistics for 1972 consumption of chrome products indicate a calculated value of less than 1 percent based on data compiled for ferrochrome, ferrochrome silicon, and chromium metal. Consequently. conservation of chromium in the marine industry would not be too fruitful. Chromium savings are possible in the galley area where its usage is considered nonessential. In other areas of the ship. chromium is more closely tied to the performance of the vessel and could be considered essential.

\subsection{SUMMARY, CONCLUSIONS, AND RECOMMENDATIONS}

\subsection{Summary}

Analysis of the chromium consumption trends of the major heavy industries over the next 20 to 30 years, (e.g.. energy, process, automotive, aviation, and railroad) does not indicate any significant upward perturbations except for the manufacture of synthetic fuels, the introduction of nuclear breeder reactors (and the eventual fusion reactor). and the possible introduction of advanced electric batteries for alutomotive and central station power plants.

The chromium needs of selected segments of the energy industry have been assessed. Between January 1, 1977, and January 1; 1990, chromium demand is projected at 20,000 to 34.000 tons per year for business-as-usual and accelerated development programs, respectively, and is about 3 to 5 percent of the probable U.S. average demand of 650,000 tons per year. About 20 percent of the energy industry demand will be required by oil exploration, production, and refining and gas processing. Nuclear power. is projected to 
consume 50 to 60 percent of the industry total. If the fission reactor is to contribute significantly to the supply of energy after 1990. the breeder reactor must be developed since the currently used boiling water and pressurized water reactors should consume the potential supply of uranium in a short time. The breeder reactor will increase chromium demand by about a factor of $f$ ive.

Automotive industry usage is currently about 8.3 pounds of contained chromium per car, with the catalytic converter and wheel covers using approximately one-half of this amount. The latter nonfunctional use can be eliminated immediately and design of engines to meet EPA requirements could eliminate the former chromium use.

Most other reviewed cases indicate a critical but rather low-level constant demand for chromium-containing metals. Numerous examples were identified where reduction in chromium requirements is achievable through conservation, processing changes, and substitution. Consideration should be given to initiating such actions now.

The role of chromium in steel is to provide properties such as corrosion resistance, hardenability, and strength. Efficient design with chromium makes suitable allowance for degradation mechanisms while minimizing usage of chromium. The ultimate design goal should be to match component life with desired product life. Conservative design factors of safety. selected arbitrarily and imposed by design specification, can cause excessive weight in a product and inefficient design; both lead to increased chromium consumption.

To provide a basis for minimum chromium use in the tonnage alloy steels without sacrificing properties, a system such as International Harvester's CHAT should be advanced on a national basis and incorporated into design handbooks and specifications. This system requires considerable data to be developed on the effect of carbide formers other than chromium -- tungsten, vanadium, titanium, and columbium -- upon properties such as hardenability. resistance to intergranular cracking. and resistance to hydrogen environments.

At this time, there is no satisfactory chromium substitute as an alloying addition to resist high temperature oxidation and sulfidic corrosion. However, if the sulfidic environment is present without a high pressure hydrogen environment, the corrosion mechanism is a surface phenomenon and a corrosion-resisting material can be applied as a thin lining. In such cases, the liner is usually a high-chromium steel. 
Nondestructive testing and evaluation can play an important role in chromium conservation by using materials at higher stress levels, screening materials for flaws before commitment to final processing, sorting mixed or salvageatle materials, evaluating repairs, and determining when useful life is ended or safety compromised. Fracture control design permits opportunities for lighter weight and higher reliability components.

Each of these approaches requires changes in curricula in engineering colleges aimed at creating an awareness of the sensitive role of alloying elements in steel. conditionling people from using stainless steel purely for aesthetic reasons, motivating engineers to work as a team using all disciplines to develop an optimized efficient design, and developing more precise handbook data that are oriented to use of optimum chromium-containing materials to perform a given function.

\subsubsection{Conclusions}

1. The design team (consisting of a designer. materials engineer, processing engineer. nondestructive evaluation engineer and a maintenance entineer) is the most effective technical approach for using and conserving materials.

2. In the design process, consideration must be given to the following factors:

- Bias -- Select material based on requirements and not on past practice.

- Available Resources -- Be aware of chromium criticality and recyclability.

- Reliability and Life Expectancy -- Design with inspectability in mind: select life cycle (short or long); initial and total cost.

- Weight - Conscious decision to reduce or increase weight can be a powerful chromium conservation tool.

- Ease of Recycling -- Design high-chromiumcontaining products so that they can be identified, disassembled, and.recycled readily. 
- Aesthetics -- Create a demand for nonchromium externals, an immediate conservation area.

- Corrosion -- A nonfruitful or limited area for conservation by design.

- Stress -- Key factors include life, design handbook data. coatings and claddings.

- Alternative Materials -- Highlighted is the International Harvester's Computer CHAT procedure for minimizing use of critical elements without sacrificing desired design properties.

3. An analysis of selected industries -- process, energy, automotive, aircraft, and marine -indicated current and future requirements, and opportunities, or lack thereof, for chromium conservation. Chromium requirements are forecast in Table 23 for the next several decades. The nuclear and fossil power and synthetic fuel industries are the key users of chromium. sociopolitical factors such as environment. growth, demand for power, regulations, and geographical impact. these demand figures.

4. No satisfactory alternative exists, at present. for chromium as an alloying addition for resisting high-temperature oxidation and sulfidic corrosion.

5. The ultimate design goal should be matching component life with desired product life. Conservative design factors of safety. selected arbitrarily and imposed by design specification. can result in excessive product weight and inefficient design, and lead to increased chromium consumption.

6. Nondestructive testing and evaluation can play an important role in chromium conservation by permitting less conservative design factors of safety. Utilizing nondestructive testing and fracture control in design provides opportunities for lighter weight and more reliable components.

7. Universities and technical societies have a major role to play in creating an awareness of the need for chromium in products through curricula changes, handbook revisions, seminars, and publications. 


\subsubsection{Recommendations}

In the interest of better chromium usage and design, it is recommended that:

1. The team design approach be implemented by top () management. To promote chromium conservation, design teams should be encouraged to ensure that:

- Materials of desired composition and properties are used

- Combinations of materials are used that are compatible with current recycle systems

- Materials have consistently high quality and reliability

- Processing variations can be adjusted by nondestructive testing, evaluation, and feedback during processing

- Finished products have the highest quality and reliability possible through in-process control and reduced reliance on final inspection

- Products in service can be inspected in use to determine their remaining useful life and safety and can be disassembled and repaired easily and at relatively low cost

2. Incentives and penalties be considered to stimulate designers to design products with a high chromium content in a manner that will permit them to be identified readily, disassembled, and recycled.

3. Research be accelerated to develop surface coatings with better high-temperature corrosion and oxidation resistance.

4. Programs for nondestructive evaluation be specified and funds allocated specifically for NDE implementation in order to improve material and product reliability, to reduce in-process waste and labor, and to permit designing to higher limits. 
REFERENCES

Air Force Materials Laboratory. Summary Report on Air Force Chromium Workshop. Wright-Patterson Air Force Base, Ohio: AFML , 1975.

Albers, J.P.., and Eawiec, W.J. Demand and Supply of NonFuel Minerals and Materials for the United States Energy Industry, 1975-1990: A Preliminary Report. U.S. Geological Survey Professional Paper 1006-A,B 75-583. Washington, D.C.: U.S. Geological survey. 1976.

American Petroleum Institute. "Conditions Causing Deterioration or Failures:" . In Guide for Inspection of Refinery Equipment. 2nd ed. Washington. D.C.: American Petroleum Institute." 1973."

American Petroleum Institute. Steels for Hydrogen service at Elevated Temperatures and Pressures in petroleum Refineries and Petrochemical plants. API Publication 941 . Washington, D.C.: American Petroleum Institute. 1977 (preprint) :

American Society for Metals. Metals Handbook. 8th ed. Vol. 1. Metals Park. Ohio: American Society for Metals. 1961;

American Society for Metals. Metals Handbook, 8th ed. Vol. "10. Metals Park, Ohio: American Society for Metals. 1975.

Armco Steel Corporation, Middletown, Ohio, unpublisheō data.

Federal Energy Administration. Project Independence Blueprint, Final Task Force Report. Volumes on "oil: Possible Levels of Future Production;" "Facilities;" "Potential future Role of oil shale: prospects and Constraints:" "Synthetic Fuels from Coal;" "Nuclear Energy;" and "Availabiliẗies, Requirements, and Constraints on Materials, Equipment and Construction." Washington, D.C.: FEA, November 1974 .

Federation of Materials Societies, Task Group on National Commission on Materials Policy study. "Conservation in Materials Utilization." In Materials Evaluation. pp. 1R-28R. Washington. D.C.: Federation of Materials Societies, April 1973.

Fontana, M.G.. and Greene, N.D. Corrosion Engineering. New York: McGraw Hili. 1967. 
Gadd. C.W., and Ochiltree, N.A. "Full Scale Fatigue Testing of Crankshafts." Proceedings of the society for Experimental stress Analysis. 2(1945):150-7.

Grossman, M.A. Hardenability Calculated from Chemical Composition. Vol. 150. New York: AIME, 1942.

Harvey, D.G. , and Menchen, W.R. A Technology Assessment of the Transition to Advanced Automotive Propulsion Systems. Columbia, Maryland: Hittman Associates, Inc.. 1974.

Jet Propulsion Laboratory. Should we Have a New Engine?. Vo1. 2. Pasadena: California Institute of Technology. Jet Propulsion Laboratory. 1975.

Krupp. W.E.. and Walker, E.K. "Influence of Fracture Parameter Interactions on the Design Process." In Fracture Prevention and Control. Metals Park, Ohio: American Society of Metals; 1974.

McConomy. H.F. "High-Temperature sulfidic corrosion in. Hydrogen-Free Environment." Proceedings of the American Petroleum Institute 43 (III) (1963):78-96.

National Materials Advisory Board. Nondestructútive Evaluuatiㅡㅇㅡ. Report NMAB-252 (NTIS Number AD692491). Washington, D.C.: National Academy of Sciences, 1969. (Available from National. Technical Information Service, 5285 Port Royal Road, Springfield, Virginia 22151.)

NATO science Committee, ad hoc Group on Materials. Conservation of Potentially scarce Metals with Emphasis on Their Dissipative Uses, Section VI: United Nations: NATO, 1976 .

Nelson, G.A. "Hydrogen Plant steels." Proceedings of the American Petroleum Institute 29M (III) (1949): 16 $3-72$.

Peterson, M.H., and Brown, B.F. "strèss Corrosion Cracking of High-Strength Steels and Titanium Alloys'in Chloride solutions at Ambient Temperature." Corrosion 23 (May 1967) : 142-8.

Tupper, N.G. "Fracture Mechanics Design Requirements -Review and Reflection." In Fracture prevention and control. Metals Park, Ohio: American Society for Metals. 1974.

Wood, H.A. "Fracture Control Considerations in Aircrät Structural Design." In Fracture prevention and control. Metals Park, Ohio: American Society for Metals. 1974. 


\section{BIBLIOGRAPHY}

Hostetter, H.E. "Determination of Most Efficient Alloy Combinations for Hardenability." proceedings of the AIME $167(1946): 643-52$.

International Nickel Company. Inc. Carburized Nickel Alloy Steels- New York: International Nickel Company. 1975.

Smith. C.S.: ed. The sorby centennial symposium on the History of Metallurgy. New York: Gordon $\varepsilon$ Breech Science Publishers, 1963 , p. 475 . 
Chapter 5

PROCESSING

\section{1 INTRODUCTION}

The following discussion focuses only on the actual processing and fabrication of stainless and alloy steels. alloys, and metal products containing chromium. The principal products of interest are chromium-containing stainless steels, alloy steels, nonferrous alloys

(especially nickel-base) and welding materials. Iimited consideration is given to cast irons and tool steels since these materials contain relatively little chromium.

Melting and refining, casting, mill product fabrication, manufacturing processing. joining, surface coatings, and recycling are considered in terms of: present status; key problems; probable future processing trends; and special opportunities, needs, and requirements for chromium conservation. For each chromium conservation opportunity identified, an attempt is made to: (1) assess its technical and economic status and identify potential problems; (2) determine how much chromium would be saved, what implementing actions must be taken, and how much time would be required for implementation; and (3) identify any peripheral effects, as well as the probability for success.

\section{2 MELTING AND REFINING}

The selection of a particular melting and refining process from today's array of technologies depends upon the type of alloy desired and its final application, economics. and specific customer specifications. Because of the widely varying requirements and the extensive technology in melting, this discussion will focus on major conservation potentials in key production uses of chromium. Important metallurgical applications of chromium, the average chromium content of the principal material groups, and the distribution of the chromium consumption are listed in Table 26.

Among the stainless steels, the austenitic stainless types (primarily Type 304) with their relatively high chromium content are dominant. The alloy constructional steels with an average chromium content of about 1 percent are the second largest users of chromium because of the large tonnages produced. Other chromium alloying uses cover a wide range of products, the major portion of which are used in high-temperature and corrosion-resisting applications. but comprise only 14 percent of the total consumption. 
TABLE 26 Key Uses of Chromium in Alloys (1974)

\begin{tabular}{lll}
\hline & $\begin{array}{l}\text { Average } \\
\text { Chromium } \\
\text { Content } \\
(\%)\end{array}$ & $\begin{array}{l}\text { Use of } \\
\text { Metallurgical } \\
\text { Chromium } \\
(\%)\end{array}$ \\
\hline Stainless steels a & 16.4 & 72 \\
Alloy steels & 1 & 14 \\
$\begin{array}{l}\text { High-temperature special } \\
\text { alloys and Ni-Co-base alloys }\end{array}$ & 18 & 7 \\
$\begin{array}{l}\text { Tool steels } \\
\text { Alloy cast irons }\end{array}$ & 6 & 2 \\
$\begin{array}{l}\text { Miscellaneous (wear resisting } \\
\text { alloys, welding, hard facing } \\
\text { alloy, others) }\end{array}$ & -1 & 2 \\
\hline
\end{tabular}

NOTE: Data from American Iron and Steel Institute 1975.

a Austenitic stainless steels contain an average of 17.9 percent chromium; ferritic stainless steels, 15.2 percent; and martensitic stainless steels, 12 percent. 
Emphasis in this discussion is placed on stainless steels, alloy constructional steels, and the hightemperature speciality alloy group. These three groups offer real potential for saving and conserving chromium. especially through continuing implementation of recent technological developments on a large scale. Greater use of lower grade chromium ferroalloys would permit the use of more readily available lower grade chromium ores. More extensive recycling of mill wastes could reduce chromium consumption significantly in future years.

\subsection{Primary Melting and Refining Methods}

The basic methods used today for making iron and steel are expected to be used in the foreseeable future to meet the growing demand; however. they do not lend themselves easily to effective processing of a combination of chromiumbearing ores, pig iron, and scrap. An investigation to determine the feasibility of using lower grade chromium ores (e.g.: chemical grade chromium ore with a chromium-to-iron ratio of about 1.5:1.0) for the production of chromium-iron in the blast furnace was carried out some time ago (Dulis 1974). The results indicated that the process was technically feasible but that the economics were questionable. Further work in this area may be advisable since chromium-bearing. blast-furnace iron could be pigged for use in alloy cast irons that would retain the full value of the contained chromium. However, chromium consumption for alloy cast iron is only 3 percent of total consumption; hence, the savings would be small. The use of chromiumbearing iron for steelmaking would not permit the retention. of chromium from alloyed pig iron and simultaneous removal of phosphorus to acceptable levels.

A more promising approach to utilizing low-grade chromium ores might be the development of a production process for chromium-bearing prereduced peilets. The blending of chromite ore with iron ore for combined reduction to a deoxidized product with 2 to 10 percent chromium or the mixing of reduced iron with ferrochrome pellets might be feasible for alloy steelmaking in electric furnaces. Research in this area should be encouraged since alloy steels currently consume about 16 percent of total metallurgical chromium; however, the cost of iron units in such materials must be competitive with alternative iron unit sources such as scrap. (The practice of using prereduced iron pellets is growing rapidly in electric furnace shops.)

Electric furnace arc melting is the predominant alloy steelmaking process for low- and high-alloy steels as compared to induction melting that is used at relatively low 
volumes by the foundry industry. In 1975, electric furnace output accounted for 21 percent of domestic steel production, approximately 70 percent of which was carbon steel. Electric furnace capacity should continue to increase steadily because of the advantages of electric melting. The electric furnace provides excellent flexibility in the selection of raw materials and in operational and metallurgical practices that can be tailored readily to specific needs and requirements. Recent developments in furnace equipment and technology have made the electric arc furnace a prime melting unit for steels of all types. The introduction of ultra-high-power (UHP) furnaces and the development of improved refractories and electrodes have made the electric arc furnace an attractive melting unit even for low-cost tonnage carbon steels. Approximately 40 percent of U.S. electric furnace capacity is UHP and the largest single furnace has a capacity of 400 tons.

UHP melting has relegated the electric furnace to a pure "melting machine" that requires the separation of the melting and refining phases for most economical practice. Starting in 1968, the trend toward separation of the meltdown phase from the refining stage led to development of a number of duplex melting systems that are used predominently in stainless steel manufacture. The electric furnace melts the charge and metallurgical treatments are performed subsequently in the ladle (ladle refining) or in separate refining units that rely on chemical heat input or auxiliary electric heating. A general overview of the various refining systems in operation today for high-alloy chromium steels is presented in Figure 23.

Decarburization of high-chromium-containing melts is somewhat different from that of unalloyed steels. The high affinity of chromium for oxygen retards decarburization, and the chromium-carbon equilibrium for a specific chromium content can be shifted to lower carbon levels only by significant temperature increases. However, by utilizing the pressure dependence of the carbon oxidation reaction. lower carbon contents can be achieved at reasonable temperatures under vacuum without significant chromium losses. The available processes are ladle refining carried out under vacuum and converter refining carried out at atmospheric pressure with inert gases.

The vacuum processes achieve somewhat lower carbon levels with lower chromium losses than converter processes that are based on lowering the carbon monoxide partial pressure by blowing with inert gas and oxygen in varying proportions. The best known processes are argon-oxygen decarburization (AOD) and the more recently developed 


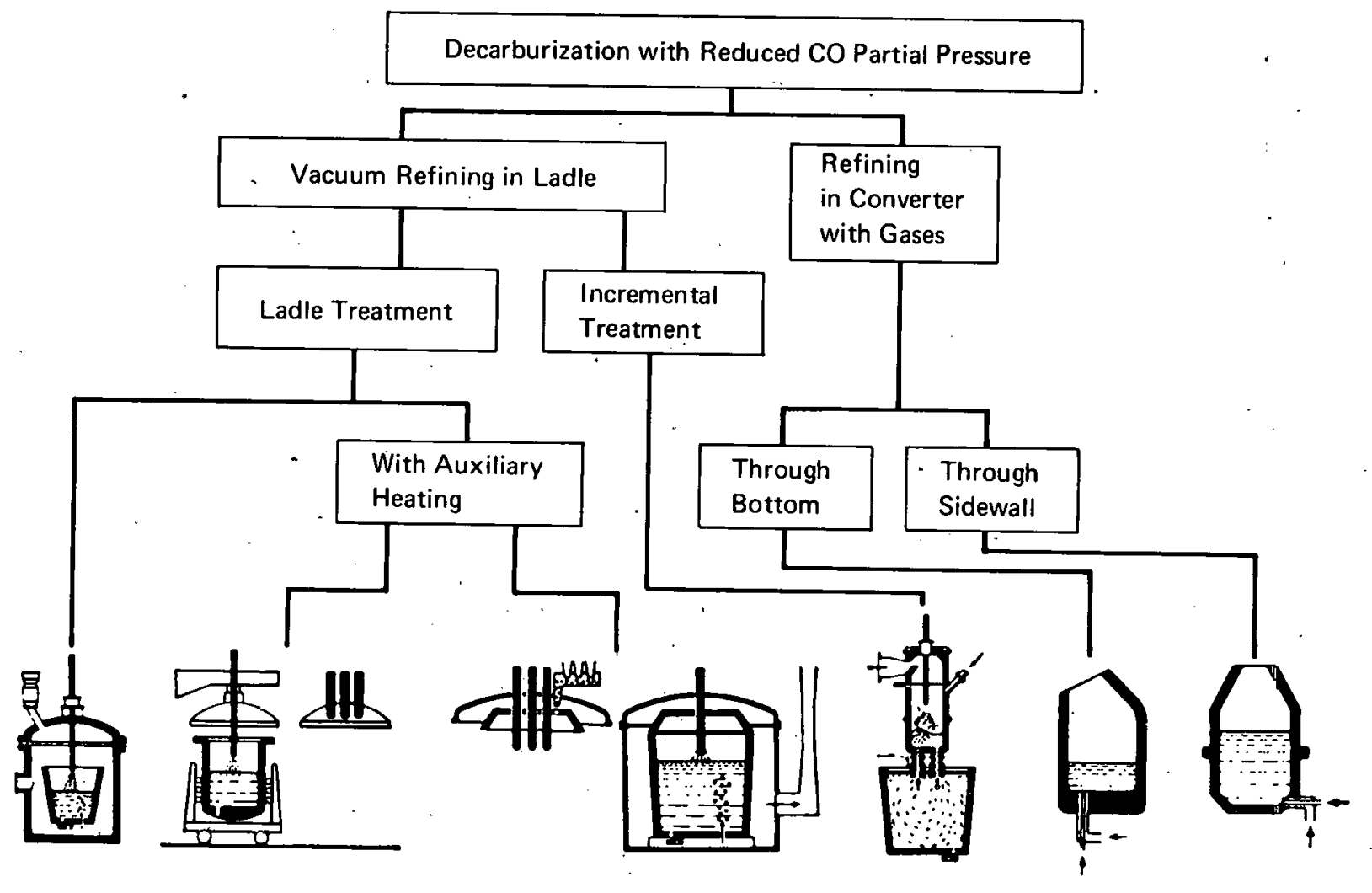

FIGURE 23 Overview of Principal Decarburization Processes Used in Stainless Steelmaking (Baum et al. 1975) 
Creusot-Loire-Uddeholm (CLU) process. The latter uses steam as the oxygen diluent and argon only for final refining and purging. The CLU converter can be charged with chrome pig iron produced directly in a reducing arc furnace from chrome ore, pellets, low-phosphorus iron ore, and nonalloyed scrap.

The development of duplexing processes has had a profound impact on stainless steelmaking. significant economic benefits result because of the use of lower cost raw materials and the much improved chromium recovery. In conventional electric furnace melting and oxygen blowing. the irreversitle chromium losses amounted to 10 to 15 percent (an average of 12 percent); with pneumatic decarburization processes, these losses are reduced to less than 6 percent using electric arc melting followed by vacuum decarburization processes. A typical sequence for stainless slab production is illustrated in Figure 24 . The charge is melted in the electric arc furnace or basic oxygen furnace and is refined by AOD or vacuum-oxygen decarburization (VOD). The processing of stainless steel heats of 100 to 150 tons is common today. In addition to greatly increased productivity and chromium recovery from lower cost highcarbon ferrochromium, duplex processing improves product quality aue to lower gas and impurity contents.

The rapid acceptance of duplex techniques is causing a major shift in raw material requirements. Scrap, the primary chromium source in stainless steelmaking. supplies about 50 to 70 percent of the needed chromium, and the balance is supplied by ferrochromium. Low-carbon ferrochromium and ferrochromium silicon are being displaced by high-carbon ferrochromium (charge chrome) that is less expensive to produce and can be made from lower grade ores. To make stainless steel using low-cost charge materials. charge chrome can be combined with high-carbon ferronickel. The higher sulfur contents of such lower cost raw materials can be reduced in the converter processes. Future use of low-carbon ferrochromium will be limited to trim additions and special alloy production. Present duplex process capacity amounts to more than 30 percent of the present production in the western world and is increasing rapidly.

The application of the basic oxygen furnace (BOF) for stainless steel production -- primarily for the 400 series -- provides some unique advantages along with a satisfactory chromium recovery rate of approximately 90 percent. This process uses hot metal from a basic water-cooled hot-blast cupola, a cold charge of stainless steel scrap. and highcarbon ferrochromium that is blown with oxygen in a BOF converter. After adding cooling scrap. a reducing agent is added to recover chromium and manganese from the slag. 

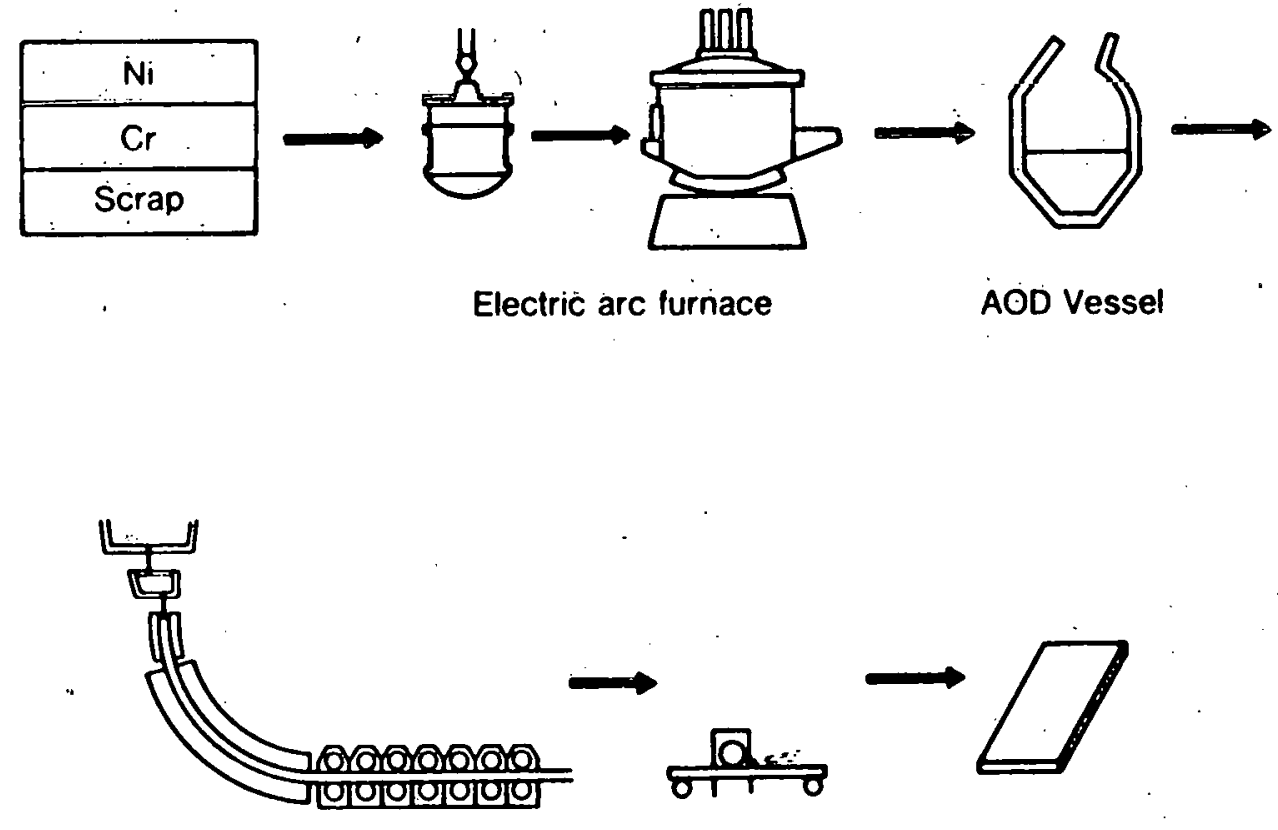

Conitinuous casting machine Slab grinding

FIGURE 24 Typical Manufacturing sequence for High Rate Production of Alloy and Stainless Steel or Billets 
In the manufacture of low-alloy constructional steels containing chromium, the application of UHP arc furnaces is growing steadily and the adoption of vacuum treatment after melting is almost universal. The trend is toward truly duplex vacuum refining systems and extended ladle treatments for premium-quality constructional grades. Low-alloy highstrength steels and tool steels also are produced by the BOF process using conventional oxygen-blowing practices.

Technological advances are being made in alloy steel production to improve alloy element recovery and to maintain narrower chemical tolerances at the lower end of specification ranges and thereby conserve alloy additions. physical specifications are met with lower total alloy contents due to improved chemical and cleanliness control with advanced melting practices. The previously irrecoverable chromium losses of 7 to 10 percent in conventional melting of low-alloy steels are estimated to be reducible to less than 4 percent with improved processing. Careful raw material selection, proper slag control, refined analytical techniques, and duplexing result in maximum chromium recovery.

Utilization of improved and more consistent properties in high-strength and special-purpose low-alloy steels obtained through secondary remelting and refining processes must be mentioned. Vacuum arc remelting (VAR) and, more recently. electroslag remelting (ESR) have upgraded the quality and performance of many alloy steels employed in critical applications, especially in the aerospace industry. Wider use of remelted materials for their improved properties, consistency, and reliability could result in appreciable chromium conservation.

A third materials group -- high-temperature alloys and nickel-cobalt-base superalloys -- consumes about 8 percent of all metallurgical chromium and requires little attention from the viewpoint of conserving chromium through improved melting technology because these costly alloys are handled carefully to minimize losses and waste. vacuum induction melting and secondary remelting operations (VAR and ESR) are employed extensively to ensure optimum properties in these high-performance materials. Different combinations of processes are used to meet highest industry standards for various alloy types and permit maximum alloy conservation. Chemical compositions of such alloys are optimized. restricted, and maintained carefully within narrow tolerance ranges for maximum property response, processability, and performance. This degree of processing and control is generally not economical for lower cost materials. No significant chromium savings are expected from further 
process developments for these types of chromium-rich alloys.

The remaining materials in Table 26 -- tool steels, alloy cast irons, and miscellaneous alloys -- represent a relatively small group of chromium users. Tool steels and wear-resisting, welding, and hard-facing alloys are produced in relatively small electric furnace heats using considerable care to conserve and recover alloying ingredients in these highly alloyed compositions. Careful scrap segregation and internal recycling are practiced, and attempts are made to. recycle customer scrap and waste effectively.

Important chromium savings could be achieved in stainless steels by avoiding over-specification and by partially substituting aluminum and silicon for chromium. Reduction of carbon from 0.05 percent to 0.02 percent in the 400 Series stainless would permit a reduction of chromium content of 0.5 percent. Such alloys, with the addition of reactive elements, require that modified melting procedures be developed and that duplexing and advanced casting techniques be adopted more widely to protect the reactive elements from excessive oxidation. vacuum melting. refining, and casting also might be mandatory in such cases. While this technology is available, economics will limit its use in large tonnage applications.

\subsection{Environmental Considerations}

The newer duplexing and refining processes for alloy and stainless steelmaking do not add burdens to proper fume and dust collection systems. Vacuum treatments are performed in completely enclosed systems and, hence, their environmental effects are insignificant; however, special problems are encountered in melting certain types of scrap. especially oily swarf. of, some concern in recycling melt shop dust is the impurity content of the dust, which contains considerable amounts of arsenic, antimony. lead. and cadmium in addition to chromium and nickel.

Chromium losses in stainless steel slags are significant. For $1.5 \mathrm{million}$ tons of stainless steel produced, approximately 30,000 tons of chromium are lost annually based on an average chromium yield of 85 percent. The wider application of modern melting systems and improved refining and deoxidation practices will reduce this chromium loss to approximațely 10,000 to 15,000 tons per year. 


\subsubsection{Energy Considerations}

The energy efficiency and power consumption of electric arc furnaces is not expected to change significantly in the future; however, power consumption may increase somewhat if prereduced pellets are substituted for scrap. Duplex melting systems, which use chemical energy for refining. tend to decrease the energy content of the material produced, but refining methods, which use auxiliary electric heating. increase energy requirements. The most energyintensive processes are combinations consisting of primary and secondary melting and refining operations (e.g.. electric or vacuum induction furnace melting plus VAR or ESR remelting). However, even a considerable expansion in use of such multiple processing would not affect significantly the total energy consumption of the metals industry.

\subsubsection{Ferrochromium in the stockpile}

In mid-1976, the U.S. stockpile contained and considered the following quantities of ferrochromium alloys as "excess": 320,000 short tons of low-carbon ferrochromium, 390,000 short tons of high-carbon ferrochromium, and 60,000 short tons of ferrochromiumsilicon. These three grades of ferrochromium do not have the same specifications as those produced for commercial use today. The stockpiled low-carbon ferrochromium has a maximum allowed sulfur content of 0.10 percent versus present commercial specifications that call for 0.025 percent maximum. In addition, the maximum carbon content of the stockpiled low-carbon ferrochromium is 0.10 percent compared with present specifications that, depending upon grade, specify a maximum carbon content of 0.025 to 0.05 percent. In the case of stockpiled high-carbon

ferrochromium, the maximum allowed sulfur is 0.10 percent versus present commercial grades that have maximum sulfur contents of: 0.04 percent, 0.05 percent, and 0.07 percent. The maximum allowable sulfur content of stockpiled ferrochromium-silicon is 0.05 percent versus present commercial specification of 0.03 percent.

Thus, all the stockpiled ferrochromium has a higher sulfur content than the current commercial grades and accordingly might have a reduced value. Since duplex melting and refining can produce stainless steels with lower sulfur contents than conventional melting, producers with duplexing facilities could use stockpiled ferrochromium while other producers of stainless steels and chromiumcontaining alloy steels must limit their use of ferrochromium to commercial grades. 


\section{3 CASTING PROCESSES}

since most metals and alloys go through a melting and casting phase at some time. opportunities to conserve chromium exist in processing innovations that improve materials utilization through advanced ingot casting. precision casting, near-net-shape forging, powder metallurgy, and reduced material removal during part and component manufacture.

\subsection{Casting Processes for Wrought Products}

To manufacture low- and high-alloy steel wrought products, molten steel generally is poured into static ingot molds. Technological advancements in this process are concerned primarily with ingot design, ingot surface quality. and exothermic and insulated hot tops to obtain higher yields of rolled products by minimizing internal defects, piping, and cropping. Efforts to improve ingot surface quality further led to limited applications of casting under a molten flux blanket and to inert gas protection of the ingot pouring stream. Most static ingot casting in the United states is by top pouring. Overseas. bottom pouring is usea more extensively. Only limited improvement is foreseen through conventional ingot casting practice.

Continuous casting of alloy and stainless steels in billet and slab sections (Figure 24) and pressure casting of slabs are recent technological developments of technical and economic significance. With the trend toward increasing melt shop output, continuous casters are being developed that permit high rates of casting and result in improved yields, reduced scrap and waste, lower energy consumption in further processing, and. lower costs. Future development efforts will be directeā toward automated-computerized process control.

\subsubsection{Casting Processes for Shape Castings}

Sand casting has become a versatile, well-engineered, and reliable manufacturing process. New molding and coremaking techniques and innovations in cast materials have improved dimensional control and surface quality that reduce machining and are particularly important for stainless and high-alloy steel castings (corrosion- and heat-resisting cast steels). The use of chromite sand in steel foundries is increasing as it replaces more expensive zircon sand in the facing mixture and, in some instances, is used as a substitute for silica sand, which is unsatisfactory in certain applications. The advantages of chromite with at least 44 percent $\mathrm{Cr}_{2} \mathrm{O}_{3}$ are its greater chilling effect (heat 
transfer) and inertness at high temperature and, hence. reduced metal penetration at high ferrostatic pressure. In 1975, an estimated 80,000 tons of chromite were consumed for facing sand.

The AOD process is another development in stainless and high-alloy steel casting aiding chromium conservation. While the tonnages of cast products are small compared to wrought-stainless and high-alloy steel, potential chromium savings are significant.

Ceramic investment precision casting provides products that require a minimum of machining and therefore are costand material-effective. A limitation to further expansion of shape casting technology is that the size and weight of such castings currently are limited to a maximum of 30 to 40 inches in diameter and about 600 pounds. Controlled inert atmospheres or a vacuum frequently are used to aid mold filling and enhance material soundness and properties. The recent introduction of hot isostatic pressing (HIP) to densify castings provides better properties in critical cross sections of investment-cast superalloys and may encourage designers to specify more castings in critical applications. HIP post-treatment improves fatigue. stressrupture, and tensile properties and may become standard practice for many high-performance castings. However. savings in chromium resulting from technological advances in this field will be small since material utilization in investment casting is already high.

other precision casting processes, such as permanent mold and pressure die casting, are designed and engineered to meet demanding product requirements with high material utilization. pressure die casting of stainless and alloy steels has been under development for many years but. despite economic incentives, has received only very limited acceptance due primarily to inadequate die life. Recently. the Ferro-Di process was reported to be operating in the United Kingăom at the Guest. Keen $\varepsilon$ Nettlefolds. Itd. (GKN) Group Technology centre where nickel and cobalt alloys, and stainless, alloy, and carbon steels are die cast to parts ranging from 0.9 to 5.6 pounds (Metals and Materials 1976). composite dies with inserts of TZM alloy are used and have a. die life of about 10,000 cycles. (The TZM alloy contains 0.5 percent titanium and 0.1 percent zirconium. and the balance is molybdenum). However. the impact of this development on chromium conservation is small.

\subsection{MILL-PRODUCT FABRICATION}

Wrought mill products are produced from cropped and prepared ingot or continuous cast product; they are either 
semi-finished (e.g., plate, rod, bar, sheet, strip and forgings) and receive subsequent processing or are finished (e.g.. large-volume structural shapes and hollows) and used essentially as produced or after heat treatment or surface conditioning. Chromium conservation in this area is related closely to the shape and surface quality of the feed materials; the efficiency and sophistication of the heating, handling. and working equipment; and the particular material used. Mill-product fabrication is integrated with a melting facility to provide nearly complete recycle of in-house scrap because the scrap is valuable and is generated near the melting facility. This scrap, in addition to ingot top crops. consists of cropped front and rear product ends that may be defective or improperly formed, cobbles, rejects. scale, and conditioning swarf.

\section{4. 1 Processes and Design Developments}

Selecting the metalworking process for a particular mill product from the available metalworking technology is relatively straightforward. Rolling mills for a specific product shape (e.g.. sheet, rod, plate, tube, and structural) are rated by maximum and minimum product sizes for a particular alloy class and involve a considerable capital investment. The selection of a particular rolling mill therefore is based on product shape, proauction required, and the alloy that is sufficiently workable to obtain the necessary minimum economical throughput. A few large mills account for most of the production of alloy and stainless steels and generate a consistent product at consistent yields unless some major changes are made to a particular facility.

The major factors affecting the consumption of chromium in mill-product fabrication are:

1. Large tonnage requirements that may encourage substitutability or cladding

2. Dimensional control and surface quality (e.g.. excess stock shipped to meet minimal dimensional and surface requirements)

3. Atmospheric contamination and required conditioning

4. Croppings, flash, and rejects

5. Cobbles 
Ingot effect's on bloom, billet, and slab quality as well as losses during melting of recycled material also must be considered.

In recent years, stainless steels have accounted for about two-thirds of the annual consumption of chromium and chromium ferroalloys and a large volume of stainless steel scrap. Second in the consumption of chromium and chromium ferroalloys is alloy steel which, although produced in the largest tonnage quantities, contains an average of only about 1 percent chromium.

The production of alloy and tool steels sometimes is combined for aiscussion but the mill-product fabrication of the two differs significantly. The tool steels typically are made by specialty mills that use less automation and produce greater percentages of reclaimable and nonreclaimable mill scrap.

The high-temperature nickel- and cobalt-base alloys (superalloys) are used principally in aircraft gas turbine engines as cast blades, vanes, guides, and nozzles; forged discs and blades; and formed sheet products. To achieve high-temperature oxidation, corrosion and sulfidation resistance and ductility, the chromium percentage in these alloys is high. (Moore and Athey 1976). Advanced developments in these alloys were as follows:

- Alloys were made to improve corrosion resistance and elevated-stress rupture properties (cast alloys) for blades (Vazquez and Hayes 1974): to reduce density; and to improve toughness and intermediate temperature (1200 to 1500 o F) strength (wrought alloys) for disc applications.

- Processes were developed to improve toughness and intermediate temperature strength of cast alloy or non-castable alloy compositions and conventional wrought alloy compositions by thermal-mechanical processing (TMP) (Proffitt and Thomas 1962) and powder metallurgy (PM) processing (Redlinger and Timura 1964).

- Processes were improved by fabricating more precise products using isothermal forging (Couts and sjoblad 1975), and shape rolling (Wick 1960) incluaing heated roll sheet and shape rolling (private communication with I. Liuzzi. Watervliet Arsenal); by hot isostatic pressing of casting defects for process improvements (private 
communication with W. D. Manly, Cabot Corporation); and by rejuvenating original properties after accumulated damage in service (Barth and Hoffmanner 1974).

standard practices in the aerospace industry are the testing of design requirements, new processes, and new materials to meet the demanding performance specifications. The critical requirements of the aircraft industry are being achieved with techniques that have been, or could be. applied by other industries to products other than finished or semi-finished mill products. Performance requirements. the poor workability of the aerospace alloys, and limited production quantities have resulted in practices that generate considerable scrap. For this reason, recent developments have coupled processing for improved performance with precision fabrication, and these developments have been applied successfully to other than aircraft structures.

\subsection{Consumption of Chromium}

To analyze chromium consumption, a material balance must be established between: input material of chromium and ferrochromium alloys; scrap (including home and purchased): and output material consisting of mill products shipped. home scrap generated, and inventory. This analysis is presented in appendix E.

\subsection{MANUFACTURING PROCESSING}

The major processing considerations involved in converting a rough piece to a preassembly component are described below as are actions that, if taken, would improve the total utilization of alloying elements, particularly chromium. Each major processing step is covered, and the major problems and needs involved in developing a process that more closely maximizes raw material utilization and minimizes raw material losses are identified. The basic process systems considered are machining and grinding. forming and deep drawing, part forging. powder metallurgy, chipless machining, and isothermal working.

The involved processes are not material-sensitive and apply to most chromium-containing alloy systems to some degree. Revising processing objectives and priorities to conserve or extend the chromium supply may require that more expensive alternates be used, and components may tend to become more expensive as alloy shortages impact on the total cost of raw products. 


\subsubsection{Machining and Grinding}

In general, machining and grinding operations, particularly in high-production industries, are designed to produce a finished part in the most economical manner by reaching an effective compromise between labor, material, and capital costs. A major new priority, such as improving the utilization of the alloying elements, requires chip recovery as a key factor in the selection of a particular metal removal technique. Thus, the form of the chip and its suitability for reprocessing are major considerations. At the same time, processes that reduce the total amount of stock removal in the finishing operations will become increasingly important. Processing methods such as precision forging and casting and cold extrusion could be useful, particularly in improving raw material utilization.

Grinding should be considered to be a specialty operation for use only when it can provide a preferred finish obtainable in no other way. Electrochenical. machining and electrical discharge machining should be limited to true specialty applications.

Thus, if chromium is to be utilized in the most effective manner, the processing must minimize chip generation. In doing so, the key problem for the processor is to minimize chip generation which depends on the near-net shape of the blank or preform available for processing.

Much of the development effort in processing has focused on providing higher rates of stock removal by higher speeds and feeds, improved coolants, and improved tools including ceramics. Modification of these objectives to concentrate on the recovery of machining chips may help to improve chromium utilization and recovery.

Future needs for the machining and grinding process are more effective machining and a reduction in machining allowances. Advances in closed-loop feedback metal removal processes and a reduction in finishing stock allowances will serve to conserve alloying elements and reduce costs. Additional opportunities for more effective use of raw material may be achieved by developing imaginative new processes that integrate metal forming, metal removal, and metal joining into totally new engineering production systems.

\subsubsection{Forming and Deep Drawing}

The cost of raw material has stimulated a major effort to reauce the blank requirements and is an important factor in the design of forming and deep draw processes. However, 
in an alloy conservation program, it may be necessary for additional operations to improve the total yield while removing excess metal in a most easily and effectively recycled form (i.e.. dense, relatively small pieces). An opportunity exists for suppliers to provide improved and more formable raw material for forming and deep drawing operations that should reduce scrap rates and the consequent scrap to be processed.

The main deterrents to improving alloy utilization in forming and deep drawing are the need for lubricants to assist in the forming process for all grades of materials and the development of forming die alloys that require less chromium than currently used alloys. Forming and drawing processes needed to improve the utilization of chromium alloys include: higher formability dies with lower total alloy content. more effective lubrication systems, and total manufacturing systems that join with other processes to maximize alloy effectiveness.

\subsubsection{Part Forging}

Forging processes have been developed to balance the costs of materia 1. labor; and equipment; however, more precise parts with more closely controlled alloy content require that forgings be more precise and that the basic process be reexamined to identify opportunities for reducing the amount of scrap generated in processing the blank to the finished part. More closed die forgings and equipment are suggested to exert higher pressures on dies. configured so as to withstand the increased pressures. These particular needs require new specialized equipment; therefore. modification of forging operation is a relatively long-range program.

A total system organization and approach is required if the forging industry is to meet alloy conservation goals by developing process combinations that provide finished parts specifically designed to meet engineering requirements at lower cost per pound installed. It is recognized that different processes may be required for various parts of the same component (i.e.. partially machined parts of simple configuration squash-formed into a complex nonmachined assembly). Most significant is the need for generalized forging equipment that will increase the flexibility of the forging operation, including better interaction with powder metallurgy, to make a finished part to precise tolerances with high physical properties but requiring little material removal. 


\subsubsection{Chipless Machining}

Chipless machining is the generic phrase describing metalworking processes, usually performed at ambient temperature, that crovide a precision product requiring. little or no machining. In many cases, conventional equipment can be used with special alignment and tooling. Typical practices include rifle barrel forging or swaging. railroad axle forging, thread rolling, precision cold forging of heading, and wrenched-socket manufacture. Typical processes incluade precision rotary swaging, radial forging. fine blanking, form rolling, and part forming. Machines usually are designed for particular parts or component lines required in large volumes.

Gesselschaft fur Fertigungstechnik und Maschinenbau Aktiengesellschaft (GFM) radial forging machines have been developed with advanced machine controls, automated part handling, heating, and quick tool change to provide flexibility and permit application of these machines to a variety of products and materials. These radial forging machines represent the most advanced technique for production fabrication of solid. contoured shafting (e.g... railroad and automobile axies), and outside diameter (O.D.) and inside diameter (I.D.) contoured products (e.g.. gun barrels and pressure bottles). Typical tolerances for coldforged rifle barrels are \pm 0.0002 inch I.D. and \pm 0.002 inch O.D. when O.D. contouring, rifling, and chamfering are accomplished in one complete machine cycle. other applications include automated ingot forging. stainless and alloy steel shapes (e.g.. squares, hexagons, rounds. rectangles) made on a single "continuous" machine in quantities not economically suited for a production rolling mill, precision tube fabrication, gas-turbine engine shafting, and preforming of precision forgings.

This technology has been used widely in Europe, and in the past few years machines have been purchased for use in the United States. Current U.S. process evaluations and machine trials involve using cast preforms for precision tube fabrication of artillery rifle barrels and general precision part fabrication.

Process specifications that are predicted on established reliability data (as in the nuclear power industry) make any process change extremely expensive and favor continuation of established and possibly obsolete methods. The capital cost of modern precision equipment is high and apparently has restricted use of the chipless forming techniques to very large volume production of a narrow class of shapes or single products. Competition will require that the use of chipless machining procedures for 
large volume production continue to increase: however, the special technology is proprietary. the cost-effectiveness of these procedures has not been widely reported, and published user information on these technologies is lacking.

The U.S. Army now is scileduling artillery barrel production (Cr-Mo-V steels) at the Watervliet Arsenal and will lease their GFM machine commercially. Army schedules permitting. Tubular mill products will be produced in large quantities by chipless machining pending the development of tube-shell (preform) casting practices. These techniques will improve yield, provide better dimensional control, and reduce scale formation.

The flexibility and quick tooling change capabilities of current automated systems provide an opportunity for a great variety of products and more complex shapes than have been produced previously. However, machine time availability has limited such developments since machine purchases usually are justified for a single product or product line. This trend probably will continue for the next several years unless restrictions are placed on material consumption.

Chipless machining technology should minimize production costs by minimizing material consumption and machining operations; however. more public demonstrations and publicizing of the applicability and production

capabilities of chipless machining processes are needed. In addition, tube-shell casting practices that effectively can use chipless machining practices for specialty steel and alloy tube protection must be developed.

\subsubsection{Isothermal Working}

Isothermal working of titanium alloys and nickel-base superalloys has been developed under U.S. Air Force and Army sponsorship. The major advantage of this processing technique is lower working pressures and improved workability (e.g.. many superalloys appear to be superplastic when appropriately prepared). This technique has been used in production to forge near-net sluapes for aircraft gas-turbine engine discs starting with alloy powders of conventional wrought superalloys and advanced compositions that normally could not be produced in the wrought form. These advanced alloys (e.g.. IN 100) have superior strength- and toughness-to-weight properties when properly fabricated and heat treated. Furthermore, the more advanced alloys, because of other alloying additions, contain reduced chromium contents for competitive hot corrosion performance and have improved mechanical properties. Therefore, this processing technique requires 
less material and can provide near-net shapes of materials with improved performance. It also is applicatle to sheet and form rolling, airfoil forging, and the fabrication of special alloys (e.g.. titanium aluminides) containing little or no chromium that can be substituted for higher-chromiumcontent alloys.

The major problems with conventional fabrication of nickel-base superalloys are that: (1) the working and machining of these alloys is difficult and costly, (2) up to 90 percent of the mill product is converted into chips in disc manufacture, (3) the use of recycle material in the aircraft industry is restricted, and (4) yield is usually very low. Accordingly, performance and cost are continuing concerns that require advances in alloy development and fabrication procedures. The major problems constraining the use of isothermal working techniques are cost, tooling life and reliability, and dimensional precision of structural shapes.

Capital equipment and operating costs are high and. in some cases, require large vacuum systems to permit the use of molybdenum-alloy dies to achieve die temperatures in excess of about 1600 o F. Tooling costs are high and reliable life data have not been established. Most proauction tooling has been made from large superalloy castings, and problems have been encountered in the scale-up from small to large castings. The most severe problem has been gross centerline porosity that increases in frequency with die size. Precision casters currently will not provide fixed price quntations on these castings, thereby increasing the uncertainty of the success of the process.

Machining costs generally depend primarily on set-up costs, not on the amount of material to be removed. The cost of a precision working process therefore can be minimized if machining is eliminated completely (although reduced machining reduces material consumption). Current die and preform preparation practices, die heating. lubrication, and product heat-treatment procedures have not eliminated the need for machining in the large product sizes (greater than about 300 square inches in plan area). The basic problem has been the lack of a methodology to accurately predict thermal expansion and contractions of the die, workpiece, and proāuct during heat treatment. Further. nondestructive inspection procedures have not yet been developed sufficiently to permit the use of net forgings for many aircraft-engine products.

Isothermal working to produce aircraft engine and structural shapes is a developing technology that will grow and improve. The investment in equipment, to date, appears 
inadequate to handle current aircraft production requirements. The factors currently forcing further developments in isothermal working are the need for improved aircraft performance and reliability, and the potential for elimination of machining costs. Raw material costs. particularly those of nickel and chromium, are also a factor. To advance this technology. improved die materials, new or improved lubricants for very-high-temperature use, improved die heating practices, better die and preform designs, and better preparations are needed.

\subsection{JOINING}

At present, each joining process is preferred for certain applications and involves some key problems; however, the future seems to favor welding and brazing. especially in the event of a chromium contingency. Certain alternatives for chromium utilization proposed in other chapters of this report, such as the substitution of lowchromium alloys for familiar high-chromium alloys of commercial significance today, may require the development of new welding filler materials. These problems are treated in appendix F. An alternative peculiar to welding is the surfacing of chromium-free base metal with corrosionresisting or wear-resisting weld metal containing chromium to achieve properties available only in that manner. In applications where chromium is the essential element, the use of clad surfaces effects economies of 80 or 90 percent in chromium usage at minimum added cost. This alternative also is discussed in appendix F.

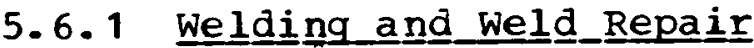

A summary chart of welding processes has been prepared by the American welding Society (Figure 25). In some of these processes, welds are made autogenously (without filler material). but in most, welds are made with filler metal addition. Almost all metallurgical uses of chromium involve alloys that are weldable by some commercial process, and the major alloys are weldable by many processes. Major users of chromium are the stainless steels, alloy steels, and certain nonferrous alloys, prircipally heat-resisting nickel-base alloys. Filler materials for welding these alloys are readily available from welding electrode manufacturers and supply houses.

Weld repairs to castings and weldments are made to match the properties of the original casting or weldment. For the most part, these repairs use fillers with matching chemical compositions. The principal exceptions are the low-alloy high-strength steels since the desired strength sometimes can be achieved with a different chemical 


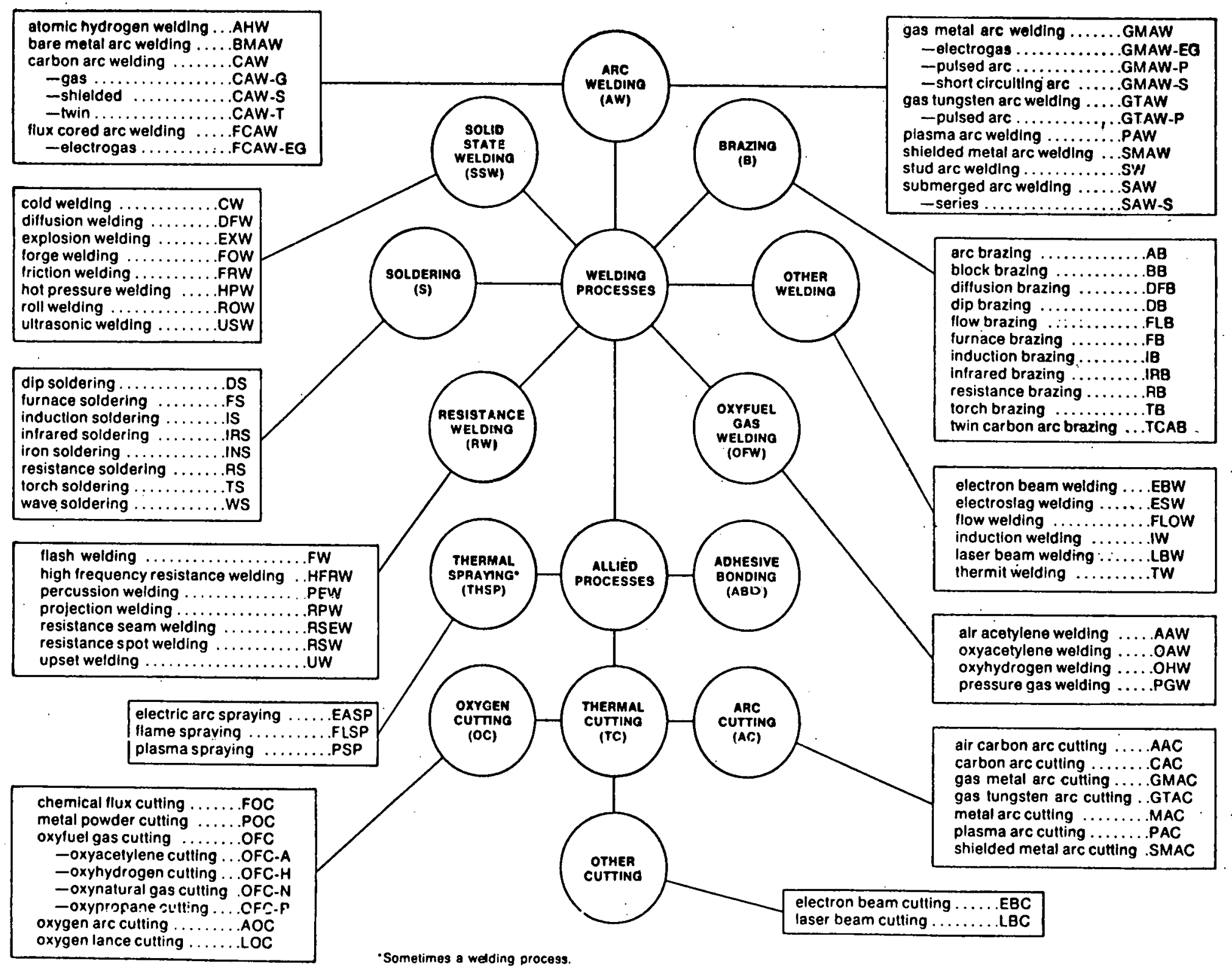

FIGURE 25 Master chart of Welding and Allied Processes (American Welding Society 1976) 
composition. In the high-chromium alloys, the properties can be achieved only with welds similarly high in chromium. Filler metals for the major chromium alloys are listed in appendix F.

If chromium were unavailable in a contingency that required remodeling existing stainless steel vessels, pure nickel electrodes probably would be used even though they are admittedly inferior in corrosion resistance and it would probably be better to remelt some vessels to provide matching welding electrodes to remodel the remainder. In a contingency during which chromium supplies were allocated to the production of new stainless steel products. proportionate quantities (about 1 percent) should be allocated to welding electrodes for joining those steels. During the contingency, autogenous welding should be adopted to the maximum extent but thick sections still would require filler materials in most weld designs.

If lean-chromium alloys are introauced, suitable filler metals must be identified or developed unless matching electrodes already exist. At some economic disadvantage, the presently popular high-nickel electrodes used for dissimilar metal joints probably would be selected.

Conservation of energy and materials encourages the use of welding in joints requiring little filler material and minimum joint edge preparation. Narrow-gap welds (made by semiautomatic and automatic processes) are important emerging chromium-conservation techniques that should be used increasingly in the future. New extensions of autogenous (no filler metal) welding techniques (electron beam. electric resistance, friction welding, diffusion bonding, etc.) permit the joining of thicker and larger sections each year and should be utilized when possible to minimize chromium use and waste.

Hard surfacing of wear parts by original equipment manufacturers increases equipment life and can be applied where clad or chromized surfaces are unreliable. Weld overlays of corrosion-resisting surfaces are particularly important on sections over 4 inches thick. Renovation of surfaces by weld overlays restores and extends life.

Matching compositions of filler materials may be needed for readily weldable substitutes for lower-chromium-content alloys proposed in chapter 6 . Less weldable substitute alloys will require suitable dissimilar filler materials. current technology would turn to nickel and nickel-base alloys, as suggested in appendix $F$; however, during certain chromium contingencies, these nickel alloys themselves might 
not be available and alternate substitutes must be identified.

\subsection{Brazing and Soldering}

Brazing requires the presence of a suitable brazing filler metal at the joint interface and, frequently, a brazing flux. Most chromium metals and alloys in the metallurgical list may be brazed with a brazing filler metal and flux, and most brazing alloys do not contain chromium. One advantage of brazing over welding is that lower temperatures are used; hence, parts may be joined in less time and with less metallurgical damage to the base metal.

Because of their corrosion- and heat-resisting properties, the nickel filler metals are used commonly to braze AISI Series 300 and 400 stainless steels. With application of a suitable flux, any brazing method (torch, furnace, induction, resistance heating) may be used.

Commercial solders do not contain chromium. Successful soldering of stainless steels requires the cleaning action of mildly corrosive or highly corrosive fluxes to obtain a sound soldered joint.

The strength of brazed joints depends greatly on joint design. The optimum gap for brazing is about 0.005 inch varying from 0.00 .1 to 0.010 inch depending on the specific brazing filler metal. The cost of joint preparation is a major expense in larger assemblies. The joint gap must be preserved until the joint has reached the brazing temperature to permit spreading of the brazing alloy by capillary action.

More developments are expected in high-temperature brazing alloys, and self-fluxing alloys are advancing in popularity. Applications of furnace brazing. vacuum brazing, induction brazing, and diffusion brazing are increasing.

Filler materials are needed with improved dynamic properties (resistance to fatigue) and corrosion (galvanic attack) resistance. Techniques for nondestructive inspection of brazed joints must be improved to determine 100 percent soundness and to monitor in-service stress distributions within large brazements.

\subsubsection{Mechanical Joining}

Chromium alloys are joined mechanically by bolts (especially high-strength bolts), rivets, sheet metal screws, pins, folded and locked seams, and retaining rings 
and keys. The weight penalty of mechanical fastening vis-avis welding restricts such applications to lightly stressed joints and to connections that must be disassembled (e.g.. turbine blades. flanges, and access ports). Much material is wasted in a mechanical joint in the bolt holes. overlap of parts, and inefficient doubling plates. sealing of joints in tanks and containers is a vexing problem. Elaborately machined surfaces fitted with o-rings or caulking are required. Preventing crevice corrosion beneath bolt heads and between lapped plates is difficult, and these are classical points of attack.

The switch from mechanical fastening to welding or brazing is accelerating. More state and city building codes and highway bridge codes now permit more efficiently designed welded or brazed connections.

\subsubsection{Adhesive Bonding}

Many metal joining applications now are bonded with adhesives but usually not stainless steels, tool and die materials, superalloys, special property alloys, or coated metals. Alumina-based cements have been developed with service temperature around 3,000 of. Weld-bonded joints are primed with an adhesive, resistance-spot welded through the adhesive layer. and cured by aging or heat treating. The adhesive protects the spot welds against tearing in fatigue loading.

Adhesives lack peel strength and cleavage strength, and thermoplastic adhesives soften when heated. Accordingly. most adhesives can not be, used for service above $3500^{\circ} \mathrm{F}$. The precleaning and setting time are lengthy. The overlap in a lap joint needed to provide sufficient load-bearing capacity is an inefficient use of materials. Some adhesives are attacked by bacteria, molds, vermin, moisture, and organic solvents. Also, inspection for completeness of bond is nearly impossible at present.

Greater use is predicted for the weld-bond technique to improve the fatigue strength of spot welds and resistanre seall welds. New applications of adhesive bonding with dissimilar materials also are expected; however, these improvements require the development of better. standard nondestructive inspection methods and stronger adhesives with higher softening temperatures.

\section{7 SURFACE COATINGS}

All of the principal methods for producing chromiumbearing surfaces are discussed below. These include: rollclad, chromizing. surface alloying, metal spraying, hard- 
facing, weld overlay, cementation, electro-deposition, chemical deposition, vacuum metallizing, vapor-phase deposition, and ion implantation.

\subsection{Clad Stainless steel}

clad stainless steel technology is over 40 years old and may be a major option for reducing the consumption of chromium contained in stainless steel. Clad steel is the substitution of a multilayered integrally bonded metal product for solid stainless. Today. over 300,000 tons of clad plate are in service in a wide variety of applications. clad is manufactured by bonding two metals together with heat and pressure during hot rolling until they are integral over their entire adjoining surfaces. As little as 2 percent or as much as 50 percent of the stainless steel can be used in making the clad sandwich. Stainless clad steel, as one example, can effectively provide the surface corrosion characteristics of solid stainless with some 10 to 20 percent of the chromium requirements of the solid material.

The technology is labor-intensive. It requires electrolytic plating on one side with pure nickel to aid in bonding and preventing carbon migration. The sandwich assembly is built up, sealed by welding along its edges, and heated and rolled to gauge. The hot work produces a metallurgical bond between the stainless insert and the steel backing. One layer of stainless clad to carbon steel is the most common form in use. This material is available in shapes including: rolled sheet. strip and plate, drawn tubing and wire, centrifugally cast tubing and pipe, and extruded tubing. The fabrication of clad plate into various shapes, tanks, pressure vessels, etc.. is standard practice with many fabricators and joining techniques that have been developed to meet nuclear pressure vessel codes.

The present usage of clad steel is based on the economics of the cost of solid stainless versus clad. clad steel is used in many of the major consuming markets requiring the optimum properties of solid stainless such as chemical, petrochemical, petroleum refining, food processing. and automotive applications.

Stainless steel plate is used for tanks and pressure vessels for various processes; thicknesses from $1 / 8$ inch to about $1 / 2$ inch are quite common while stainless clad steel is more common in thicknesses over $1 / 2$ inch. stainless clad steel is manufactured by roll bonding thicknesses from $3 / 16$ inch to about 10 inches. Explosive bonding generally is used for thicknesses greater than 1-1/2 inch. Weld overlay is used for thicknesses over 4 inches. 
The stainless steel plate portion of the market is estimated at 150,000 to 200,000 tons, of which a substantial tonnage could be serviced by clad material. The present. clad plate tonnage is estimated at less than 10 . percent of the plate market or some 15,000 tons annually.

A wide range of flat-rolled product thicknesses from sheet and strip to heavy-gauge plate should be available in commercial tonnages from a variety of clad producers. Substantial expansion of production capacity could be induced with relatively modest capital requirements should chromium contingency plans dictate immediate implementation.

The substitution of a multilayered integrally bonded metal product for solid stainless is a highly developed technology. The present usage of clad steel could be expanded substantially to conserve chromium without new technology.

The application of stainless clad steel can provide surface corrosion-resisting characteristics of solid stainless plate steel effectively with only 10 to 20 percent of the chrome requirement of the solid material. The process presently is labor-intensive and would require additional space. Conventional rolling mills could produce clad product immediately with a minimum of lead time. requiring only a shifting or adjustment of rolling schedules. Substantial expansion of present production capacity could be effected with relatively modest capital requirement in the event of a chrome availability problem. Because chromium-bearing scrap can be recycled into lowalloy steel, consideration should be given to the amount of chromium in the $f$ inal product; a 10 percent clad product contains one-tenth the amount of chromium as its solid counterpart and a 20 percent clad product, one-fifth the amount.

\section{7 .2 Weld_overlay}

Weld overlays are applied , where clad steel surfaces are unavailable or are unreliable. Typical applications have been the flanges (14 inches thick) for nuclear reactors; dished heads for pressure vessels, nozzles welded into boilers and chemical retorts, and cylindrical vessels with wall thickness greater than 4 inches. These overlays provide a corrosion-resisting surface equivalent to commercially clad product. Weld overlays also are applied for wear resistance. Electrodes are available with special properties of hardness, hot hardness, impact strength. oxidation resistance, corrosion resistance, abrasion resistance, resistance to metal-to-metal wear. mechanical properties in compression, and machinability. Methods used 
for overlay welding primarily aim for low dilution (low penetration) but high deposition rate.

Oxyfuel gas welding is excellent for depositing thin. undiluted overlays of the chromium-cobalt stellite compositions on wear surfaces and overlays of tungsten carbide granules. The low-temperature deposition achieved with an oxyacetylene flame leaves undissolved tungsten carbide grains dispersed in the weld deposit, whereas arc welding tends to dissolve most of the granules in the matrix. Shielded metal arc welding (manual deposition) is used in difficult welding positions. Submerged arc welding with series-arc (two wire) deposition achieves rapid coverage of the surface being overlaid with about 12 percent dilution. Submerged arc welding with strip electrodes achieves about the same dilution at faster deposition speeds. Gas tungsten or plasma arc welding with hot wire feed achieve dilutions as low as 5 percent.

Weld cracking is a common, difficulty. especially with the harder alloys. With some electrodes, peening of each bead after deposition reduces stresses, and preheating and post-heating schedules often are recommended. The copperbase alloys used for bearing surfaces are deposited with braze-welding techniques. Uniform coverage of the base metal is required. Penetration variations dilute the weld composition. Multiple layers often are deposited to guarantee the required alloy content of the surface layer. Inspection techniques are available to evaluate the soundness and adequacy of overlay welds, but research is needed on the selection and application of barrier layers to combat dilution effects.

Conservation of chromium should encourage extensive use of clad steels. Welding sequences and electrode

recommendations are ready now for all popular alloys. Most weldments require only the butt-welding of clad plates but many constructions will have nozzles and flanges that preferably will be surfaced by weld overlay techniques. Use

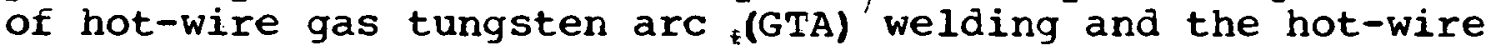
plasma arc process are expected to increase because they achieve extremely low dilution at high deposition rates.

Substitute coatings without chromium are proposed in chapter 6, and while their development may not be possible, studies to identify equivalent weld deposits should be initiated. It also should be noted that low-chromium alloys will lack the corrosion resistance of higher chromium compositions. 


\subsubsection{Chromized Sheet_steel}

Chromized steel is essentially a stainless-coated sheet steel that is produced by mechanically bonding an ironchromium alloy powder on the surface of a low-carbon sheet steel, and diffusing the chromium into the surface at elevated temperatures. The stainless surface that is formed is approximately 0.002 inch thick with a chromium content of 25 percent at the outer surface and of 12 to 13 percent at the base steel-coating interface for an average coating chromium content of 18 percent.

The Bethlehem Steel company uses a higher grade, lowcarbon ferrochrome powder in its chromizing process than is used in melting stainless where high-carbon ferrochrome can be used. With more stainless producers changing to the less expensive high-carbon ferrochrome, suppliers are not having problems in delivering the higher priced, low-carbon ferrochrome powder.

Chromized steel has been used basically for ferritic (AISI 400 series, particularly AISI 409) stainless applications. It is limited to applications (e.g.. automotive exhaust and heat exchangers) where cut edges and appearance are not a factor. It is not a substitute for. AISI 300 series ( $\mathrm{Ni}-\mathrm{Cr})$ applications.

Present chromized sheet applications include furnace heat exchangers and silo components. Chromized steel has replaced AISI 409 stainless steel in roof top installations of commercial heating and air conditioning units. The 30 percent lower cost of chromized steel versus AISI 409 stainless and its better forming and welding characteristics are reasons cited for the changes. The heat exchanger application is limited and should not have a major impact on chromium requirements.

Silo applications of chromized steel include conveyor troughs and wall panels. Chromized steel is used in sheettype applications but not in rods or tubing. Chromized steel exhaust cylinders are rolled from sheet and resistance welded.

The introduction of catalytic converters for automotive exhaust systems created a strong ajemand for AISI 409

stainless steel. Reporteâly. the General Motors Corporation (GMC) alone was using 75,000 tons of it for converters, and when the $Y$-pipes off the manifold were added, total. consumption was 110,000 tons (Metal Progress 1974). (Note: This summary does not include the chromium required in AISI 300 series $\mathrm{Ni}-\mathrm{Cr}$ stainless steel for which chromized steel is not a substitute.) 
Bethlehem steel estimated that the total AISI 409 stainless steel demand in the 1978-1982 period for U.S. automotive exhaust systems may reach 250,000 tons annually. The amount of chromium in 250,000 tons of AISI 409 stainless (11 to 12 percent chromium) is estimated at 28,750 tons. If the recovery rate of the chromium in processing is 90 percent, it will require approximately 32,000 tons of chromium to make the 250,000 tons of AISI 409 stainless.

The stainless sheet steels used in the GMC catalytic converters are all 0.050-inch-thick. To produce a $0.050-$ inch-thick chromized sheet requires only 15 to 20 percent of the chromium required for a 0.050-inch-thick AISI 409 stainless sheet. Therefore, 250.000 tons of $0.050-$ inch chromized sheet will require only 5,100 to 6,800 tons of chromium, compared to 32,000 tons for AISI 409 stainless. The recovery rate of chromium in chromized steel is slight ly lower at 85 percent, partially because chromized steel scrap is not recycled specifically for chromizing while AISI 409 scrap can be remelted for stainless products.

Chromized sheet is not used now for the catalytic converter systems by automotive manufacturers because of the difficulties in meeting emission requirements with new systems. The manufacturers were conservative and chose a solid stainless material. However, chromized steel use is under review by industry since the cost of stainless has risen, the availability of chromium has become questionable. and many unknowns in the catalytic converter systems have been resolved.

The present technology can produce chromized steel sheet in sufficient volume to effect significant chromium metal conservation in automotive emission applications. Bethlehem steel's current chromized steel capacity is 12,000 tons per year. An expansion program to increase the present facility capacity to 20,000 tons and then to 40,000 to 50,000 tons is under study. Iong-range plans include increasing capacity to 100,000 tons per year.

Conservatively, the cost of a 100,000-ton-per-year mill is estimated at $\$ 50$ million including chromizing bases. furnaces, washer-brushers, compactor to apply. powder, a skin mill, and a building to house the unit. Expansion of the existing 12,000-ton-per-year facility to 40,000 to 50,000 tons is estimated at $\$ 15$ million because the skin mill and building are available. Conversion of additional bases and furnaces and improvement of washer-brusher and compacting equipment is not as expensive as the installation of all new equipment. 
A minimum of 2 additional 100-ton facilities is estimated as necessary to supplement Bethlehem steel's present and intermediate chromizing capacity to meet the projected annual automotive requirement of 250,000 tons. Total estimated cost is $\$ 100$ to $\$ 150$ million.

\subsubsection{The Dilex Chromizing Process}

The Dilex process (formerly called surfalloy) for surface alloying of ferrous materials in molten lead alloys is at an early stage of commercialization. The first of several patents was issued in 1971 (Rausch and Van Thyne

- 1971). but some details had been reported previously (Van Thyne and Rausch 1974). Although complex surface alloys may be produced, the early effort has been directed primarily to the formation of a simple chromized ferritic stainless steel surface case that has a composition of about $30 \mathrm{Cr}-70 \mathrm{Fe}$ and grades inwardly with lessening chromium content.

In the principal step of the process, the ferrous product is immersed in a lead bath within some retort form; alloying additions (e.g.. ferrochromium) are included; and motion or agitation is provided. Lead melts at 620 of and typical processing temperatures are 1750 to $19500^{\circ} \mathrm{F}$. Conventional materials are used for equipment. The surface alloying occurs by simple metallic diffusion; no chemical or electrochemical processes are involved. Molten lead is an ideal medium and exhibits the following useful characteristics for this application:

1. Lead is inexpensive and readily available.

2. Lead is reusable and simply refined by skimming off impurities that float to the surface.

3. Leads heats and cools rapidly because of its high heat transfer and relatively low energy consumption (the specific heat of lead is about one-third that of steel).

4. Chromium transfer through the molten lead is rapid even though the solubility is only 0.04 percent at 1900 oF.

5. An excess of chromium may be used with the chromium dissolving into the bath as required.

6. Multiple alloyed products are produced readily.

The elements used in surface alloying having the greatest commercial significance are chromium anā aluminum that can be diffused individually to produce solid solution 
alloy layers. Also, chromium and aluminum can be codiffused to provide a variety of compositions having a good combination of oxidation resistance and fabricability. The surface composition and composition gradient can be controlled.

In typical small machined parts, a 0.003-inch chromized surface layer accounts for 6 percent of the total volume of the part. The diffusion alloying process described herein offers opportunities for further savings in chromium by multiple alloying (i.e., use of an Fe-Cr-Al surface alloy with lower chromium content for oxidation resistance).

The substitution of surface diffusion alloy products for solid stainless steel has been very limited to date. Further expansion of this market will depend upon the investment in capital equipment to make certain products and the marketing effort to convince potential users of the economic advantages. Field tests required before such substitutions are made, often take six months or longer.

Initially, the molten lead diffusion alloying process was directed to small screw machined parts because the economic advantages could be demonstrated at relatively low cost. Although material savings result, the principal advantage is the substantial reauction in machining costs because. free machining steels may be used and machined at much greater speeds than stainless steels. A commercial facility to process such parts is being constructed now by Materials sciences Corporation, which is licensed by the Surfalloy Corporation to apply the process to machined and fabricated parts and mill products:

This process has been tried on various product forms (such as sheet, tubing, and wire) and on test commercial components using batch or continuous processing. The mechanical and corrosion test results have been reported to be very acceptable.

\subsubsection{Electroplating}

Electroplating of chromium is one of several commercial methods for increasing the chromium level of the surface of a substrate such as carbon steel. The main difference between "hard" and "decorative" chromium plates is thickness, hard being thick (up to 0.1 inch) and decorative being thin $(0.00001$ to $0.00003 \mathrm{inch})$. The thin decorative plates tend to be porous and the thicker coatings often are cracked. The primary purpose of chromium plating is to confer a hard, abrasion- and tarnish-resisting surface to a substrate material. Since chapter 6 presents detailed information on the physical and mechanical properties of 
chromium plates, an indication of where chromium plates are and could be used in commercial application, and statistics on the savings in chromium consumption that might be realized in the electroplating area, such material will not be discussed here. Rather, an attempt will be made to identify and discuss only those aspects that relate to processing. These include chromium in the effluent, the status of the plating technology for substitute materials. and scale-up possibilities of existing facilities.

Decreasing the chromium in the effluent is of major importance since more chromium. is lost than is plated in commercial plating operations. An estimated 2.000 tons of chromium per year are lost in the waste of commercial electroplating processes. Two reasonable approaches are to recycle the waste material and to use trivalent rather than hexavalent chromium. Recycling is becoming commercially feasible and probably will solve this problem. A strong impetus for developing recovery techniques is based on current Environmental Protection Agency regulations calling for zero discharge of chromium (and other materials) by 1983.

of the several substitute materials considered in chapter 6. plating stainless steel is attractive on the basis of its physical and mechanical properties and tarnish resistance. Electroless nickel-phosphorus (or nicke1-boron) alloy, although unsuitable for decorative applications, is suitable for wear or functional applications.

Much effort has been expended in researching and developing the technology for plating stainless steel (rather than chromium) with marginal success and little indication that a development beyond the beaker stage is in the offing. In the case of electroless nickel-phosphorus, on the other hand, the processing technology appears to be developed sufficiently. In particular, the much better throwing power of electrolessly deposited metals is a big plus. Additional research and development are needed, however, to put these processes on a competitive cost basis.

Plating from fused salts, other high-temperature processes, and vacuum deposition may be viable alternatives since they allow additional metals to be considered as. substitutes. Tungsten electrodeposited from molten salt baths and boride diffusion coatings from molten salts are two possible substitutes for applications where wear and hardness are prerequisites. Titanium alloy coatings can be deposited by high-temperature methods, offer the advantage of excellent tarnish resistance and good color, and are in the early stages of commercialization. Further development is needed on scale-up techniques, handling and container 
materials, and reducing costs that, for the high temperature process generally, are an order of magnitude (or more) more costly than their counterparts at ambient temperature.

Two factors, expansion capability and lag time, are important in evaluating the scale-up possibility for existing facilities. Expanding existing "hard" chromium shops is possible. The time required for conversion would depend mainly on the procurement of additional tanks, floor space, and electrical power. Converting decorative plating shops probably is not feasible since their conversion takes different and much more demanding expertise.

\subsubsection{Ion Implantation}

Ion implantation is a method of producing changes in the composition and physical properties of the surface of a solid by bombarding the surface with a beam of energetic ions. In the context of producing a corrosion-resisting surface alloy, it involves bombarding a metal having poor corrosion resistance with ions of the desired alloying addition (e.g.. chromium). The depth of implantation can be varied in the range $10^{-6}$ to $10^{-5}$ inch by control of the incident energy.

Although only preliminary results are available, the corrosion resistance of chromium-implanted steel seems comparable to steels where chromium layers were applied by other techniques. Since the total amount of chromium involved in ion plating usually will be much less (order of magnitudc or more) than the coating method it replaces (e.g.. electroplates and clads), the projected savings in chromium are considerable.

The U.S. Bureau of Mines is exploring actively the commercialization of the chromium ion plating process as well as continuing to evaluate the properties of chromiumrich surfaces produced by ion implantation. Several years probably will be needed to develop a commercial process. even for small limited applications.

\section{5:8 ECONOMIC AND TECHNICAL DIMENSIONS OF CHROMIUM RECYCLING}

Recycling provides an alternative to the supply of virgin materials. With the possible exception of easily recoverable ferrous and nonferrous metal scrap, only smail fractions of the U.S. waste stream are recovered and reused. Recycling is not profitable under current economic conditions in the United States since the cost of collection, separation, shipment, and reprocessing is excessive in relation to the cost of competitive virgin materials. However, environmental controls increase the 
disposal cost and thereby encourage reuse. (Recycling conditions differ abroad, and in Japan. Italy. Austria. Germany, etc.. more wastes are recycled than in the United States.)

\subsubsection{Economics and the Materials Cycle}

There are two types of basic materials -- nonrenewable and renewable. Nonrenewable materials (mineral fuels. ferrous and nonferrous metals, and nonmetallic minerals) represent a fixed stock of resources with variable proportions being economically recoverable. For renewable materials (forest and agriculture-based products). a substantial flow of primary materials can be maintained by appropriate management and conservation techniques without impairing regeneration.

The national materials cycle is presented in schematic form in Figure 26. Virgin materials, together with secondary materials that can be utilized economically, are fed into productive processes or into the generation of energy. Both the energy and production sectors generate primary waste (e.g.. slag and ash, metal shavings, and plastic trimmings). some of which is not recovered and enters the environment as solid, liquid, or gaseous emissions and effluents. The remainder is recovered and used directly or is collected and enters the secondary materials sector.

Part of the output of the production sector is used for capital equipment and part is funneled to the consumption sector. Worn-out capital equipment and goods that have reached the end of their useful lives become secondary or obsolescent waste. Part of this flow is not recovered and enters the environment, largely as solid waste. The principal functions of the secondary materials sector involve collection and transport of wastes, separation of waste into cátegories sufficiently homogeneous for reuse. and reprocessing of waste to quality levels reasonably competitive with virgin materials.

The materials flow metwork deplcted in Figure 26 is a dynamic system. The volume of material throughput depends on the level of economic activity that determines the overall volume of generated waste. Lags of varying duration exist in the network. Most primary waste is associated closely with current output levels and quickly becomes available for recovery (e.g.. home and prompt industrial scrap) or injection into the environment. Secondary waste lags are product-specific. For some materials (e.g.. newsprint and most packaging materials), the lags are short. Fọr others (e.g., textiles, automobiles, and many consumer 


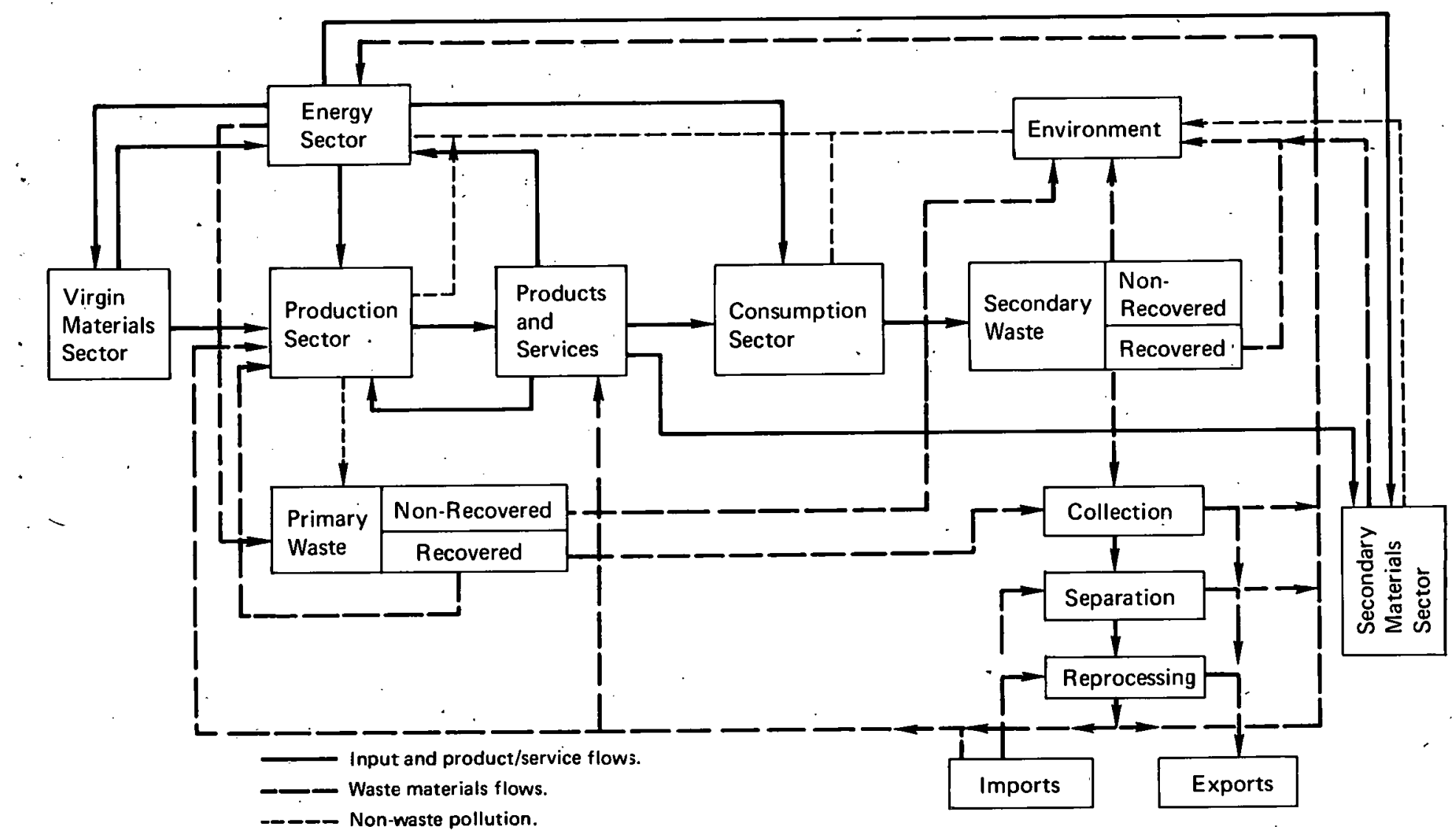

FIGURE 26 Network of Materials Flows and Recovery (Walter 1975) 
durables). the lag is of intermediate duration, perhaps 1 to 10 years. For still others (e.g.. capital equipment), the lag may be even longer before scrappage occurs. These lags are important in defining the general characteristics and economic dimensions of waste management.

Finally, what is technically feasible in recycling is not necessarily economically viable. Moreover, the economic incentives influencing the behavior of industry encourage the minimization of the private cost of production incurred. From a social viewpoint, these private costs fail to account for certain externalities, such as pollution and the risk of interruptions in the supply of virgin materials. Thus, the optimal social rate of recycling is probably greater than the rate acceptable to the private sector.

If society applies the "polluter pays" principle via a system of taxes, pollution charges or prohibitions, the effective cost of disposal and consumer products should rise, as should the likelihood of recycling. Society benefits from a cleaner environment, extended life of virgin resources, reduced pollution, and reduced susceptibility to foreign supply constraints. However, recycling itself may be pollutive and uses energy and other resources, and these costs must be accounted for before the net social benefit of recycling can be determined.

Government policies can promote recycling when subsidies favor recovered materials and may retard recycling if labeling requirements make recycled materials appear to be of inferior quality. They also may retard recycling by providing tax benefits to extractive industries, thereby reducing the cost of virgin materials. Reprocessing costs can be excessive; technological constraints can make it impossible to attain competitive quality levels; and certain wastes can be dissipated so highly that effective collection is prohibitively costly. With some notable exceptions, the secondary materials industry is poorly capitalized, highly fragmented, and localized. The result is inefficiency. uneconomic levels of operation, and high costs.

Recycling serves two functions -- conservation of resources and materials, and reduction of waste. The quantity of materials that enters the primary and secondary waste streams creates both economic and social benefits. Reductions in the quantity of waste generated can be reduced by promoting product durability, repairability, and maintainability.

The lowest life-cycle cost (i.e.. initial purchase price plus maintenance and repair costs plus longevity) should become the prime motivating force in product 
selection if maximum material conservation is to be achieved. Recycling from design through collection. sorting. and remelting must become a way of life that is encouraged by all possible means.

The technical and economic dimensions of secondary materials recovery represent a highly complex problem, one that is sensitive to a large number of variables and policy measures and one wherein cost-benefit analyses are subject to many uncertainties. Yet, the volume of waste materials together with nonfunctioning, obsolete, and discarded products available for recycle and recovery is substantial. as is the gap between what actually is recovered and what technically could be recovered.

\subsubsection{Chromium Recovery and Reuse}

To promote chromium conservation, designers and manufacturers should be sure that:

1. Materials of the desired composition and properties are used

2. Materials have consistently high quality and reliability

3. Combinations of materials are used that are compatible with current recycle systems

4. Process variations can be adjusted by nondestructive testing, evaluation, and feedback during processing (for more detall; see chapter 4)

5. The finished product has the highest quality and reliability possible through in-process control and reduced reliance on final inspection

6. Products in service can be inspected to determine their remaining usefulness and safety, and can be dissassembled and repaired easily and at relatively low cost

During the actual processing of chromium-containing materials, conservation of chromium can be achieved by:

1. Minimizing material removal in blanking. shearing. machining, cutting, grinding, etc.

2. Using hot and cold deformation

3. Using powder metallurgy to produce parts or preforms 
4. Casting to shape or to preform

5. Using surface coatings and treatment

6. Using proper joining

7. Using heat treatment

While there appears to be significant technical

recovery potential, the economics of chromium recycling have yet to be tested on a large scale. However, recycling technology is beginning to develop in a variety of products and sectors. of the approximately 600,000 tons of chromium consumed in the United States in 1974, only a small percentage (about 10 percent) was recycled chromium.

\subsubsection{Stainless Steel and Heat-Resisting Alloy Scrap}

Almost half of the chromium consumed is used in the production of stainless steel and heat-resisting alloys. Every steel mill generates a certain amount of "revert" scrap in the production process. This scrap is retained by the mill and is reused.

The steel mills ship their products to manufacturers who convert them into consumer durables, capital goods, and intermediates. At this stage of the manufacturing process. additional scrap is generated, usually called "prompt industrial" scrap. This scrap usually is segregated and reshipped to a steel mill either directly or through a secondary metal processor or broker. If properly segregated. most of the chromium in this scrap can be recycled effectively without degradation of the alloy.

Products are sold directly, or after further manufacturing, to a consumer who uses the product until it becomes obsolete or no longer serviceable, at which point it is scrapped. Unless it is dumped in open or lanafill sites. much of this material ultimately finds its way to a secondary metal processor who attempts to segregate and prepare it for sale in a form usable to a steel mill.

The chromium in AISI 300 series stainless steels and high-temperature alloys tends to be recovered since these materials are high-value steels and alloys due to their nickel, molybdenum, and cobalt contents. In the case of AISI 400 series stainless steels, the contained chromium is mostly lost since the value of the 400 series steels is less and they do not contain other high-value alloying elements. (To date, chromium itself has been relatively inexpensive and not worth recovering.) Most steel mills buy 400 series scrap only when business is good and they are melting large 
quantities of these particular alloys. In slack periods. steel mills buy ferrochromium because of a price advantage rather than 400 series scrap, which then is lost or mingled with low-value scrap.

Even when steel mills purchase AISI 400 series scrap, they buy at a cost under that of equivalent primary metals because of the manufacturing risk incurred as opposed to using virgin material. The lower the price, the more uneconomical it becomes to properly segregate these grades. This relationship discourages recycling and is particularly important when ferrochromium is readily available at today's reasonable cost. The steel mill's evaluation of scrap depends on the price of ferrochromium, not on resource conservation goals, and the price of scrap, particularly AISI 400 series, rises only when ferrochromium is very expensive or in short supply. only if steel mills have consistent and realistic buying policies regarding chromiumbearing scrap, such as long-term contracts with reliable processors at prices that cover recycling costs, can reasonable supply be assured them on a consistent basis and at stable prices. (Such conditions also contribute to increased recycling of chromium.)

Because of the lags mentioned earlier, it is not possible to estimate accurately the potential chromium recovery from stainless steel scrap. especially obsolete scrap. However, based on sources associated with production processes in a variety of industries, potential chromium recovery has been estimated, as noted in Table 27. More than 60,000 tons annually are recoverable potentially from these sources and each is discussed below.

\subsubsection{Metallurgical Industry Wastes}

The principal chromium-bearing process wastes in the metallurgical industry are: (1) ferroalloy flue dusts. fumes, and slags; (2) stainless steel steel furnace flue dust, centerless grinding swarfs, mill scale, pickle liquor. and slag; and (3) Electrochemical machining and electrical discharge machining sludges.

Experimental processes have been developed by the U.S. Bureau of Mines to convert in-plant waste generated during stainless steel production to a recyclable alloy containing iron, nickel, molybdenum, and some lead and zinc as well as chromium. The alloy has been produced from three kinds of wastes: flue dust from metallurgical furnaces making stainless steels, mill scale, and grinding swarf made up of fine metal chips mixed with abrasive particles and cutting oils. The chromium currently wasted that could be recycled 
TABLE 27 Estimates of Potential Chromium Recoverable from Industrial Process Wastes

\begin{tabular}{lc}
\hline Source & $\begin{array}{c}\text { Recoverable } \\
\text { Chromium } \\
\text { (tons/year) }\end{array}$ \\
Ferroalloy flue dusts & 3,500 \\
Ferroalloy slags & 1,000 \\
Stainless steel furnace dusts & 2,500 \\
Stainless steel centerless grinding swarfs & 2,000 \\
Stainless steel mill scale & 3,600 \\
Stainless steel pickel liquor & 800 \\
Stainless steel slags & 1,000 \\
ECM and EDM sludges & 1,300 \\
Foundry sand & 21,000 \\
Chrome-bearing refractories & 19,000 \\
Etching wastes & 1,000 \\
Plating wastes & 2,000 \\
Catalysts & $1,000 \underline{\mathrm{a}}$ \\
Chromate and dichromate & $60 \underline{\mathrm{a}}$ \\
Leather tanning & 270 \\
Paint pigments & 75 \\
Textiles & $-60,106 \underline{\mathrm{b}}$ \\
&
\end{tabular}

NOTE: Data from Dressel et al. 1976.

a Recoverable chromium from catalysts is 700 to 1,000 tons per year; from chromate and dichromate, 50 to 60 tons per year.

b Total recoverable chromium is 59,796 to 60,106 tons per year. 
in a commercial application of this experimental process amounts to several million pounds per year.

In this process, the wastes are blended, moistened, pelietized, and smelted in 10- to 25-pound batches in an electric induction furnace at 2.550 to $2.910 \mathrm{oF}$ with the addition of carbon. Virtually all the iron and nickel and about one-third of the chromium are recovered. While the economies of commercial-scale recovery systems of this type remain to be proven, hopefully, they could be commercially attractive.

In stainless steel production, the slags contain sizable amounts of chromium. About 30,000 tons of chromium are lost annually in slag generated with stainless steel produced by conventional methods. However, general adoptions of modern duplexing systems should reduce this chromium loss to 10,000 to 15,000 tons per year. An additional 1,000 tons of chromium are lost in slags generated in ferrochromium production. No efforts to recover chromium from such slags appear to be under way in the United. States today.

International Nickel company. Inc.. has announced plans to construct a facility in western Pennsylvania to process some 40,000 tons per year of specialty steel mill wastes and to convert them into a nickel-chromium stainless steel remelt alloy. The facility reportedly will have a positive ecological impact while reclaiming metals vital to industry.

on the effluerit side, mixed-acid pickling wastes generated annually contain an additional 800 tons of chromium. Acid currently is recovered from pickling wastes, but the chromium content of the sludge -- averaging 1.6 percent chromium -- is not. A solvent extraction process precipitates chromium hydroxides that could be recycled to metal.

Wastes produced by the electrical discharge machining (EDM) and electrochemical machining (ECM) of chromiumbearing alloys contain 1,300 tons of chromium annually. While EDM wastes are nonpolluting and can be used in landfills. ECM wastes cause serious pollution problems and now are subject to strict EPA guidelines. A drain-filter techrique increases the solids content of ECM wastes, with the resultant filter cake being dried and reprocessed to remove the metal content including chromium. Other metalliferous sludges can be treated to recover the metals content although commercial application still seems some years in the future. 


\subsubsection{Refractory Industry Wastes}

Another recycling possibility is chromite sand recovery from the foundry industry. Over 80,000 tons of chromite were consumed in molding and coremaking in the United States during 1975, primarily due to the widespread use of specialty sands. About 90 foundries currently use chromite and little recycling has been undertaken. The sand can be separated and chromite reclaimed by magnetic, air. hydraulic, or electrodynamic techniques with over 75 percent of the original chromite recoverable. However, only 6 to 10 foundries are estimated to have sufficient sand volume and chromite content to make such separation economically viable and the recovery process itself may be pollutive.

Refractory brick is another possible source of recoverable chromite although destructive consumption in steelmaking is increasing because of the use of electric furnaces and the AOD process. Very little recycling of refractory brick is undertaken in the United States, but some recycling seems to be under way in the United Kingdom.

While recycling of chromite in spent foundry sands and refractory brick is an obvious recommendation to conserve important quantities of chromite, substitution of other materials (zircon in foundry sand and magnesite-chromite in refractories) for chromite in these applications would result in larger total savings and would be less expensive and technically easier to accomplish (see chapter 6).

\subsubsection{Chemical Industry wastes}

Chromium wastes in the chemical industry are generated from a number of sources; the most important appear to be etching wastes, plating waste, catalyst, dichromatephotosensitive material, chromate, paint pigment, watertreatment chemicals; and leather tanning chemicals. Chemical uses amount to about 130,000 tons of chromium annually with 20,000 to 30,000 tons being used in the plating industry; 23.000 tons, in the paint and pigment industry; and 10,000 tons, in the leather tanning industry.

It is estimated that: (1) sludges from the paint and pigment industry contain about 75 tons of chromium annually; (2) 35 pounds of waste sodium chromate are produced for every 1,000 tons of ammonium sulfate produced; (3) several tons of ammonium chromate are wastea each year in the graphic arts industry; (4) 39 pounds of sodium chromate are wasted for every 1,000 tons of nitric acid produced; (5) dye manufacturing wastes contain $100 \mathrm{ppm}$ of chromium: (6) lubricating oil production waste contains $16 \mathrm{ppm}$ of chromium; and (7) 1 pound of chromium is lost for every ton 
of sodium dichromate produced. Chromium chemicals also are used as mordants and ayes in the textile industry; however, with waste water containing approximately 2 to $8 \mathrm{ppm}$ of chromium, and in view of the large volume of water used, the chances for economic recycling are slim.

A major potential source of recycled chromium is electroplating waste sludge, most of which is piped into water systems or dumped in landfills which creates substantial environmental hazards. As environmental restrictions mandate increasing levels of effluent treatment. correspondingly larger amounts of electroplating sludge, typically containing 30 to 39 percent zinc. 11 to 17 percent iron, up to 6 percent cadmium and up to 2 percent chromium, will be created. The technically recoverable wastes from this source in the chicago area alone are estimated at 1.2 million pounds of zinc, 120,000 pounds of cadmium, and 40,000 pounds of chromium per year. Catalytic uses of chromium in the production of formaldehyde and methanol also may provide a recycling feedstock from sludge, and additional chromium-bearing sludge arise in the photochemical and leather-tanning industries.

In one recent series of experiments, chromium, copper. zinc, and nickel were recovered from waste solutions used to etch and brighten brass fittings. One sample plant was estimated to discard 100 tons of chromium. 100 tons of copper, and 70 toris of zinc annually in such solutions.

Low-cost reagents (e.g.. shredded paper) have been used by the U.S. Bureau of Mines to reduce hexavalent to

trivalent chromium. copper is recovered by cementation with zinc or electrolysis, and the zinc and chromium are

precipitated as hydroxides from which either chromic oxide or sodium chromate can be derived. These experiments indicate that semi-pilot plants might verify the technically feasible recovery, and economic factors seem likely to bring forth commercially viable. development. However, at present the chemical industry seems to make little effort to recover chromium.

\subsection{SUMMARY, CONCLUSIONS, AND RECOMMENDATIONS}

\subsubsection{Summary}

Major opportunities for chromium conservation exist in melting and refining, in which almost 20,000 tons per year of chromium can be saved, and in surface coating. in which some 80,000 tons per year of chromium can be saved. Recycling also offers an opportunity to recover up to 20,000 tons per year of chromium that is now lost. A single processing step. joining. is a problem that relates 
specifically to edge and joint protection for surface-coated materials. Table 28 summarizes the panel's findings and quantifies the potential chromium savings.

\section{9 .2 Conclusions}

1. The most fruitful area for achieving substantial chromium conservation in melting and refining is through the wider application of duplex.melting and refining systems for stainless, alloy, and low-alloy constructional steels. The separation of the melting and refining steps results in the most economical, efficient, and alloy-conserving practice. Duplex melting and refining systems minimize the loss of chromium in slags during melting and refining. In conventional electric furnace melting followed by oxygen blowing, the irreversible chromium losses are 10 to 15 percent; these losses are reduced to under 6 percent with combined electric furnace and argon oxygen decarburization (AOD) or vacuum oxygen decarburization (VOD).

2. The U.S. stockpile contains over 750,000 tons of various graajes of ferrochromium, all of which has sulfur limits exceeding those of current commercial grades. with duplex melting and refining processes, the steel industry can produce stainless steels with a lower sulfur content than is possible with conventional electric furnace practice; therefore, steel producers with duplexing facilities could utilize, with some cost penalty. much of the ferrochromium in the stockpile. Without duplexing. most of the ferrochromium in the stockpile would be expensive to use for stainless steels and might not be usable at all for chromium-containing alloy steels, tool steels, and high-performance alloys.

3. Continuous-strand casting of slabs and billets for subsequent working into mill product forms of chromium-bearing stainless and alloy steels results in significantly higher yields from molten steel to slab or billet (about 95 percent as contrasted to 85 percent via conventional ingot pouring practice and breakdown rolling). Continuous casting reduces material losses. inventory requirements, energy consumption in further processing. and costs. Particular opportunities exist for chromium conservation in technically proven casting processes such as nearnet-shape preforms, hollow cast forms for pipe and 
TABLE 28 Potential Chromium Savings through Processing Modifications

\begin{tabular}{|c|c|c|c|c|c|c|c|c|}
\hline \multirow[b]{3}{*}{ Material } & \multirow[b]{3}{*}{ Process } & \multirow{2}{*}{\multicolumn{2}{|c|}{ Alternatives }} & \multicolumn{2}{|c|}{$\begin{array}{l}\text { Baseline Quantities Con- } \\
\text { sumed in Current Process, } \\
1970-1974 \text { (short tons/year) }\end{array}$} & \multirow{3}{*}{$\begin{array}{l}\text { Chromium } \\
\text { Saved } \\
\text { (short tons/ } \\
\text { year) }\end{array}$} & \multirow{3}{*}{ Remarks } & \multirow{3}{*}{$\begin{array}{l}\text { Implementation } \\
\text { Requirements }\end{array}$} \\
\hline & & & & \multirow{2}{*}{$\begin{array}{l}\text { Total } \\
\text { Material }\end{array}$} & \multirow{2}{*}{$\begin{array}{l}\text { Contained } \\
\text { Chromium }\end{array}$} & & & \\
\hline & & From & To & & & & & \\
\hline $\begin{array}{l}\text { Stainless and } \\
\text { alloy steel }\end{array}$ & $\begin{array}{l}\text { Melting and } \\
\text { refining }\end{array}$ & $\begin{array}{l}\text { Electric fur- } \\
\text { nace practice }\end{array}$ & $\begin{array}{l}\text { Duplex melting } \\
\text { and refining }\end{array}$ & $1,600,000$ & 270,000 & 19,000 & $\begin{array}{l}\text { Rapidly becoming standard } \\
\text { practice }\end{array}$ & Modest investment \\
\hline $\begin{array}{l}\text { Stainless and } \\
\text { alloy steel }\end{array}$ & & $\begin{array}{l}\text { Ingot break- } \\
\text { down practice }\end{array}$ & $\begin{array}{l}\text { Continuous- } \\
\text { strand casting }\end{array}$ & $1,600,000$ & 270,000 & 3,000 & $\begin{array}{l}\text { Most producers have ade- } \\
\text { quate capacity for ingot } \\
\text { practice }\end{array}$ & \\
\hline $\begin{array}{l}\text { Stainless steel } \\
\text { and superalloys }\end{array}$ & Casting & $\begin{array}{l}\text { Conventional } \\
\text { casting }\end{array}$ & $\begin{array}{l}\text { Neair-net-shape } \\
\text { preform }\end{array}$ & 40,000 & 10,000 & 1,000 & No current incentive & Cost reduction \\
\hline Superalloy & Casting & $\begin{array}{l}\text { Conventional } \\
\text { casting }\end{array}$ & $\begin{array}{l}\text { Investment } \\
\text { casting }\end{array}$ & 20,000 & 5,000 & 500 & No current incentive & Cost reduction \\
\hline $\begin{array}{l}\text { Cast super- } \\
\text { alloys }\end{array}$ & Casting & $\begin{array}{l}\text { Conventional } \\
\text { casting }\end{array}$ & $\begin{array}{l}\text { Post casting hot } \\
\text { isostatic pressing } \\
\text { treatment }\end{array}$ & 30,000 & 6,000 & 800 & $\begin{array}{l}\text { Reduced chromium con- } \\
\text { sumption through improved } \\
\text { product life and performance }\end{array}$ & $\begin{array}{l}\text { Cost reduction and } \\
\text { established specifications }\end{array}$ \\
\hline $\begin{array}{l}\text { Superalloys and } \\
\text { stainless steel }\end{array}$ & Casting & $\begin{array}{l}\text { Conventional } \\
\text { casting }\end{array}$ & $\begin{array}{l}\text { Slush, squeeze and } \\
\text { rheocasting }\end{array}$ & 30,000 & 6,000 & 100 & $\begin{array}{l}\text { Opportunity for chromium } \\
\text { conservation appears low }\end{array}$ & Cost reduction \\
\hline Alloy steel castings & & & & 150,000 & 1,500 & 200 & & \\
\hline $\begin{array}{l}\text { Alloy steel, } \\
\text { stainless steel } \\
\text { Nickel and co- } \\
\text { balt alloys }\end{array}$ & Casting & $\begin{array}{l}\text { Conventional } \\
\text { casting }\end{array}$ & $\begin{array}{l}\text { Tube shell prefo:ms } \\
\text { Castings plus } \\
\text { radial forging }\end{array}$ & $\begin{array}{r}300,000 \\
50,000 \\
4,000\end{array}$ & $\begin{array}{l}6,000 \\
9,500 \\
1,000\end{array}$ & $\begin{array}{r}1,300 \\
2,000 \\
150\end{array}$ & $\begin{array}{l}\text { Improved casting yield - } \\
2 \% \text { alloy savings }\end{array}$ & $\begin{array}{l}\text { Large capital investment } \\
\text { or rental of Watervliet } \\
\text { machine }\end{array}$ \\
\hline $\begin{array}{l}\text { ickel and co- } \\
\text { lt alloys }\end{array}$ & $\begin{array}{l}\text { Mill product } \\
\text { fabrication }\end{array}$ & $\begin{array}{l}\text { Forging and } \\
\text { rolling }\end{array}$ & Isothermal forging & 20,000 & 5,000 & 500 & $\begin{array}{l}\text { Minimal machining and } \\
\text { improved properties }\end{array}$ & $\begin{array}{l}\text { Reduced processing costs } \\
\text { for near-net-shapes }\end{array}$ \\
\hline
\end{tabular}




\begin{tabular}{|c|c|c|c|c|c|c|c|c|}
\hline $\begin{array}{l}\text { tainless and } \\
\text { loy steel }\end{array}$ & $\begin{array}{l}\text { Manufacturing } \\
\text { processing }\end{array}$ & $\begin{array}{l}\text { Conventional } \\
\text { metal removal } \\
\text { processing }\end{array}$ & $\begin{array}{l}\text { Precision formed } \\
\text { parts }\end{array}$ & $\begin{array}{l}2,000,000 \text { to } \\
4,000,000\end{array}$ & 40,000 & 2,500 & No current incentive & Reduced product $\mathrm{c}$ \\
\hline $\begin{array}{l}\text { Stainless and } \\
\text { alloy steel and } \\
\text { superalloy }\end{array}$ & $\begin{array}{l}\text { Manufacturing } \\
\text { processing }\end{array}$ & $\begin{array}{l}\text { Conventional } \\
\text { metal removal } \\
\text { processing }\end{array}$ & $\begin{array}{l}\text { Non-metal re- } \\
\text { moval process- } \\
\text { ing-rolling, coin- } \\
\text { ing and chipless } \\
\text { machining }\end{array}$ & $\begin{array}{l}1,000,000 \text { to } \\
2,000,000\end{array}$ & 20,000 & 2,000 & No current incentive & $\begin{array}{l}\text { Needs process development } \\
\text { and capital investment }\end{array}$ \\
\hline $\begin{array}{l}\text { Stainless and } \\
\text { alloy steels and } \\
\text { superalloys }\end{array}$ & $\begin{array}{l}\text { Manufacturing } \\
\text { processing }\end{array}$ & $\begin{array}{l}\text { Grinding ECM } \\
\text { and EDM } \\
\text { processing }\end{array}$ & $\begin{array}{l}\text { Trimming, drilling } \\
\text { and milling }\end{array}$ & 500,000 & 60,000 & 4,000 & No current incentive & Reduced product cost \\
\hline $\begin{array}{l}\text { Stainless and } \\
\text { alloy steels }\end{array}$ & Joining & Welding & Brazing & Small & 500 & 50 & $\begin{array}{l}\text { Little opportanity to } \\
\text { save chromium }\end{array}$ & - \\
\hline $\begin{array}{l}\text { Stainless and } \\
\text { alloy steels }\end{array}$ & Joining & $\begin{array}{l}\text { Mechanical } \\
\text { joints }\end{array}$ & $\begin{array}{l}\text { Welding and } \\
\text { brazing }\end{array}$ & $\begin{array}{l}25,000 \text { to } \\
40,000\end{array}$ & 5,000 & 100 & $\begin{array}{l}\text { Better properies saves } \\
\text { material }\end{array}$ & $\begin{array}{l}\text { Feasible except for compo- } \\
\text { nents that need to be dis- } \\
\text { assembled }\end{array}$ \\
\hline $\begin{array}{l}\text { Stainless and } \\
\text { alloy steels }\end{array}$ & Joining & $\begin{array}{l}\text { Conventional } \\
\text { welding }\end{array}$ & $\begin{array}{l}\text { Narrow gap } \\
\text { welding }\end{array}$ & $\begin{array}{l}25,000 \text { to } \\
40,000\end{array}$ & 5,000 & 200 & $\begin{array}{l}\text { Less waste in preparation } \\
\text { for welding }\end{array}$ & $\begin{array}{l}\text { Capital investment re- } \\
\text { quired }\end{array}$ \\
\hline $\begin{array}{l}\text { Stainless and } \\
\text { alloy steels }\end{array}$ & Joining & $\begin{array}{l}\text { Conventional } \\
\text { welding }\end{array}$ & $\begin{array}{l}\text { Autogeneous } \\
\text { welding }\end{array}$ & 100,000 & 10,000 & 1,000 & Reduces wastage & $\begin{array}{l}\text { Capital izvestment re- } \\
\text { quired }\end{array}$ \\
\hline $\begin{array}{l}\text { Stainless clad } \\
\text { plate }\end{array}$ & $\begin{array}{l}\text { Surface } \\
\text { coating }\end{array}$ & $\begin{array}{l}\text { Solid stainless } \\
\text { steel plate }\end{array}$ & Clad plate & 150,000 & 35,000 & 29,000 & $\begin{array}{l}\text { Established product; } \\
\text { heavy plate mLch more } \\
\text { economical }\end{array}$ & $\begin{array}{l}\text { Economic incentive } \\
\text { needed }\end{array}$ \\
\hline $\begin{array}{l}\text { Chromized } \\
\text { steel sheet }\end{array}$ & $\begin{array}{l}\text { Surface } \\
\text { coating }\end{array}$ & $\begin{array}{l}\text { Solid stainless } \\
\text { steel sheet }\end{array}$ & Chromizing sheet & 250,000 & 32,000 & 29,000 & $\begin{array}{l}\text { Established prcduct use for } \\
409 \text { stainless st eel primarily } \\
\text { for automotive exhaust } \\
\text { systems }\end{array}$ & $\begin{array}{l}\text { Large cafital investment } \\
\text { required }\end{array}$ \\
\hline $\begin{array}{l}\text { Carbon, alloy and } \\
\text { stainless steel }\end{array}$ & $\begin{array}{l}\text { Surface } \\
\text { coating }\end{array}$ & $\begin{array}{l}\text { Solid steel } \\
\text { (stainless and } \\
\text { alloy) }\end{array}$ & Weld overlays & 25,000 & 5,000 & 4,000 & $\begin{array}{l}\text { Established prozess, espe- } \\
\text { cially applicable for heavy } \\
\text { sections over } 4^{\prime \prime} \text { thick }\end{array}$ & $\begin{array}{l}\text { Incentive to expand its use } \\
\text { needed }\end{array}$ \\
\hline
\end{tabular}


TABLE 28 Potential Chromium Savings through Processing Modifications (continued)

\begin{tabular}{|c|c|c|c|c|c|c|c|c|}
\hline \multirow[b]{2}{*}{ Material } & \multirow[b]{2}{*}{ Process } & & \multicolumn{2}{|c|}{$\begin{array}{l}\text { Baseline Quantities Con- } \\
\text { sumed in Current Process, } \\
\text { 1970-1974 (short tons/year) }\end{array}$} & \multirow{2}{*}{$\begin{array}{l}\text { Chromium } \\
\text { Saved } \\
\text { (short tons/ } \\
\text { year) }\end{array}$} & \multirow[b]{2}{*}{ Remarks } & \multirow[b]{2}{*}{$\begin{array}{l}\text { Implementation } \\
\text { Requirements }\end{array}$} \\
\hline & & $\frac{\text { Alternatives }}{\text { From }}$ & To & $\begin{array}{l}\text { Total } \\
\text { Material }\end{array}$ & $\begin{array}{l}\text { Contained } \\
\text { Chromium }\end{array}$ & & & \\
\hline $\begin{array}{l}\text { Chromium- } \\
\text { bearing effluent }\end{array}$ & $\begin{array}{l}\text { Surface } \\
\text { coating }\end{array}$ & $\begin{array}{l}\text { Chromium } \\
\text { plating }\end{array}$ & $\begin{array}{l}\text { Chromium } \\
\text { plating with ef- } \\
\text { fluent recycle }\end{array}$ & 2,000 & 2,000 & 2,000 & $\begin{array}{l}\text { Affects small shops, of } \\
\text { which there are many; some } \\
\text { may be forced out of business }\end{array}$ & $\begin{array}{l}\text { EPA regulations will force } \\
\text { recycling }\end{array}$ \\
\hline $\begin{array}{l}\text { Chromium-plated } \\
\text { steel for func- } \\
\text { tional applications }\end{array}$ & $\begin{array}{l}\text { Surface } \\
\text { coating }\end{array}$ & $\begin{array}{l}\text { Chromium } \\
\text { plating }\end{array}$ & $\begin{array}{l}\text { Electroless } \\
\text { plating }\end{array}$ & 3,500 & 3,500 & 3,500 & $\begin{array}{l}\text { A substitute for "hard" chro- } \\
\text { mium, but poor tarnish re- } \\
\text { sistance and color }\end{array}$ & Needs an incentive \\
\hline $\begin{array}{l}\text { Chromium-plated } \\
\text { steel for decora- } \\
\text { tive applications }\end{array}$ & $\begin{array}{l}\text { Surface } \\
\text { coating }\end{array}$ & $\begin{array}{l}\text { Chromium } \\
\text { plating }\end{array}$ & $\begin{array}{l}\text { Stainless steel } \\
\text { and zinc plating }\end{array}$ & 7,000 & 7,000 & 7,000 & $\begin{array}{l}\text { Stainless steel is a substitute } \\
\text { with comparable tarnish resis- } \\
\text { tance and good color. Zinc } \\
\text { would protect but is not } \\
\text { decorative }\end{array}$ & Needs research effort \\
\hline $\begin{array}{l}\text { Chromium-plated } \\
\text { steel }\end{array}$ & $\begin{array}{l}\text { Surface } \\
\text { coating }\end{array}$ & $\begin{array}{l}\text { Chromium } \\
\text { plating . }\end{array}$ & Ion implantation & & & & Laboratory process today & $\begin{array}{l}\text { Needs extensive research } \\
\text { effort }\end{array}$ \\
\hline Stainless steel & $\begin{array}{l}\text { Surface } \\
\text { coating. }\end{array}$ & $\begin{array}{l}\text { Solid stainless } \\
\text { steel }\end{array}$ & $\begin{array}{l}\text { Dilex (surfalloy) } \\
\text { processing }\end{array}$ & 150,000 & 23,000 & 20,000 & Established process & $\begin{array}{l}\text { Capital investment and } \\
\text { product evaluation }\end{array}$ \\
\hline Waste & Recycle & Waste & $\begin{array}{l}\text { Chromium } \\
\text { recovery }\end{array}$ & & 30,000 & 20,000 & $\begin{array}{l}\text { Little economic incentive } \\
\text { to recover }\end{array}$ & $\begin{array}{l}\text { International Nickel Co. } \\
\text { has announded a facility } \\
\text { that will process some spe- } \\
\text { cialty steel mill wastes con- } \\
\text { taining chromium }\end{array}$ \\
\hline
\end{tabular}


tube production, and investment and other precision casting techniques. Toàay, economics is the primary restraint to more widespread use of these processes.

4. More than 95 percent of the raw stainless steel melted and converted into steel mill products is either shipped to customers or recycled (as home scrap) indicating that, within the stainless steel mills themselves, little opportunity exists for further chromium conservation during processing. In the case of chromium-bearing alloy and lowalloy steel, improved chromium conservation may be possible.

5. To maximize chromium utilization in chromiumcontaining steels and alloys, established manufacturing practices that currently are the most economical processing operations must be reassessed. First, and most important, is the ability to provide precision-formed intermediate stock that is created by processes such as forging, powder metal processing or casting that requires minimum metal removal. Second is to use finishing processes such as rolling, coining, and chipless machining that do not involve conventional metal removal. A third. but less attractive, option is to supply a work piece that closely approximates the finished-form configuration and is $f$ inished by a conventional machining or trimming operation so that the little excess metal removed is in the most convenient and recoverable form.

6. With more public demonstrations and publication of information and data on its applicability and production capabilities, chipless machining (e.g.. GFM machines) could be developed and applied to certain operations such as specialty steel and alloy tube production using tube shell castings as the starting material.

7. Isothermal forging, especially for chromiumcontaining nickel-base superalloys, is well suited to the production of aircraft engine and structural shapes. Particular needs for advancing this processing technology are improved die materials, new or improved lubricants for high temperature use, improved die heating practices, and better preform design and die preparation methods. 
8. Current methods of joining alloys containing chromium include welding, brazing, soldering. mechanical fastening, and adhesive bonding. Welding is the most efficient method. Brazing and soldering are of commercial significance but few brazed joints match the strength of the chromiumcontaining alloys being joined. Mechanical

fastening using high-strength bolts, rivets, lockseams, sheet-metal screws, and keys is stili done but only with weight and strength penalties. Nevertheless, items that must be unfastened later are usually keyed or bolted. Adhesive bonding is far behind other joining techniques in strength.

9. Stainless steel clad plate offers an important chromium-conservation opportunity. The application of clad plate can provide effectively the surface-corrosion-resisting characteristics of solid stainless steel plate with only 10 to 20 percent of the chromium requirement of a solid plate. The process is labor-intensive. The technology of production and of joining by welding is proven, and currently over 300.000 tons of clad plate are in service in a wide variety of applications. Conventional rolling mills could produce clad product with a minimum of lead time. and substantial expansion of present productive capacity could be effected with modest capital requirements in a short time frame.

10. Present chromized sheet applications are typical replacements of AISI 409 stainless steel. potentially the most important uses of several applications are the automotive emission exhaust components and catalytic containers. Present technology is adequate. Substantial investment in additional production facilities is needed to meet projected automotive exhaust requirements of 250.000 tons per year since present capacity is only 12,000 tons per year. The capital requirements for 250.000 tons of new capacity exceed $\$ 100$ million and cannot be justified on economic grounds today.

11. Dilex processing involves surface alloying of steel products at high temperatures for improved corrosion or wear resistance. The process employs a liquid metal medium (molten lead) at a temperature in the range of 1950 of to transport the alloying elements to the steel surface where alloying occurs by diffusion. Principal application to date has involved the use of 
chromium to produce small parts with high-chromium surfaces, although aluminum and other elements may be employed effectively either singly or in combination. The molten lead offers many technological and economic advantages. Effective prociedures have been developed to remove the lead from the surface after processing. Parts coated by the Dilex process are used because of lower cost, improved properties, or ability to produce unique properties. Greater use of Dilex treated parts requires extensive evaluation by manufacturers of stainless steel components.

12. Weld overlays can be applied where clad or chromized surfaces are unreliable. Weld overlays of corrosion-resisting materials are particularly important on sections over 4 inches thick. Weld overlays also are applied for wear resistance and to extend product and component life. Welding electrodes are available to impart special hardness, hot hardness, impact strength, abrasion resistance, metal-to-metal wear, and oxidation and corrosion resistance. Efforts to conserve. chromium will encourage the extensive use of weld overlays. Welding sequences and electrode recommendations are available today for most popular electrodes.

13. Of the various substitutes for chromium plating; electroless nickel-phosphorus or nickel-boron alloy plating. although unsuitable for decorative applications. is suitable for wear and functional applications. The processing technology is developed sufficiently but additional research and development are needed to make these processes competitive on a cost basis with hard-chromium plating.

14. Converting decorative chromium-plating shops to hard-chromium shops is probably not feasible since they require different and more demanding expertise. Expansion of hard-chromlum shops is possible but the lag time would be significant.

15. Environmental Protection Agency regulations calling for zero discharge of chromium and plating wastes will result in the recovery of 2,000 tons per year of chromium now lost in plating effluent.

16. Ion implantation may have the potential of producing a corrosion-resisting chromium layer on steels. Since the total chromium involved in ion 
plating probably will be an order of magnitude less than the coating method it replaces, the projected chromium savings are considerable. However, the process is several years away from becoming commercial even in a small way.

17. Recycling conserves materials resources by reducing waste. Reducing the quantities of materials that enter the waste stream creates economic and social benefits. The key problem in recycling chromium is that the recovery of secondary chromium is not cost-effective because primary or virgin chromium is relatively inexpensive at present.

18. The maximum technical recovery of chromium from process wastes in the ferroalloy. stainless steel. refractory, and chemical industries in the United States currently is estimated at 60,000 tons per year. Very little of this waste is recovered now for economic reasons, although some stainless steel and specialty alloy producers are recovering some scrap values from such wastes. Reductions in generated waste can be made by promoting product durability, repairability, and maintainability.

19. Increased recycling of mill materials used by part or product manufacturers is possible through better segregation of scrap (offal) that is returned to steel and alloy producers either directly or by scrap dealers. A similar opportunity exists for obsolescent scrap if product design provides for ready part disassembly and identification of relatively valuable alloys. Normally, the cost of collecting. separating, and shipping obsolete scrap is high and recovery is low.

\subsubsection{Recommendations}

1. The use of duplex melting and refining processes for alloy steels, especially for tool steels and high-chrome-content alloy steels, should be increased. The resultant savings could amount to 20,000 tons of chromium annually.

2. Steel producers should upgrade and modernize their facilities to include continuous casting so that up to 3.000 tons of chromium can be saved annually. 
3. New processes (such as hot isostatic pressing [HIP] to heal casting defects and improve the mechanical properties of castings, and

rheocasting. slush and squeeze casting) should be evaluated fully to establish their technical and economic reasibility and their potential chromium conservation possibilities.

4. Better separation and segregation of potentially recyclable home scrap in steel mills that produce chromium-containing alloy and low alloy is recommended to conserve the chromium now lost when home scrap is remelted.

5. Near-net-shape semi-finished forms should be supplied for finishing to reduce metal loss. energy, and the cost per pound of the part in place in the product.

6. To maximize chromium utilization, manufacturing operations should be used that minimize scrap generation but produce scrap in a readilyrecyclable form (i.e.. discrete, relatively large chips free of foreign material) through turning. drilling, or milling rather than through grinding. ECM, or EDM, which produce sludges, require more energy, and result in high chromium losses during recycling if such sludges are recycled.

7. Welding and brazing should be used as replacements for bolted, riveted, and. mechanically joined surfaces.

8. Where possible, brazing should be used rather than welding since most brazing alloys contain little or no chromium.

9. Autogenous (no filler metal) welding techniques -electron beam, electric resistánce, friction welding. diffusion bonding, etc. -- should be used where possible to minimize chromium use and wastage.

10. Narrow-gap welds, made by several semi-automatic and automatic processes, are important emerging chromium-conservation techniques that should be used increasingly in the future.

11. The new lower-chromium-content alloys proposed in chapter 6 may require welding in certain applications. Existing technology may require such alloys to be weided with available high- 
chromium-content welding electrodes. Advanced planning and, research should be encouraged to develop lower-chromium-content or matching filler material electrodes for the new alloys proposed.

12. When the availability or cost of chromium dictate, the following surface coating techniques are recommended, where appropriate, to reduce chromium usage: stainless steel cladding of steel plate. chromizing or other forms of diffusing chromium into steel sheet and products, weld overlays for very thick plates or shapes, and electroless nickel-phosphorus or nickel-boron plating.

13. Further research and development is recommended for ion implantation since the required chromium is an order of magnitude less than the chromium coatings that it might replace.

14. Scrap recycling, particularly by part and product manufacturers and by product designs that promote ready disassembly and identification of obsolete scrap. should be encouraged.

15. To promote chromium conservation, designers and manufacturers should promote greater usage of the following elements:

- Materials of desired composition and properties

- Combinations of materials that are compatible with current or more effective recycle systems

- Materials of consistently high quality and reliability

- In-process control that is monitored effectively by nondestructive testing and evaluation, and can be adjusted by feedback during processing

- Reduced reliance on final inspection of finished products consistent with maintenance of the highest quality and reliability

- Design products so that they can be monitored in use to determine their safety and remaining useful life, and be inspected readily and repaired easily for increased durability 
16. The lowest life-cycle cost (initial purchase price plus maintenance and repair costs plus longevity) should be the prime factor in product selection to achieve maximum material and energy conservation.

17. To improve the recovery of secondary chromium material, efforts should be made to stabilize the secondary market that currently is subject to extreme price fluctuations.

18. Laboratory research should be undertaken to solve specific technical problems in recycling such as removing harmful impurities, improving and developing new recycling processes, and developing recycling technology for currently nonrecyclable chromium-containing materials.

\section{REFERENCES}

American Iron and Steel Institute. Annual statistical Report. Washington, D.C.: American Iron and Steel Institute, 1975.

American Welding Society. Welding Handbook Vol. 1. Miami. Florida: American Welding Society. 1976.

Barth, C.F. and Hoffmanner, A. L. Advanced Manufacturing Procedures for $7.62 \mathrm{~mm}$ Rifle Barrels Fabricated from Erosion and Corrosion Resistant Materials. Preparea under Contract No. DAAF03-72-C-0170. Washington, D.C.: U.S. Army. January 1974.

Baum, R., Schaefer, K.. Kreutzer, H.W.. and Sperl, H. "Dislocation of Metallurgical Process steps of steelmaking to Subsequent Plant." Stahl u. Eisen 95 (1975):973-81

Couts, W.H., and sjoblad, R.E. Process Development of Large, Close Tolerance Forgings of Nickel-Base Superalloys. Final Report AFML-TR-67-347. Worcester, Mass.: WymanGordon Company. 1967.

Dressel. W.M.. George. L.C.; and Fine. M.M. "Chromium and Nickel Wastes -- A Survey and Appraisal of Recycling Technology." In Proceedings of the Fifth Meeting of the Waste Utilization Symposium, April 1976, pp. 262-70.

Metals and Materials. "Europe's First Ferrous Die-Casting Facility Opens for Business." Metals and Materials 10 (January 1976): 29-30. 
Moore, J. and Athey, R. "P/M State of the Art." Vol. 31 of Progress in Powdered Metallurgy. Princeton, N.J.: American Powder Metallurgy Institute; 1975. pp. 243-68.

National Materials Advisory Board. Trends in Usage of Chromium. Report NMAB-256 (NTIS no. AD707175) - Washington, D.C.: National Academy of Sciences, 1970. (Available from National Technical Information Services, 5285 Port Royal Road, Springfield, Virginia 22151.)

Pearce, D.W. "Fiscal Incentives and the Economics of Waste Recycling: Problems and Limitations." Paper presented at the Institute of Fiscal studies (U.K.) Conference on Fiscal Policy and the Environment. May 1974.

Profitt, C.E., and Thomas, H.C. Close Tolerance steel Forging Development. Prepared under AFML Contract No. AF33(600)-36659. Wright-Patterson Air Force Base, Ohio: Air Force Military. Laboratory. April 1962.

Rausch, J.J.. and Van Thyne, R.J. Methods of Diffusion Coating Metal substrates Using Molten Lead as Transport Medium. U.S. Patent No. $3,620,816$ issued November 16, 1971 .

Redlinger. R.W., and Timura, J.A. Precision Forging Program for Turbine Whee 1 s and Gears. Prepared under AFML Contract No. AF33(657)-8791. Wright-Patterson Air Force Base, Ohio: Air Force Military Laboratory, October 1964.

Van Thyne, R.J.. and Rausch, J.J. "Stainless Steel Surfaces Applied to Carhon Grades." Metal Progress (June 1974):68.

Vazquez, A.J., and Hayes, A.F. Isothermal Forging of Reliable structural Forgings. Final Report AFML-TR-74-123 prepared under AFML Contract No. F33615-71-C-1264. WrightPatterson Air Force Base, Ohio: Air Force Materials Laboratory. June 1974.

Wick, C.H. Chipless Machining. New York: The Industrial Press, 1960.

\section{BIBLIOGRAPHY}

Barde, J.P. "National Policy Alternatives for Environmental Management." In studies in International Environmental Economics, edited by I. Walter. New York: WileyInterscience, 1976.

Buckley. F. Interview. Metal Progress (November 1974):46. 
Charles River Associates. Inc. Economic Analysis of the Chromium Industry. Cambridge, Mass.: Charles River Associates, Inc., 1970.

Dulis, E.J. Summary Report on Air Force Chromium workshop. Wright-Patterson Air Force Base, Ohio: Air Force Materials Laboratory. Metals and Ceramics Division, May 1975. pp. 109-19.

Lherbier, L.W. "Stainless Steels." In Summary Report on Air Force Chromium Workshop. Wright-Patterson AFB, Ohio: Air Force Materials Laboratory. Metals and Ceramics Division, May 1975, pp. 93-107.

Mayer, E.H., and Willison, R.M.: "Bethlehem's Sheet Chromizing Process." Paper presented at AISI General Meeting. New York, N.Y., May 1967.

Melloy. G.F., and Brubaker, E.H. "Chromized Steel - Welds Are Strong and Corrosion Resistant." Metal Progress 91 (January 1967) : 104-7.

Metal Progress.: "GM Gears up to Meet Manufacturing Challenges." Metal progress 106 (November 1974): 46 .

Pearce, D.W. "Environment Protection, Recycling, and the International Materials Economy." In studies in

International Environmenta 1 Economics, edited by $I$. Walter. New York: Wiley-Interscience, 1976.

Powe11, H.E., Dressel, W.M.; and Crosby, R.L. Converting Stainless steel Furnace Flue Dusts and Wastes to a Recyclable Alloy. USBM Report 8039. Washington. D.C.: U.S. Bureau of Mines, 1975.

Refractory Journal. "Reclaimed Materials: A Part to Play." Refractory Journal (May 1973): 23 .

Smailer. R.M. "An Overview of Clad steel Manufacture and Application with Respect to Chromium Utilization." Unpublished report presented to the Committee, February 1976.

Spiegelberg, W.D. and Lake, F.N. Isothermal_Forging of Ti6A1-4V Alloy as an Improved process for Fabricating Weapon Components. Quarterly Engineering Reports ER-7665-1 to ER7665-3, prepared under Contract No. DAAF03-73-C-0093. washington, D.C.: U.S. Army. Weapons Command, September 1973 through February 1974 .

Spofford, W.O. "Solid Residuals Management: Some Economic Considerations." Natural Resources Journal 11 (1971). 
U.S. Bureau of Mines. Minerals Yearbook. Vol. I. Washington, D.C.: U.S. Bureau of Mines, 1968, 1970, 1972, 1974.

Walter. I. "A Discussion of the International Dimensions of Secondary Materials Recovery." Contemporary Issues No. 2 . Washington, D.C. International Economic Studies Institute. December 1975.

Willison, R.M., and Forstmann, J. v. D." "Chromized Steel - Corrosion Resistance at Less Cost than stainless Stee 1." Metal Progress 91 (January 1967):99-103. 


\title{
Chapter 6
}

\author{
SUBSTITUTION
}

\subsection{INTRODUCTION}

Substitution, a possible action to anticipate and prevent scarcity. may be defined as the use of alternative materials that are able to provide relatively equivalent benefits to the user. It can reduce the demand for critical materials by replacing them with noncritical materials having equivalent effectiveness in specific end uses and may be cost-effective except when the replacement material is inferior or requires paying additional costs in terms of materials, design, or processing. Unfortunately, the technology of substitution is not well developed and long lead times are required for implementation (Bittner 1974, Gold 1976), and the economy is not helped in an emergency scarcity situation.

In considering substitution, each commodity must be examined separately since each has a well-established supply, demand, and price history based on import dependence, available alternative material, productive capacity, and other factors (Radcliffe 1974). Chromium is an especially unusual commodity in that it confers unique properties on a wide variety of alloys and compounds and historically has been a relatively low-cost and plentiful material. Thus, current research efforts are devoted more to finding new uses for chromium than to searching for chromium-free substitutes. Previous investigations mainly serve to confirm the unique and superior properties of chromium in applications requiring properties such as hardenability, creep strength, hot strength; impact resistance, wear resistance, and corrosion and oxidation resistance (U.S. Air Force Materials Laboratory 1975. Brown 1976. Department of Commerce 1962, Committee on International Economic Policy 1974. Guy 1960, National Materials Advisory Board 1970).

This situation creates a special challenge to any study of the substitutability of chromium-free materials for the chromium-containing materials used almost exclusively in the applications listed in Table 29. For some of these applications, the present state of the art offers no substitute for chromium and, for others, suggested alternatives are not supported by the technology development and service experience that would permit confident predictions. The best current step is to identify the directions that research, development, and testing should take and to assign probabilities for research success. 
TABLE 29 Typical Applications of Chromium-Containing Materials

\begin{tabular}{|c|c|}
\hline Material Designation & End Use \\
\hline \multicolumn{2}{|l|}{ Metals } \\
\hline High-strength, multiple-alloy & $\begin{array}{l}\text { Building and construction } \\
\text { Bridges }\end{array}$ \\
\hline Low-alloy engineering steels & $\begin{array}{l}\text { Gears and work rolls } \\
\text { Ball and roller bearings } \\
\text { Shafting }\end{array}$ \\
\hline Cast iron and steel & $\begin{array}{l}\text { Industrial machinery } \\
\text { Engines } \\
\text { Transportation equipment }\end{array}$ \\
\hline Tool and die steels & $\begin{array}{l}\text { High-speed cutting tools } \\
\text { High-temperature forging, die casting, } \\
\text { and extrusion dies } \\
\text { Aircraft and missile components }\end{array}$ \\
\hline Hard-facing alloys & $\begin{array}{l}\text { Rolls and crushers } \\
\text { Exhaust valve seats } \\
\text { Pump parts }\end{array}$ \\
\hline $\begin{array}{l}\text { Hardenable chromium stainless } \\
\text { steels }\end{array}$ & $\begin{array}{l}\text { Turbine blades } \\
\text { Cutlery } \\
\text { Mining machinery } \\
\text { Sports equipment }\end{array}$ \\
\hline $\begin{array}{l}\text { Non-hardenable chromium } \\
\text { stainless steels }\end{array}$ & $\begin{array}{l}\text { Auto trim } \\
\text { Catalytic converters } \\
\text { Small parts and fasteners }\end{array}$ \\
\hline
\end{tabular}


Non-hardenable chromiumnickel stainless steels

High-temperature alloys

\section{Refractories}

Chrome-magnesite

Chrome-alumina

Chromia

\section{Coatings}

Chromium compounds

\section{Chemicals}

Chromium compounds
Food and chemical processing equipment Home appliances

Complex welded structures

Engine exhaust valves Gas turbine and jet engines

Electric heating elements

Chemical and metallurgical process equ ipment

Furnace bricks and linings

Mortars and cements

Electrocast refractories

Electroplated components Plasma spraying and welding

Clad sheet and plate

Mordants and dyes

Catalysts

Drilling mud.s

Leather tanning

Pigments and paints 
By assuming a complete cessation of supplies to the United states, attention can be focused on the specific, serious consequences of the sudden unavailability of chromium. In most applications, the substitutability of candidate alternate materials has three aspects:

1. The elimination of chromium has little effect on properties but substitute materials carry a significant cost penalty. Examples might be lowalloy. heat-treatable steels and some alloy cast irons.

2. The elimination of chromium causes a significant degradation of properties that can be compensated through short-term research in areas such as design restraints and improved processing. Direct or indirect cost penalties are involved. An example might be the replacement of oil-hardening steels with water-hardening varieties.

3. The elimination of chromium causes major degradation of properties without fruitful research being evident. Either the product must be discontinued or new technology that might include designing for new classes of materials, such as ceramic or composite materials, is required. Examples might be heat-resisting engine exhaust valves. gas turbine components, and electrical heating elements.

In this discussion, the possibilities for substitution are separated into eight major areas of chromium usage: stainless steels, tool steels, wrought alloy steels, cast iron and steels, coatings and claddings, refractories, nonferrous alloys, and chromium chemicals. Because the complexities involved in material selection and substitutability vary from one type of chromium usage to another, a uniform tabular format is used to present the findings related to each usage area in a manner that will help the reader grasp the substitutability situation for each chromium-containing material considered. Information is presented in terms of current material, typical material application, contained chromium, chromium demand, role of chromium (i.e.. special properties are endowed or enhanced by chromium) substitute material, chromium content of proposed substitute material, chromium savings if substitute material is used, property deficiencies resulting if substitute material is used, remarks (i.e.. urgency of research, guidelines, restraints, amplifying statements). research needed to conserve and preserve chromium, and probability of research success (i.e.. qualitative assessment of near-term success if research is begun now). 
This chapter, therefore, should permit estimation of the amount of chromium needed for essential applications and indicates where and how substitutions might be effected for other applications. It is intended to provide policymakers with suggested alternatives upon which they may base future decisions. Tt also should be helplul to designers. materials engineers, and industry procurement managers who use chromium-containing materials. Areas where research and new technology are needed to provide chromium-free materials with required properties are identified to serve as a guide to those planning future research programs in both the public and private sectors. The implications of chromium curtailment on industry, technology; economy, and environment also are evaluated.

\subsection{SUBSTITUTABILITY}

\section{2. 1 Ferrous Materiais}

\subsubsection{Chromium Demand and Substitutability in stainless} and Heat Resisting steels

The largest single use of chromium in the United States is for the production of stainless steels. In 1968, 70 percent of total U.S. chromium consumption was used for metallurgical purposes and 51 percent of that total was used for stainless steels (National Materials Advisory Board 1970). The amount currently used for stainless steel is probably greater since stainless steel has a higher growth rate than other chromium-bearing products.

The chromium used in the production of stainless steels comes from three sources: ferrochromium, purchased stainless steel scrap, and internal recirculating scrap. Included under ferrochromium are low-carbon ferrochromium, high-carkon ferrochromium, and ferrochromium silicon. Metallic chromium has been omitted since it is negligible. AISI ingot production data (Form 104) have been used to calculate the chromium used for stainless steel production. The details of the calculations and assumptions made are shown in appendix G. The average annual production for 1965 to 1975 amounted to 1.52 million ingot tons and has been used. first, to calculate the current use of chromium and, second: as the basis for growth to 1980 and 1990. The projected estimates are listed in Table 30.

To select proper substitutes for stainless steel, it is advisable to remember that:

1. Chromium provides passivation in iron-base alloys. A minimum of about 12 percent chromium is required. for this purpose: At the present state of 
TABLE 30 Stainless Steel Production (ingot tons)

\begin{tabular}{lccr}
\hline & $\begin{array}{l}1965-1975 \\
\text { Average }\end{array}$ & $\begin{array}{l}1980 \\
\text { Estimate }\end{array}$ & $\begin{array}{r}1990 \\
\text { Estimate }\end{array}$ \\
\hline Annual production & $1,520,000$ & $1,850,000$ & $3,015,000$ \\
Total contained chromium & 249,300 & 303,400 & 494,460 \\
Total chromium used & 282,700 & 325,600 & 530,640 \\
$\begin{array}{l}\text { Chromium from ferrochrome } \\
\begin{array}{l}\text { Chromium from purchased } \\
\text { scrap }\end{array}\end{array}$ & 113,300 & 131,350 & 214,060 \\
$\begin{array}{l}\text { Chromium from recirculated } \\
\text { scrap }\end{array}$ & 69,000 & 79,890 & 118,810 \\
\hline
\end{tabular}

NOTE: Data from American Iron and Steel Institute 1975. 
technology. passivation cannot be achieved with less chromium or without chromium. Replacement of 12 percent chromium in stainless steels therefore is not feasible.

2. The addition of from.12 lo 30 percent chromium to iron-base alloys increases their resistance to corrosion or oxidation to various degrees as needed to meet industrial or environmental requirements. Replacement by other elements of the chromium present in excess of 12 percent is feasible to a certain extent. Molybdenum, copper, and silicon can be used for corrosion resistance and aluminum, silicon, and yttrium, for oxidation resistance.

3. The function of chromium in austenitic stainless steels is to impart corrosion resistance and to stabilize the austenitic structure by depressing the martensitic transformation temperature below the ambient temperature. Replacement of chromium by other elements to perform this function is feasible.

Chromium savings in stainless steels can be accomplished into two ways: by partially replacing the chromium in excess of 12 percent with other alloying elements, and by completely replacing stainless steel with a different material containing very little or no chromium. A detailed listing of these savings follows:

1. Replacement of higher chromium steels with existing lower chromium stainless steels. It is known that the stainless steels used in a large number of applications are over-designed for corrosion resistance. This has occurred because chromium has been a readily available, relatively low cost element and because some higher chromium steels (especially the austenitic 18-8 $\mathrm{CrNi}$ stainless steels) offer outstanding fabricating characteristics. Accordingly. stainless steels are used in places where their corrosion resistance is not absolutely necessary and where lower chromium steels would have adequate corrosion resistance. For example, considerable chromium could be saved by replacing AISI 302 and 304 stainless steels (containing 18 percent chromium) with AISI 429 (containing 15 percent chromium) or 405 (containing 13 percent chromium).

2. Development of new 12-14 chromium austenitic stainless steels. About 25 to 30 percent of the 
chromium in AISI 301, 302, and 304 stainless steels, by far the largest tonnage group. could be saved by developing a new family of stainless steels with 12 to 14 percent chromium. The chromium must be replaced by nickel; copper. manganese, or molybdenum in order to duplicate the stability of austenite in the AISI 300 series. Corrosion resistance can be enhanced by molybdenum and copper addition, and oxidation resistance, by aluminum and silicon addition. While this new series of austenitic stainless steels could not substitute for the AISI 300 series in all applications, its development is technically feasible.

3. Clad Products. In principle, stainless steel metallurgicaliy bonded to a carbon steel. lowalloy steel, or other metal substrate could replace most monolithic metals. Application of this existing technology is restricted. however. to a limited combination of alloys and especially to certain thicknesses. To become a viable substitute that maximizes chromium savings, the. clad material must be expanded to all thicknesses. particularly to products where the stainless steel layer would be very thin. Fabrication. joining. and edge protection technology also would require further development if clad products were to be usable on a large scale.

4. Coated Products. Many coating methods are available; some are in production and othcre axe in the developmental stage. Chromium plating, stainless steel cladding, chromizing, and weld overlay are well-established production processes; ion implantation, Dilex coatings, and organic coatings are still under development. Although some chromium is used in these methods, the amount is so small that considerable chromium would be saved if coated products were used in lieu of stainless steels. Coatings have great potential for replacing stainless steels, but more research and development are needed to improve processing technology and to identify those applications for which they are especially suited.

5. Alternate Materials. Metals such as titanium, aluminum, tantalum, and zinc and thermoplastic and thermosetting plastics can replace stainless steels in many functional and decorative applications. Each of these materials could replace stainless steels only in specific areas. 
For instance, titanium could be used in chemical apparatus and in gas turbines at the lower end of the temperature range; aluminum could replace stainless steels in decorative and some structural applications; tantalum and lead, in chemical apparatus. The plastics could replace stainless steels in both functional and decorative applications. The role of these materials is discussed in more detail in section 6.2.6.

The principles outlined above have been used to formulate the detailed master list of substitute materials for current standard steels presented in appendix $\mathrm{H}$ and summarized in Table 31. The current steels have been grouped according to structure, chromium level, product form, and application. A total of 47 substitute materials are listed. The substitute materials are either chromiumfree or have a much lower chromium content than their standard counterparts. The technical or economical limitations of the substitutes have been included. The research needed and the probability of success conclude the 1ist. This approach has been used during previous material shortages. During the early 1950s, a shortage of nickel resulted in the development of the AISI 200 series stainless steels that use about half as much nickel as the AISI 300 series. The balance of the nickel was replaced by manganese. Development of lower chromium stainless steels requires additional research.

A calculation of potential chromium savings by resorting to the alternate materials shown in Table 32 requires quantitative market data such as that contained in the Department of Commerce 1972 U.S. Standard Industrial Classification (SIC) of chromium-containing products. Using the SIC data. the chromium content was calculated from the ferrochromium, silicon chromium, and metallic chromium quantities on the assumption that the chromium content was 65 percent, 40 percent, and 100 percent, respectively. This was done only for the two-digit code and is shown in Table 32. The SIC data do not provide any information regarding the type of stainless steel used or any details concerning application; therefore, they are nut suitable for a quantitative treatment of chromium savings. However, the SIC market categories do provide an indication of potential chromium savings possibility based on what is considered their industrial importance: For instance, for SIC No. 25 . Furniture and Fixture, 95 percent of chromium presumably could be saved if practically all the stainless steel were replaced by other materials. On the other hand. for SIC No. 19, Ordnance and Accessories, the assumption was that all stainless steel is essential and irreplaceable. Similar assumptions were made for the other market categories. The 
TABLE 31 Alternate Materials for.Stainless Steels

\begin{tabular}{|c|c|c|c|c|c|c|c|c|c|c|c|}
\hline $\begin{array}{l}\text { Current } \\
\text { Material }\end{array}$ & $\begin{array}{l}\text { Material } \\
\text { Application }\end{array}$ & $\begin{array}{l}\text { Con- } \\
\text { tained } \\
\mathrm{Cr}, \%\end{array}$ & $\begin{array}{l}\text { Chromium } \\
\text { Demand } \\
\text { tons/year } \\
1972\end{array}$ & $\begin{array}{l}\text { Role of } \\
\text { Chromium }\end{array}$ & Substitute Material & $\begin{array}{l}\text { Chromium } \\
\text { Content, \% }\end{array}$ & $\begin{array}{l}\text { Potential } \\
\text { Chromium } \\
\text { Savings } \\
\text { tons/year } \\
\end{array}$ & Property Deficiencies & Remarks & $\begin{array}{l}\text { Research } \\
\text { Needed. }\end{array}$ & $\begin{array}{l}\text { Proba- } \\
\text { bility of } \\
\text { Success }\end{array}$ \\
\hline \multirow{4}{*}{$\begin{array}{l}18 / 8 \mathrm{Cr}-\mathrm{Ni} \\
\text { type aus- } \\
\text { tenitic } \\
\text { stainless } \\
\text { steels: } \\
\text { Types } 301 \text {, } \\
302,304 \text {, } \\
304 \mathrm{~L}, 303 \text {, } \\
347,321 \text {, } \\
201,202 \text {, } \\
204,203 \text {, } \\
305 \\
\text { All } \\
\text { wrought } \\
\text { product } \\
\text { forms }\end{array}$} & $\begin{array}{l}\text { Functional } \\
\text { and decorative } \\
\text { application re- } \\
\text { quiring corro- } \\
\text { sion and oxi- } \\
\text { dation resis- } \\
\text { tance through- } \\
\text { out industry. }\end{array}$ & 18 & . & . & $\begin{array}{l}\text { 1. Clad stainless steel } \\
\text { on carbon steel sub- } \\
\text { strate }\end{array}$ & approx. 3\% & Major & $\begin{array}{l}\text { Loss of corrosion re- } \\
\text { sistance at all exposed } \\
\text { edges and welds. } \\
\text { Limited high temp. } \\
\text { and cryogenic prop- } \\
\text { erties. }\end{array}$ & $\begin{array}{l}\text { Restricted to sheet } \\
\text { and plate. } \\
\text { See Section } 3.4 .6 \\
\text { and also Processing } \\
\text { section on Surface } \\
\text { Coatings. }\end{array}$ & & \\
\hline & $\begin{array}{l}\text { SIC Nos. } \\
25,30,33,34, \\
35,36,37,38, \\
39,19,11-14, \\
13,15-17\end{array}$ & & $\begin{array}{l}91,000 \\
\text { (based on } \\
1972 \text { AISI } \\
\text { ingot pro- } \\
\text { duction } \\
60 \% \text { yield) }\end{array}$ & $\begin{array}{l}\text {-Corrosion } \\
\text { resistance } \\
\text {-Oxidation } \\
\text { resistance } \\
\text {-Formation } \\
\text { of aus- } \\
\text { tenitic } \\
\text { structure }\end{array}$ & $\begin{array}{l}\text { 2. Cr coatings on car- } \\
\text { bon steel (electrolytic, } \\
\text { vapo- deposition or } \\
\text { solid state diffusion). }\end{array}$ & Negligible & Minor & $\begin{array}{l}\text { Damaged surface } \\
\text { causes loss of corro- } \\
\text { sion resistance. } \\
\text { Limited high temp. } \\
\text { and cryogenic prop- } \\
\text { erties. }\end{array}$ & $\begin{array}{l}\text { Size and shape } \\
\text { limitations. } \\
\text { Limited fab- } \\
\text { ricability. } \\
\text { See Sections } \\
3.4 .1,3.4 .3 \text {, } \\
3.4 .4 \text { and also } \\
\text { Processing sec- } \\
\text { tion on Surface } \\
\text { Coatings }\end{array}$ & $\begin{array}{l}\text { New and } \\
\text { improved } \\
\text { coatings } \\
\text { and } \\
\text { methods }\end{array}$ & High \\
\hline & & & & & 3. $c \% \mathrm{Ni}$ steel & . & Minor & $\begin{array}{l}\text { Adequate substitute } \\
\text { only in cryogenic end } \\
\text { use. }\end{array}$ & & & \\
\hline & . & & . & & $\begin{array}{l}\text { 4. Aluminum } \\
\text { allovs }\end{array}$ & . & Major & $\begin{array}{l}\text { Not adequate for } \\
\text { high temperature } \\
\text { application. } \\
\text { Some corrosion } \\
\text { and structural prop- } \\
\text { erty limitations. }\end{array}$ & $\begin{array}{l}\text { See Section } \\
3.2 .4\end{array}$ & & . \\
\hline & & 1 & & . & 5. Plastics: & . & Major & $\begin{array}{l}\text { Limited fabricability. } \\
\text { Not suitable above } \\
\text { about } 400^{\circ} \mathrm{F} \text {. } \\
\text { Lower strength. }\end{array}$ & $\begin{array}{l}\text { See Section 3.6.3, } \\
\text { 3.6.4 }\end{array}$ & $\begin{array}{l}\text { Develop } \\
\text { improved } \\
\text { plastics }\end{array}$ & High \\
\hline
\end{tabular}




\begin{tabular}{|c|c|c|c|c|c|}
\hline $\begin{array}{l}\text { 6. New ferritic } \mathrm{Cr}- \\
\text { free steel with } \mathrm{Al} \text {, } \\
\mathrm{Ti}, \mathrm{Si} \text { addition for } \\
\text { high temp. oxida- } \\
\text { dation resistance }\end{array}$ & 54,600 & $\begin{array}{l}\text { Low-high temp. } \\
\text { strength }\end{array}$ & $\begin{array}{l}\text { Low-high temp. } \\
\text { strength inherent } \\
\text { to ferritic stain- } \\
\text { less steels }\end{array}$ & $\begin{array}{l}\text { Develop } \\
\text { new ferritic } \\
\text { steel and } \\
\text { dispersion } \\
\text { hardened } \\
\text { ferritic } \\
\text { steels }\end{array}$ & . \\
\hline $\begin{array}{l}\text { 6. New Ferritic } \mathrm{Cr} \text { - } \\
\text { free steel with } \mathrm{Al}, \mathrm{Ti} \text {, } \\
\text { Si addition for high } \\
\text { temperature oxida- } \\
\text { dation resistance }\end{array}$ & Minor & $\begin{array}{l}\text { Ferritic steels have } \\
\text { low strength at high } \\
\text { temperatures. }\end{array}$ & $\begin{array}{l}\text { Oxidation resis- } \\
\text { tance of } \mathrm{Cr}-\mathrm{Ni} \\
\text { steels probably } \\
\text { attainable. } \\
\text { Dispersion } \\
\text { strengthening } \\
\text { system probably } \\
\text { needed for high } \\
\text { temperature } \\
\text { strength. }\end{array}$ & $\begin{array}{l}\text { Derelop } \\
\text { new fer- } \\
\text { ritic Cr- } \\
\text { free steel. } \\
\text { Develop } \\
\text { dispersion } \\
\text { strengthen- } \\
\text { ing system. }\end{array}$ & Medium \\
\hline
\end{tabular}

Total substitutes for

above categories

ح22 8,800

Applications

CrNitis

involving high

8,80

-Oxidation

1972 ingot

temperature

1972 ingot

Corrosion

$60 \%$ yield)

resistance

oxidation,
carburization

$\therefore$ Overlay

$308,309, \therefore$ Overlay

310,314 ,

welding.

800 , valve SIC Nos.

steels (21- $\quad 13,15,16,17$

$4 \mathrm{~N}, 21-2 \mathrm{~N}) \quad 33,34,35,38$

wrought

product

forms

Total substitutes for

above categories

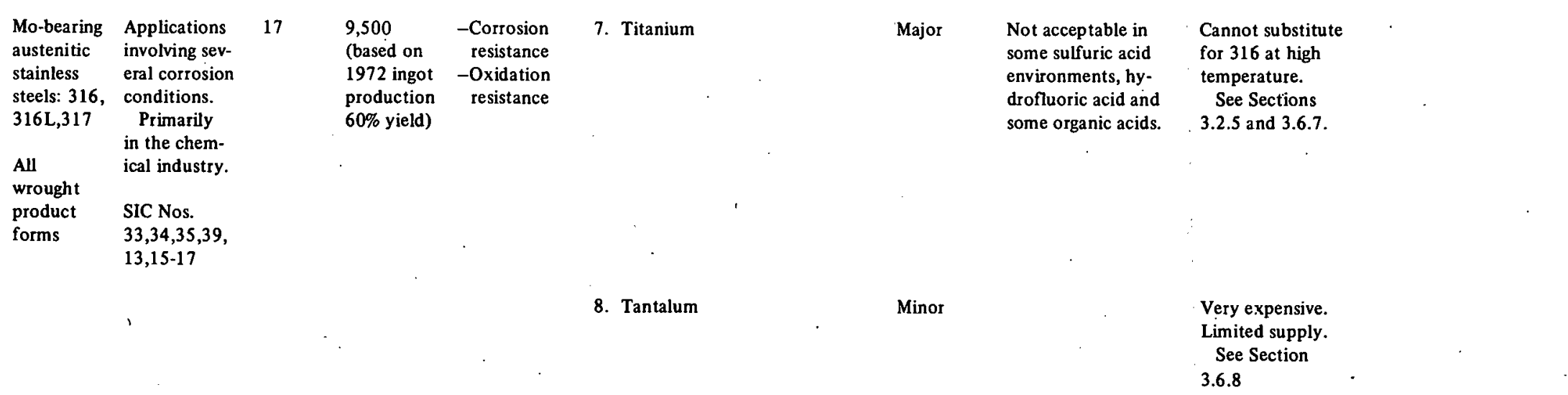


TABLE 31 Alternate Materials for Stainless Steels (continued)

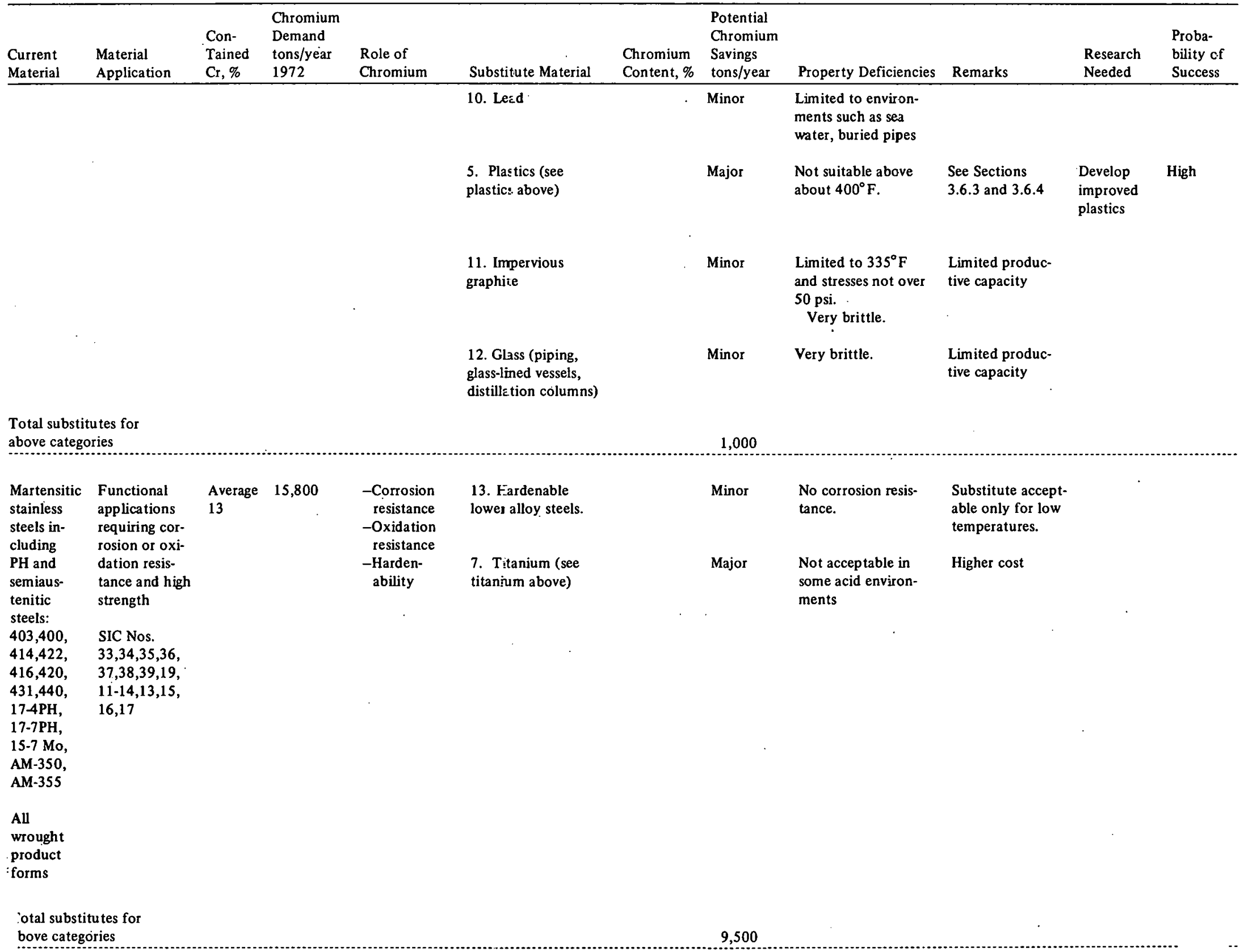




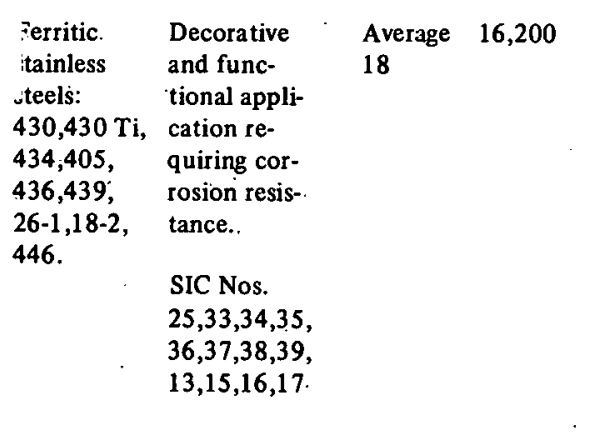

-Corrosion
resistance
-Oxidation.
resistance:

1. Clad stainless

steel on carbon stee

substrate (see above)

2. Chromium coatings on carbon steel (electrolytic, vapor deposition or solid state diffusion).(see above)

4. Aluminum alloys

(see above)

Major See above

See above

Minor See above

See above

New and

improved

5. Plastics (see above)

Major

See above

See Section

3.2.4

.

6. New ferritic $\mathrm{Cr}$ -
free steel with $\mathrm{Al}, \mathrm{Ti}$,
Si addition for high
temp. oxidation re-
sistance (see above)

Minor

See above

See Sections

Develop

plastics

High

plas:ics

Develop
new fer-

ritic steel

and tisper-

sionhard-

ened fer-

ritic steels

Total substitutes for

above categories

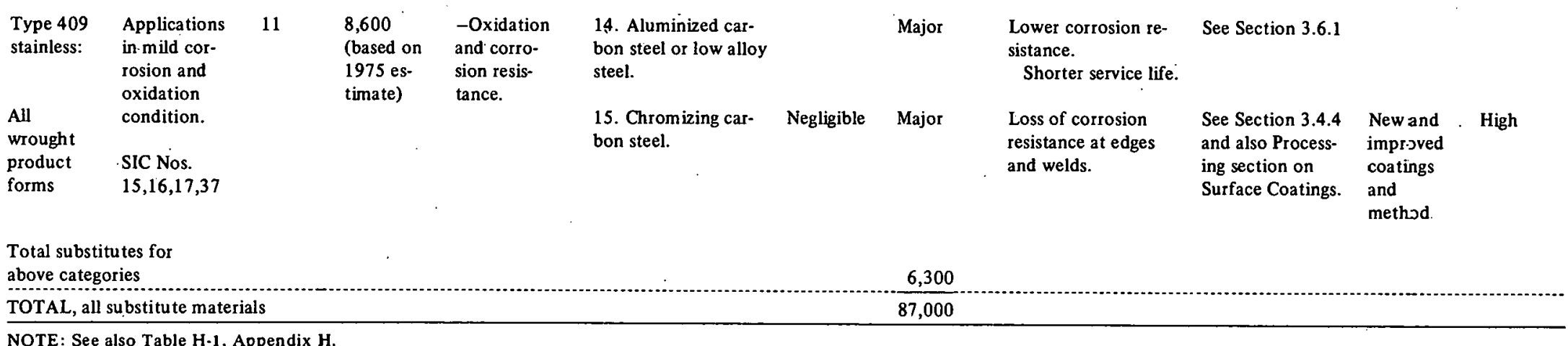


TABLE 32 Example of Possible Chromium Savings in Stainless Steel (tons)

\begin{tabular}{|c|c|c|c|c|}
\hline SIC Number & SIC Code & $\begin{array}{l}\text { U.S. Chromium } \\
\text { Demand in } 1972\end{array}$ & $\begin{array}{l}\text { Possible } \\
\text { Chromium Savings }\end{array}$ & $\begin{array}{l}\text { Chromium Use } \\
\text { After Savings }\end{array}$ \\
\hline 25 & Furniture and fixtures & 2,400 & $2,280(95 \%)$ a & 120 \\
\hline 33 & Primary metal industries & 13,000 & $11,700 \quad(90 \%)$ & 1,300 \\
\hline 34 & Fabricated metal products & 61,000 & $30,500 \quad(50 \%)$ & 30,500 \\
\hline 35 & Machinery, except electrical & 40,000 & $20,000 \quad(50 \%)$ & 20,000 \\
\hline 36 & $\begin{array}{l}\text { Electrical machinery, equipment } \\
\text { and supply }\end{array}$ & 10,000 & $4,000 \quad(40 \%)$ & 6,000 \\
\hline 37 & Transportation equipment & 19,500 & $18,100 \quad(93 \%)$ & 1,400 \\
\hline 38 & Instruments and related products & 2,800 & $(20 \%)$ & 2,240 \\
\hline 39 & Misc. manufacturing industry & 8,000 & 7,600 & 400 \\
\hline 19 & Ordnance and accessories & 1.250 & $(0 \%)$ & 1,250 \\
\hline $11,12,13,14$ & Mining, petroleum, natural gas & 170 & $(0 \%)$ & 170 \\
\hline $15,16,17$ & Building construction, contractors & 9,400 & 4,700 & 4,700 \\
\hline \multirow[t]{2}{*}{13} & \multirow{2}{*}{$\begin{array}{c}\text { Crude petroleum, natural gas } \\
\text { Total }\end{array}$} & 330 & $0 \quad(0 \%)$ & 330 \\
\hline & & 167,850 & 99,440 & 68,530 \\
\hline
\end{tabular}

NOTE: Data from U.S. Department of Commerce, Standard Industrial Classifications, 1972.

a The figures in parentheses indicate the percentage of possible chromium savings in that category. 
only well-founded assumption is for SIC No. 37. Transportation Equipment, since the automotive industry is a wel1-defined market for which a detailed stainless substitution calculation could be made and is presented in appendix I. The total potential chromium savings, hased on the assumption for SIC 37 and chromium supply cut-off, is approximately 93 percent.

The total chromium usage implied by Table 32 is much lower than that given in the summary table (see section 6.4.2. Table 50) which presents a summary of potential savings. Because the available data on stainless steel in specific end uses are so incomplete. the larger figure appears more realistic and is used in Table 50 with the assumption that its end use category distribution is the same as that in Table 32 .

The most important substitutes, as a group, are existing materials, such as aluminum, titanium and plastics, that require no developmental work: Many of these materials currently compete with stainless steels and therefore have a proven record as alternatives. They are chromium-free and provide the optimum chromium-saving solution.

The second group consists of clad products in which the amount of stainless steel used in a particular application may be reduced by as much as 90 percent. The advantage of these products is that the corrosion and oxidation properties of the original material are maintained. Coated (or other than clad) products can be included in this group when the coatings are thin chromium-bearing layers that permit substantial savings of chromium. Coatings have many technical limitations and probably are the substitutes requiring the most research and development, particularly in the area of fabricating and joining composite materials.

The last group of substitutes, modified stainless steels possessing lower chromium content, provides the least chromium savings but their mechanical and fabricating characteristics could duplicate those of the standard steels. The loss in corrosion and oxidation resistance caused by the lower chromium content can be partly or completely compensated by the addition of other alloying elements.

\subsubsection{Substitutability of Chromium in Tool steels}

Table 33 presents information on chromium in the following classes of tool steels: high-speed steels, hotwork tool steels, cold-work tool steels, shock-resisting steels, special-purpose steels, and water-hardening steels. The production figures used were the 1974 AISI shipped tons 
TABLE 33 Chromium Demand and Substitutability in Tool Steels

\begin{tabular}{|c|c|c|c|c|c|c|c|c|c|c|c|}
\hline $\begin{array}{l}\text { Current } \\
\text { Material }\end{array}$ & $\begin{array}{l}\text { Materials } \\
\text { Applications }\end{array}$ & $\begin{array}{l}\text { Contained } \\
\text { Chromium, } \\
\%\end{array}$ & $\begin{array}{l}\text { Chromium } \\
\text { Demand, } \\
\text { pounds }\end{array}$ & $\begin{array}{l}\text { Role of } \\
\text { Chromium }\end{array}$ & $\begin{array}{l}\text { Substitute } \\
\text { Material }\end{array}$ & $\begin{array}{l}\text { Contained } \\
\text { Chromium } \\
\text { pounds }\end{array}$ & $\begin{array}{l}\text { Chromium } \\
\text { Savings }\end{array}$ & $\begin{array}{l}\text { Property } \\
\text { Deficiencies }\end{array}$ & Remarks & $\begin{array}{l}\text { Research } \\
\text { Needed }\end{array}$ & $\begin{array}{l}\text { Probability of } \\
\text { Success }\end{array}$ \\
\hline $\begin{array}{l}\text { High speed } \\
\text { steels }\end{array}$ & $\begin{array}{l}\text { Cutting tools, } \\
\text { hot work dies }\end{array}$ & 4 & $3,000,000$ & $\begin{array}{l}\text { Harden- } \\
\text { ability, } \\
\text { hardness, } \\
\text { wear re- } \\
\text { sistance }\end{array}$ & $\begin{array}{l}\text { Sintered } \\
\text { carbides }\end{array}$ & None & $3,000,000$ & & $\begin{array}{l}\text { High cost, de-- } \\
\text { sign limita- } \\
\text { tions }\end{array}$ & $\begin{array}{l}\text { New design } \\
\text { concepts }\end{array}$ & High \\
\hline $\begin{array}{l}\text { Hot work } \\
\text { tool steels }\end{array}$ & $\begin{array}{l}\text { Dies-forging, } \\
\text { molding and } \\
\text { extrusion } \\
\text { tooling }\end{array}$ & 5 & $1,500,000$ & $\begin{array}{l}\text { Same as } \\
\text { above }\end{array}$ & $\begin{array}{l}\text { No replace- } \\
\text { ment }\end{array}$ & - & - & & $\begin{array}{l}\text { No replace- } \\
\text { ments in } \\
\text { sight }\end{array}$ & None & - \\
\hline \multirow[t]{2}{*}{$\begin{array}{l}\text { Cold work } \\
\text { tool steels }\end{array}$} & $\begin{array}{l}\text { Blanking, } \\
\text { forming, draw- } \\
\text { ing, and slit- } \\
\text { ting tools }\end{array}$ & 12 & $2,300,000$ & $\begin{array}{l}\text { Same as } \\
\text { above }\end{array}$ & $\begin{array}{l}\text { Sintered } \\
\text { carbides }\end{array}$ & None & $2,300,000$ & & $\begin{array}{l}\text { High cost, } \\
\text { design } \\
\text { limitations }\end{array}$ & $\begin{array}{l}\text { New design } \\
\text { concepts } \\
\text { needed }\end{array}$ & High \\
\hline & & 5 & 900,000 & $\begin{array}{l}\text { Same as } \\
\text { above }\end{array}$ & $\begin{array}{l}1 \% \mathrm{Cr} \\
\text { cold work } \\
\text { steel }\end{array}$ & $1 \%$ & 720,000 & & $\begin{array}{l}\text { Substantial } \\
\text { chromium re- . } \\
\text { duction likely }\end{array}$ & $\begin{array}{l}\text { Optimize } \\
\text { composi- } \\
\text { tion }\end{array}$ & High \\
\hline $\begin{array}{l}\text { Special } \\
\text { purpose } \\
\text { steels }\end{array}$ & $\begin{array}{l}\text { Bearings, } \\
\text { rolls, gages }\end{array}$ & 1 & 300,000 & $\begin{array}{l}\text { Same as } \\
\text { above: }\end{array}$ & $\begin{array}{l}\text { Cold work, } \\
\text { oil harden- } \\
\text { ing steels }\end{array}$ & Low & 250,000 & & $\begin{array}{l}\text { Substitution } \\
\text { should not } \\
\text { cause difficulty }\end{array}$ & None & - \\
\hline
\end{tabular}


data. The total amount of contained chromium is 4.167 tons or less than 1 percent of total U.S. consumption. The largest use is in high-speed steels in which chromium plays an important role in the hardening mechanism and is considered irreplaceable. In any case, the relatively small chromium tonnage for this case hardly would justify such research. The second largest use is in the high-carbon. high-chromium cold-work steels in which chromium is essential for hardness and wear resistance, and again is irreplaceable. sintered carbides make adequate substitute materials for high-speed and high-carbon high-chromium steels if serious cost penalties are accepted. Replacement of chromium hot-work tool steels is not feasible and present technology does not indicate the development of chromiumfree substitutes. In view of the relatively small amount of chromium involved, no research is recommended. Some of the other tool steels can be replaced by lower chromium steels or chromium-free materials but, again, the quantity of chromium used or saved is negligible.

The replacements for tool steels are assumed to conserve 3,135 tons, or 78 percent, of the chromium used in this application. Most of these savings would be the result of replacement by sintered carbides. In view of the small amount of chromium used in tool steels, the importance of tool steels for the industry, and the high cost of the replacing materials, it might be advisable to consider the chromium in tool steels irreplaceable.

\subsubsection{Substitutability of Chromium in Wrought Alloy} Steels and Iron and steel Castings

Although the major metallurgical use of chromium is in stainless and heat-resisting steels, a significant amount also is used to produce wrought alloy steels and alloy iron and steel castings. Historically, these latter categories account for 20 to 25 percent of all new chromium consumed within a given year.

Chromium is used in wrought and cast steel primarily for its influence on hardenability. Many opportunities exist to eliminate or renuce the chromium. iuntent of these steels by using other alloying elements that also have a strong influence on hardenability. In most cases. the addition of these substitute elements carries an economic penalty given current chromium prices (i.e... the chromium contribution to hardenability on a dollar basis is relatively high compared to most other alloying elements).

In this section, an attempt has been made to quantify the present use of chromium in wrought alloy steels and castings of irons and steel, and to identify the chromium- 
containing grades that are the most likely candidates for alternative lower chrome grades. Substitution for chromium in iron and steels by nonferrous materials has not been considered because the fundamental premise is the necessity for ferrous base materials. However, materials other than iron and steel (e.g.. aluminum, titanium, and reinforced plastics) could be considered for applications where chromium-containing alloys are used presently at a substantial increase in cost by current economics.

Alternatives for present chromium usage in wrought and cast alloy steel and alloy irons are discussed by major alloy categories (e.g.. Ni-Cr, $\mathrm{Ni}-\mathrm{Cr}$-Mo steels). While it is very difficult to discuss this subject in terms of the major SIC categories. Table 34 presents the best estimate of chromium consumption in alloy steels attributable to the major SIC markets. These 1972 data originally were in the form of chromium products consumed but, for this discussion, the data were converted into tons of actual chromium consumed.

\subsection{Wrought_Alloy_steels}

The amount of chromium used in 1974 in wrought alloy steels was determined from the production figures reported in AISI Form 7A. Assumptions were made concerning the average chromium content contained in the reported grades and the amount of chromium contained in the scrap charge. The reported tonnage for each grade was assumed to represent 90 percent of the actual tonnage produced. The latter aceumption was made because a few alloy steel companies do not report their production figures tu AISI. Table 35 shows 1974 chromium consumption in wrought alloy steels by alloy grade classification. As can be seen, the majority of chromium consumed by wrought alloy steels is associated with straight chromium, the $\mathrm{Cr}-\mathrm{MO}$, and the Ni-Cr-Mo composition.

Table 36 presents a forecast of chromium usage in wrought alloy steels through 1985. This consumption estimate is based on historic data that relate the specific chromium content from the scrap and additions used in making these steels as a percentage of total alloy steels, and that relate total alloy steels as a percentage of total raw steel production.

Unfortunately, available statistics do not permit the broad alloy categories shown in Table 35 to be classified into quantities of a specific grade produced; however, by using past experience as a guide, the major grades that contribute to the tonnages shown can be identified even though the specific tonnages are unknown. The material below identifies these grades and suggests alternate steels. 
TABLE 34 Consumption of Chromium in Alloy Wrought and Cast Steel by Market Category, 1972

\begin{tabular}{llcr}
\hline SIC Number & SIC Code & $\begin{array}{c}\text { Chromium Consumed } \\
\text { (short tons) }\end{array}$ & $\begin{array}{c}\text { Percent of } \\
\text { Total Market }\end{array}$ \\
\hline 25 & Furniture and fixtures & 500 & 0.9 \\
33 & Primary metal industries & 13,730 & 24.8 \\
34 & Fabricated metal products & 7,390 & 13.3 \\
35 & Machinery, except electrical & 9,130 & 16.5 \\
36 & Electrical machinery & 3,150 & 5.7 \\
37 & Transportation equipment & 6,110 & 11.0 \\
38 & Instruments & 70 & 0.1 \\
39 & Misc. manufacturing industry & 320 & 0.6 \\
19 & Ordnance & 1,970 & 3.6 \\
$11,12,14$ & Mining and quarrying & 1,680 & 3.0 \\
13 & Crude petroleum and natural gas & 4,040 & 7.3 \\
$15,16,17$ & Construction & 7,380 & 13.2
\end{tabular}

NOTE: Data from U.S. Department of Commerce 1972. 
TABLE 35 Chromium Consumption in Wrought Alloy steels in 1974 (1,000 tons)

\begin{tabular}{|c|c|c|c|c|c|}
\hline Alloy & $\begin{array}{l}\text { Steel } \\
\text { Produced a }\end{array}$ & $\begin{array}{l}\text { Average } \\
\text { Chromium } \\
\text { Content (\%) }\end{array}$ & $\begin{array}{l}\text { Chromi } \\
\text { From } \\
\text { Scrap }\end{array}$ & Chromium Consumption & mption \\
\hline Chromium $\underline{b}$ & 1,250 & 0.85 & 1.59 & 9.04 & 10.63 \\
\hline Chromium $\subseteq$ & 330 & 1.45 & 0.72 & 4.07 & 4.79 \\
\hline $\mathrm{NiCr}$ & 120 & 0.65 & 0.12 & 0.66 & 0.78 \\
\hline $\mathrm{CrV}$ & 55 & 0.90 & 0.07 & 0.43 & 0.50 \\
\hline NiCrMoV & 160 & 0.50 & 0.12 & 0.68 & 0.80 \\
\hline CrMo & 2,750 & 1.05 & 4.30 & 24.58 & 28.88 \\
\hline $5-9 \%$ CrMo & 44 & 6.00 & 0.66 & 1.98 & 2.64 \\
\hline CrMoV & 210 & 1.05 & 0.33 & 1.87 & 2.20 \\
\hline NiCrMo & $\underline{2,470}$ & 0.50 & 1.84 & 10.51 & 12.35 \\
\hline Total & 7.389 & & 9.75 & 53.82 & 63.57 \\
\hline
\end{tabular}

NOTE: Data from American Iron and Steel Institute 1975.

a Froduction figures from ATSI Form 7A adjusted (increased. 10 percent) to compensate for nonreporting companies.

$\underline{b}$ AISI 5100 series of steels.

C AISI 52100 . 
TABLE 36 Chromium Consumption Forecast for Wrought Alloy steel

\begin{tabular}{llll}
\hline & \multicolumn{4}{l}{ Chromium } & Consumption & $(1,000$ & short \\
Year & $\begin{array}{l}\text { From } \\
\text { Scrap }\end{array}$ & $\begin{array}{l}\text { From } \\
\text { Additions }\end{array}$ & Total \\
\hline 1974 a & 10 & 54 & 64 \\
1975 & 9 & 50 & 59 \\
1976 & 10 & 55 & 65 \\
1980 & 12 & 62 & 74 \\
1985 & 14 & 78 & 92 \\
\hline
\end{tabular}

a Production figures from AISI Form 7 A adjusted (increased 10 percent) to compensate for nonreporting companies. 
The nominal chemical analysis of the reference AISI and EXsteels are given in Table 37.

The broad group of chromium-molybdenum grades accounts for approximately 50 percent of all new chromium attributed to wrought alloy steels. The most widely produced grades under this general category are AISI 4118, AISI 4130. AISI 4140. AISI 4142, AISI 4150, and the ASTM elevatedtemperature steels (e.g. . 2-1/4Cr-1Mo, 1-1/4Cr-1/2Mo, 1/2Cr1/2Mo, and the 5 to $9 \mathrm{Cr}$ heat-resisting alloys). The following alternates are available:

1. AISI 4118. For most products, the use of other carburizing grades such as AISI 4023. AISI 4027. and AISI 4419 or one of the AISI 1500 grades could be adapted with little or no change in present heat-treating practice.

2. AISI 4130 through 4150. Adjustments in the levels of manganese and molybdenum and the use of boron should permit, with minimal problems, chromiumfree replacement steels in constructional applications.

3. 4100 Types Used in oil country Tubular. Increases in manganese, molybdenum, and possibly silicon plus consideration of boron-containing steels should allow the use of chromium-free steels at most strength levels. Where resistance to $\mathrm{H}_{2} \mathrm{~S}$ corrosion is necessary, more basic data are needed to determine the feasibility.

4. Elevated Temperature and Heat Resisting ChromiumMolybdenum steels. Although chromium could be replaced in these steels if hardenability were the sole consideration, the environments in which these steels normally operate necessitate using from 5 to 9 percent chromium to provide the required corrosion-resisting and heat-resisting characteristics. The elimination or reduction of chromium in these steel would require extensive research and is not considered a likely area for chromium substitutability.

The $\mathrm{Ni}-\mathrm{Cr}-\mathrm{Mo}$ grades account for approximately 20 percent of all new chromium used in the production of wrought alloy steels. The larger tonnage grades in this category are the carburizing grades (i.e.. AISI 8615-25. AISI 8822, AISI 4320. AISI 8115-17. AISI 8720 and AISI 9310) and the through-hardening grades (i.e.. AISI 4340 and-its various aircraft steel modifications, AISI 8630-60, and 
TABLE 37 Nomiral Chemical Analysis of Standard and EX Steels Referenced in Report

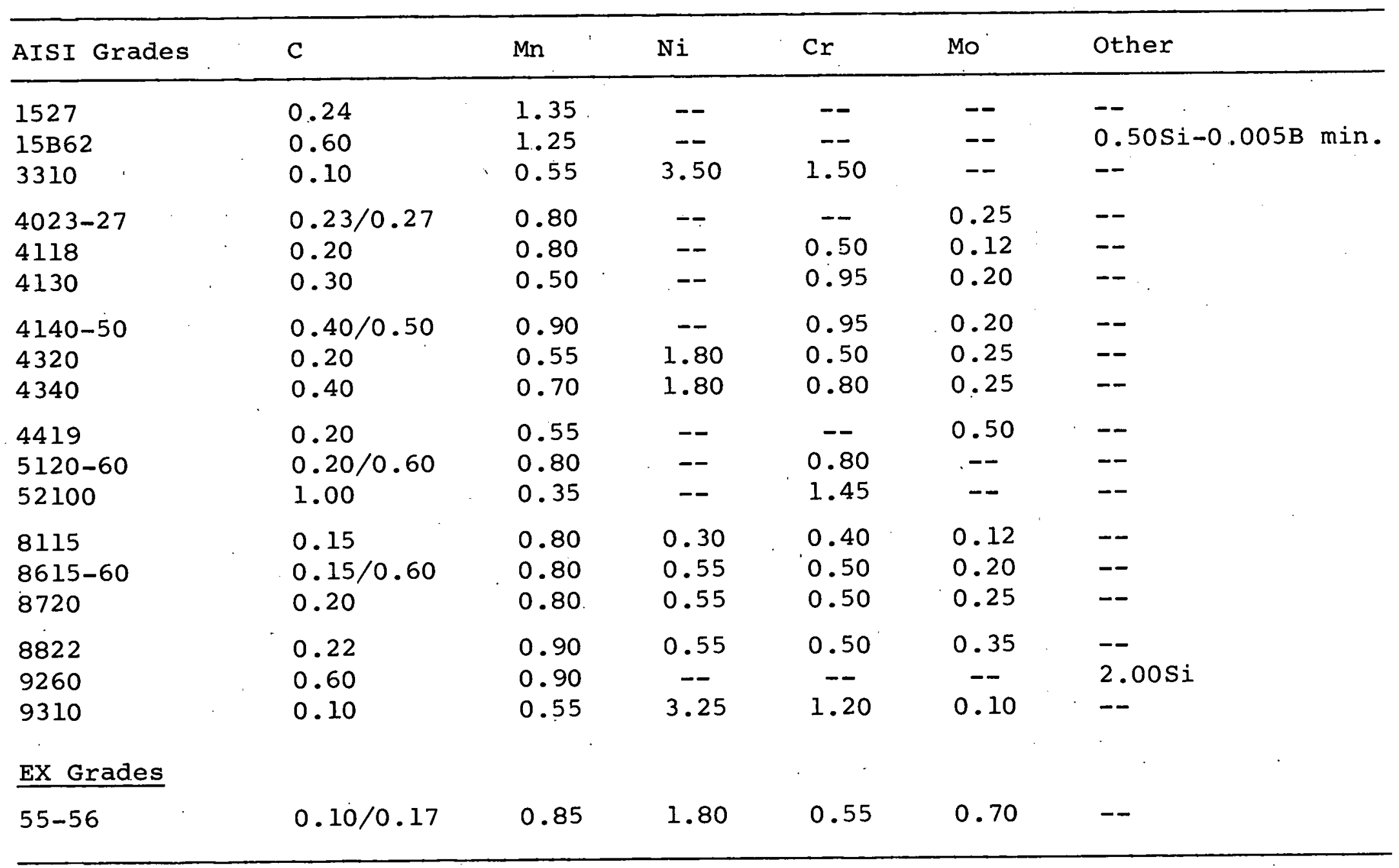


armor steels such as HY-80, STS, and high-hardness armor compositions). The following alternates are available:

1. Carburizing Grades. The majority of the chromiumcontaining carburizing steels is produced to a 0.35 to 0.65 percent chromium specification. The case and core hardenability provided by this amount of chromium could be attained by substituting increased amounts of manganese and molybdenum and, possibly, the combination of molybdenum and silicon that exhibits a strong synergism at high carbon levels. At least twothirds of the chromium used in the carburizing grade AISI 9310 can be replaced with no loss in case or core hardenability by increased additions of manganese and molybdenum. The SAE EX-55 and 56 steel compositions exemplify this approach.

2. Through-Hardening Grades. Chromium-free alternates for the AISI 4300 and 8600 compositions. when used for construction applications, could be developed by adjusting manganese and molybdenum levels and by additions of boron. The aircraft and armor compositions. however, have combinations of toughness. strength, weldability, and ballistic characteristics that would entail considerable testing of newly developed chromium-free replacement steels before their suitability would be accepted. Although alternate steels could be developed for the present materials, the total chromium used in these materials probably would not justify the time and money necessary to gain acceptance of the new alloys.

3. Chromium Grades. The straight chromium grades account for approximately 25 percent of the chromium used in wrought alloy steels. The major uses of these steels are in springs (AISI 5150-60), bearings (AISI 52100), throughhardening construction applications (AISI 5140). grinding mill balls, and some carburized applications (AISI 5120). The following alternates are available:

a. Spring steels. The most extensively produced single alloy grade in the United States is AISI 5160, whose greatest usage is in springs. Presently, two chromium-free standard grades of steel, AISI 15B62 and 9260, can be used in lieu of AISI 5160 . Considerable effort also is under way to 
develop spring steels that are chromium-free or possess less chromium than AISI 5160. These steels (under development) have a hardenability equivalent to that of AISI 5160, and include MnCrMo, SiCr, SiCrMo, and siMo combinations. Economics permitting. these low-chromium steels appear to be acceptable substitutes for AISI 5160 .

b. Bearing steels. Substitutes for AISI 52100 with lower chrome levels and increased amounts of manganese, silicon, and molybdenum have been, and could be, developed further. Their lack of acceptance primarily is associated with higher cost and requirements for extensive qualifiation testing. Also. the ease of machinability might be less than that of AISI 52100 .

c. Medium Carbon AISI 5100 steels. These steels could be replaced without any problems by increasing manganese contents and making small additions of molybdenum.

d. Grinding Mill Balls (Wrought) Steels. These balls normally are produced from high-carbon manganese-chromium steel (1.15Mn-0.45Cr). At least one steel producer successfully substituted a 1.3Mn-0.2Mo chemistry for this application.

e. Carburizing steels. AISI 5120 could be replaced by chromium-free steels such as the ones previously mentioned for chromiummolybdenum grades as possible alternates for AISI 41.18.

4. Other Alloys. The remaining alloy combinations. account for only 8 percent of the total chromium used in wrought alloy steels. The most notable grades include the $\mathrm{Cr}-\mathrm{Mo}-\mathrm{V}$ and $\mathrm{Ni}-\mathrm{Cr}-\mathrm{Mo}-\mathrm{V}$ rotor steels, the T-1 type plate steels and the carburizing grade. AISI 3310. The following alternates are available:

a. Rotor steels- Extensive research and development is required to alter the composition of these long established rotor steel chemistries.

b. T-1 Type Chemistries Identified as ASTM A-517 Grades $A$ to $P$ : Depending on the gauge and 
the steel producer, these 100,000 minimum yield strength quenched and tempered steels vary widely in chromium content and include four grades that do not specify any chrome. Thus, chromium-free substitutes that meet the ASTM A-517 specification are available, but they have thickness limitations.

c. AISI 3310. At least two-thirds of the chromium used in this carburizing steel can be replaced with no loss in case or core hardenability by increased additions of molybdenum. The SAE EX-55 and EX-56 steel compositions are examples of this approach.

The chromium demand and substitutability in wrought alloy steels are summarized in Table 38.

\section{2.1.3.2 Alloy Steel Castings}

The present and anticipated future consumption of chromium in alloy steel castings is shown in Table 39. This category accounts for about 4 percent of new chromium used in the production of metallurgical products. For. market analysis purposes, alloy steel castings generally are divided into the following groups:

1. Low-alloy constructional cast steels including modified AISI grades such as $8600,8700,4100$. $4300,4700,5000$, and 5100 along with nonclassified proprietary grades. The average chromium content. of this group is estimated at 0.7 percent. The present trend, unless reversed by economic or metallurgical factors, is toward increasing chromium content.

2. High-alloy cast steels including the 4 to 6 percent chromium steels, the austenitic AISI. 300 series stainless, the martensitic or ferritic AISI 400 series, and heat-resisting alloys containing between 18 and 30 percent chromium and 0 to 65 percent nickel.

3. Abrasion-resisting steels comprised of the highmanganese austenitic steels (between 6 and 12 percent manganese) the pearlitic $\mathrm{Cr}$-Mo steels with carbon contents in the 0.5 to 1.0 percent range, and the air-hardening or quenched and tempered multiple alloy martensitic steels with nominal carbon ranging between 0.25 and 0.45 percent. 
The major market for low-alloy chromium-containing cast steels is in railroad equipment: $\mathrm{Cr}$-Mo castings are used extensively in the truck body components and the couplers. sufficient data exist to permit the development of chromiumfree grades by increasing one or more of the following elements: manganese, nickel, mulybdenum, and boron. This probably could be accomplished without hardship in a short period of time.

The high-alloy cast steel group accounts for over 60 percent of the new chromium used in cast alloy steels and would be the most difficult group of materials in which to decrease chromium consumptinn. Since the majority of materials in this group are stainless steels and heatresisting materials, the recommendations for chromium substitutions made in section 6.2 also are applicable to the cast materials.

In the majority of applications of abrasion-resisting cast alloys, chromium could be replaced by combinations of manganese, nickel, molybdenum, ana boron.

\subsection{Alloy Cast Irons}

The primary chromium consumption of this group accounts for approximately 5 percent of the total primary metallurgical chromium consumption. Present and forecast use of chromium is shown in Table 40. For purcoses of estimating chromium consumption and possible substitutability, this group of irons has been subdivided into rolling mili rolls, abrasion-resisting castings, and engineering castings.

Indefinite chill rolls with chromium contents of 1.5 to 2 percent are interchangeable with cast steel rolls with less than 1.0 percent chromium or with spheroidal graphitic rolls containing 0.4 percent molybdenum and no chromium. These substitutions, if made, probably would reduce roll performance in the mills.

Recent experience has demonstrated that shortages of chromium cause a renuction in the production of cast iruss. containing 28, 20, and 15 percent chromium. For applications requiring higher impact resistance than can be obtained with Ni-Hard ${ }^{\circledR}$ Type 2 irons, Ni-Hard ${ }^{\circledR}$ Type 4 with a chromium content of between 6 and 8 percent could be used. For most other applications. Ni-Hard ${ }^{\circledR}$ Type 2 with a chromium content of between 1.5 and 2 percent could be used. Other possible, suitable alternatives include wrought low-alloy steels or $\mathrm{Cr}-\mathrm{Mo}$ pearlitic or oil quenched and tempered steels containing less than 2 percent chromium. Such changes would not be difficult for the major foundries 
TABLE 38 Chromium Demand and Substitutability in Wrought Alloy Steel

\begin{tabular}{|c|c|c|c|c|c|c|c|c|c|c|c|}
\hline \multirow[b]{3}{*}{$\begin{array}{l}\text { Current } \\
\text { Material }\end{array}$} & \multirow[b]{3}{*}{$\begin{array}{l}\text { Material } \\
\text { Application }\end{array}$} & \multirow[b]{3}{*}{$\begin{array}{l}\text { Contained } \\
\text { Chromium, } \\
\%\end{array}$} & \multirow{3}{*}{$\begin{array}{l}\text { Chromium } \\
\text { Demand } \\
\text { (million } \\
\text { pounds) }\end{array}$} & \multirow[b]{3}{*}{$\begin{array}{l}\text { Role of } \\
\text { Chromium }\end{array}$} & \multicolumn{4}{|c|}{ Available Alternative Materials } & \multirow{2}{*}{\multicolumn{3}{|c|}{ Required New Technology-Remarks }} \\
\hline & & & & & & & Chromium & & & & \\
\hline & & & & & $\begin{array}{l}\text { Substitute } \\
\text { Materials }\end{array}$ & $\begin{array}{l}\text { Contained } \\
\text { Chromium, } \\
\% \\
\end{array}$ & $\begin{array}{l}\text { Saved } \\
\text { (million } \\
\text { pounds) }\end{array}$ & $\begin{array}{l}\text { Property } \\
\text { Deficiencies } \\
\end{array}$ & $\begin{array}{l}\text { Research } \\
\text { Needed }\end{array}$ & $\begin{array}{l}\text { Priority of } \\
\text { Research }\end{array}$ & $\begin{array}{l}\text { Probability of } \\
\text { Research } \\
\text { Success } \\
\end{array}$ \\
\hline Cr-Mo & & $0.5 / 9.00$ & & & & & & & & & \\
\hline $\begin{array}{l}\text { Carburizing } \\
\text { steels, e.g., } \\
4118\end{array}$ & $\begin{array}{l}\text { Gears and } \\
\text { bearings }\end{array}$ & 0.5 & 8 & $\begin{array}{l}\text { Case and } \\
\text { core hard- } \\
\text { enability }\end{array}$ & $\begin{array}{l}\text { Mn-Mo and } \\
\text { Mo steels }\end{array}$ & 0 & 8 & Cost & None & None & High. \\
\hline $\begin{array}{l}\text { Thru harden- } \\
\text { ing e.g., } 4130 \text {, } \\
4140 \text { and oil } \\
\text { country tubu- } \\
\text { lar goods }\end{array}$ & $\begin{array}{l}\text { Construction } \\
\text { and machinery } \\
\text { equipment }\end{array}$ & $0.5 / 1.00$ & 33 & $\begin{array}{l}\text { Harden- } \\
\text { ability and } \\
\text { toughness }\end{array}$ & $\begin{array}{l}\text { Mn-Mo-B } \\
\text { and Mn-Mo } \\
\text { steels } \\
\quad\end{array}$ & 0 & 33 & $\begin{array}{l}\text { Cost and cor- } \\
\text { rosion in oil } \\
\text { country tubu- } \\
\text { lar applications }\end{array}$ & $\begin{array}{l}\text { Improved cor-- } \\
\text { rosion resis- } \\
\text { tance to certain } \\
\text { environments }\end{array}$ & Low & High \\
\hline $\begin{array}{l}\text { Elevated } \\
\text { temperature } \\
\text { steels, e.g., } \\
\text { ASTM A387 }\end{array}$ & $\begin{array}{l}\text { Electrical } \\
\text { machinery and } \\
\text { power equip- } \\
\text { ment }\end{array}$ & $0.5 / 2.00$ & 15 & $\begin{array}{l}\text { Corrosion } \\
\text { resistance }\end{array}$ & $\begin{array}{l}\text { No exist- } \\
\text { ing steels }\end{array}$ & $0.5 / 2.0$ & 0 & $\begin{array}{l}\text { Corrosion } \\
\text { resistance }\end{array}$ & $\begin{array}{l}\text { Long range } \\
\text { basic research }\end{array}$ & High & Low \\
\hline $\begin{array}{l}\text { Heat resist. } \\
\text { steel 5-9\% } \\
\text { Cr-Mo }\end{array}$ & $\begin{array}{l}\text { Chemical pro- } \\
\text { cess and petro- } \\
\text { leum reference }\end{array}$ & $5.0 / 9.0$ & 5 & $\begin{array}{l}\text { Oxidation } \\
\text { resistance }\end{array}$ & $\begin{array}{l}\text { No exist- } \\
\text { ing steels }\end{array}$ & $5.0 / 9.0$ & 0 & $\begin{array}{l}\text { Oxidation } \\
\text { resistance }\end{array}$ & $\begin{array}{l}\text { Long range } \\
\text { basic research }\end{array}$ & Low & Low \\
\hline Subtotal & & & 61 & & & & 41 & & & & \\
\hline $\mathrm{Ni}-\mathrm{Cr}-\mathrm{Mo}$ & & $0.5 / 1.50$ & & & & & & . & & & \\
\hline $\begin{array}{l}\text { Carburizing } \\
\text { steels, e.g., } \\
8620,8822, \\
4320,9310\end{array}$ & $\begin{array}{l}\text { Gears and } \\
\text { bearings }\end{array}$ & $0.5 / 1.00$ & 12 & $\begin{array}{l}\text { Case and } \\
\text { core hard- } \\
\text { enability } \\
\text { and } \\
\text { toughness }\end{array}$ & $\begin{array}{l}\text { Mn-Mo and } \\
\text { Mn-Ni-Mo } \\
\text { steels }\end{array}$ & 0 & 12 & Cost & None & None & High \\
\hline $\begin{array}{l}\text { Thru hard- } \\
\text { ening steels, } \\
\text { e.g., } 4340 \text {, } \\
8640 \text { and } \\
\text { HY steels }\end{array}$ & $\begin{array}{l}\text { Construction } \\
\text { and trans- } \\
\text { portation } \\
\text { equipment }\end{array}$ & $0.5 / 1.50$ & 13 & $\begin{array}{l}\text { Harden- } \\
\text { ability and } \\
\text { toughness }\end{array}$ & $\begin{array}{l}\text { Mn-Mo-B } \\
\text { and } \\
\text { Mn-Ni- } \\
\text { Mo-B }\end{array}$ & 0 & 13 & $\begin{array}{l}\text { Cost and im- } \\
\text { pact resistance }\end{array}$ & $\begin{array}{l}\text { Verify com- } \\
\text { parable tough- } \\
\text { ness, weld- } \\
\text { ability and } \\
\text { ballistic char- } \\
\text { acteristics }\end{array}$ & Low & High \\
\hline ubtotal & & & 25 & . & & & 25 & & & & \\
\hline
\end{tabular}


$5160,52100, \quad$ Springs, bear- 1.00

and $\mathrm{Mn}-\mathrm{Cr}$ ings, and thru-

31

Si-Mo and $\quad 0$

31

Cost

Qualification

Medium

ability,

Mn-Mo

bearing steels

grinding

hardening con-

fatigue re-

steel appli-

sistance,

abrasion-

and sag

resistance

Subtotal .

Cr-Mo-V and

Ni-Cr-Mo-V

T-1 types

Constructional $\quad 0.50$

1

$\begin{array}{ll}\text { Harden- } & \text { Mn-Mo-B } \\ \text { ability and } & \text { (listed in } \\ \text { impact } & \text { ASTM }\end{array}$

strength

A517)

$\begin{array}{lll}\begin{array}{l}\text { Rotor } \\ \text { forgings }\end{array} & \begin{array}{l}\text { Electrical } \\ \text { machinery }\end{array} & 0.50 / 1.00\end{array}$

forgings

machinery

Creep and No existent 0

stress rup- steels

ture

strength

and impact

strength

\begin{tabular}{|c|c|c|c|c|c|c|c|c|c|c|c|}
\hline AISI 3310 & $\begin{array}{l}\text { Heavy duty } \\
\text { gears and } \\
\text { bearings }\end{array}$ & 1.50 & 1 & $\begin{array}{l}\text { Harden- } \\
\text { ability and } \\
\text { toughness }\end{array}$ & $\begin{array}{l}\text { EX-55 } \\
\text { and } 56\end{array}$ & 0.3 & 0.7 & None & None & None & High \\
\hline Subtotal & & & 6 & & & & 5.7 & & . & & \\
\hline TOTAL & & & 123 & & & & 102.7 & & & & \\
\hline
\end{tabular}


TABLE 39 Chromium Consumption in Alloy Steel Castings (1,000 short tons)

\begin{tabular}{|c|c|c|c|c|c|}
\hline \multirow[b]{2}{*}{ Year } & \multirow[b]{2}{*}{ Alloy } & \multirow[b]{2}{*}{ Production } & \multicolumn{3}{|c|}{ Chromium Consumption a } \\
\hline & & & $\begin{array}{l}\text { From } \\
\text { Scrap }\end{array}$ & $\begin{array}{l}\text { From } \\
\text { Additions }\end{array}$ & $\begin{array}{l}\text { Total } \\
\text { Consumption } \underline{b}\end{array}$ \\
\hline 1974 & $\begin{array}{l}\text { High alloy } \\
\text { Low alloy. } \\
\text { Abrasion resisting } \\
\text { Total }\end{array}$ & $\begin{array}{r}70 \\
369 \\
257 \\
696\end{array}$ & $\begin{array}{l}7.0 \\
0.4 \\
1.3 \\
8.7\end{array}$ & $\begin{array}{l}7.0 \\
2.2 \\
1.3 \\
10.5\end{array}$ & $\begin{array}{r}14.0 \\
2.6 \\
2.6 \\
19.2\end{array}$ \\
\hline 1975 & $\begin{array}{l}\text { High alloy } \\
\text { Low alloy } \\
\text { Abrasion resisting } \\
\text { Total } \subseteq\end{array}$ & $\begin{array}{r}70 \\
338 \\
255 \\
663\end{array}$ & $\begin{array}{l}7.0 \\
0.4 \\
1.3 \\
8.7\end{array}$ & $\begin{array}{l}7.0 \\
2.0 \\
1.3 \\
10.3\end{array}$ & $\begin{array}{r}14.0 \\
2.4 \\
2.6 \\
19.0\end{array}$ \\
\hline 1976 & $\begin{array}{l}\text { High alloy } \\
\text { Low alloy } \\
\text { Abrasion resisting } \\
\text { Total }\end{array}$ & $\begin{array}{r}75 \\
365 \\
276 \\
716\end{array}$ & $\begin{array}{l}7.5 \\
0.4 \\
1.4 \\
9.3\end{array}$ & $\begin{array}{r}7.5 \\
2.2 \\
1.4 \\
11.1\end{array}$ & $\begin{array}{r}15.0 \\
2.6 \\
2.8 \\
20.4\end{array}$ \\
\hline 1980 & $\begin{array}{l}\text { High alloy } \\
\text { Low alioy } \\
\text { Abrasion resisting } \\
\text { Total }\end{array}$ & $\begin{array}{r}84 \\
410 \\
337 \\
831\end{array}$ & $\begin{array}{l}8.4 \\
0.4 \\
1.7 \\
10.5\end{array}$ & $\begin{array}{l}8.4 \\
2.5 \\
1.7 \\
12.6\end{array}$ & $\begin{array}{r}16.8 \\
2.9 \\
3.4 \\
23.1\end{array}$ \\
\hline
\end{tabular}

NOTE: Chromium content of alloy groups is as follows:

\begin{tabular}{llcc}
\hline & $\begin{array}{l}\text { Average } \\
\text { \% Chromium } \\
\text { Content }\end{array}$ & $\begin{array}{l}\text { \% Chromium } \\
\text { Contributed } \\
\text { from Scrap }\end{array}$ & $\begin{array}{c}\text { \% Chromium } \\
\text { Additions }\end{array}$ \\
\hline High alloy & 20.0 & 10.0 & 10.0 \\
Low alloy & 0.7 & 0.1 & 0.6 \\
$\begin{array}{l}\text { Abrasion } \\
\text { resisting }\end{array}$ & 1.0 & 0.5 & 0.5 \\
\hline
\end{tabular}

a specific chromium contents are assumed to remain constant.

b Estimates of total chromium consumption do not include estimated 10-15 percent loss occurring during melting. This estimated loss would normally be compensated for under the chromium addition column.

c Modest decline of 4.7 percent is projected for 1975 production of alloy castings.

d Growth projections for total alloy steel assume 4.0 percent increase in 1976 , followed by 3.6 percent through 1980 . 
TABLE 40 Chromium Consumption in Alloy Cast Irons $(1,000$ tons)

\begin{tabular}{|c|c|c|c|c|}
\hline \multirow[b]{2}{*}{ Year } & \multirow[b]{2}{*}{ Product } & \multicolumn{3}{|c|}{ Chromium Consumption } \\
\hline & & From Scrap & New & Total \\
\hline \multirow[t]{4}{*}{1974} & Rolls & 1.4 & 0.5 & 1.9 \\
\hline & Abrasion resisting & 1.0 & 8.8 & 9.8 \\
\hline & Engineering castings & 4.8 & 4.8 & 9.6 \\
\hline & Total & $\overline{7.2}$ & $\overline{14.1}$ & $\overline{21.3}$ \\
\hline \multirow[t]{4}{*}{1975} & Rolls & 1.5 & 0.5 & 2.0 \\
\hline & Abrásion resisting & 1.0 & 9.1 & 10.1 \\
\hline & Engineering castings & 3.9 & 3.9 & 7.8 \\
\hline & Total & $\overline{6.4}$ & $\overline{13.5}$ & $\overline{19.9}$ \\
\hline \multirow{4}{*}{1976} & Rolls & 2.0 & 0.7 & 2.7 \\
\hline & Abrasion resisting & 1.0 & 9.4 & 10.4 \\
\hline & Engineering castings & 4.7 & 4.7 & 9.4 \\
\hline & Total & 7.7 & $\overline{14.8}$ & $\overline{22.5}$ \\
\hline \multirow[t]{4}{*}{1977} & Rolls & 2.9 & $1.0^{\circ}$ & 3.9 \\
\hline & Abrasion resisting & 1.1 & 9.8 & 10.9 \\
\hline & Engineering castings & 5.4 & 5.4 & 10.8 \\
\hline & Total & $\overline{9.4}$ & $\overline{16.2}$ & $\overline{25.6}$ \\
\hline \multirow[t]{4}{*}{1978} & Rolls & 3.8 & 1.3 & 5.1 \\
\hline & Abrasion resisting & 1.1 & 10.1 & 11.2 \\
\hline & Engineering castings & 6.0 & 6.0 & 12.0 \\
\hline & Total & $\overline{10.9}$ & $\overline{17.4}$ & $\overline{28.3}$ \\
\hline \multirow[t]{4}{*}{1979} & Rolls & 4.6 & 1.5 & 6.1 \\
\hline & Abrasion resisting & 1.2 & 10.6 & 11.8 \\
\hline & Engineering castings & 6.1 & 6.1 & 12.2 \\
\hline & Total & 11.9 & 18.2 & 30.1 \\
\hline
\end{tabular}


supplying the mining industry since they have both iron and steel casting facilities. Alloy combinations of manganese. boron, tellurium, molybdenum, and tungsten could be considered as replacements for chromium; however, no prior technology has been developed for such a change.

In the production of cylinder heads or blocks, alloys containing tin. copper, and molybdenum have been acceptable substitutes for chromium. The present trend is toward irons with less or no chromium for use in many engineering castings in section sizes of 2 inches or less. This trend should continue as the advantages of Cu-Mo or $\mathrm{sn-Mo}$ irons become more widely known.

The chromium demand and substitutability in cast alloy iron and steel are summarized in Table 41.

\subsection{Substitute Materials}

From this analysis it is apparent that numerous opportunities exist for substituting other alloying elements for chromium in wrought and cast alloy steels and cast irons. For the most part, this substitution can be accomplished with little research and would cause no detrimental effects on properties or processing. Tables 40 and 41 present tabular summaries of the chromium demand. suggested alternate materials, and estimates of the chromium that can be saved using these alternates.

\subsubsection{Substitutability of Chromium in Nonferrous Alloys}

Chromium is an important and widely used alloying element in nonferrous alloys, and chromium-containing compositions are found in virtually all major families of nonferrous alloys. Six alloy families are considered in this report -- i.e.. those based on nickel, iron-nickel. cobalt, aluminum, titanium, and copper. Although the metallurgical role of chromium is somewhat different in each family, one important distinction can be used to separate the alloys into two groups. In alloys of nickel, ironnickel and cobalt, chromium is used primarily to confer corrosion and oxidation resistance and, as a rule, no adequate substitutes are available for chromium in these alloys. In alloys of aluminum, titanium and copper. chromium is used primarily to control microstructure and improve physical and mechanical properties, and substitutes are readily available for chromium in these alloys. 
TABLE 41 Chromium Derrand and Substitutability in Cast Alloy Iron and Steels

\begin{tabular}{|c|c|c|c|c|c|c|c|c|c|c|c|}
\hline \multirow{3}{*}{$\begin{array}{l}\text { Current } \\
\text { Material }\end{array}$} & \multirow[b]{3}{*}{$\begin{array}{l}\text { Material } \\
\text { Application }\end{array}$} & \multirow[b]{3}{*}{$\begin{array}{l}\text { Contained } \\
\text { Chromium, } \\
\%\end{array}$} & \multirow{3}{*}{$\begin{array}{l}\text { Chromium } \\
\text { Demand } \\
\text { (million } \\
\text { pounds) }\end{array}$} & \multirow{3}{*}{$\begin{array}{l}\text { Role of } \\
\text { Chromium }\end{array}$} & \multicolumn{4}{|c|}{ Available Alternate Materials } & \multirow{2}{*}{\multicolumn{3}{|c|}{ Required New Technology }} \\
\hline & & & & & & & Chromium & & & & \\
\hline & & & & & $\begin{array}{l}\text { Substitute } \\
\text { Materials }\end{array}$ & $\begin{array}{l}\text { Contained } \\
\text { Chiromium, } \\
\%\end{array}$ & $\begin{array}{l}\text { Saved } \\
\text { (million } \\
\text { pounds) }\end{array}$ & $\begin{array}{l}\text { Property } \\
\text { Deficiencies }\end{array}$ & $\begin{array}{l}\text { Research } \\
\text { Needed }\end{array}$ & $\begin{array}{l}\text { Priority of } \\
\text { Resear:h }\end{array}$ & $\begin{array}{l}\text { Probability of } \\
\text { Research } \\
\text { Success }\end{array}$ \\
\hline $\begin{array}{l}\text { Low alloy steel } \\
\text { e.g., } 8600 \text {, } \\
4100,5100\end{array}$ & $\begin{array}{l}\text { Shafts, } \\
\text { bearings }\end{array}$ & $0.5 / 1.00$ & 5 & $\begin{array}{l}\text { Harden- } \\
\text { ability }\end{array}$ & $\begin{array}{l}\text { Same as } \\
\text { shown for } \\
\text { wrought al- } \\
\text { loy steels }\end{array}$ & 0 & 5 & Cost & None & None & High \\
\hline $\begin{array}{l}\text { High alloy } \\
\text { steels, e.g., } \\
\text { stainless and } \\
\text { heat } \\
\text { resistant }\end{array}$ & $\begin{array}{l}\text { Industrial } \\
\text { machinery and } \\
\text { equipment } \\
\text { and engines }\end{array}$ & $0.5 / 30$ & 28 & $\begin{array}{l}\text { Corrosion } \\
\text { resistance }\end{array}$ & $\begin{array}{l}\text { Refer to } \\
\text { recommen- } \\
\text { dations } \\
\text { made by } \\
\text { wrought } \\
\text { stainless } \\
\text { committee }\end{array}$ & & $?^{*}$ & & $\begin{array}{l}\text { Much basic } \\
\text { research }\end{array}$ & High & Low \\
\hline $\begin{array}{l}\text { Abrasion } \\
\text { resistant } \\
\text { steels }\end{array}$ & $\begin{array}{l}\text { Transportation } \\
\text { and machinery }\end{array}$ & $0.5 / 1.0$ & 5 & $\begin{array}{l}\text { Abrasion } \\
\text { resistance, } \\
\text { hardness } \\
\text { and } \\
\text { toughness. }\end{array}$ & $\begin{array}{l}\mathrm{Mn}, \mathrm{Ni}, \mathrm{Mo} \\
\text { and } \mathrm{B} \text { com- } \\
\text { positions }\end{array}$ & 0 & 5 & Cost & $\begin{array}{l}\text { Alloy } \\
\text { development }\end{array}$ & Low & High \\
\hline $\begin{array}{l}\text { Engineering } \\
\text { cast irons }\end{array}$ & $\begin{array}{l}\text { Transportation } \\
\text { equipment }\end{array}$ & $0.5 / 2.0$ & 20 & $\begin{array}{l}\text { Wear } \\
\text { resistance, } \\
\text { strength, } \\
\text { and di- } \\
\text { mensional } \\
\text { stability }\end{array}$ & $\begin{array}{l}\text { Ni-Hard } 4 \\
\text { or Ni-Hard } \\
2\end{array}$ & 0 & 20 & $\begin{array}{l}\text { Wear } \\
\text { resistance, } \\
\text { machinability } \\
\text { and cost }\end{array}$ & $\begin{array}{l}\text { Improve } \\
\text { jrocess tech- } \\
\text { zology, wear } \\
\text { zesistance and } \\
\text { machinability }\end{array}$ & Low & High \\
\hline $\begin{array}{l}\text { Abrasion re- } \\
\text { sistant cast } \\
\text { iron }\end{array}$ & $\begin{array}{l}\text { Machinery } \\
\text { equipment }\end{array}$ & $15 / 28$ & 20 & $\begin{array}{l}\text { Abrasion } \\
\text { and impact } \\
\text { resistance }\end{array}$ & $\begin{array}{l}\mathrm{Ni}-\mathrm{Hard} \\
\text { alloy }\end{array}$ & 2 to 8 & 7 to 26 & $\begin{array}{l}\text { Impact re- } \\
\text { sistance, } \\
\text { abrasion } \\
\text { resistance } \\
\text { and cost }\end{array}$ & $\begin{array}{l}\text { Improve } \\
\text { process tech- } \\
\text { nology and } \\
\text { impact } \\
\text { resistance }\end{array}$ & $\begin{array}{c}\text { Low } \\
. \\
.\end{array}$ & High \\
\hline Rolls & $\begin{array}{l}\text { Steel mill } \\
\text { equipment }\end{array}$ & $1.5 / 2.0$ & 4 & & $\begin{array}{l}\text { Spheroidal } \\
\text { graphitic } \\
\text { irons }\end{array}$ & 0 & 4 & $\begin{array}{l}\text { Roll } \\
\text { performance } \\
. .\end{array}$ & . & Medium & Medium \\
\hline TOTAL & & & 82 & & & & 41 to 60 & & & & \\
\hline
\end{tabular}

*No estimate made for high alloy steels. 


\subsubsection{Iron-Nickel-Base Alloys Including Nickel-Base Al loys other than Superalloys}

This alloy category spans a broad class of materials ranging from iron-rich to nickel-rich compositions and includes both solid-solution and age-hardening alloy types. These alloys typically contain 15 to 25 percent chromium and are used in a wide variety of applications requiring corrosion or oxidation resistance at temperatures ranging from ambient up to $2000 \mathrm{oF}$. Chromium is essential for adequate corrosion resistance.

Present annual consumption of chromium (in the form of ferrochromium) in the Fe-Ni-base alloys is estimated at 18 million pounds, which is by far the largest of the nonferrous alloy classes considered in this study. No reliable estimates of growth in the U.S. demand for the Fe$\mathrm{Ni}$-base alloys were found but, considering the anticipated increase in use of high-nickel alloys by the nuclear power industry, the demand for chromium in this class of alloys probably will increase.

For some applications, titanium or titanium-base alloys probably could replace the iron-nickel alloys although the cost penalties might be inhibiting. Coatings or claddings also might be suitable alternates in some cases and ceramic materials (e.g...Sic) might be used successfully for heating element applications. New alloys (with increased amounts of aluminum, titanium, molybdenum, silicon, etc.,) that do not rely on the formation of a protective chromium-rich oxide film for their corrosion and oxidation resistance possibly could be developed; however, in a number of applications (e.g.. nuclear reactor components), extensive and lengthy test programs would be required before a substitute material could be accepted. Furthermore, the broad spectrum of service conditions to which these alloys are exposed requires substitute alloys or coatings that perform adequately in many different environments. Thus, many different alternative materials probably must be employed, greatly complicating materials selection. In the near future, only limited substitution apparently could be accomplished and, for most applications, it would be very difficult to effect any significant reduction in chromium consumption.

\subsubsection{Nicke1-Base Superalloys}

Nickel-base superalloys are used principally in gas turbine engines. Many commercial alloys contain, and rely on, chromium to provide at least part of the necessary hot corrosion resistance. At present, the trend in nickel-base superalloy development is towards alloys with higher 
chromium contents so as to better withstand hot corrosion. This trend is dictated by the desire to burn lower grade fuels that increase corrosive attack and to prolong the operating times between engine overhauls. Consequently. current chromium consumption of about 7 million pounds per year (as shromium metal) may increase at a rate more rapid than the 8 percent annual growth rate projected for nickelbase superalloys during the next decade (Stanford Research Institute 1972).

Two potential routes for reducing chromium consumption in nickel-base superalloys are substitution by coated superalloys with lower chromium contents and by ceramics. At the present state of development, both of these substitution routes involve unacceptable performance penalties.

Considerable coating development work has been done in the past, and aluminum-rich coatings now are applied commonly to turbine blades to improve resistance to oxidation and sulfidation attack. However, coatings tend to deteriorate during service and the underlying alloy must resist the corrosive attack or be replaced quickly. Thus, while available coatings can prolong the service lives of alloys having adequate intrinsic resistance to degradation in the service environment, coatings cannot be used safely to remedy a major basic deficiency of the substrate material. To satisfactorily protect materials that lack adequate intrinsic oxidation or corrosion resistance, the coatings must possess self-healing characteristics. Unfortunately, to date, no completely satisfactory coating has emerged. In view of the extensive research and development effort already expended in this area, the probability of success is considered low. If presently available coatings were used on alloys with very low chromium contents, the service lives of the various engine components would be impaired significantly. Frequent replacement of the corroded parts to keep the engines in service is a theoretical possibility but is an impractical or uneconomical solution to the problem.

Ceramic materials, paxticularly $\mathrm{SiC}$ and $\mathrm{Si}_{3} \mathrm{~N}_{4}$, have been promoted widely as potential substitutes for superalloys in gas turbines capable of operating at substantially higher inlet temperatures. Hot-pressed $\mathrm{si}_{3} \mathrm{~N}_{4}$ is probably the most advanced material in terms of overall properties. Current grades of this material (e.g.. HS130 and NC132) combine exceptional resistance to oxidation and hot corrosion with good thermal shock resistance and adequate high-temperature creep strength. However, these and other ceramics exhibit very low fracture resistance in comparison to superalloys (e.g.. the plane strain fracture 
toughness of HS130 is more than an order of magnitude less than that of the cast superalloy IN738IC). At present, the problems of using brittle materials in tensile load-bearing components are far from solved. Moreover, the methods used to fabricate $\mathrm{SiC}$ and $\mathrm{Si}_{3} \mathrm{~N}_{4}$ components are slow and expensive. Although ceramics eventually may compete with nickel-base superalloys in gas turbine applications. significant substitution is certainly not possible at present.

\subsubsection{Cobalt-Base Alloys}

Cobalt-base alloys are used in gas turbines and in a number of industrial applications. Current consumption of chromium (predominantly in the form of chromium metal) in these alloys is estimated at 2 million pounds per year, and chromium consumption is expected to grow at an 8 percent annual rate during the next 10 years (Stanford Research Institute 1972).

The situation with respect to the jet engine uses of cobalt-base alloys is much the same as for the nickel-base superalloys. Here again. chromium is essential for hot corrosion resistance, and the potential substitutes are ceramics or coated products. but no fully satisfactory substitutes are available. The performance deficiencies of ceramics and coatings described above are equally important here, and the near-term reduction of chromium consumption would involve unacceptable performance penalties. If adequate coatings become available. low-chromium or chromium-free alloys must be developed. Although such a development appears feasible, achieving improvements in properties is less certain than in the case of the nickelbase alloys. In some industrial applications, cobalt-base alloys might be replaced by titanium or titanium-base alloys but, for most applications; no adequate substitute presently exists for this use of chromium.

\section{2 .2 .4 Aluminum-Base Alloys}

Chromium is used as a minor alloying addition (typically 0.1 to 0.3 percent) in many of the 5000,6000, and 7000 series alloys. These high-performance wrought alloys are used in space vehicles, aircraft, marine craft, and surface vehicles in a variety of load-bearing applications. U.S. consumption of chromium as metal in aluminum alloys for 1975 is estimated at 1.5 million pounds. Industry sources project a chromium demand of 2 million pounds for 1980, which represents an annual growth rate of approximately 6 percent. 
The chromium alloying additions in aluminum alloys control recrystallization behavior and help achieve consistent product performance. In the 7000 series. chromium also improves resistance to stress corrosion cracking. Zirconium and manganese produce effects that are similar to those produced by chromium, and replacement of the alloys containing chromium with chromium-free grades is possible in many applications; however the slight performance penalties involved could be important in some critical structural uses. Some research and development work therefore would be desirable to optimize the chromiumfree alloys. Also of some concern are the lead time and expense involved in materials substitution in applications, such as aircraft structures, for which the replacement material must be qualified before it would be acceptable. However, in the event of a cessation of chromium supply, the use of chromium in aluminum alloys could be reduced substantially or possibly eliminated without incurring major penalties.

\subsubsection{Titanium-Base Alloys}

Chromium is used as an alloying addition in several commercially available titanium alloys including the venerable 13-11-3 beta-alloy (11 percent chromium), the 6-2-2-2-2 alpha-beta alioy (2 percent chromium) and 3-8-6-4-4- $(\beta-C)$ beta-alloy (6 percent chromium). In addition. General Electric recently announced a new alloy called Ti-17 that contains 4 percent chromium. As yet, none of the chromium-containing titanium alloys has captured a major application successfully. Consequently, the $1975 \mathrm{U}$.S. consumption of chromium as metal in titanium alloys was very smal1. perhaps even less than the Committee estimate of 50.000 pounds. Demand for chromium could increase significantly if the $\mathrm{Ti}-17$ alloy captures a significant fraction of the market for aircraft gas turbine engine compressor and fan disks, as seems possible at present. However, even with the most optimistic assumptions, the consumption of chromium in titanium alloys is unlikely to reach 100,000 pounds by 1980 .

Chromiua alluying additions stabilize the beta (high temperature) allotrope of titanium. Several other alloying elements, notably molybdenum and vanadium, produce similar effects and frequently are used instead of, or in combination with, chromium. Therefore, chromium-free alloys are available that have similar, although not identical, characteristics to those of the chromium-containing grades. Accordingly, in most instances, chromium demand could be reduced by alloy substitution combined with a slight redesign. The Ti-17 alloy is a possible exception to this general conclusion, and a considerable lead time would be 
required to replace it, if it finds widespread use in jet engines, because of the necessity for qualifying the substitute material.

\section{2 .2 .6 , Copper-Base Alloys}

A very minor amount of chromium metal, about 10,000 pounds per year, is consumed in copper-base alloys. Chromium additions of about 1 percent produce useful strengthening effects in copper alloys, but chromiumcontaining alloys do not exhibit particularly unique property combinations. Apparently, chromium-free grades could be substituted in most applications without significant penalties in either cost or performance.

\subsubsection{Substitute Materials}

Table 42 presents a. summary of current U.S. demand of chromium in nonferrous alloys, outlines the major substitution possibilities, and identifies research and development needs: Since the quantity of chromium used in nonferrous alloys is relatively small, only a moderate priority should be assigned to research and development of potentially promising substitutes. Areas of major emphasis should include the development of superior coatings, the further development of engineering ceramics and hightemperature composite materials, and additional work on the refractory metals.

\section{2 .3 Ceramic Products}

6.2.3.1 Chromite Uses (Brick, Gunning, and Ramming Mixes, and Chromite_sands)

Chromite in the mineral spinel form is used mostly in basic refractories. Such chromite-bearing refractories essentially range from all chromite to various mixtures of chromite and magnesia. They are designated as chrome (essentially all chromite). chrome magnesite (with chromite equal to or greater than weight percent magnesitel, and magnesite chrome (with greater than 50 weight percent magnesite) to distinguish them from chrome-free basic refractories (American Society for Testing and Materials 1975).

Refractories are supplied as granular material or shaped brick. The former consists essentially of chromite granules with minor additives and is supplied in formulations for mortars, ramming, or gunning mixes. Chromite in large amounts is used in formulations for gunning maintenance of in-use basic refractories structures 
(e.g.. open hearth roofs and sidewalls, and electric furnace sidewalls).

The brick may be bonded chemically (unburned) , burned. or fusion cast. Currently, the average content of such brick is about 55 percent magnesia and 45 percent chromite (about 15 to 18 percent $\mathrm{Cr}_{2} \mathrm{O}_{3}$ dependent on chrome ore source) (Mikami 1975). Chromite imparts thermal shock and slag resistance, volume stability, and structural strength. For chemically bonded and conventionally burned brick, only massive (nonfriable) refractory grade chromite ores

(Philippine and Cuban) are used to provide the requisite coarse sizing of the chromite content of the brick. For chemically bonded brick, such ore is still preferred. With the advent of high-temperature firing to effect bonding of Mgo to Mgo and chromite to produce "direct bonded" brick. the use of chromite ore concentrates or fines, formerly used in granular refractory products, has increased. Concurrently, the use of chemical grade ores (Transvaal. Turkish, etc.) and, in isolated instances, chromia has increased in preference to refractory grade (Philippine) chromite ores for the most technically advanced brick compositions.

To gain insight on the production and usage trends of chrome-bearing refractories, a questionnaire was sent to the 10 major domestic basic refractories producers. This survey was conducted with the cooperation, and under the auspices, of The Refractories Institute and is summarized below in a manner that does not identify the replies of individual producers. Of the 10 suppliers, 9 responded and account for over 94 percent of American production and shipment of chrome-bearing refractories.

The survey revealed that the steel industry is the predominant consumer of chrome-bearing refractories (over 85 percent). The major usage is in the open hearth (OH) furnace, the electric furnace (EF), and the new vacuum oxygen decarburizing (VOD) and argon oxygen decarburizing (AOD) processes. Minor amounts are used in the slag line area of soaking pit bottoms and reheating furnace bottoms. Virtually no chrome-bearing refractories are used in the basic oxygen furnace (BOF) process.

In 1960, a pronounced shift from the OH to the BOF process for steelmaking began. By 1969, equal tonnages of steel were made by both processes and, by 1974, the BOF process produced 2.3 times more steel than the $O H$ process. Because of this swing to the BOF process, projections in 1968 (Miska) and in 1970 (National Materials Advisory Board) indicated a 4 percent per year reduction in steel plant usage of chrome-bearing refractories. Obviously. what was 
TABLE 42 Chromium Demand and Substitutability in Nonferrous Alloys'

\begin{tabular}{|c|c|c|c|c|c|c|c|c|c|c|c|}
\hline \multirow[b]{2}{*}{$\begin{array}{l}\text { Current } \\
\text { Material } \\
\end{array}$} & \multirow[b]{2}{*}{$\begin{array}{l}\text { Material } \\
\text { Application }\end{array}$} & \multirow[b]{2}{*}{$\begin{array}{l}\text { Contained } \\
\text { Chromium } \\
\text { (\%) }\end{array}$} & \multirow{2}{*}{$\begin{array}{l}\text { Chromium } \\
\text { Demand } \\
\text { (millions } \\
\text { of pounds) }\end{array}$} & \multirow[b]{2}{*}{$\begin{array}{l}\text { Role of } \\
\text { Chromium }\end{array}$} & \multicolumn{4}{|c|}{ Available Alternative Materials } & \multicolumn{2}{|c|}{ Required New Technology } & \multirow[b]{2}{*}{ Remarks } \\
\hline & & & & & $\begin{array}{l}\text { Avaubble A } \\
\text { Substitute } \\
\text { MGterials }\end{array}$ & $\begin{array}{l}\text { Contained } \\
\text { Chromium }\end{array}$ & $\begin{array}{l}\text { Ilals } \\
\text { Chromium } \\
\text { Savings }\end{array}$ & $\begin{array}{l}\text { Property } \\
\text { Deficiencies }\end{array}$ & $\begin{array}{l}\text { Research } \\
\text { Needed }\end{array}$ & $\begin{array}{l}\text { Probability } \\
\text { of Research } \\
\text { Success }\end{array}$ & \\
\hline $\begin{array}{l}\text { Fè-Ni and } \mathrm{Ni}- \\
\text { base alloys } \\
\text { except } \\
\text { super-alloys. }\end{array}$ & $\begin{array}{l}\text { Nuclear reac- } \\
\text { tors, chemical } \\
\text { plants, heat } \\
\text { treating } \\
\text { hardware }\end{array}$ & 15 to 25 & 18. & $\begin{array}{l}\text { Oxidation } \\
\text { and corro- } \\
\text { sion resis- } \\
\text { tance }\end{array}$ & $\begin{array}{l}\text { None in } \\
\text { most } \\
\text { cases }\end{array}$ & - & $\begin{array}{l}80 \text { to } 100 \% \\
\text { of con- } \\
\text { tained } \mathrm{Cr} \\
\text { in applica- } \\
\text { tions where } \\
\text { substitution } \\
\text { is possible }\end{array}$ & - & $\begin{array}{l}\text { Coating } \\
\text { develop- } \\
\text { ment } \\
\text { Low Cr } \\
\text { alloys }\end{array}$ & $\begin{array}{l}\text { Medium } \\
\text { High }\end{array}$ & $\begin{array}{l}\text { Coated and clad materials, } \\
\text { ceramics and Ti-alloys can } \\
\text { be used in a few applica- } \\
\text { tions (probably <20\% of } \\
\text { total). Use of alternates in } \\
\text { other applications would } \\
\text { involve unacceptable per- } \\
\text { formance and/or cost pen- } \\
\text { alties. Ferrochromium is } \\
\text { the required melt stock } \\
\text { with.present trend towards } \\
\text { high-C ferrochromium. }\end{array}$ \\
\hline $\begin{array}{l}\text { Ni-base } \\
\text { superalloys }\end{array}$ & Gas turbines' & 15 & 7 & $\begin{array}{l}\text { Oxidation } \\
\text { and cor- } \\
\text { rosion } \\
\text { resistance } \\
\end{array}$ & None & - & None & - & $\begin{array}{l}\text { Coating } \\
\text { develop- } \\
\text { ment } \\
\text { Low-Cr } \\
\text { super- } \\
\text { alloys }\end{array}$ & High & $\begin{array}{l}\text { Strategically essential appli- } \\
\text { cation with no immediate } \\
\text { substitution possibilities. } \\
\text { Electrolytic grade chro- } \\
\text { mium metal is required } \\
\text { melt stock. }\end{array}$ \\
\hline & & & & & & & & & Ceramics & Medium/Low & \\
\hline
\end{tabular}




\begin{tabular}{|c|c|c|c|c|c|c|c|c|c|c|c|}
\hline $\begin{array}{l}\text { Co-base } \\
\text { alloys }\end{array}$ & \multirow[t]{2}{*}{$\begin{array}{l}\text { Gas turbines, } \\
\text { chemical } \\
\text { :plants }\end{array}$} & \multirow[t]{2}{*}{17} & \multirow[t]{2}{*}{2} & \multirow[t]{2}{*}{$\begin{array}{l}\text { Oxidation } \\
\text { and cor- } \\
\text { rosion } \\
\text { resistance }\end{array}$} & \multirow[t]{2}{*}{ None } & \multirow[t]{2}{*}{-} & \multirow[t]{2}{*}{ None } & \multirow[t]{2}{*}{-} & $\begin{array}{l}\text { Coating } \\
\text { develop- } \\
\text { ment } \\
\text { Low } C_{\text {I }} \\
\text { alloys }\end{array}$ & $\begin{array}{l}\text { Low } \\
\text { High } \\
\text {. }\end{array}$ & \multirow[t]{2}{*}{$\begin{array}{l}\text { Strategically ess jpli- } \\
\text { cation with no immediate } \\
\text { substitution possibilities. } \\
\text { Electrolytic grade chro- } \\
\text { mium metal melt stock is } \\
\text { required for most alloys. }\end{array}$} \\
\hline . & & & & & & & & & Ceramics & Medium/Low & \\
\hline $\begin{array}{l}\text { Al-base } \\
\text { alloys }\end{array}$ & $\begin{array}{l}\text { Aerospace } \\
\text { and land } \\
\text { vehicle } \\
\text { structures }\end{array}$ & .0 .1 to 0.5 & $1: 5$ & $\begin{array}{l}\text { Micro- } \\
\text { structure } \\
\text { control, } \\
\text { corrosion } \\
\text { resistance }\end{array}$ & $\begin{array}{l}\text { Other } \\
\text { Al-base } \\
\text { alloys }\end{array}$ & None & $\begin{array}{l}100 \% \text { of } \\
\text { Cr now } \\
\text { used }\end{array}$ & $\begin{array}{l}\text { Slightly } \\
\text { less } \\
\text { consistent } \\
\text { properties }\end{array}$ & $\begin{array}{l}\text { Optimiza- } \\
\text { : tion of } C r \\
\text { free alloys }\end{array}$ & High & $\begin{array}{l}\mathrm{Zr} \text { and } \mathrm{Mn} \text { are alternate al- } \\
\text { loying elemen ts. Use of } \\
\text { substitute materials for } \\
\text { some applications could re- } \\
\text { quire qualification testing } \\
\text { involving long lead times } \\
\text { (years) and high.costs } \\
\text { (millions of dollars). }\end{array}$ \\
\hline $\begin{array}{l}\text { Tibbase } \\
\text { alloys }\end{array}$ & $\begin{array}{l}\text { Aerospace } \\
\text {-structures, } \\
\text { :gas turbines }\end{array}$ & 2 to 11 & 0.05 & $\begin{array}{l}\text { Micro- } \\
\text { structure } \\
\text { control } \\
\text { strength }\end{array}$ & $\begin{array}{l}\text { Other } \\
\text { Ti-base } \\
\text { alloys }\end{array}$ & None & $\begin{array}{l}100 \% . \text { of } \\
\text { Cr now } \\
\text { used }\end{array}$ & $\begin{array}{l}\text { Probably } \\
\text { none }\end{array}$ & $\begin{array}{l}\text { Probably } \\
\text { none }\end{array}$ & - & $\begin{array}{l}\text { Mo and V are alternate } c 1- \\
\text { loying elements. Use of } \\
\text { substitute materials for } \\
\text { some applications could re- } \\
\text { quire qualification testing } \\
\text { involving long lead times } \\
\text { (years) and high costs } \\
\text { (millions of dollars). }\end{array}$ \\
\hline $\begin{array}{l}\text { Cuibase } \\
\text { alloys }\end{array}$ & $\begin{array}{l}\text { Heat } \\
\text { resistant } \\
\text { alloys }\end{array}$ & 1 & 0.01 & $\begin{array}{l}\text { Strength- } \\
\text { :ener }\end{array}$ & $\begin{array}{l}\text { Other } \\
\text { Cu-base } \\
\text { alloys }\end{array}$ & $"$ None & $\begin{array}{l}100 \% \text { of } \\
\text { Cr.now } \\
\text { used }\end{array}$ & $\begin{array}{l}\text { Probably } \\
\text { none }\end{array}$ & $\begin{array}{l}\text { Effects of } \\
\text { other } \\
\text { hardeness }\end{array}$ & ..Very:high & $\begin{array}{l}\text { No significant problems are } \\
\text { foreseen in using alternative } \\
\text { materials but Cr consump- } \\
\text { tion is insignificant. }\end{array}$ \\
\hline
\end{tabular}


not foreseen when the projections were made was the increased steel production by the EF and the new VOD and $A O D$ processes that consume significantly larger amounts of chrome-bearing refractories (up to six times more) than the OH process.

As noted in Table 43 , between 1969 and 1974, steel production increased by 3.16 percent from 141.2 to 145.7 million tons. OH production decreased $25.4 \mathrm{million}$ tons, and EF production increased by 8.53 million tons (American Iron and steel Institute 1975). Combining these statistics with those derived from replies to the refractories industry survey (Table 44), it appears that the steel industry increased its consumption of $\mathrm{Cr}_{2} \mathrm{O}_{3}$ in refractories by 4.923 tons, an increase of 3.2 percent approximately matching the 3. 16 percent increase in steel production. More significantly, however, by converting the statistics to pounds of $\mathrm{Cr}_{2} \mathrm{O}_{3}$ consumed per ton of steel produced by the processes using chrome-bearing refractories, an actual increase of 30.3 percent (i.e.. 3.786 pounds/ton in 1969 to 4.935 pounds/ton of $\mathrm{OH}$ and EF steel processed in 1974) is noted. This increase reflects not only the higher consumption by the EF process but also the increased production from such processing. Virtually all of the steel processed in $A O D$ and VOD units is melted first in electric furnaces and is reported as EF steel in the AISI statistics. Most industry projections indicate continued growth for EF steelmaking, which presages an even higher demand for chrome-bearing refractories in the future (unpublished data from Data Resources. Inc. 1976) unless substitute materials are found.

Glass, nonferrous; rotary kilns and all other industries increased their consumption of $\mathrm{Cr}_{2} \mathrm{O}_{3}$ in refractories by 7,925 tons between 1969 and 1974. Aside from increased business activity, this increase (120 percent for rotary kilns, 49 percent for nonferrous, and 27 percent for glass) represents a growing preference for chromebearing refractories over other refractories.

Respondents' estimates of the use of chrome-bearing refractories in the future ranged from the same consumption, to less than a 10 percent decrease. to an increase of 15 to 25 percent, and related consumption to the level of steel production (see above). Granular material producers predict a marked decrease in consumption in the future. Both production statistics and replies show a trend toward use of chromite ores with higher $\mathrm{Cr}_{2} \mathrm{O}_{3}$ and lower $\mathrm{SiO}_{2}$. iron oxide, and $\mathrm{Al}_{2} \mathrm{O}_{3}$ contents. All respondents emphasized lower silica and iron oxide ores as most desirable, and beneficiation of Philippine ores to remove the silica would meet this requirement. The use of chromia $\left(\mathrm{Cr}_{2} \mathrm{O}_{3}\right)$ as an additive to 
TABLE 43 Iron and Steel Industry Consumption of Chromium-Bearing Refractories, 1969 and 1974.

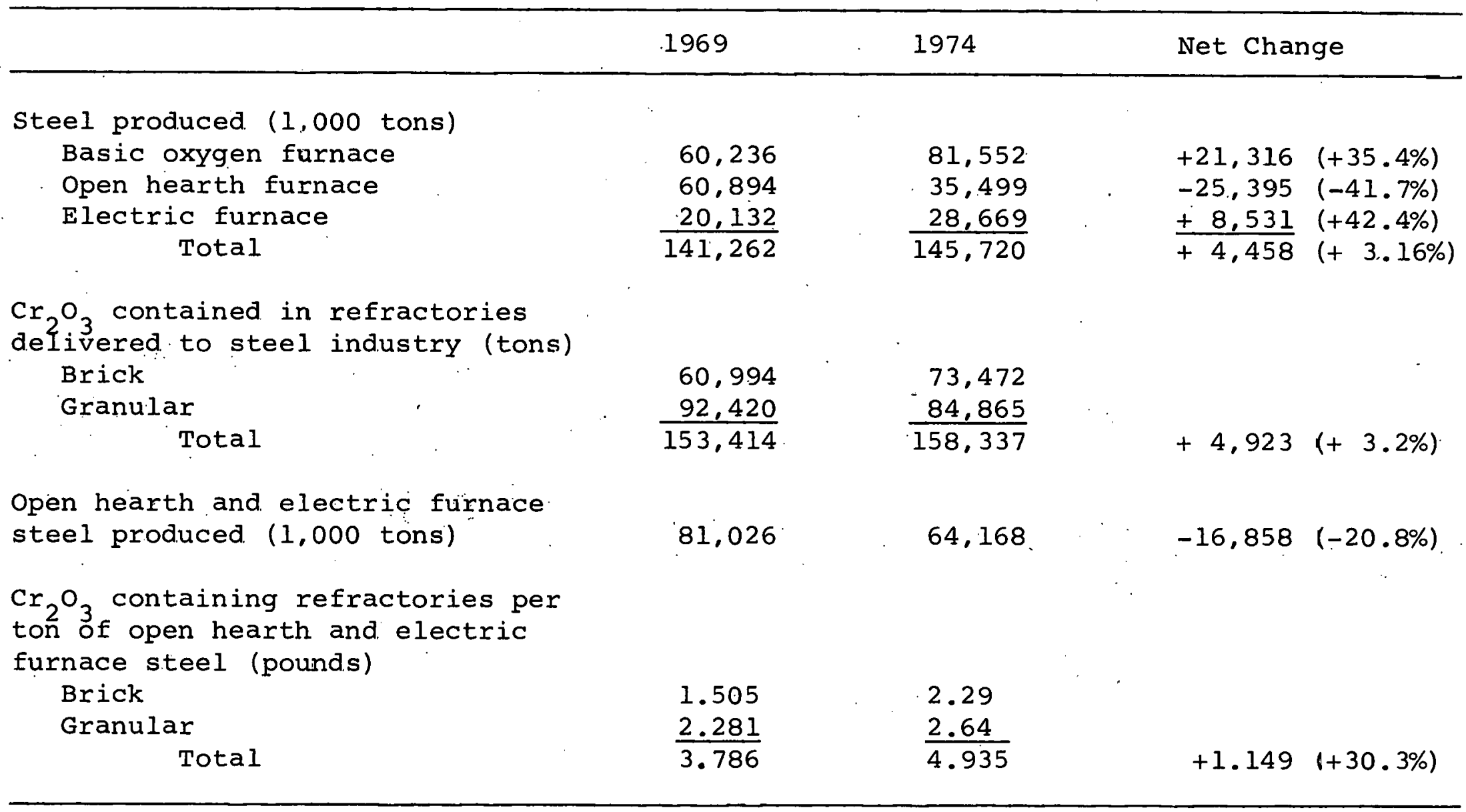

NOTE: Data based on American Iron and Steel Institute 1975 and the replies to the questionnaire distributed by The Refractories Institute in 1976. 
TABLE 44 Summary of Replies to The Refractories Institute Questionnaire on Chrome-Bearing Refractories, April 1976 .

\begin{tabular}{|c|c|c|c|c|c|c|c|c|c|c|c|c|c|}
\hline \multirow[b]{2}{*}{$\begin{array}{l}\text { Industry } \\
\text { Delivered To }\end{array}$} & \multicolumn{6}{|c|}{$1969-\mathrm{Cr}_{2} \mathrm{O}_{3}$ Contained in Refractories } & \multicolumn{6}{|c|}{$1974-\mathrm{Cr}_{2} \mathrm{O}_{3}$ Contained in Refractories } & \multirow{2}{*}{$\begin{array}{l}\text { 1969-1974 } \\
\text { Increase in } \\
\text { Total } \mathrm{Cr}_{2} \mathrm{O}_{3} \\
(\%)\end{array}$} \\
\hline & $\begin{array}{l}\text { Shaped } \\
\text { (tons) }\end{array}$ & $\begin{array}{l}\text { Brick } \\
(\%)\end{array}$ & $\begin{array}{l}\text { Granula } \\
\text { (tons) }\end{array}$ & $\begin{array}{l}\mathrm{r} \frac{\mathrm{a}}{} \\
(\%)\end{array}$ & $\begin{array}{l}\text { Total } \\
\text { (tons) }\end{array}$ & $(\%)$ & $\begin{array}{l}\text { Shaped } \\
\text { (tons) }\end{array}$ & $\begin{array}{l}\text { Brick } \\
(\%)\end{array}$ & $\begin{array}{l}\text { Granula } \\
\text { (tons) }\end{array}$ & $\begin{array}{l}2 \% \bar{a} \\
(\%)\end{array}$ & $\begin{array}{l}\text { Total } \\
\text { (tons) }\end{array}$ & $(\%)$ & \\
\hline Iron and stee $i$ & 60,994 & 81.9 & 92.420 & 97.20 & 153,414 & 90.5 & 73,472 & 78.2 & 84,865 & .96 .0 & 158,337 & 86.8 & 3.2 \\
\hline Glass & 3,866 & 5.2 & 505 & 0.53 & 4,371 & 2.6 & 5,112 & $5: 4$ & 438 & 0.5 & 5,550 & 3.0 & 27.0 \\
\hline Nonferrous & 4.171 & 5.6 & 586 & 0.62 & 4,757 & 2.8 & 6,283 & 6.7 & 803 & 0.9 & 7,086 & 3.9 & 48.9 \\
\hline Rotary kilns & 2,240 & 3.0 & 34 & 0.03 & 2,274 & 1.3 & 4,921 & 5.2 & 102 & 0.1 & 5,023 & 2.8 & 120.9 \\
\hline Other & 3,167 & 4.3 & 1,561 & 1.62 & 4.728 & 2.8 & 3,617 & 4.4 & 2,224 & 2.5 & 6,396 & 3.5 & 35.3 \\
\hline Total reported & 74,438 & 43.9 & 95,106 & 56.1 & 169,594 & 100.0 & 93,960 & 51.5 & 88,432 & 48.5 & $: 182,392$ & 100.0 & \\
\hline
\end{tabular}

NOTE: Data based on replies from 9 companies producing over 94 percent of American chrome-bearing refractories. Survey sponsored by The Refractories Institute, 1976.

a Gunning, ramming, mortars, etc. 
refractories to enhance slag resistance has increased from 150 tons in 1969 to over 400 tons in 1974. Interest is growing in its use in both basic and high alumina refractories.

Historically, chromite ore was priced significantly lower than refractory magnesia (periclase). This fixed the price of basic refractories in direct proportion to the magnesia content and, consequently. lower cost, higher chromium content brick was favored where it would give equal performance. In recent years, the price of chromite ore has been rising to close the gap. For copper convertors and the new $A O D$ and VOD processes, higher chromium compositions reportedly give better performance. In most other applications. substitution of magnesite chromite 170 percent or more $\mathrm{MgO}$ ) for chromite and chromite magnesite can be made at no penalty in performance and minimal increase in initial cost. The extent of such substitution could yield a savings in $\mathrm{Cr}_{2} \mathrm{O}_{3}$ consumption for brick well in excess of 50 percent.

The new $A O D$ and VOD processes consume up to six times more refractories per ton of processed steel than conventional EF processing. Recent experience indicates a growing interest in the use of dolomite refractories for these applications.

Six of the nine respondents to the refractories survey practice some measure of in-house salvage and reuse of chromite. Two respondents stated that they are negotiating for salvage from consumer plants. With favorable cost incentives and a scarcity of chromite, considerable potential exists for salvage and reuse of chromium-bearing brick in all consuming industries. Chromium-bearing bricks in many units are distinctly different and recognizable from chromium-free refractories even after use, and the bricks can be separated by hand and stacked separately for salvage. reprocessing, and reuse. The experience of several steel companies shows that up to 33 percent of the bricks in an original structure can be salvaged by such practice. Wasted $\mathrm{OH}$ roofs and endwalls, EF sidewalls, and $A O D$ and VOD linings fall into this category.

\section{2.3.2 Chromium Carbides and Borides}

Chromium carbides, and to a lesser extent chromium borides, have been developed and marketed as unique refractory materials. The chromium carbide grades are highly resistant to both acids and alkalies -- more so than the more conventional tungsten carbide grades -- and possess good oxidation resistance. These qualities lead to applications such as extrusion dies, valve parts, and seals for food and chemical process equipment, and high- 
temperature bearing races. Excellent wear resistance. coupled with an expansion coefficient close to that of mild steel. makes chromium carbide attractive for dimensional gauges. Chromium borides are used principally as a hardfacing material applied by gas torch fusion of a paste. The amount of chromium used for these refractory compounds is insignificant and, with very few exceptions, nearly comparable performance can be obtained with other hard. corrosion-resisting matérials.

\subsubsection{Chromite and Chromium oxide Grains and Powders}

The two major uses of chromite in granular form are as maintenace gunning mixtures for steelmaking furnaces and as facing sands in steel foundries. Chromium-bearing gunning materials are used mostly for, $O H$ roof and wall and EF wall maintenance. With the swing away from OH to BOF steel processing. the use of such material is decreasing. (8.2 percent between 1969 and 1974) (Table 44). Substitutes for such material include magnesite, dolomite, and salvaged and reprocessed chromite, and chromium-free basic materials.

The steel foundry industry is using in excess of 20.000 tons of chromium as chromite for facing sand. This usage is expanding (Dressel et al. 1976) and became the preferred material when the price and availability of zircon made the use of chromite economical. The preferred chromite must have a low content of low fusing gangue. The high-iron. high-chromite Transvaal ore is used mostly. Such ore responds to gravity or magnetic separation, recovery, and reuse, although recycling is not practiced generally: Substitute materials include zircon. olivine, and silicon sands. Olivine (magnesium ortho-silicate) sands are popular and preferred only for high-manganese steel castings. silica sands still are used primarily as back-up, not as facing sands.

Minimal amounts of chromite and chromium oxide powders are used as colorants in glass and structural clay products. Chromia. green $\mathrm{Cr}_{2} \mathrm{O}_{3}$, is being used increasingly as an additive to enhance the slag resistance of high alumina refractories.

\subsubsection{Material Substitutes}

The largest use of chromium in ceramic products is as chromite in basic steel plant refractories and as facing sands in steel foundries. The onus of reducing the usage of chromite in ceramics by finding suitable substitutes, by salvage, and by reuse falls on the major industrial consumers (i.e.. the steelmaking and steel foundry industries). The data in Table 45 indicate that these 
TABLE 45 World Total Chromium Production Cumulated through 1974 (million tons)

\begin{tabular}{lccc}
\hline Chromium End Usage & Now in Use & Losses & Total \\
\hline Metallurgical & 13 & 13 & 26 \\
Chemical & 1.5 & 6.5 & 8 \\
Refractories & 0.5 & 5.5 & 6 \\
\hline
\end{tabular}


materials are a fruitful source of chromium conservation. Table 46 presents a tabular summary of chromium demand for ceramic products, suggested alternate materials, and estimates of how much chromium could be saved if these alternates were to be used.

\section{2 .4 plated Coatings}

Although chromium plating is an important and highly visible industry, it uses only about 4 percent of the chromium consumed in the United States. Chromium savings in this market would have little impact on the overall availability of chromium (National Materials Advisory Board 1970). Chromium chemicals, used in all chromium plating and other metal finishing operations, are made from chemical grade rather than metallurgical grade ore. Chemical grade ore is only marginally competitive at present, but this is beginning to change (Smith 1976).

Derhaps 60 percent of the chromium consumed in electroplating is used in decorative end uses. 30 percent is used in engineering (hard) chromium plating, and a smaller amount is used in other forms of metal finishing such as chromate conversion coatings and chromic acid anodizing of aluminum. In an emergency, decorative chromium plating could be discontinued with some sacrifices. In automotive bumpers, the chromium plate is, to some extent, functional since it helps to prevent premature rusting. Anodized aluminum or organic-coated bumpers could be used but the chromium savings would be minor since decorative chromium on autos only uses about 600,000 pounds $(0.05$ percent) of the total U.S. coneumption: Except for the bumpers, derorative chromium plating on automobiles is not functional and could be discontinued.

Hard chromium plating is used mainly for its excellent physical properties, hardness, wear resistance, and low coefficient of friction. The only apparent substitute is electroless nickel-phosphorus alloy that is better than hard chromium for wear resistance in certain applications (Tope 1975. Johnson 1976). In addition, its "throwing power" is far superior and it does not degrade the fatigue properties as hard chromium plating sometimes does. This substitution could be considered in appropriate applications if the chromium saving appeared worthwhile. Costs probably would be higher although overall (life cycle) costs might be comparable (Safranek 1974).

Another use for chromium plating is in the manufacture of "tin-free steel" (chromium type) that can replace tinplate in some canning uses and is now in production. According to the AISI, total shipments of tin-free steel in 
1975 were 28.5 million base boxes with a contained chromium content of 164,000 pounds, a relatively insignificant amount (Lamantia 1975). These figures for chromium plating. however, do not accurately represent the demand situation since the total amount of chromic acia sold for this application contains at least 500,000 pounds of chromium (personal communication from A: J. Lowenheim, Consultant, Plainfield, N.J., 1976). Only 15 to 20 percent of the chromic acid used actually ends up on the plate, and a marginally useful saving of chromium could be made by recycling the wasted material. Active research is under way in this area, supported by the existing stiff pollution control regulations.

There is some hope for chromium conservation in the development of plating baths using trivalent chromium compounds in place of chromic acid. The savings would result from the use of less chromic acid spray and effluent rather than from any direct reduction in actual chromium metal on the parts plated. Intensive research has been performed but the outlook seems questionable (Bride 1972, Carter and Christie 1973, Ward and Christie 1971, ward et al: 1971).

Many alloy deposits have been investigated on a laboratory "beaker" scale with some promise for corrosion resistance, hardness, and other properties that approach those of stainless steel. None of these investigations has been carried far enough to indicate their practical possibilities or whether intensive research in this area should be supported. Such research must be undertaken with government funds since the profit motive is minimal (Krohn 1974).

Another use for chromic acid and chromium chemicals in metal treatment is the anodizing of aluminum. Since most aluminum anodizing uses sulfuric acid, chromic acid anodizing is important only to the aircraft industry. Chromium savings in this application would be small, as it would be for other metal treatments and uses of chromic acid and chromates in conversion coatings.

There seems to be little economic incentive to save chromium by eliminating the use of chromic acid or chromates in metal plating, anodizing, and other treatments. zinc plate could be substituted for decorative chromium in a few cases but not, on the whole, satisfactorily. Chromates are used in post-dip processes for brightening zinc. Aluminum coatings can be produced by hot dipping and not by electroplating but they are no more decorative than zinc. Anodized aluminum is used in some automotive hardware as a substitute for chromium-plated parts. Table 47 presents a 
TABLE 46 Alternatives for Ceramic Products

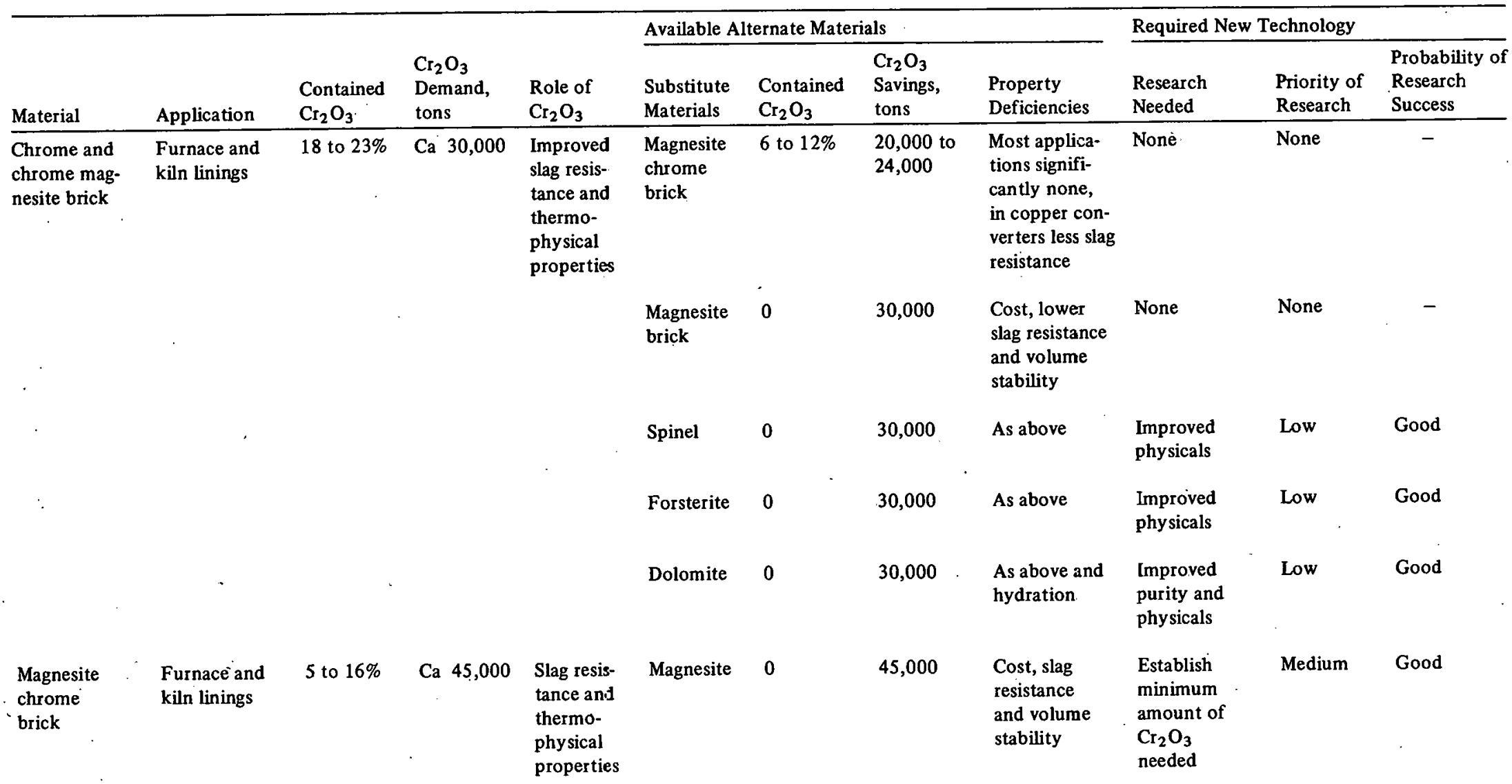




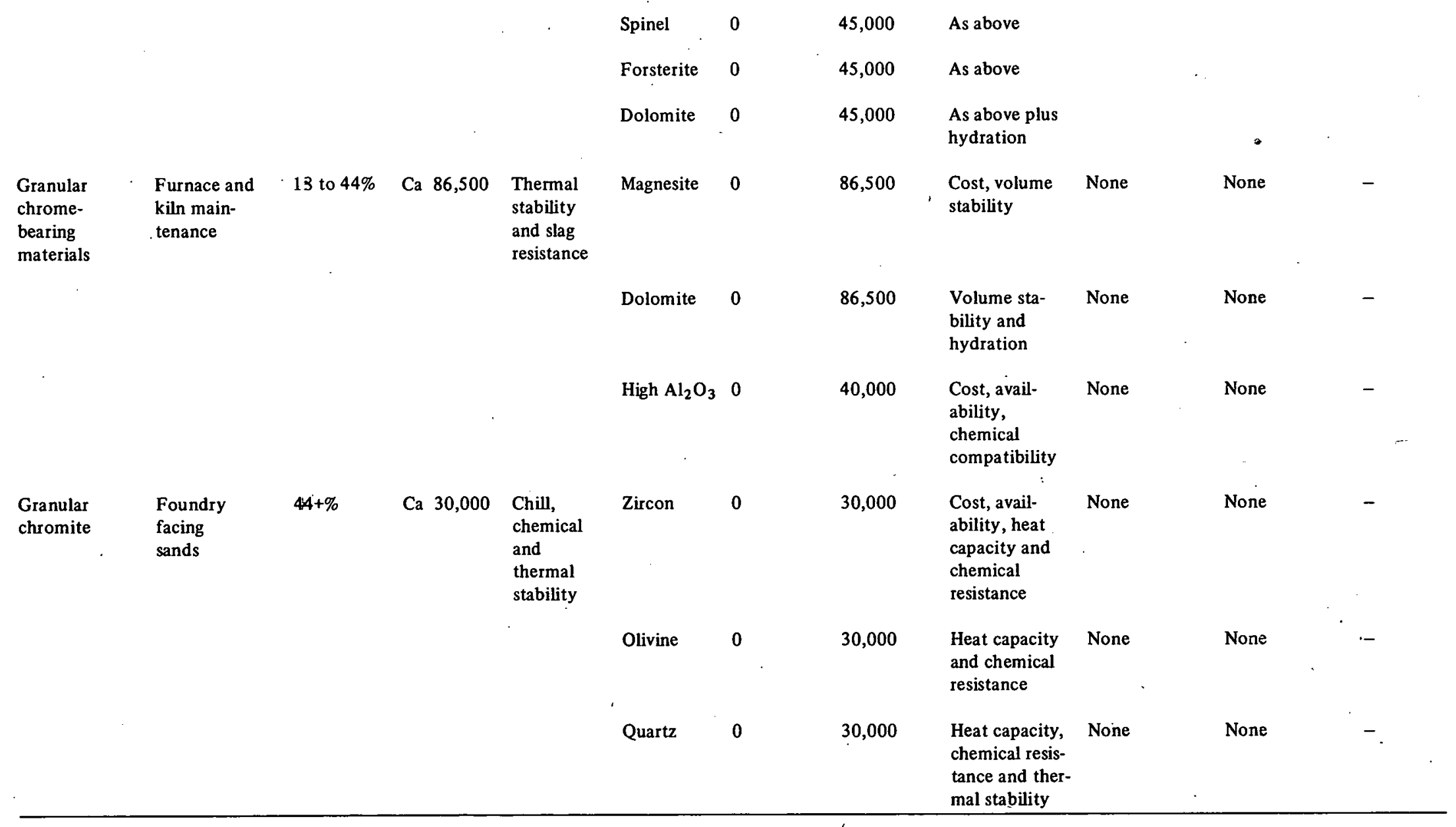


TABLE 47 Chromium in Electroplating Applications

\begin{tabular}{|c|c|c|c|c|c|c|c|c|c|c|c|}
\hline \multirow[b]{3}{*}{$\begin{array}{l}\text { Current } \\
\text { Material }\end{array}$} & \multirow[b]{3}{*}{$\begin{array}{l}\text { Material } \\
\text { Application }\end{array}$} & \multirow[b]{3}{*}{$\begin{array}{l}\text { Contained } \\
\text { Chromium }\end{array}$} & \multirow{3}{*}{$\begin{array}{l}\text { Chromium } \\
\text { Demand } \\
\text { (million } \\
\text { pounds) }\end{array}$} & \multirow[b]{3}{*}{$\begin{array}{l}\text { Role of } \\
\text { Chromium }\end{array}$} & \multicolumn{4}{|c|}{ Available Alternate Materials } & \multirow{2}{*}{\multicolumn{3}{|c|}{ Required New Technology }} \\
\hline & & & & & & & Chromium & & & & \\
\hline & & & & & $\begin{array}{l}\text { Substitute } \\
\text { Material }\end{array}$ & $\begin{array}{l}\text { Contained } \\
\text { Chromium }\end{array}$ & $\begin{array}{l}\text { Savings } \\
\text { (million } \\
\text { pounds) }\end{array}$ & $\begin{array}{l}\text { Property } \\
\text { Deficiencies }\end{array}$ & $\begin{array}{l}\text { Research } \\
\text { Needed } \\
\end{array}$ & Remarks & $\begin{array}{l}\text { Probability of } \\
\text { Research } \\
\text { Success } \\
\end{array}$ \\
\hline \multirow[t]{2}{*}{$\begin{array}{l}\text { Cr Electro- } \\
\text { plate } 10 \text { to } \\
30 \text { micro-in. }\end{array}$} & $\begin{array}{l}\text { Decorative } \\
\text { trim, auto- } \\
\text { motive, } \\
\text { appliances }\end{array}$ & $<0.1 \%$ & 14 & $\begin{array}{l}\text { Reflectiv- } \\
\text { ity, hard- } \\
\text { ness, cor- } \\
\text { rosion re- } \\
\text { sistance }\end{array}$ & $\begin{array}{l}\text { Zn Electro- } \\
\text { plate }\end{array}$ & None & 14 & $\begin{array}{l}\text { Low hardness, } \\
\text { low reflectiv- } \\
\text { ity, high coeff. } \\
\text { friction, low } \\
\text { service temp. }\end{array}$ & None & $\begin{array}{l}\text { Poor sur- } \\
\text { face texture, } \\
\text { not decora- } \\
\text { tive, low } \\
\text { priority }\end{array}$ & . \\
\hline & & & & . & $\begin{array}{l}\text { Cd Electro- } \\
\text { plate }\end{array}$ & None & 14 & $\begin{array}{l}\text { Low hardness, } \\
\text { low reflectivity, } \\
\text { high coeff. fric- } \\
\text { tion, low service } \\
\text { temp., toxic }\end{array}$ & None & $\begin{array}{l}\text { Poor sur- } \\
\text { face texture, } \\
\text { not decora- } \\
\text { tive, high } \\
\text { cost }\end{array}$ & \\
\hline $\begin{array}{l}\text { Cr Electro- } \\
\text { plate } \\
10^{-2} \text { to } \\
10^{-4} \text { in. }\end{array}$ & $\begin{array}{l}\text { "Hard" } \\
\text { chromium } \\
\text { machine } \\
\text { parts }\end{array}$ & $<1 \%$ & 7 & $\begin{array}{l}\text { Hardness } \\
\text { wear re- } \\
\text { sistance, } \\
\text { low coeff. } \\
\text { friction }\end{array}$ & $\begin{array}{l}\text { Electroless } \\
\text { nickel }\end{array}$ & None & 7 & $\begin{array}{l}\text { Higher cost, } \\
\text { slower }\end{array}$ & $\begin{array}{l}\text { Lower cost } \\
\text { chemicals, } \\
\text { faster } \\
\text { processing }\end{array}$ & $\begin{array}{l}\text { May be bet- } \\
\text { ter in wear } \\
\text { resistance } \\
\text { and other } \\
\text { properties }\end{array}$ & High \\
\hline
\end{tabular}


summary of the current demand for chromium in electroplating. lists some possible substitutes, and indicates possible chromium savings that might result from the use of substitutes.

\subsubsection{Chemicals_Conlaining_Chromium}

Historically and today, practically 100 percent of the chemical grade chromite ore is imported from South Africa and shipped through the port of Maputo in Mozambique. Chemical grade chromite ore is roasted with soda ash and lime to convert the $\mathrm{Cr}_{2} \mathrm{O}_{3}$ to $\mathrm{Na}_{2} \mathrm{CrO}_{4}$. The resultant roast is leached with water to extract the water soluble sodium chromate. Sodium chromate then is converted to the principal chromium chemical, sodium dichromate, by acidifying with the sulfuric acid or carbon dioxide. Most chromium chemicals, such as chromic acid, basic chromium sulfate, tanning. compounds and chromium pigments, are made from sodium dichromate (Table 48).

\subsubsection{Pigments and Paints}

Chromium pigments represent the largest outlet for sodium dichromate, and this market has been increasing about 3 percent per year. The main chrome pigments are chrome yellow, molybdenum orange, zinc chromate, chrome green, and chrome oxide green. The primary uses for chromium pigments are for coloring plastics and printing inks. The other large use is in paints for yellow lines on roads, and industrial finishes for automobiles, school buses, appliances, tractors, and heavy equipment. zinc chromate is used mainly as a corrosion inhibitor primer for metals. Chromium pigments are inexpensive in comparison to other proven colored pigments, and in most cases their replacement with proven nonchromium pigments to obtain the same color would involve a price penalty of 300 to 2,000 percent. However, recent very strict recommendations by the National Institute for Occupational safety and Health Administration (NIOSHA) regarding chromium in air could result in no growth in the future and possibly could result in some decrease in their use.

In a chrome shortage, chrome pigments could be eliminated, along with the colors of yellow, orange and red, in over 50 percent of their uses. The chrome pigments could be replaced with pigments such as carbon black, iron oxide, and titanium oxide pigments, but these substitutes would limit the number of colors. 
TABLE 48 U.S. Consumption of Chromium Chemicals

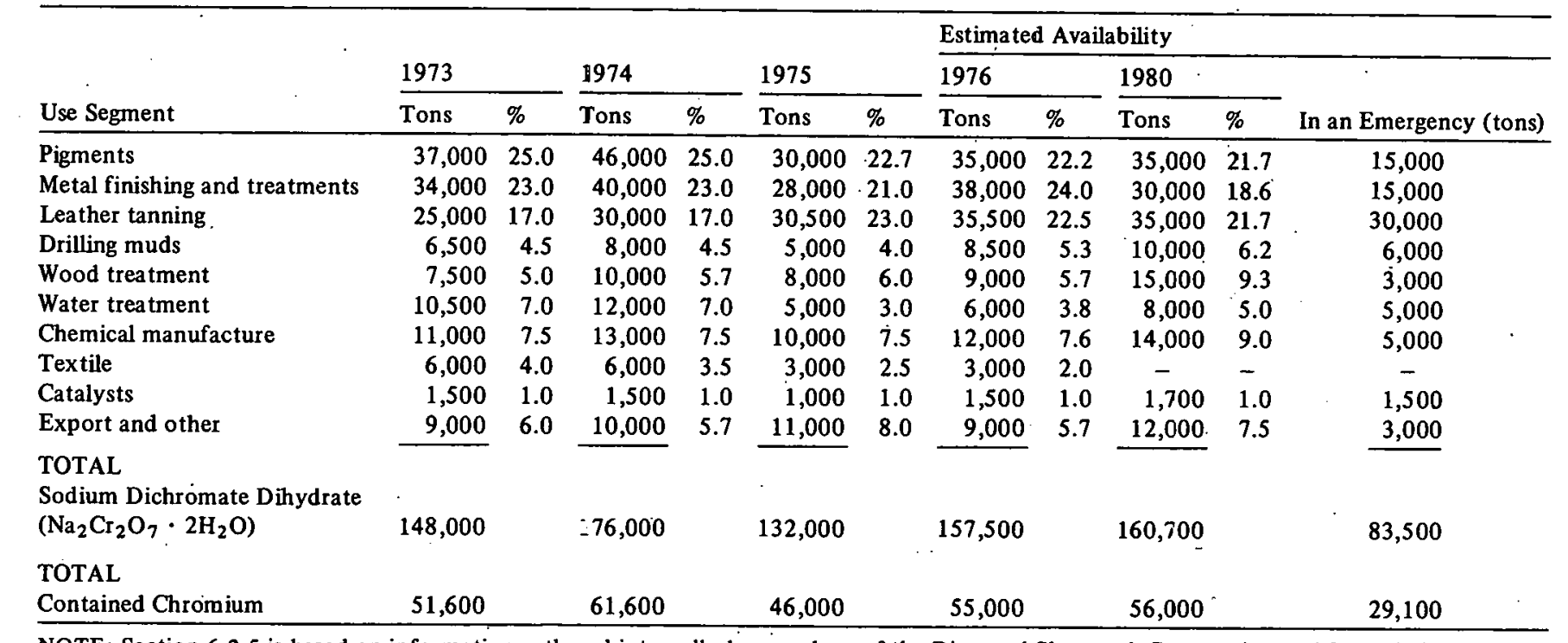

NOTE: Section 6.2 .5 is based on information gathered internally by members of the Diamond Shamrock Corporation and from their contacts with knowledgeable individuals in related industries. 


\subsubsection{Leather Tanning}

Sodium dichromate is used to make chromium compounds that $\tan$ the bulk of the leather produced in the United states. No practical substitute exists for chromium in tanning the majority of this leather without a definite price and performance penalty. The most practical substitutes, vegetable tanning compounds, also are imported completely, and the majority of U.S. tanners do not have the proper equipment to use vegetable tanning compounds in place of chromium. Government regulations will force most tanners to recycle 15 to 20 percent of their present chromium consumption, probably making this area a no-growth market for chromium in the foreseeable future.

In an emergency, it would be very difficult to reduce the use of chromium for tanning leather. Although substitutes, such as plastics. could replace leather in most uses, the problem would be the millions of cattle hides whose only practical use is for leather.

\subsubsection{Metal Finishing and Treatment}

Chromium is used for chromium plating (decorative and engineering) and the treatment of copper, brass, $z$ inc, and cadmium alloys and galvanized steel. This market has grown about 2 percent per year. About 80 percent of the chromium in metal. treatment is for chromium plating. of which over 50 percent is for decorative purposes. No known substitutes exist for chromium chemicals in metal treatments and plating that would not result in a severe performance and cost penalty. Environmental protection Agency (EPA). regulations will result in the recycling of considerable chromium that is used now in decorative chromium plating and lost as.dragout. This chromium recycling should result in reduced chromium demand in the metal treatment field.

In an emergency, considerable chromium could be saved by eliminating most decorative chromium plating. Materials now being plated for decorative purposes either could be painted or made from plastics or other chromium-free materials,

\subsubsection{Drilling Mud_Additives}

Sodium dichromate is used to produce chromium lignosulfonates, an additive to drilling muds. This market is growing about 3 percent per year, and no known satisfactory substitutes exist (especially for drilling deep wells over 10.000 feet). Chromium compounds also are used as a corrosion inhibitor in additives to drilling mud to greatly extend the life of the drilling equipment. In an emergency. 
reducing the use of chromium in this area would not be in the national interest since less exploration for oil and gas. could result.

\subsubsection{Water Treatment Compounds}

Sodium dichromate is used to make water treatment compounds, such as corrosion inhibitors for cooling towers and air conditioners. This market is growing about 10 percent a year and is projected to continue at that rate in the foreseeable future. The largest users are petrochemical and chemical plants and oil refineries. No substitutes have been satisfactory as corrosion inhibitors for use in waters at temperatures of 150 oF or higher. the temperatures usually found in petrochemical and oil refinery operations. Substitutes are available for less critical applications. such as air conditioners and cooling towers operating at temperatures of 120 of or less. but they result in a performance and price penalty. In an emergency, it is questioned whether much chromium could be saved in the national interest due to its essential role in petrochemical plants and oil refineries.

\subsubsection{Wood Treatment compounds}

Sodium dichromate is used to make copper-chromiumarsenic compounds to treat wood as a protection against termites, fungus, etc. This market is growing in excess of 10 percent a year and is expected to continue do so unless government regulations restrict use. Other preservatives, such as creosote and pentachlorophenol, can be used to treat wood; however, the substitution for chromium-containing compounds in some cases would result in a performance penalty. primarily in paintability. In an emergency. copper-chromium-arsenic compounds for wood treating could be eliminated, and most woods could be treated with other known compounds.

\subsubsection{Chemical Manufacture and other Uses}

Sodium dichromate is used to manufacture other chemicals such as potassium dichromate; chromium organic complexes for treating textiles, papers, and leathers; chromium dioxide for magnetic tapes; and chromium-containing catalysts. Chromium catalysts are used to synthesize , ammonia and methanol and for many hydrogenation and polymerization reactions. Growth in these areas has been about 4 percent a year and is expected to continue at this rate. In most cases, no substitute is known for these specific chromium uses, and the elimination of chromium would result in a performance penalty in practically all cases. In an emergency. restricting chromium for use in 
catalysts could create a serious problem. The chemical manufacturing and other uses probably could be cut 50 percent or more:

\subsubsection{Material Substitution Considerations}

Using chromium chemicals for the above applications essentially provides a substantial price advantage over any known proven substitute materials; therefore, substitutes are not expected to replace chromium naturally. Government regulations (EPA and NIOSHA) will result in the recycling of much of the chromium that presently is wasted, particularly in the metal finishing and leather tanning areas. Recycling the chromium in pigments, leather tanning, wood treatment compounds and the chromium deposited in metal treatments is impractical because of the very thin layers involved or the difficulty of obtaining the chromium in a recyclable form. In the case of pigments, proposed regulations regarding their toxicity to humans exposed during their manufacture could result in some contraction of this market. However. the economic advantage of chromium pigments over proven substitutes to obtain the same color could initiate the development of methods to meet the proposed regulations.

In an emergency, certain uses could be eliminated. This happened in World War II when chromium plating on automobiles and other appliances was replaced by painting or plastics. Also, colored pigments could be replaced for many uses. The projected possible savings are shown in Table 49.

\subsubsection{Chromium-Free Coatings}

\subsubsection{Aluminum, Zinc and Aluminum-zinc Alloy Coatings}

Steel may be zinc coated by hot dipping or electroplating on one or both sides. The zinc coating protects the steel from corrosion due to exposure to humidity or outdoor elements. The ability to withstand such exposure is directly proportional to the thickness of the sacrificial zinc coating and the painted surface applied for appearance. Phosphate or chromate coatings usually are applied before painting to improve paint adhesion and improve corrosion resistance. While zinc is excellent for protecting steel from atmospheric corrosion, it cannot be used in the presence of strong acids or strong alkalies where stainless sometimes is used. The zinc sacrificially protects the iron and steel from corroding for some distance beyond the zinc coating, especially at minor discontinuities such as sheared edges or scratches extending to the substrate. 
TÁBLE 49 Chromium Demand and Substitutability in Chemicals Containing Chromium

\begin{tabular}{|c|c|c|c|c|c|c|c|c|c|c|c|c|}
\hline \multirow[b]{3}{*}{$\begin{array}{l}\text { Current } \\
\text { Material }\end{array}$} & \multirow[b]{3}{*}{$\begin{array}{l}\text { Material } \\
\text { Application }\end{array}$} & \multirow[b]{3}{*}{$\begin{array}{l}\text { Contained } \\
\text { Chromium }\end{array}$} & \multirow{3}{*}{$\begin{array}{l}\text { Chromium } \\
\text { Demand } \\
\text { (millions } \\
\text { of pounds) } \\
\end{array}$} & \multirow[b]{3}{*}{$\begin{array}{l}\text { Role of } \\
\text { Chromium }\end{array}$} & \multirow{2}{*}{\multicolumn{4}{|c|}{ Available Alternative Materials }} & \multirow{2}{*}{\multicolumn{2}{|c|}{ Required New Technology }} & \multirow{2}{*}{\multicolumn{2}{|c|}{$\begin{array}{l}\text { Remarks } \\
\begin{array}{l}\text { Probability } \\
\text { of }\end{array}\end{array}$}} \\
\hline & & & & & & & & & & & & \\
\hline & & & & & $\begin{array}{l}\text { Substitute } \\
\text { Materials } \\
\end{array}$ & $\begin{array}{l}\text { Contained } \\
\text { Chromium }\end{array}$ & $\begin{array}{l}\text { Chromium } \\
\text { Savings (\%) } \\
\end{array}$ & $\begin{array}{l}\text { Property } \\
\text { Deficiencies }\end{array}$ & $\begin{array}{l}\text { Research } \\
\text { Needed } \\
\end{array}$ & $\begin{array}{l}\text { Priority of } \\
\text { Research } \\
\end{array}$ & $\begin{array}{l}\text { Research } \\
\text { Success }\end{array}$ & $\begin{array}{l}\text { Type of } \\
\text { Research }\end{array}$ \\
\hline $\begin{array}{l}\text { Chrome } \\
\text { pigments }\end{array}$ & $\begin{array}{l}\text { Paints, plastics, } \\
\text { and inks }\end{array}$ & $10-15 \%$ & 24 & $\begin{array}{l}\text { Color and } \\
\text { corrosion } \\
\text { inhibitor }\end{array}$ & $\begin{array}{l}\text { Organic } \\
\text { pigments }\end{array}$ & 0 & 100 & $\begin{array}{l}3 \text { to } 20 \\
\text { times more } \\
\text { expensive }\end{array}$ & $\begin{array}{l}\text { Low. cost } \\
\text { substitute }\end{array}$ & Low & Medium & \\
\hline $\begin{array}{l}\text { Chrome } \\
\text { tanning } \\
\text { compounds }\end{array}$ & $\begin{array}{l}\text { Tan } \\
\text { leather }\end{array}$ & $15-17 \%$ & 24 & $\begin{array}{l}\text { Tanning } \\
\text { agent }\end{array}$ & $\begin{array}{l}\text { Vegetable } \\
\text { tannins }\end{array}$ & 0 & 100 & $\begin{array}{l}7 \text { to } 14 \\
\text { times longer } \\
\text { tanning } \\
\text { time } \\
\end{array}$ & $\begin{array}{l}\text { Tanning } \\
\text { compound } \\
\text { containing } \\
\text { domestic } \\
\text { produced } \\
\text { materials }\end{array}$ & Low & Low & Long term \\
\hline $\begin{array}{l}\text { Metal } \\
\text { finishing } \\
\text { and } \\
\text { chrome } \\
\text { plating }\end{array}$ & $\begin{array}{l}\text { Corrosion } \\
\text { protection }\end{array}$ & $\begin{array}{l}\text { Decorative } \\
10-30 \\
\text { microinches } \\
\text { Engineering } \\
1-10 \text { mils }\end{array}$ & 26 & $\begin{array}{l}\text { Protective } \\
\text { coating }\end{array}$ & $\begin{array}{l}\text { Nickel, } \\
\text { cobalt }\end{array}$ & 0 & 100 & $\begin{array}{l}\text { High costs } \\
\text { and short } \\
\text { supply }\end{array}$ & $\begin{array}{l}\text { More } \\
\text { economical } \\
\text { methods of } \\
\text { recycling } \\
\text { unused } \\
\text { chromium }\end{array}$ & Low & Medium & Medium \\
\hline $\begin{array}{l}\text { Drilling } \\
\text { muds }\end{array}$ & $\begin{array}{l}\text { Drilling } \\
\text { muds }\end{array}$ & $5-10 \%$ & 5.6 & $\begin{array}{l}\text { Corrosion } \\
\text { control and } \\
\text { fluidity } \\
\text { of mud }\end{array}$ & $\begin{array}{l}\text { Bentonite, } \\
\text { lime, } \\
\text { tannins }\end{array}$ & 0 & 100 & $\begin{array}{l}\text { Not suit- } \\
\text { able for } \\
\text { well } 10,000 \\
\text { ft or more }\end{array}$ & $\begin{array}{l}\text { Non-chrome } \\
\text { containing } \\
\text { additive to } \\
\text { drilling muds }\end{array}$ & Low & Medium & Long term \\
\hline $\begin{array}{l}\text { Water } \\
\text { treatment }\end{array}$ & $\begin{array}{l}\text { Corrosion } \\
\text { control in } \\
\text { cooling } \\
\text { towers }\end{array}$ & $\begin{array}{l}5-20 \text { parts } \\
\text { per million }\end{array}$ & 4.2 & $\begin{array}{l}\text { Corrosion } \\
\text { inhibitor }\end{array}$ & $\begin{array}{l}\text { Phosphates, } \\
\text { silicates }\end{array}$ & 0 & 100 & $\begin{array}{l}\text { Not suit- } \\
\text { able for } \\
\text { higher } \\
\text { tempera- } \\
\text { tures, } \\
\text { higher cost }\end{array}$ & $\begin{array}{l}\text { Effective } \\
\text { corrosion } \\
\text { inhibitor } \\
\text { for water } \\
150^{\circ} \mathrm{F} \text { or } \\
\text { higher }\end{array}$ & Low & Medium & Medium \\
\hline $\begin{array}{l}\text { Wood } \\
\text { treatment }\end{array}$ & $\begin{array}{l}\text { Wood } \\
\text { preservation }\end{array}$ & & 6.0 & $\begin{array}{l}\text { Bond } \\
\text { copper and } \\
\text { arsenic to } \\
\text { wood }\end{array}$ & $\begin{array}{l}\text { Creosote, } \\
\text { pentachlo- } \\
\text { rophenol }\end{array}$ & 0 & 100 & $\begin{array}{l}\text { Appearance } \\
\text { and } \\
\text { paintability }\end{array}$ & None & & & \\
\hline $\begin{array}{l}\text { Chrome } \\
\text { catalysts }\end{array}$ & $\begin{array}{l}\text { Chemical } \\
\text { reactions }\end{array}$ & $3-10 \%$ & 1.0 & $\begin{array}{l}\text { Promote } \\
\text { reactions }\end{array}$ & $\begin{array}{l}\text { Other } \\
\text { metal }\end{array}$ & & 100 & $\begin{array}{l}\text { Cost and } \\
\text { perfor- } \\
\text { mance }\end{array}$ & $\begin{array}{l}\text { Catalyst not } \\
\text { containing } \\
\text { chrome }\end{array}$ & Low & Medium & Long term \\
\hline
\end{tabular}


For hot dipping and electro-galvanizing. the steel must be cleansed of oil and lubricants, and surface oxide must be removed. In hot dip coating, a molten flux covers the liquid zinc bath for its protection and to ensure a clean surface after oxide removal. The coating produced by hot dip galvanizing consists of several layers; those closest to the base metal are composed of various zinc-iron compounds while the outer layer is almost pure zinc.

Galvanized steel can be welded easily and the galvanized sheet is as readily formable as uncoated steel but not with the same tooling. Since the melting point of zins is 787 of. it limits the temperature to which galvanized steel may be used.

In 1976, the United states produced about 7 million tons of galvanized sheet and 140,000 tons of galvanized fixtures. Although the galvanizing capacity is somewhat higher than this, it has not been determined accurately. since the areas in which galvanized steel could be substituted for stainless are limited by temperature and lack of resistance to acids and alkalies or oxidizing materials, the additional galvanized material that would be used for this purpose probably could be absorbed at this time. With a full economy, this capacity would not be available, and the lead time to increase capacity is about two to three years.

An alternative to galvanizing is a proprietary system called zincrometal ${ }^{\circledR}$. registered to the Diamond Shamrock company. This is a two-coat system in which the first layer contains, in part, zinc dust and hexavalent chromium while the second layer is a formable and weldable zinc-rich primer. Each of the layers is applied to steel on a coil roller-coating machine at speeds up to 500 feet per minute and the coatings are baked after each application.

The $\mathrm{zincrometal}^{\circledR}$ has excellent corrosion resistance, formability, and weldability. It can be formed to the rupture strength of the steel, can be deep drawn, and meets the automotive standards for spot welding. However, it cannot he used in acid or st.rong organic solvent atmospheres and is limited to applications where ambient temperatures do not exceed 500 of (Smith 1976). The protection of cut edges would not be as good as galvanized steel. It is supplied as a precoated coil or sheet steel and usually is painted after forming.

Present U.S. capacity is about 1 million tons per year. Lead time on additional coil coating machines to increase capacity by about 400,000 tons per year would be 18 months. 
Aluminum coatings on steel can be applied in many ways. the most common of which are hot dipping (both continuous and batch) spray coating, and pack diffusion. To some extent, their uses depend on the method of application.

Hot dipped aluminum coated steel can be divided into two general categories. The first type, without special diffusion of the iron-aluminum interface, resists atmospheric corrosion very well and has good formability. The second type, with diffused interface, withstands high temperatures. Both of these coatings are bright and have the appearance and properties of pure aluminum. The hightemperature coating shows no discoloration at temperatures up to $9000^{\circ} \mathrm{F}$ and provides resistance to heat scaling up to 1.250 of. Formability gets progressively poorer as the diffusion layer thickens. The heat required for aluminizing is much higher than that for galvanizing.

The pack diffusion process usually employs an aluminum powder, a ceramic phase, and a volatile halide. These materials are packed into a retort and held at temperatures of 1.500 to 1.800 of for 6 to 24 hours. In this process. the entire coating is a diffusion alloy and no pure aluminum layer forms. These coatings depend on the diffusion alloy for resistance to oxidation. scale formation and abrasion. and for high hardness.

Sprayed aluminum coatings are obtained by melting aluminum wire, atomizing the droplets, and propelling them against the surface to be coated. The spray of droplets is cooled during transfer and the partially oxidized particles flatten on impact to make a coating with a density of 85 to 90 percent of theoretical and an oxide content of 0.5 to 3 percent. Thicker coatings are required to eliminate pores. The work then is heat treated to form a good bond with the base metal. Various sealers may be used to improve heat resistance. For protection from atmospheric corrosion, the aluminum thickness should be 5 to $12 \mathrm{mils}$. This type of coating has been used. for example, on automobile exhaust poppet valves because of its resistance to high temperature and sulfur dioxide fumes. Welding of aluminized steel causes a loss of ductility and corrosion resistance in the weld due to the formation of iron-aluminum alloys.

In March 1976, aluminum coated sheet steel was quoted at $\$ 17.15$ to $\$ 17.20$ per 100 pounds as compared to galvanized steel quoted at $\$ 15.40$ to $\$ 16.20$ per 100 pounds (Mock 1976). It is estimated that steel tubing and pipe coated by pack cementation will cost between two to three times as much as
uncoated. 
The U.S. capacity for aluminum coated sheet steel is estimated as 455,000 tons in 1972,624,000 tons in 1973, and 657.000 tons in 1974. About 100,000 tons of excess capacity are believed to exist, but requirements appreciably above this amount would necessitate a new plant and two to three years lead time. Data on the capacity for pack diffusion and spray coatings were not obtained, but the estimated lead time to increase pack diffusion capacity markedly would be two to three years. The substitution of aluminum coated products for stainless steel could increase aluminum usage appreciably and cause an aluminum shortage.

\subsubsection{Plated Coatings as Substitutes for Chromium- Containing Alloys}

The wide range of stainless steel end uses and the different properties that each end use requires discourage quantifying the extent to which candidate coating systems may be substituted. Where chromium alloys are used for their mass properties. plated coatings offer no prospect for satisfactory substitution since a coating alters only the surface properties of a material and not its massive properties.

Where stainless steels and other chromium alloys are used for their corrosion-, heat- or wear-resisting properties. plated coatings may be considered for many applications. Substitutability depends on the criticality of the end use, the ability to inspect, and the type of exposure to which the component will be subjected. The limitation of plated coatings must be recognized in attempting to substitute them for solid stainless steel or other corrosion-resisting alloys.

Unless plated coatings are essentially nonporous. corrosion can be initiated through the pores. In such cases, the following electrochemical relationships between the coating and the substrate must be considered:

1. If the coating is less noble (more active electrochemically) than the substrate, protection will continue in spite of pores until the coating is corroded away. Such coatings on steel are limited practically to zinc and cadmium. zinc is cheap. easily plated, and widely used. Its properties are so well known that zinc-coated steel (galvanized, either hot or electrolytic) would be used already if it were a satisfactory substitute for stainless steel. Cadmium is expensive and poisonous, and its supply is relatively inelastic since it is a by-product of the mining of other metals, particularly zinc. It 
is used extensively by the aircraft industry and. if it were a satisfactory substitute for a specific stainless steel application, it already would be used.

2. If the coating is more noble (less active electrochemically) than the substrate, corrosion would be aggravated by a porous coating. Nickel. copper, and chromium are in this category. These coatings can be produced in a nonporous condition if they are relatively thick, cost is no object. and various precautions can be taken. plated coatings can be inspected for porosity if the application is critical.

Another limitation of plated coatings also must be considered: Without special anode configurations, plated coatings do not "throw" (deposit) weli into recesses, blind holes, small internal angles, and similar configurations. The design of the article itself may determine whether electroplated coatings can substitute for stainless steel in applications requiring corrosion resistance.

"Electroless" or autocatalytic plating does not suffer from this last defect. Its "throwing power" is essentially unlimited so that heavy, nonporous coatings may be produced. currently, the only relevant metal is nickel and its alloy with phosphorus and boron. These coatings could be considered in corrosion and wear applications, and their corrosion resistance is good in many environments. The limitation is mainly cost. Nickel is more costly than chromium and the plating process itself uses very expensive chemicals (Safranek 1974).

Many attempts have been made to plate various chromiumnickel alloys. None has proceeded beyond the laboratory "beaker" stage and no breakthrough is in sight (Chisholm 1968. Bazzard 1972). On the whole, the substitution of plated coatings for solid stainless steel does not promise chromium savings. Each end use should be considered on a case-by-case basis because few generalizations seem possible.

\subsubsection{Coated Plastics and Polymer-Coated steel}

Coated plastics may be used as replacements for either chromium-plated parts or stainless steel in many decorative applications. The coating, in this case, serves mainly as an aesthetic function. A number of processes (vacuum metallizing, electroplating, painting with argent paint, chemical vapor deposition, adhesive bonding of thin metal films) can be used to obtain a bright, metallic appearance 
(see appendix J). These coatings differ from one another in factors such as durability, corrosion resistance, appearance, and cost. They all share one characteristic -relatively poor scratch and abrasion resistance -- and coated plastics intrinsically are not as strong as metals.

In some specific applications where stainless steel is used because of its corrosion resistance, coated plastics or polymer-coated mild steel may be acceptable substitutes. Neither coated plastics nor polymer-coated steel are suitable for high-temperature applications since current high-temperature plastics and other polymers are expensive. unavailable, or too difficult to use to be of general practical applicability. Another limitation of polymercoated steel is that, in general. its corrosion resistance is inferior to that of stainless steel; moreover, the polymer coating may be degraded by exposure to solvents or to sunlight. Because of these and similar considerations, the substitutability of chromium plating and stainless steel by coated plastics and polymer-coated steel must be examined in terms of the specific conditions of each application.

The use of chromium in applications such as automotive trim and household hardware is based mainly on appearance without any stringent functional requirements. In this case, many substitutes are available. Appendix $\mathrm{K}$ examines these uses in detail in the case of automotive trim. The conclusion is that substitutes are available for all automotive applications in which chromium is used for appearance.

Similar substitutions are possible for many household items such as chromium plated door knobs, bright mirror frames and light fixtures. but the problems are more complex for many other household appliances. For instance, most kitchen utensils must resist frequent scrubbing, the use of aggressive cleaning agents, and, in some cases, heating. Most polymeric materials are not suitable for these uses. Either enameled steel or corrosion-resisting metals such as silver. copper, and brass may be used in many of these cases. If the bright appearance is not needed and the temperature uf use is moderate. it may be possible to use rubber- or vinyl-coated steel. These coatings are relatively abrasion resisting and have found acceptance in uses such as dish drainers. trays for dishwashers, and refrigerator components.

Stainless steel products are used generally in applications involving the corrosive environments of chemical equipment such as stainless steel pipes, valves, and pumps. If the temperature of use is sufficiently low. polymer-coated steel may be used in most of these cases even 
though its durability usually is greatly inferior to that of stainless steel. The types of coatings that may be used depend on conditions. For instance, most thermoplastics soften above 200 of and are not satisfactory above this temperature. Moreover, most thermoplastics are attacked to some extent by solvents. Thermosets have greater resistance both to temperature and solvents. but thermoset-coated steel cannot be deformed appreciably without cracking the coating. Thermosets are suitable only when they can be applied to the finished part. Cleanliness is more difficult to achieve with coated steel since the coating often absorbs contaminants and vigorous cleaning procedures may be unacceptable because of the limited resistance of the coating to scouring, heating, and chemical cleansing (e.g.. polymer-coated steel would be greatly inferior to stainless steel in such applications as milk tanker trucks).

\subsubsection{Ceramic Coatings as Replacement for stainless Steel}

The stainless steel used for domestic appliances and plumbing fixtures often can be replaced by porcelain-enamelcoated steel or cast iron. Enamel coatings containing little or no chromium are quite attractive to the consumer because of their wide color spectrum, corrosion and abrasion resistance, ready cleansability, and modest cost: Their principal disadvantage is their susceptibility to chipping. Except for highly stressed parts or those subject to impact loads, enameled steels could substitute for stainless in most applications in the above classes.

\section{2.6.5 Titanium and Titanium-Clad Metals}

Titanium is really two separate products -- titanium metal and titanium oxide. The metal is used widely by the aerospace industry (Brooks 1965. U.S. Bureau of Mines 1970. Aviation week 1976). The oxide is used as a pigment by the paint and plastic industries and as a paper coating. About 5 percent of the titanium is used as metal while 95 percent of U.S. Consumption is used as pigment (Committee on International Economic Policy 1974).

Titanium and its alloys are noted primarily for outstanding strength-to-weight and stiffness-to-weight ratios, good fatigue strength, toughness, and good cryogenic properties. It is more inert than aluminum and has better corrosion resistance to sea water and marine atmospheres than stainless steel. It is highly resistant to chloride ion attack (Materials Engineering 1974). Commercially pure titanium is available in wrought mill forms, castings, and powder (Modern Metals 1975). It is used for aircraft skins and components, commercial heat exchangers, marine 
components, and chemical processing equipment. Titanium alloys are produced by melting in vacuum or inert gas and are used primarily in, aerospace applications where a high strength-to-weight ratio is essential (Aviation Week 1976):

Titanium is produced from titanium oxide (rutile) by the Kroll process (National Materials Advisory Board 1974). A lower grade but more plentiful ore, ilmenite, is usable for pigment production but requires costly beneficiation for metal production (Committee on International Economic Policy 1974. U.S. Bureau of Mines 1970).

U.S. demand for titanium in 1975 was 35 milliọn pounds of which 25 percent was imported. Total productive capacity of U.S. titanium producers is estimated at 35 million pounds annually (Modern Metals 1975). Demand by 1980 is expected to rise to $50 \mathrm{million}$ pounds, including $20 \mathrm{million}$ pounds in nonaerospace applications. With the abortion of the $\mathrm{B}-1$ bomber program, total demand will be much lower (Aviation Week 1976).

Titanium is an expensive metal compared to stainless steel. Ingot prices are about $\$ 6$ per pound with sheet and strip running up to $\$ 15$ per pound. Serious consideration of titanium as an emergency substitute for stainless steel must await resolution of several negative factors:

1. High cost relative to stainless steel

2. Iimited domestic productive capacity

3. High cost and long lead times of new productive capacity

4. Iimited world reserves of titanium ore. particularly rutile

5. No domestic reserves of rutile although ilmenite is available in the United states.

Titanium probably could be most effective when used as a thin overlay or cladaing on a base materlal such as aluminum or carbon steel." Such clad materials have been made by roll-bonding and explosion bonding. Using as little as 10 percent of titanium in the composite is feasible (Smith 1976). With satisfactory edge protection, such composites might find application in chemical processing equipment where longer service life and freedom from maintenance: and downtime would justify a premium price. Typical end uses might be in acid recovery. copper refining. paper and pulp processing. petroleum refining. chemical heät 
exchangers, desalination, and sewage treatment (Modern

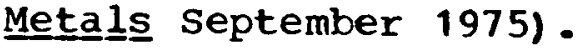

Many of the problems associated with titanium technology must be solved if titanium-clad materials are to be accepted. These composites are difficult to fabricate and to provide with adequate edge protection. Titanium is highly reactive and has a low tolerance for contamination (Sayre and Chang 1975). Commercially pure titanium can be considered as several distinct alloys with selected ranges of tramp or residual elements. Control of the identity and concentration of these residuals is difficult and costly but essential for the titanium producer (Smith 1976). Temperatures above 700 of must be avoided because of possible creep and stress-corrosion problems. Titanium sheet and strip also exhibit variance in texture and microstructure that can affect fatigue strength and corrosion resistance adversely.

\subsubsection{Tantalum and Tantalum-Clad Metals}

Tantalum has long been an attractive material because it is less active chemically than any other metal, has the corrosion-resisting properties of glass, and is particularly resistant to most acids. It is ductile but tends, to gall. seize, and tear unless care is taken in fabrication. Because it does not work-harden rapidly. it can be deepdrawn readily (Emerson 1975).

Tantalum retains its strength and undiminished corrosion resistance up to about 400 oF. Above that temperature, surface coatings are required in strongly oxidizing environments. Tantalum must be cold-worked since it absorbs gases (particularly oxygen) when hot, resulting in embrittlement (U.S. Bureau of Mines 1970).

Up to the present, the United States has been almost entirely dependent on foreign sources for raw tantalum. Unless new sources materialize, tantalum shortages beyond 1977 could lead to explosive price increases (Emerson 1976). Much of the primary tantalum production comes from developing countries so that political considerations are important. 
U.S. consumption of tantalum in 1974 was as follows (Emerson 1976):

Use

Electronics

structural

Cutting Tools

Alloys
Consumption (pounds)

$1.000,000$

300,000

240,000

6.000

Tantalum is an expensive metal (Brooks 1965). The price of tantalite in 1974 was $\$ 12$ to $\$ 15$ per pound and that of tantalum metal was $\$ 48$ to $\$ 115$ per pound depending on product form.

The major uses of tantalum are in applications where its unique properties provide a distinct cost and

performance or cost and service-life-cycle advantage. By far, the largest use is in tantalum capacitors for the electronics industry.

The excellent welding and fabricating characteristics of tantalum make it an economical liner material for chemical process towers, large acid-handling valves, nuclear reactor tubing, and other applications where long service life and freedom from downtime and maintenance are vitally important. Recent improvements in process technology have been vitally important and have led to tantalum sheet flat enough for bonding to carbon steel by an explosive-bonding process (Jenstrom and Schussler 1974). Such tantalum-clad materials should provide a higher quality. lower cost alternative to solid tantalum or tantalum liners in the applications listed above. In an emergency, the tantalumclad material could replace stainless steel in critical applications at a severe cost penalty but with no degradation in performance.

\section{3 EVALUATION}

The unique properties, low cost, and plentiful supply of chromium-containing materials have, over the years, made important eegmentc of $U . \varepsilon$. industry virtually dependent on the continued availability of these materials. These same factors almost inhibited both research on possible substitutes for chromium and serious efforts to conserve, reclaim, or recycle chromium-containing materials. Apparently, a drastic curtailment of this availability would have serious consequences -- some short-term but others more far reaching. It is instructive to consider the implications of such an event for the United states. Assuming that all of the conclusions of this report are valid and that all the alternative actions proposed are 
accepted and implemented, what would be the foreseeable impacts on the United States?

\subsection{Ef fects on Industry and Technology}

Some industries will be affected slightly by

drastically reduced availability of chromium and strong efforts to conserve it. Examples are:

Industry
Tool steels
Superalloys
Chromium chemicals

Use

Metal cutting and forming Jet engines, gas turbines water treatment and leather tanning

This result is expected since chromium is essentially irreplaceable for these applications and the total amounts are small compared to all U.S. consumption. Hence, the available chromium will be allocated preferentially to these end uses.

Some industries will benefit by the drastically reduced availability of chromium and strong efforts to conserve it. Examples are manufacturers of alternative substitute materials such as titanium, tantalum, aluminum, zinc. plastics, porcelain enamel coatings, and metal paints. A lack of chromium because of high prices or government taxes to restrain the use of the material and to enforce its recycling will encourage strongly the use of substitute materials whenever possible. The industries listed above are examples of those that might benefit by recapture of old markets previous $l y$ lost to chromium-containing materials or by the creation of new ones. Since no one alternative material possibly could substitute across-the-board, the impact of any given alternative would be modest but always positive.

other industries likely to benefit are those associated with recycling efforts. Examples are:

Industry

Scrap sorting

Crushing and grinding

Chemical processing

Beneficiation

\section{Application}

Metals

Refractories and foundry sands Chemical wastes and effluents Stock-piled material and lowgrade ore

An immediate demand to use state-of-the-art equipment and technology in the above applications can be predicted as 
well as incentives to develop more efficient and less costly new processes.

Other industries likely to benefit are associated with the production of clad and coated materials and their subscquent testing and proccssing. In the event of a requirement to reduce chromium demand substantially, the use of stainless clads and coatings applied to less corrosionand oxidation-resisting materials will increase. Widespread adoption of this approach would require both new technology and increased productive capacity. More importantly. demand would arise for equipment capable of forming. joining and edge-sealing such composite materials. New nondestructive testing equipment would be required to assure the integrity of the protective surface layer after initial production and after subsequent in-plant processing.

A number of industries will be affected unfavorably by drastically reduced availability of chromium and strong efforts to conserve it. Examples are:

\section{Industry}

Refractories

Nonferrous alloys

stainless steels

Alloy steels

\section{$\underline{\text { Use }}$}

steel producers and foundries

Broad spectrum of users

Fabricated metals, machinery other than electrical, transportation

Primary metals, machinery other than electrical. fabricated metals

Refractory manufacturers and nonferrous alloy producers would not be affected over the long term because little or no loss of markets would be anticipated. A period of intensive research and development is required to achieve the products and processing technology for chromium-free or low-chromium materials. The same is true to a somewhat lesser extent with the alloy steel producers and users who would have new and posibibly more costly alloys to reduce their chromium demand. The greatest impact would be on stainless steel producers and users because the opportunity to apply or develop low-chromium stainless alloys is limited. In a truly drastic supply situation, it will be necessary to live with less stainless steel. While the consequences for some user industries would be modest or only economic in nature, the effects would be devastating for others, such as the nuclear power industry. Long-range 
(greater than 15 years) research would be required with no identifiable substitutes in sight.

\subsubsection{Effects on the Economy}

It seems certain that all innovations to reduce chromium consumption will involve substantial costs and some sacrifice in service performance. These added costs can arise in several ways -- from more complex designs, from additional processing steps, from additional testing, or from more expensive substitute materials that do not contain chromium. For example, painted steel has been proposed as a substitute for stainless steel in some applications. For many paints, however, chromium chemicals are essential ingredients so that increasing their use to combat corrosion and extend product life will cause an increase in chromium demand, at least partially offsetting the savings generated by using less stainless steel.

Another example of the almost mandatory use of stainless steel is the manufacture of the myriad small miscellaneous parts and fasteners used universally in the assembly of various durable goods. The important properties required are the outstanding corrosion resistance, formability. high elastic modulus, and good strength possessed almost exclusively by stainless steel. stainless steel is one of the most widely used materials for combatting corrosion, the major cause of short product life and early replacement. Assembling is a logical place to reduce chromium demand by going to more welds, brazed joints. locking tabs, rivets, etc., in joining operations. Such a move, however: would frustrate the drive for chromium conservation, which calls for a greater use of threaded fasteners in order to improve maintainability. repairability, and recyclability. Apparently. compromises and trade-offs must be made everywhere to identify those end uses where chromium-containing materials are absolutely necessary for acceptable product life.

This report suggests many fruitful areas where research and development could alleviate demand for chromium. increase primary supply. or improve industry capability for recycling. However, much of the necessary investigative work is inappropriate to university or government laboratories; rather, the expertise, the facilities, and the environment of industry are required. Because much of the work is high risk in nature or provides national insurance against international political blackmail; substantial government financial support may be required in the form of direct subsidy, tax privileges. guaranteed markets, or relaxation of regulations. 
If adoption of new chromium-free or low-chromium materials is enforced rather quickly by circumstances, incentives will be created to settle promptly on some new standard materials to replace older, well-known and reliable ones. In turn, this will force much testing of new or lesswell-known materials. Although it will be urgently needed, this type of research generaliy is not favored by academic institutions.

Once the new engineering information is available for the new materials, intensive effort will be needed to make the potential users aware of the existence of the materials as well as their advantages and disadvantages. Handbooks. data banks, and other information services will be needed to 'make the engineering data quickly accessible.

The maintenance of a strategic stockpile of chromiumcontaining materials generally is accepted as a necessary and effective strategy. On the other hand, the desirability of a separate economic stockpile is a controversial subject both in and out of Congress. It does seem. however, that an economic stockpile could take advantage of the cyclical nature of world industry by accumulating excess stocks of minerals and metals when times are slack. Stockpiling would provide some insulation for emergency conditions and allow valuable time for the research and development necessary to prepare for coming minerals shortages.

\subsubsection{Effects on the Environment}

One of the alternative actions is to press exploration in the United States, Canada, and other friendly countries to discover new deposits of chromium-containing materials. Unfortunately. public opinion is largely negative to such proposals at present. Ever-expanding production and use of minerals in the past have been a cause of environmental deterioration. Environmental regulations and economics have increased the shift to foreign sources for chromite and ferrochromium. These include:

1. Depletion of deposits mineable at low cost

2. Diminishing availability of land for exploration

3. Costly measures to protect air and water quality and to reclaim the lanä surface after mining

if pollution is regarded as waste of the polluting materials then, over the long term, their recovery as useful material and land may more than pay for the cost of pollution control. If the environmental impacts of all activities in a system (mining, processing, fabrication, manufacturing and 
disposal, along with interspersed transportation steps) are measured, a system using secondary. materials causes less air and water pollution, generates less solid waste, and uses less energy than a system using virgin materials. Up to now, these costs have not been identified, evaluated, and assessed against those responsible elements. At present and over the short term, the private sector has no real incentive to conserve chromium-containing materials, to recycle wastes in place of waste disposal, or to gather and recycle obsolescent scrap for reuse. Government support will be needed to reverse this trend by long-term projects aimed at:

1. Exploration for yet undiscovered resources

2. Improvement of the economics of utilizing poorer quality ores

3. Less wasteful mining, extraction, and ore cleaning

4. Efficient recycling of discarded products and materials

6. 4 SUMMARY, CONCLUSIONS, AND RECOMMENDATIONS

\section{4 . 1 Summary}

Table 50 summarizes the findings concerning substitutability. It should be noted that the assigned development times predicted assume a reasonably well-funded and well-staffed investigation. Clearly. a crash program fully supported by government and industry might achieve the desired results in much less time. On the other hand. a poorly funded and understaffed program might run indefinitely with no tangible results. In addition, only the time required to arrive at a viable technological solution to the substitution problem is estimated. Determining the time required to implement the technology is beyond the scope of this committee and depends on economic. social, and political factors that are too complex to evaluate quantitatively.

\subsubsection{Conclusions}

1. Substituting other materials for chromiumcontaining stainless steel, tool steel, wrought alloy steel, cast iron and steel, nonferrous alloys, electroplate, refractories, and chemicals can result in a total chromium savings of 744 million pounds. 
TABLE 50 Potent:al Savings of Chromium-Containing Materials by Substitution (million pounds)

\begin{tabular}{|c|c|c|c|c|c|c|c|c|}
\hline \multirow[b]{2}{*}{ Material Designation } & \multirow{2}{*}{$\begin{array}{l}\text { Total } \\
\text { Chromium } \\
\text { Used }\end{array}$} & \multirow{2}{*}{$\begin{array}{l}\text { Total } \\
\text { Chromium } \\
\text { Saved }\end{array}$} & \multicolumn{5}{|c|}{ Time Required for substitution } & \multirow[b]{2}{*}{$\begin{array}{l}\text { Irreplaceable } \\
\text { Chromium } \text { e }\end{array}$} \\
\hline & & & $\begin{array}{l}\text { Immedi- } \\
\text { ately a }\end{array}$ & $\begin{array}{l}\text { Within } \\
5 \text { Years } \underline{b}\end{array}$ & $\begin{array}{l}5 \text { to } 10 \\
\text { Years } \subseteq\end{array}$ & $\begin{array}{l}\text { At } \\
10 \\
\end{array}$ & $\begin{array}{l}\text { Least } \\
\text { Years d }\end{array}$ & \\
\hline Stainless stee 1 & 569 & 332 & 203 & -- & 129 & -- & & 237 \\
\hline Tool steel & 7 & -- & -- & -- & -- & -- & & 7 \\
\hline Wrought alloy steel & 123 & 103 & 22 & 35 & 46 & -- & & 20 \\
\hline Cast iron and steel & 82 & 54 & 5 & 10 & 35 & 4 & & 28 \\
\hline Nonferrous alloys & 29 & 2 & -- & -- & 2 & -- & & 27 \\
\hline Chromium electroplate & 21 & 17 & 14 & 3 & -- & -- & & 4 \\
\hline Refractories & $249 \stackrel{f}{\underline{f}}$ & 225 & 110 & -- & 115 & -- & & 24 \\
\hline Chromium chemicals & 68 & 11 & 6 & $=$ & 5 & $\underline{z}$ & & 57 \\
\hline Total & 1,148 & 744 & 360 & 48 & 332 & 4 & & 404 \\
\hline
\end{tabular}

NOTE: The assigned development times imply a reasonably well-funded and well-staffed investigation -- a crash program supported by government and industry might achieve desired results in much less time, while a poorly funded and under-staffed program might drag indefinitely with no tangible results. The development times estimate only the time required to arrive at a viable technological solution to the substitutability problem involved. The time required to implement the technology depends on economic, political and social factors that are too complex to evaluate in any quantitative way and are beyond the scope of this study.

a Amount saved by functionally acceptable chromium-free substitutes currently available. Direct or indirect cost penalties are incurred.

$\underline{b}$ Amount saved by functionally acceptable chromium-free substitutes provided after short develcpment (less than 5 years) with a high probability of success. Direct or indirect cost penalties are incurred.

C Amount saved by fuzctionally acceptable chromium-free substitutes provided after intermediate-term (5 to 10 years) research with a high probability of success. Direct or indirect cost penalties are incurred.

d Amount saved by functionally acceptable chromium-free substitutes provided after long-term (more than lo years) research with a high probability of success. 'Direct or indirect cost penalties are incurred.

e Amount considered irreplaceable. No functionally acceptable chromium-free substitutes are identifiable. Basic research and new technology are needed.

f. Includes refractorg types not reported by the U.S. Bureau of Mines. 
2. An assessment of the end-use requirements of major stainless steel categories indicates that:

- 10 percent (about 32 million pounds of chromium) could be replaced by existing chromium-free materials without serious degradation of service performance

- 50 percent (about 160 million pounds of chromium) might be replaced with a high probability of success after a short-term research and development effort

- 40 percent (about 125 million pounds of chromium) are in end uses where severe service requirements prevent a major reduction in chromium content unless compensated by design or process improvements because it would result in unacceptable degradation of service performance

Economical chromium-free substitutes are unavailable for chemical processing where corrosion or elevated temperature resistance are required. In a chromium cut-off, these applications must be supplied by allocation or abandoned until new technology is developed.

Alternative copper- and nickel-base alloys also are subject to serious scarcities and are produced in limited quantities. Titanium and titanium-clad steels might be suitable substitutes for chemical tanks and piping where their service temperatures are relatively low. Coatings, clad materials, aluminum alloys, and plastics need more research and evaluation before qualifying as substitutes in many applications.

3. The primary contribution of chromium to wrought and cast steel is its influence on hardenability. Several other elements that influence hardenability can eliminate or reduce chromium usage but at a significant economic penalty. An assessment of the end-use requirements of wrought alloy steels indicates that:

- 50 percent (about 64 million pounds of chromium) of the chromium now used probably could be replaced with little difficulty 
- 30 percent (about 39 million pounds of chromium) more might be replaced after a short-term research and development effort

- 20 percent (about 20 million pounas of chromium) is considercd irreplaceable

opportunities for substitution are substantial in iron and steel castings where an estimated 50 million pounds of chromium could be saved. In high-alloy steel castings where chromium is essential, 32 million pounds of chromium are considered irreplareable.

4. Chromium in tool steels is considered irreplaceable in view of the relatively small amount of chromium used (less than 1 percent of total U.S. consumption), the importance of tool steels to the national economy, and the high cost of replacement materials.

5. Although the number of nonferrous alloy compositions containing chromium is large, the amount of chromium consumed represents only about 2 to 3 percent of total U.S. consumption.

In aluminum-base, titanium-base, and copperbase alloys, chromium primarily alters phase relationships to produce specific and preferred microstructures. Although lead times of several years might be required to qualify a substitute alloy for a critical application, reducing or eliminating chromium consumption in aluminum, titanium, and copper-base alloys would not cause major difficulties.

The chromium content of nickel-base, ironnickel-base, and cobalt-base alloys ranges from 10 to 25 percent and no other alloying elements approach conferring the same degree of oxidation and corrosion resistance. Although further research and development, especially in the areas of coatings and engineering ceramics, eventually may decrease chromium dependence, it is impossible at present to reduce chromium consumption significantly in these alloys by material substitution. For the foreseeable future, it will be necessary to ensure the availability of chromium for these alloys.

6. The largest use of chromium in ceramic products is as chromite refractories in basic steel plants and 
as facing sands in steel foundries, and, to a great extent, non-critical materials may be substituted at some cost or performance penalty. About 50 percent of the chromite could be replaced with little trouble if magnesite chrome refractories were used instead of chrome or chrome magnesite refractories. The refractory industry currently is not geared to producing promising chromium-free substitutes such as spinel. fosterite, and dolomite in suitable form and quantity, and considerable research, development. and evaluation of these materials is warranted. With favorable cost incentive and chrome scarcity, the potential for salvage and reuse of chromebearing refractories is considerable in all consuming industries.

7. Electroplating uses about 4 percent of total U.S. chromium consumption, and the chromium chemicals used are made from chemical-grade chromite ore that generally has been unacceptable for metallurgical processing. About 60 percent of the chromium used in electroplating is for decorative applications, about 30 percent is for engineering (hard) chromium plate, and the remainder is for other metal finishing. Painted steel, aluminum, or plastic could be used to replace decorative chromium plate, resulting in an annual savings of about 14 million pounds of chromium.

A promising available substitute for hard chromium plate is electroless nickel deposition, and about 3 million pounds of chromium could be saved annually by substituting this process; however. considerable development would be necessary to provide the needed productive capacity.

More chromic acid is lost or wasted in processing than actually is deposited as chromium metal in the plated parts, and total consumption of chromium could be reduced substantially by successful recycling.

8. U.S. consumption of chromium chemicals amounts to about 100 million pounds of contained chromium annually: The primary chemical, sodium dichromate, is made from chemical grade chromite ore.

Considerable research has been done in all areas of chemical application (pigments and 
paints, leather tanning, drilling muds, water treatment, and wood treatment) to find acceptable substitutes. Their substitutability status is as follows:

- Pigments and Paints -- In an emergency. chrome pigments could be eliminated in about half their uses, drastically reducing the producible colors and saving about 14 million pounds of chromium annually.

- Leather Tanning -- No practical substitute exists for chromium in tanning leather. The alternate tanning compounds are imported and require new U.S. technology to be used. besides imposing a severe cost and performance penalty. Furthermore, any wide use of leather substitutes would cause serious dislocations because of the vast number of animal hides whose only practical use is to make leather.

- Drilling Muds -- No known satisfactory substitutes exist for chromium lignosulfates used as mud additives for the drilling of deep oil and gas wells. Since this is a critical and strategic industry; it would not be in the national interest to attempt chromium savings in this application.

- Water Treatment -- Corrosion-inhibiting chromium compounds are used widely for water treatment by petrochemical plants and oil refineries. No satisfactory substitutes are known for water treatments over $150{ }^{\circ} \mathrm{F}$. The relatively low chromium usage and the economic importance of this end use make it inadvisable to attempt chromium savings.

- Wood Treatment -- A relatively small amount of chromium chemicals is used for wood treatment and preservation. While the use of known substitutes would result in a loss of paintability, chromium savings of about 6 million pounds annually could be made without serious trouble.

\subsubsection{Recommendations}

1. Incentives and penalties should be considered to stimulate the design of high-chromium-content 
products in a manner that makes them readily identifiable for disassembly and recycling.

2. Research should be accelerated to develop surface coatings with better high-temperature corrosion and oxidation resistance, including very thin coatings high in chromium.

3. Programs should be expedited for the development of stainless steels of lower chromium content. (alloyed with aluminum, titanium; and silicon) that might be substituted for many current stainless steel applications.

4. Low-alloy, chromium-free steel compositions should be developed and tested to replace steels where chromium is used mainly for its hardenability characteristics.

5. Economic incentives should be created to spur the development and use of lower chromium or chromiumfree refractories.

6. Fuither research should be undertaken to develop economic chromium-free water treatment compounds.

REFERENCES

Air Force Materials Laboratory. Summary Report on Air Force Chromium Workshop. Wright-Patterson Air Force Base, Ohiv: Air Force Materials Laboratory. Metals and Ceramics Division, May 1975.

American Iron and Steel Institute. Annual statistical Report. Washington, D.C.: American Iron and Steel Institute, 1975.

American Society for Testing and Materials. "Standard Specification for Electrodeposited Coatings of Nickel Plus Chromium," ASTM B456-71. In Annual Book of ASTM Standards. Philadelphia. Pa.: American Society for Testing and Materials, 1974.

American Society for Testing and Materials. Annnual Book of ASTM Standards, Part 17, Philadelphia, Pa.: American Society for Testing and Materials, 1975.

Aviation Week. "Titanium Industry Banks on Use in B-1." Aviation Week. (January 26, 1976):83-4. 
Bazzard, R.. and Boten, P.J. "Nickel-Chromium Alloys by Codeposition." Transactions of the Institute of Metal Finishing $50(1972): 63-9$.

Bittner, F.H. "Stockpiling for the Future." In proceedings of the Third Conference on National Materials Policy.

UP. 147-56. Washington. D.C.: Office of Technology

Assessment, 1974.

Brenner, A. Electrodeposition of Alloys, Vol. II. New York: Academic Press, 1963.

Bride, J.E. "Low Valence Decorative Chromium Plating." plating, $59(1972): 1027$.

Brooks, D. Supply and Competition in Minor Metals.

Baltimore, Ma.: Johns Hopkins Press, 1965.

Brown, B.F. "Corrosion: Role in Materials Shortages." ASM News (March/April, 1976): 4-5.

Carter, V.E., and Christie, I.R.A. "Outdoor Exposure Performance of Chromium Electrodeposited from Trivalent Electrolyte." Transactions of the Institute of Finishing. $51(1973): 41$.

Chisholm, S.U. "Electrodeposition of Nickel-Chromium Binary Alloys." Plating 55 (July 1968):735-9.

Committee on International Economic Policy. Special Report: Critical Imported Materials, pp. 16-21. Washington, D.C.: Executive office of the President. December 1974.

Dresse1, W.M.; George, L.D.; and Fine, M.M. "Chromium and Nickel Wastes -- A Survey and Appraisal of Recycling

Technology." In proceedings of the Fifth Meeting of the Waste Utilization Symposium, pp. 262-70. Chicago. Illinois: IIT Research Institute, April 1976.

Emerson. M. "Tantalum." Engineering and Mining Journal (March, 1975):206.

Emerson, M. "Tantalum." Engineering and Mining Journal (March 1976): 158 .

Gold, B. "Stockpiles: Security. Market stability and Developmental Incentives." ASM NewS. (June/July 1976):6-8.

Guy. A.G. Elements of Physical Metallurgy. Reading, Mass.: Addison-Wesley. 1960 . 
Jenstrom, E.. and Schussler, E. "Tantalum Takes on New Applications." Metal_Progress (December 1974):67-71.

Johnson, E.. and Ogburn, F. "Hardness of Heat Treated Electroless Nickel." ' Surface Technology 4 (1976): 161 .

Lamantia. A.J. "High speed Chromium Plating steel strip." Plating 62 (January 1975):46-8.

Materials Engineering. "Titanium and Its Alloys." Materials Enqineering (July 1974):61-70.

Mikami. H.M. "Chromite." In Industrial Minerals_ore Rocks. 4th ed. New York: AIME, 1975.

Miska, W.S. Refractory Use Patterns in the Iron and steel Industry of the United states. Information Circular 8382 . Washington, D.C.: U.S. Department of Interior, 1968.

Mock. J.A. "Precoated Steel (Manual 259)." Materials Engineering (March 1976) 43-52.

Modern Metals. "Titanium Aircraft Biz Dips; Industrial Uses Take up slack." Modern Metals (September 1975):34-5.

Modern Metals. "P/M; Thrifty Use Short Cut to Titanium Parts." Modern Metals (November 1975):81.

Modern Plastics. "Restoring the Luster to Metallized Markets." Modern Plastics (December 1974):42-6.

National Materials Advisory Board. Trends in Usage of Chromium. Report NMAB-256 (NTIS No.AD707175) - Washington, D.C.: National Academy of Sciences, 1970. (Available from National Technical Information Service. 5285 Port Royal Road, Springfield, Virginia 22151.)

National Materials Advisory Board. Direct Reduction processes for the Production of Titanium Metal. Report NMAB-304 (NTIS No. PB232545). Washington, D.C.: National Academy of Sciences, 1974. (Available from National Technical Information Service, 5285 Port Royal Road. Springfield, Virginia 22151.)

Penfold, A.S: and Thornton, J.A. "A Post Magnetron Sputtering system for Front Loading Chambers." In proceedings of the $19 \mathrm{th}$ Annual Technical Conference of the Society of vacuum coaters. Cleveland, Ohio: Society of vacuum Coaters, 1976. 
Penfold. A.S., and Thornton, J.A. Electrode-Type Glow Discharge Apparatus. U.S. Patents Nos. 3,884,793 (May 20, 1975) and 3,995,187 (November 30, 1976).

Radcliffe, S.V. "Materials: The Next Crisis." In Requirements for Fulfilling a National Materials Policy. pp. 158-65. Washington, D.C.: Office of Technology Assessment, 1974.

Safranek, W. Properties of Electrodeposited Metals and Alloys. New York: American E,lsevier Publishing Company. 1974 .

Sayre, E., and Chang, W. "Chromium Shortages in the Engine Industry." Summary Report on Air Force Chromium Workshop. Wright-Patterson Air Force Base, Ohio: AFML, May 1975.

The Refractories Institute. Survey on $\mathrm{Cr}_{2} \mathrm{O}_{3}$ Usage in Refractories. Pittsburgh, Pa.: The Refractories Institute, 1976 .

TTope, N.. Baker, E., and Jackson, B. "Evaluation of Wear Properties of Electroless Nickel." plating and Surface Finishing (October 1976):30.

U.S. Bureau of Mines. Mineral Facts and Problems. Bulletin 650. Washington. D.C.: U.S. Bureau of Mines, 1970. pp. 385, 773-94.

U.S. Bureau of Mines. Mineral Facts and Problems. Bullet in 667. Washington, D.C.: U.S. Bureau of Mines. 1975.

U.S. Department of Commerce. Census of Manufacturers. Washington, D.C.: U.S. Department of Commerce, 1975.

U.S. Department of Commerce. Materials survey: Chromium. Washington, D.C.: U.S. Department of Commerce.

ward. J.B., and Christie, I.R.A. nElectrodeposition of Chromium from Trivalent Salts." Transactions of the Institute of Finishing 49 (1971): 148 .

Ward, J.B., Christie, I.R.A., and Carter, V.E. "Pilot Scale Evaluation of Trivalent Chromium Plating." Transactions of the Institute of Finishing, vol. 49, 1971, p. 97.

Zapffe, C.A. Stainless steels. Metals Park, Ohio: American Society for Metals, 1949. 


\section{BIBLIOGRAPHY}

Grabfield, P.R. "Chrome Ore Sources and Availability with Emphasis on Metallurgical Use." IㅌM. (October 1975): 26-35.

Holland, I. Vacuum Deposition of Thin Films. London, England: Chapman \& Hall, Ltd.. 1956.

Hoover, S. "Extruded Bumpers Score with Chevy." Metal Progress 105 (June 1974): 45 .

Journal of Metals. "Metals Resources: Chromium:" Journal of Metals (December 1973): 43-4.

Product Finishing. "Vacuum Metallized Auto Grilles for 176 Models." Product Finishing 40 (November 1975): 80 . 


\author{
Appendix A \\ STEEL SELECTION \\ BY HARDENABILITY AND ALLOY ELEMENTS
}

Computer harmonized (CH) steels are designed to meet one of three objectives: (1) to provide a special steel that meets a component's application tailored (AT) requirements - quantitative metallurgical requirements. to aid in the selection of the most economical standard steel that meets a component's AT requirements, or (3) to develop replacements for standard AISI H steels. The use of computer harmonizing to achieve the first or second objective depends on whether the tonnage or other requirements of the component justify a special steel (e.g.. if the component under consideration is a low-tonnage item. the engineer may lean toward a standard steel that will be readily available from a steel mill or warehouse). Using computer harmonizing to achieve the thira objective provides a systematic method for devising chemical compositions for replacement steels that match the base and case hardenability and other characteristics of the original steel.

In each instance, the resulting $\mathrm{CH}$ steel has a chemical composition that is optimized with respect to the cost of alloying elements and, generally, the steel has an optimum price in terms of its "chemistry grade extra," as covered in the steel product price book. The difference between cost and price in this context must be understood; there is not always a one-to-one correspondence between the two although a close correlation does exist.

The need for using a computer approach to develop a least-cost steel is apparent when the various aspects of the problem are considered. A least-cost steel that must meet only a specified $D_{\text {Ib }}$ (base composition) value could be designed fairly easily by a manual method with tables for nomographs) containing alloy costs and hardenability multiplying factors. When a carburizing grade is designed, however, at least one additional restriction, a minimum $\mathrm{D}_{\text {Ib }}$ value, is added to the problem. Because hardenability factors for the individual alloying elements are different for the case and the base composition, a steel designed to have a least-cost base composition most likely would not satisfy the $D_{\text {IC }}$ (case composition) requirement. If further restrictions such as the martensite start temperature (MS) of the case and base analyses are added, the least-cost combination of alloying elements to satisfy the multiple requirements becomes impossible to find manually. Because 
of the multiple restrictions discussed below, the problem of cost optimization requires separate programming techniques.

The $\mathrm{CH}$ procedure is designed to optimize one property while simultaneously satisfying multiple restriction. Described here is the Computer Harmonized Application Tailored (CHAT) system which determines the least costly alloy combination that will satisfy specified values for $\mathrm{D}_{\text {Ib. }} \mathrm{D}_{\mathrm{Ic}}$, and $\mathrm{M}_{\mathrm{S}}$ (martensite starting). other properties can be optimized and other restrictions added, provided all features can be expressed as quantitative functions of the chemical element. Working with hardenability and $\mathrm{M}_{S}$ temperatures as a basis, the $\mathrm{CH}$ process solves the leastcost alloy problem by using a modified linear programming technique known as separable programming.

Shortcomings of the CHAT system (e.g., using a multiplier for boron, residual stress effects, and grain size) do not detract from its utility but simply indicate that it is not a panacea. As is the situation for many useful tools, the system should be manipulated and applied with discretion, utilizing all available technology as a base.

In addition to these prime engineering and cost aspects, definition of the CHAT system creates an awareness of the explicit definition of a steel. A steel cannot be defined using a simple single analysis as might be implied by the standard numbering system and as is assumed by many design engineers. Instead, a large, finite number of analyses having quantifiable statistical characteristics, in terms of items such as base and case hädenability, is required. This comprehension by designers as to what comprises a steel is an important link in a viable, flexible materials engineering activity.

The principle of optimum steel usage has never been ignorea completely by the maker of machine parts and assemblies although it has been relegated at times to a subordinate role when profits are good and the climate for change is unfavorable. This climate is complex and is influenced by the personality of the final decision maker.

As shown in Figure A-1, many metallurgical developments of alloy steels stem from national or international crises (Breen et al. 1973) and are not necessarily favorable to the metallurgical community. With the knowledge that history repeats itself, an acceptable system for changing from one alloy system to another certainly would be useful in the future. Perhaps heat-treatable steels will be defined in the future essentially in terms of their response to heat treating rather than composition, and then periodic 


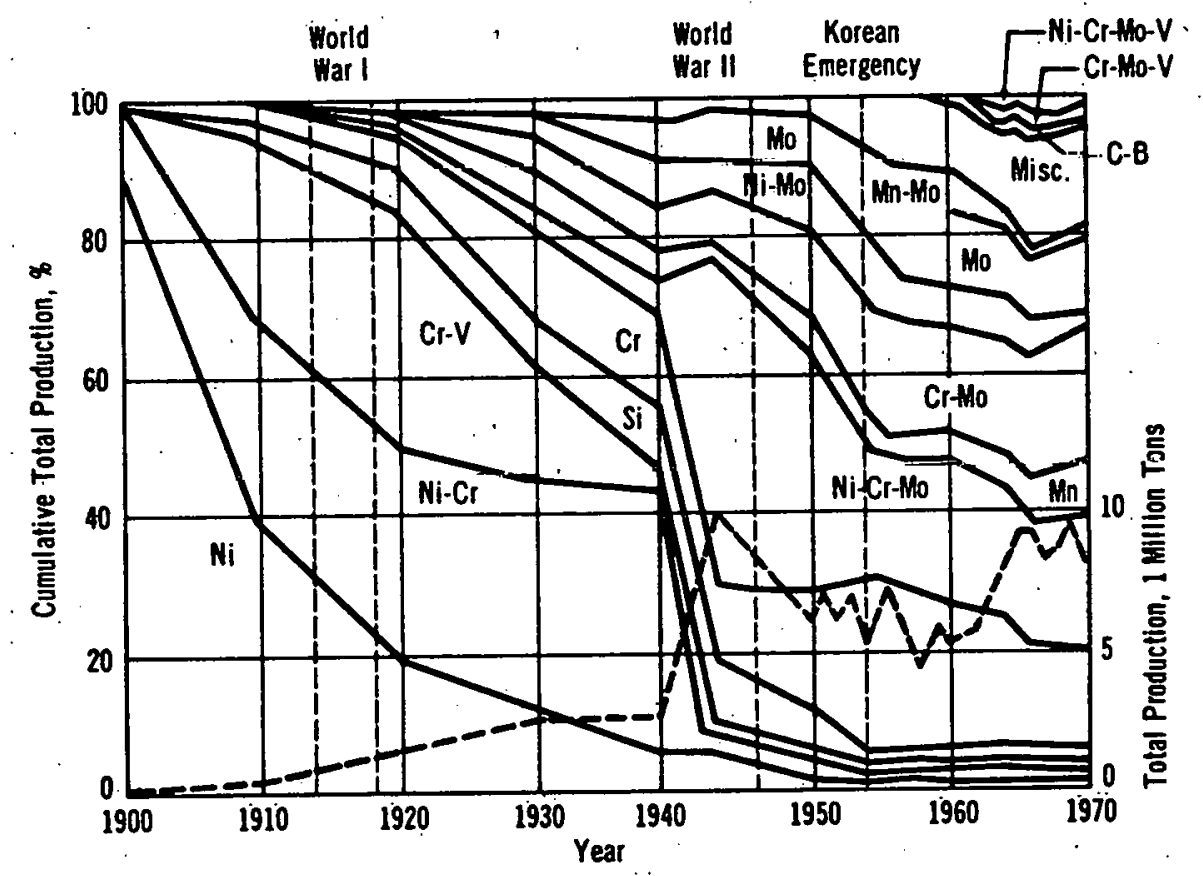

FIGURE A-1 History of Alloy Steel Usage (Smith 1963)

NOTE: Since 1900, the pattern of alloy steel usage has changed greatly. The dotted line indicates alloy steel production. 
adjustments in alloy content could be made unhesitatingly, taking immediate advantage of changing alloy costs or availability.

The strategic alloy problem has become the subject of much discussion given the fact that the nation's dependence on foreign ores could be an important factor in future international relationships. A weak link principle has been described in which an advantage could be gained by a potential enemy who subtly promoted dependence on a strategic alloy import that would require alternate approaches during a war (Sutton 1969). Having well known, established principles could influence reaction time considerably if the need for change arose.

\section{REFERENCES}

Breen, D.H., Walter, G.H., Keith, C.J., and Sponzilli, J.T. "Computer-Based System Selects Optimum Cost Steels." American Society for Metals. () Metals Progress (November 1973) : 46-8.

Sutton, A.C. "Soviet Strategy." Ordnance Magazine (November-December, 1969). 


\author{
Appendix B \\ CHROMIUM CONTENT \\ IN CARS, TRUCKS, BUSES, AND TRUCK TRAILERS
}

The traditional chromium uses in cars include

decorative and functional stainless steel, alloy in steel and cast iron, and chromium plate. The average 1976 car. weighing. 3,750 pounds, contains approximately 6.75 pounds of chromium in the above categories as shown in Table B-1 (presentation to the Committee by J. LaBelle, General Motors Corporation, July 1976). This 6.75 pounds includes 2.59 pounds of chromium in the catalytic converter and its accessories.

From 1972 to 1975, total truck and bus production was about $1 / 3$ of that for passenger cars. Fifty-two percent of these trucks and buses weighed under 6,000 pounds (gross) and therefore would require a catalytic converter similar to that in passenger cars (see Table B-2). None of the remainder had the catalytic converter. Without the catalytic converter the average truck would contain significantly less chromium than the average passenger car. In some exceptional cases, the chromium content of buses and truck trailers greatly exceeds that of passenger cars. 1 Also, a significant number of heavy-duty trucks, which constitute only 4 percent of the total truck population. have large quantities of external decorative and functional stainless steel, much of which is optional equipment. In considering the large assortment of ways in which chromium is used in the total truck, bus, and trailer industries, the passenger car figure of 6.75 pounds per vehicle could be used as a reasonable estimate of the chromium content in heavy trucks and buses if the chromium used in truck trailers also is included. In this appendix, the total.

population of cars, trucks, and buses, as well as the annual production, will be considered to have 6.75 pounds per vehicle for the year 1976 and to be subject to the same changes as passenger cars in the event of an emergency. After 1980, heavy-duty diesels are expected to average 5.48 pounds of chromium. but all other diesels are expected to average 4.33 pounds.

The automotive industry in its processing generates large volumes of recyclable metal scrap and takes elaborate precautions to properly isolate and collect this useful chromium-containing scrap. This segregation of chromiumcontaining material includes the offal from stainless steel stamping operations (sold to stainless steel mills). forging offal, and iron and steel turnings as well as scrap parts (sold to the foundries producing automotive castings). In 
TABLE B-1 Chromium Usage in U.S.-Built Passenger Cars Powered by Conventional Otto Cycle Piston Engines (pounds)

\begin{tabular}{|c|c|c|c|}
\hline . & $\begin{array}{l}\text { Actual } \\
\text { Typical } 19.75 \\
\text { Full-Size Car } \\
(4,450 \quad 1 \mathrm{~b})\end{array}$ & $\begin{array}{l}\text { Estimated } \\
\text { Average U.S. } \\
197.6 \mathrm{Car} \\
(3,750 \quad \mathrm{lb}) \\
\end{array}$ & $\begin{array}{l}\text { Projected } \\
\text { Average U.S. } \\
1980 \text { Car } \\
(3,000 \quad \mathrm{~b}) \\
\end{array}$ \\
\hline \multicolumn{4}{|l|}{ Propulsion System } \\
\hline Cylinder block, head, camshaft, valves & 1.277 & 1.077 & 0.860 \\
\hline Cooling system & 0.017 & 0.014 & 0.011 \\
\hline Electrical system & 0.007 & 0.006 & 0.005 \\
\hline Carburetor, air intake, exhaust & 0.118 & 0.099 & 0.079 \\
\hline Catalytic converter & 3.335 & 2.587 & 2.070 \\
\hline Transmission (automatic) & 0.169 & 0.142 & 0.114 \\
\hline Propulsion shaft, rear axle, differential & $\underline{0.061}$ & $\underline{0.051}$ & $\underline{0.041}$ \\
\hline Subtotal & 4.984 & 3.976 & 3.180 \\
\hline \multicolumn{4}{|l|}{ Chassis } \\
\hline Deluxe wheel covers & 1.440 & 1.214 & 0.971 \\
\hline Front suspension & 0.250 & 0.211 & 0.169 \\
\hline Brakes & 0.047 & 0.040 & 0.032 \\
\hline Steering gear & 0.019 & 0.016 & 0.013 \\
\hline Steering wheel & 0.028 & 0.024 & 0.019 \\
\hline Rear suspension & 0.136 & 0.115 & 0.092 \\
\hline Lights & 0.071 & 0.060 & 0.048 \\
\hline Miscellaneous & $\underline{0.067}$ & 0.056 & $\underline{0.045}$ \\
\hline Subtotal & 2.058 & 1.736 & 1,389 \\
\hline \multicolumn{4}{|l|}{ Body } \\
\hline Windshield wipers & 0.265 & 0.265 & 0.265 \\
\hline Seat belts & 0.355 & 0.355 & 0.355 \\
\hline 'Windshield lower molding & 0.276 & $0.069 a$ & -- \\
\hline Roof drip moldings & 0.203 & 0.171 & 0.137 \\
\hline Door window moldings & 0.155 & $0.131^{-}$ & 0.105 \\
\hline Chromium plate & $\underline{0.060}$ & $\underline{0.051}$ & $\underline{0.041}$ \\
\hline Subtotal & $\underline{1.314}$ & $\underline{\underline{1.042}}$ & $\underline{\underline{0.903}}$ \\
\hline Total chromium per car & 8.356 & 6.754 & $\overline{5.472}$ \\
\hline Total without catalytic converter & 5.766 & 4.764 & 3.402 \\
\hline
\end{tabular}

a Used on an estimated 25 percent of total production. 
TABLE B-2 U.S. Production of Passenger Cars, Buses, and Trucks, 1972-1975

\begin{tabular}{|c|c|c|c|c|c|}
\hline Year & Cars & $\begin{array}{l}\text { Total Buses } \\
\text { and Trucks }\end{array}$ & $\begin{array}{l}\text { Total } \\
\text { Vehicles }\end{array}$ & $\begin{array}{l}\text { Ratio of } \\
\text { Total Vehicles } \\
\text { to Cars }\end{array}$ & $\begin{array}{l}\text { Light Trucks } \\
\text { under } 6,000 \text { Ib a }\end{array}$ \\
\hline 1972 & $8,823,938$ & $2,482,503$ & $11,067,095$ & 1.29 & $1,414,551$ \\
\hline 1973 & $9,884,446$ & $3,014,361$ & $.12,898,807$ & 1.30 & $1,735,645$ \\
\hline 1974 & $7,324,504$ & $2,746,538$ & $10,071,042$ & 1.37 & -- \\
\hline 1975 & $6,717,177$ & $2,266,567$ & $8,983,774$ & 1.34 & 897,292 \\
\hline Total & $32,510,719$ & $10,509,969$ & $43,020,688$ & 1.32 & -- \\
\hline
\end{tabular}

NOTE: Derived from data from Jet Propulsion Laboratory 1974 and Automotive Industries 1976 .

a Ratio of light trucks to total buses and trucks in 1972, 1973, and 1975 is 0.52 . 
some cases, such foundries are part of the same company or division. One General Motors' foundry, which casts cylinder heads, blocks and camshafts, obtains about 80 percent of its chromium (typical for the industry) from a combination of chromium-containing steel and iron turnings from its own returns. 1 Therefore, the chromium content of productiongenerated scrap should not be added to the chromium content of a vehicle as additional usage.

Recycling junk cars has not been extensive until recently. Economic conditions have increased the scrap value, and new salvaging equipment and methods have improved the situation. A shredder of scrap car bodies, for example, can produce 1 ton of metal per minute. However, the amount of chromium-containing alloys that is recovered and used in similar chromium alloys from these operations is questionable. One installation handling large volumes of scrap cars is recovering nonmagnetic stainless steel of enough value to pay for the cost of separation. No other chromium-containing alloy is recovered from scrap cars and identified as such. Magnetic stainless is shredded along with steel sheet and sold only as shredded car body steel. Cylinder blocks are sold without publicizing the chromium content; however, some foundries use the chromium content beneficially. While actual figures are unavailable, an estimated 1 pound of chromium is recovered beneficially from each of the $8 \mathrm{million}$ cars scrapped per year. In an emergency, methods for recovering a total of 3 pounds per car should be possible. Both catalytic converters and deluxe wheel covers are identifiable and recoverable under economic and emergency stimulation.

Service parts used to repair vehicles in the field are supplied by new vehicle manufacturers and many after-market suppliers. Actual chromium consumption has been calculated at 0.023 pounds per year per car in operation (Harvey and Menchen 1974). Since the discarded parts have a high content of exhaust valves, camshafts and cylinder blocks, and head castings, they are not converted as readily into comparable chromium-bearing products as the decorative trim on passenger cars.

The Clean Air Energy Acts have changed automobile design significantly and can have an important effect on future chromium consumption. As a result of the Energy Act, cars will be lighter and engines smaller. The clean Air Act has an important effect on the specific kind of engine that may be used and may result in substantially more chromium being used. Currently, however, it does not appear that any alternate engine can replace the conventional ot to type. It is estimated that 500,000 urban cars per year will. be powered by batteries by the early 1980's. Appraisals of 
each of the proposed power plants including the rotary. Rankine, Brayton and Stirling are presented in Lists B-1 through $B-7$.

Table B-3 forecasts gains in diesel and electric vehicles starting in 1980. The diesel is expected to be used in small trucks and large cars; now uncommon applications for U.S. manufacturers. Their efficiency should allow the 1985 energy standards to be met by larger cars and their better fuel economics favor their use in both light and medium trucks, which constitute the bulk of the truck market. In all likelihood, the passenger car diesel will handle the light trucks while something heavier will take over at about 10,000 pounds gross vehicle weight. By the year 2000 , the forecast assumes total production of 18 million vehicles of which 13.3 million will be otto powered. 4 million will be diesel powered, and 0.7 million will be electric powered.

The forecast of chromium usage by the automotive industry and the action that can be taken in an emergency has two parts. Table $B-4$ shows vehicle parts requiring chromium until alternates are developed. Table B-5 shows the changes in chromium content per car that are almost immediately. possible in an emergency and the means for achieving them. The details of such changes are covered in chapter 6 .

From a design standpoint, deluxe stainless steel wheel covers, regular stainless or aluminum hub caps, and chromium-plated acorn-capped nuts all provide equal protection for the wheel stud threads. They are required to prevent thread damage so the wheels can be removed. In some cases. special cast aluminum or magnesium wheels with special nuts are considered more decorative than the deluxe wheel covers. The least expensive system is either the aluminum hub caps or the acorn nuts.

About 80 percent of the $85 \mathrm{million}$ cars in service are believed to have the deluxe wheel covers that have about 8 pounds of stainless steel per car. The stainless is either AISI Type 302 or 434 . Assuming 17.5 percent chromium, the total chromium content is 47,600 tons in the deluxe wheel covers of cars presently in service. From a conservation standpoint, the most unique thing about them is their easy retrievability and replaceability in an emergency chromium shortage; if the industry substitutes something else for the deluxe stainless steel covers, this reserve supply of chromium might not exist in an emergency.

Another design change, already effected on some cars. involves the lower windshield molding. In some cars with a 


\section{Current Status}

Dominates market.

\section{Advantages}

Least expensive combustion engine; best performance; good durability; good fuel consumption; least development required to achieve realistic energy and emission goals.

\section{Disadvantages}

Higher fuel consumption than diesel or Stirling; higher emission levels with converter than Brayton, Stirling, battery electric, or Rankine.

\section{Future}

A version of the piston otto probably will continue as the dominant engine for the foreseeable future. Some engine design concepts will improve emissions, fuel economy, or both. Among these are: stratified charge -- lean fuel/air ratio, fuel injection, smaller engine -- automatic four-speed transmission with positive lockup, wide distillation range fuel capability. and electronically controlled spark timing. Actual direction depends on whether or not emission standards are frozen at the 1976. level to optimize fuel economy. No version of the otto presently can meet the 0.40 grams/mile $\mathrm{NO}_{\mathbf{x}}$ limit mandated for 1978.

\section{Chromium Usage (lb per total car)}

Not expected to be significantly effected by above options. Chromium usage for normal and emergency conditions in 1976 and projected for 1980-2000 is:

\begin{tabular}{|c|c|c|c|}
\hline Condition & $\begin{array}{l}1976(3,750 \mathrm{lb} \\
\text { per Average car) } \\
\text { With Catalytic } \\
\text { Converter }\end{array}$ & $\begin{array}{l}1980-2000 \quad(3,000 \\
\text { With Catalytic } \\
\text { Converter }\end{array}$ & $\begin{array}{l}\text { 1b per Average Car) } \\
\text { Without Catalytic } \\
\text { Converter }\end{array}$ \\
\hline Normal & 6.75 & 5.48 & 3.41 \\
\hline Emergency & 3.08 & 2.46 & 0.39 \\
\hline
\end{tabular}


LIST B-2 Characteristics of the Rotary Otto Engine

\section{Current status}

Limited usage in some Japanese and European cars. No present or contemplated U.S. production.

\section{Advantages}

Light weight; compact size; good performance.

\section{Disadvantages}

Higher fuel consumption, emissions, and cost than piston otto engine. Durability still questionable.

\section{Future}

Not expected to reach production stage in United States.

Chromium Usage (lb per total car) No usage is predicted for 1980. Chromium usage for 1976 follows:

1976

3,750 lb per Average Car

Condition With Catalytic Converter

\section{Normal}

$6.45 *$

Emergency

$2.80 *$

* Estimate only, based on experimental information. 


\section{Current Status}

Limited production of foreign cars. Bxtensive usage in U.S. and foreign trucks. General Motors anticipates U.S. production in about 1978.

\section{Advantages}

Best fuel consumption of any developed and in-production engine; excellent durability; good emission control without converter.

\section{Disadvantages}

Heavier, more costly, and noisier than otto engine.

\section{Future}

A diesel designed for maximum efficiency may achieve 50 percent more miles per gallon of fuel

than an otto engine. This would mean saving about $\$ 10$ per $1,000 \mathrm{miles}$ if the fuel cost is $\$ 0.60$ per gallon and the car achieves 20 miles per gallon with the Otto engine. If the diesel costs $\$ 500$ more than the otto, the payback on a straight cost basis would require 50,000 miles. For $\$ 1.00$ per gallon fuel, the period is 30,000 miles. The diesel future is obviously dependent on the actual engine cost differential, the cost of fuel, and government-mandated fuel consumption and exhaust emission control requirements. Much greater use in lighter trucks and heavier passenger cars is forecast.

\section{Chromium Usage (lb per total car)}

Chromium usage predicted for 1980 for normal and emergency conditions is:

\begin{tabular}{ll} 
& 1980 \\
& $3.000 \mathrm{lb}$ Car \\
Condition & Without Catalytic Converter \\
\hline Normal & 3.83 \\
Emergency & 0.39 \\
\hline
\end{tabular}




\section{Current Status}

Some minor use for lightweight, limited-range transportation to combat air pollution and noise. Batteries are lead acid, recharged on off-peak hours.

\section{Advantages}

Minimum air and noise pollution at point of use. No power consumption in propulsion unit when vehicle is stopped. Multifuel capability since commercial power generating stations are power source.

\section{Disadvantages}

Low energy and power density in lead acid battery type seriously limits performance and range. No viable alternate battery exists at present. Car heating and other similar devices might. require added nonelectrical heat source.

\section{Future}

The use of lead acid battery powered utility vehicles is expected to increase in short-range urban usage as an alternate to a second conventional family car. No prediction is possible on alternate battery development. Containment of the sodium-sulfur or lithium-sulfur

elevated temperature types is unsolved but expected to require at least 15 percent chromium. About 500,000 vehicles per year are possible with either lead acid or more advanced katteries. Battery charging is possible in off-peak hours with no added power generation equipment. Recent Congressional action advocating battery research could have an upward effect on the usage numbers.

Chromium Usage ( $1 \mathrm{~b}$ per total car)

Chromium usage for normal and emergency conditions is:

\begin{tabular}{|c|c|c|}
\hline Condition & $\begin{array}{l}\text { Lead-Acid Type } \\
2,900 \text { lb Car } \\
30 \text { mile range }\end{array}$ & $\begin{array}{l}\text { Sodium-Sulfur or } \\
\text { Lithium-Sulfur Type* } \\
3,500 \text { lb Car } \\
235 \text { mile range }\end{array}$ \\
\hline Normal & 2.48 & $8.48-22.48$ \\
\hline Emergency. & 0 & $6-20$ \\
\hline
\end{tabular}

* Data from presentation to the Committee by S. Gratch, Ford Motor Company, July 1976. 


\section{Current Status}

Under development at Chrysler, General Motors, Ford, and independent engineering organizations. None in production.

\section{Advantages}

Good emission control in regenerative version with variable air intake system. Some multifuel capability.

\section{Disadvantages}

High cost; questionable durability; high fuel consumption in the lower power output ranges.

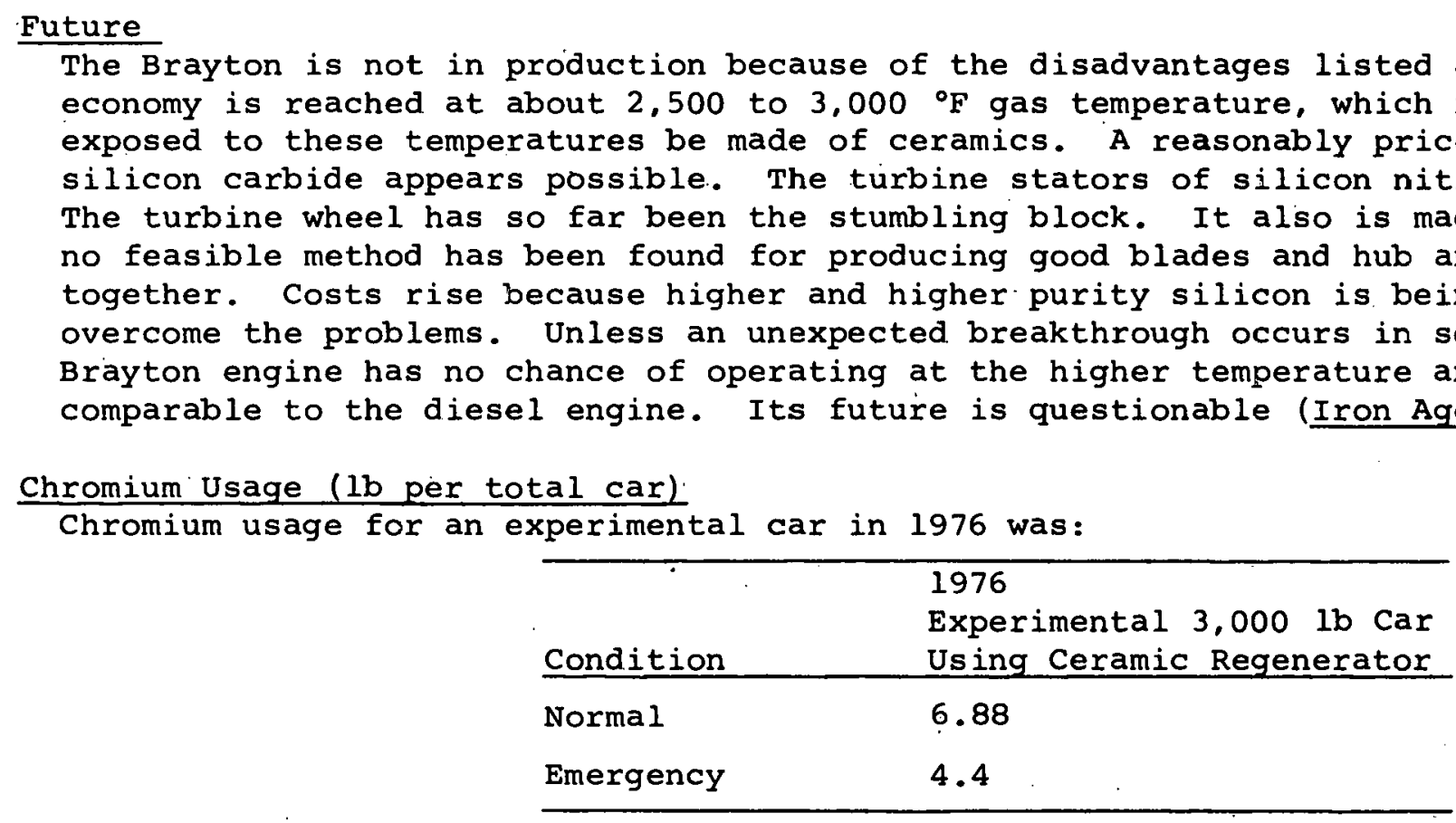




\section{LIST B-6 Characteristics of the Rankine (Steam) Engine}

\section{Current status}

Under development by independent engineering organizations only. None in production.

\section{Advantages}

Good emission control and multifuel capability.

\section{Disadvantages}

Adverse weight, cost, and fuel consumption. High usage of heat- and corrosionresisting alloys.

\section{Future}

Poor.

Chromium Usage (1b per total car)

Chromium usage of an experimental Rankine engine (Jet Propulision Laboratory 1975) was:

\begin{tabular}{ll}
\hline & 1975 Experimental \\
Condition & $3 ., 000$ 1b Car \\
\hline Normal & 34.48 \\
Emergency & 32 \\
\hline
\end{tabular}




\section{LIST B-7 Characteristics of the Stirling Engine}

\section{Current status}

Under development at Ford. None in production.

\section{Advantages}

Good emission control. Good fuel consumption.

Disadvantages

High cost; questionable durability; design and manufacturing complexity. High usage of heat-resisting alloys.

\section{Future}

The engine is a closed cycle piston engine operating with external combustion at high internal temperatures. There are significant durability problems. Ceramic $=-$ matérials may be helpful.

Chromium Usage (lb per total car)

Chromium usage of an experimental stirling engine (Jet Propulsion Laboratory 1975) was:

\begin{tabular}{ll}
\hline & 1975 Experimental \\
Condition & 3,000 lb Car \\
\hline Normal & 43.48 \\
Emergency & 41 \\
\hline
\end{tabular}


TABLE B-3 Chromium Balance for Automotive Vehicles

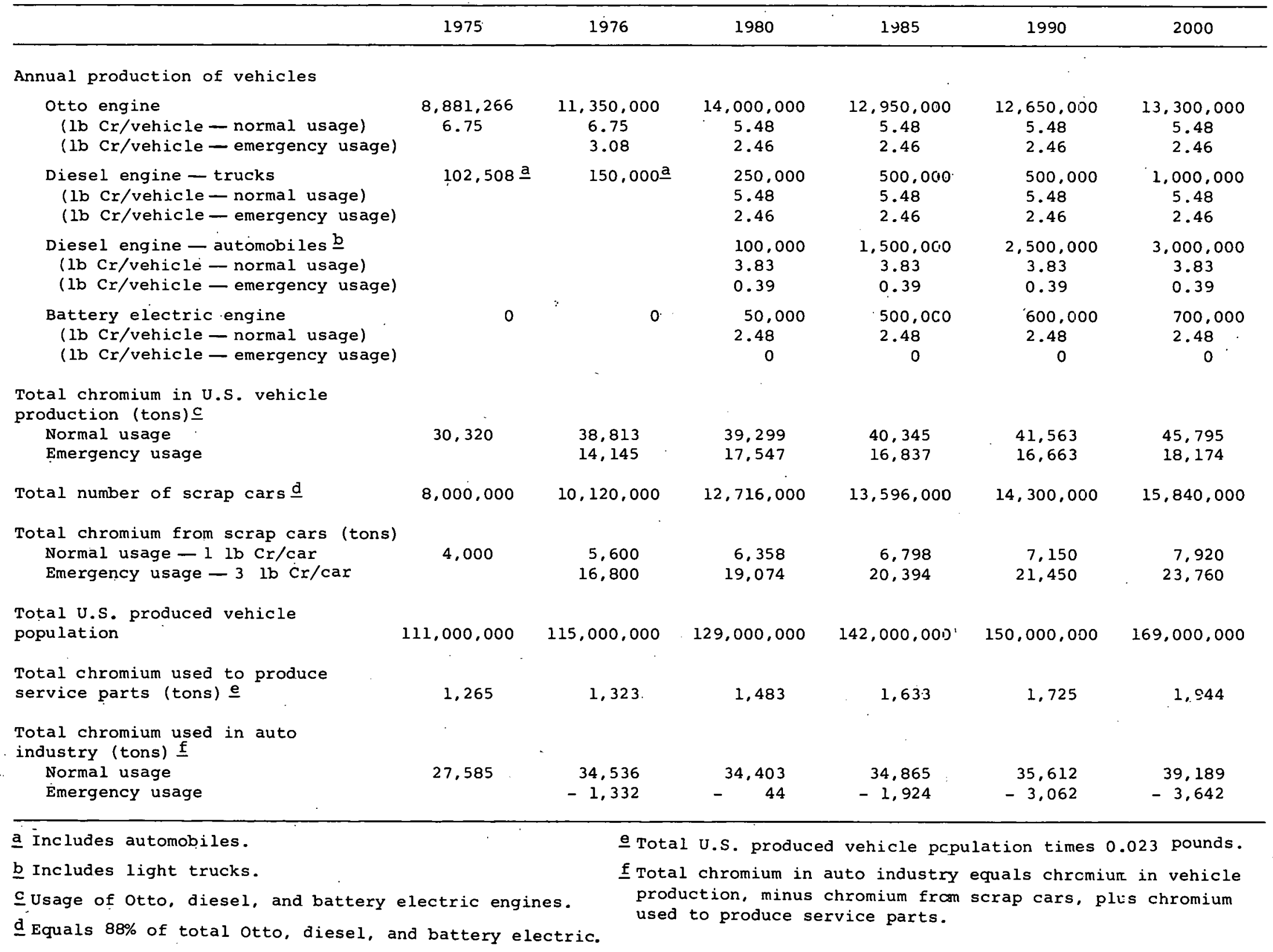


TABLE B-4 Vehicle Parts Requiring Chromium in an Emergency until Alternatives Are Developed

\begin{tabular}{llcc}
\hline Vehicle Parts & \multicolumn{2}{c}{ Pounds of } & Chromium Required Per Vehicle \\
\hline Exhaust valves & 1976 Car & 1980 Car & 1976 Diesel \\
Camshafts and tappets & 0.319 & 0.255 & 0.319 \\
Catalytic converters & 0.087 & 0.070 & 0.087 \\
$\begin{array}{l}\text { Miscellaneous heat- } \\
\text { resisting parts }\end{array}$ & 2.587 & 2.070 & -- \\
\multicolumn{1}{c}{ Total } & 0.084 & 0.067 & 0.084 \\
& 3.077 & 2.462 & 0.490 \\
\hline
\end{tabular}


TABLE B-5 Emergency Chromium Reductions in Vehicles

\begin{tabular}{|c|c|c|c|c|}
\hline \multirow{2}{*}{$\begin{array}{l}\text { Vehicle Parts } \\
\text { Exterior trim and } \\
\text { wheel covers }\end{array}$} & \multirow{2}{*}{$\begin{array}{l}\text { Methods of Reducing } \\
\text { Chromium Usage } \\
\text { Elimination, redesign, } \\
\text { or substitution }\end{array}$} & \multicolumn{3}{|c|}{ 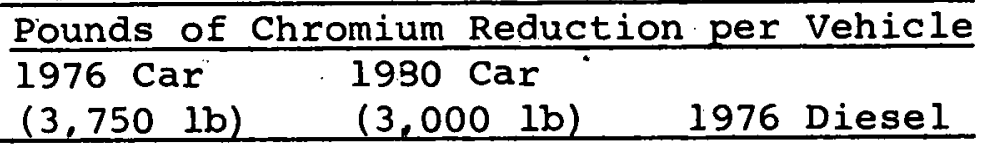 } \\
\hline & & 1.585 & 1.213 & 1.585 \\
\hline $\begin{array}{l}\text { Seat belts and } \\
\text { windshield wipers }\end{array}$ & $\begin{array}{l}\text { Using zinc or } \mathrm{Cu}-\mathrm{Ni}-\mathrm{Cr} \\
\text { plate on plain steel } \\
\text { in place of stainless }\end{array}$ & 0.620 & 0.620 & 0.620 \\
\hline Suspension springs & $\begin{array}{l}\text { Using a non-chromium } \\
\text { spring steel instead } \\
\text { of } 5160\end{array}$ & 0.326 & 0.261 & 0.326 \\
\hline $\begin{array}{l}\text { Cylinder blocks, } \\
\text { heads, and other } \\
\text { iron castings }\end{array}$ & $\begin{array}{l}\text { Substituting other } \\
\text { alloying elements } \\
\text { for chromium }\end{array}$ & 0.617 & 0.537 & 0.862 \\
\hline $\begin{array}{l}\text { Gears, ball and } \\
\text { roller bearings, } \\
\text { and other chromium } \\
\text { alloy steel parts }\end{array}$ & $\begin{array}{l}\text { Substituting another } \\
\text { alloy without chromium }\end{array}$ & 0.480 & 0.384 & 0.480 \\
\hline Total chr & um reduction & 3.682 & 3.015 & 3.844 \\
\hline
\end{tabular}


windshield well, this molding has been eliminated completely and its lack is hardly noticeable. The glass merely extends down into the well and is sealed on the bottom. The molding was made of 1.699 pounds of AISI Type 430 stainless steel containing 0.272 pounds of chromium. However, it still might be used on about 3 million cars per year, and 408 tons of chromium could be saved if it were eliminated.

Another highly interesting part, from a volume standpoint, is the windshield wiper blade. These blades presently are marketed with a stainless steel holder attached to the rubber blade. An optional replacement design provides only a rubber blade that can be inserted in the existing holder. Unfortunately, one must buy most of the wiper assembly to take advantage of this feature, since it is not available on new cars.

An estimated 41 million replacement wiper blades containing 0.1 pound of AISI Type 430 stainless steel are used per year (Harvey and Menchen 1974). This, plus new car blades, amounts to about 488 tons of chromium per year that could be saved with another design.

Another existing design option involves the hydraulic valve lifter -- 16 per typical car with a total weight of 2. 336 pounds of cast iron containing 1 percent chromium or 0.0234 pounds of chromium per car. It is estimated that an additional 15 million are sold in the after-market. About 130 tons of chromium would be needed if all lifters contained this amount. The optional design is a 5-gram wafer of 1 percent chromium cast iron that is brazed to an cxtruded steel hody and would require only 9.69 tons of chromium per year. Over 50 percent of the hydraulic valve lifters made have this chromium-saving design.

The catalytic converter of the typical 1975 car (Table B-1) contained a total of 3.335 pounds of contained chromium in three parts made of 29 pounds of AISI Type 409 stainless steel. The average for all U.S. cars is approximately 22.5 pounds of AISI Type 409 steel. Reductions in chromium usage are possible in this area if stainless clad steel is substituted for AISI Type 409 steel. Another approach would be to use a lean-burn electronic carburetor system without the convertor.

Figure B-1 was calculated by combining the information in Table $\mathrm{B}-2$ with the various factors previously discussed in this report. It shows both normal usage and essential usage in the event of a critical shortage of chromium. The forecast can be altered in the event any of the alternate power plants become a reality using the data in Lists $B-1$ through $\mathrm{B}-7$ for initial production. If any of the Jet 
Propulsion Laboratory (JPL) advanced engines ever become reality, the figures in Table $B-6$ could be used (presentation to the Committee by J. LaBelle, General Motors corporation. July 1976).

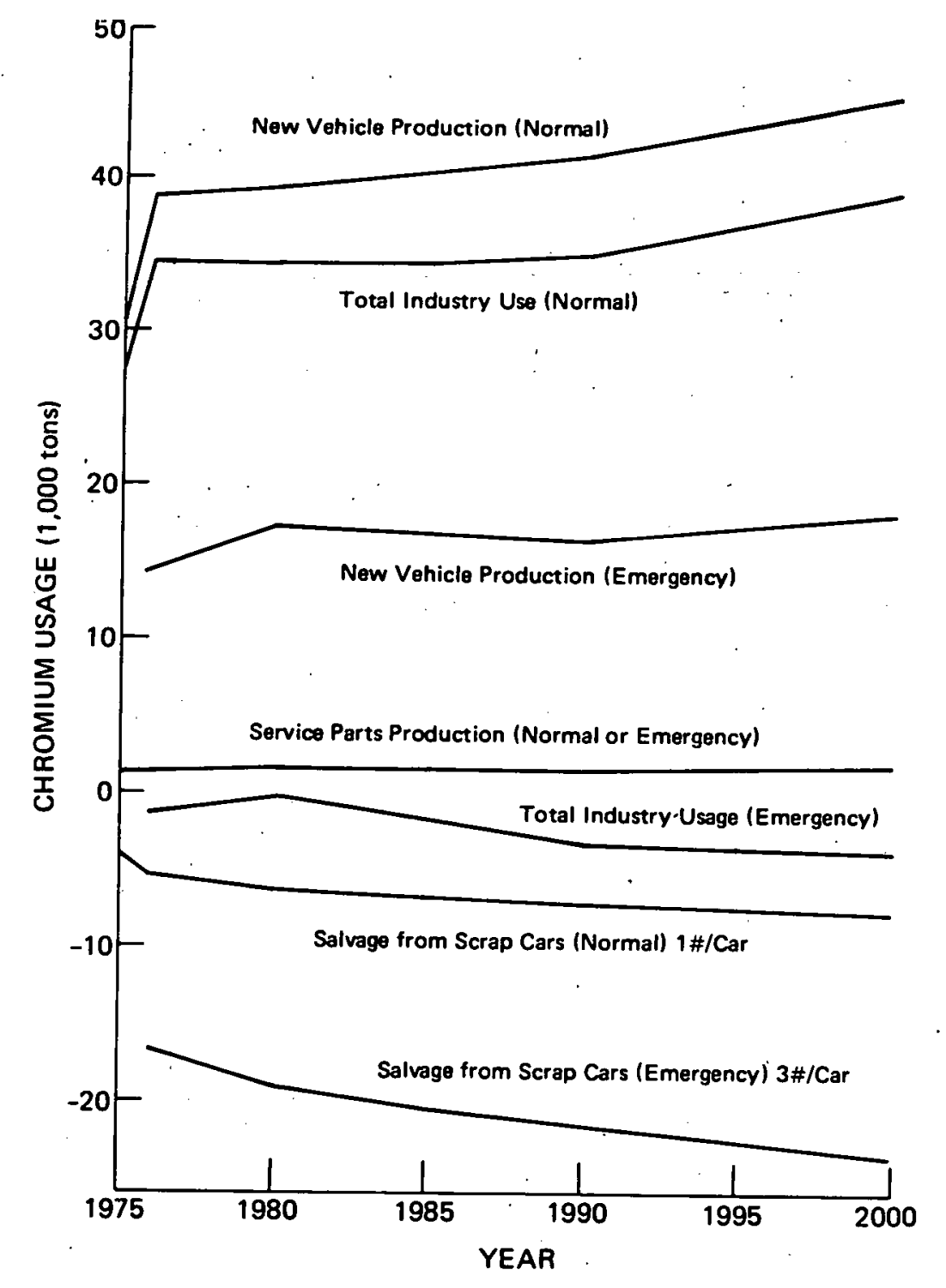

FIGURE B-1 Forecast of Automotive Industry Usage of Chromium in Cars, Trucks, and Buses, 1975-2000 (based on data from Jet Propulsion Laboratory 1975, and 1976 presentation to the Committee by J. E. LaBelle, Detroit Diesel Allison, General Motors, Detroit). 
TABLE B-6 Total Chromium Content (pounds) in Various Engines ${ }^{a}$

\begin{tabular}{|c|c|c|c|c|c|c|c|c|c|c|c|c|}
\hline \multirow{2}{*}{ Materials } & \multirow{2}{*}{$\begin{array}{l}\text { Present } \\
\text { Piston. } \\
\text { Otto; } \\
150 \text { hp }\end{array}$} & \multirow{2}{*}{$\begin{array}{l}\text { Present } \\
\text { Diesel, } \\
150 \mathrm{hp}\end{array}$} & \multirow{2}{*}{$\begin{array}{l}\text { Battery } \\
\text { Electric, } \\
50 \mathrm{mph} \text {, } \\
4 \text { Passenger }\end{array}$} & \multicolumn{2}{|c|}{$\begin{array}{l}\text { Free Turbine: } \\
\text { Brayton, } 150 \mathrm{hp}\end{array}$} & \multicolumn{2}{|c|}{$\begin{array}{l}\text { Single-Shaft } \\
\text { Brayton, } 150 \mathrm{hp}\end{array}$} & \multicolumn{3}{|c|}{ Stirling, $170 \mathrm{hp}$} & \multicolumn{2}{|c|}{ Rankine, $150 \mathrm{hp}$} \\
\hline & & & & Mature & Advanced & Mature. & Advanced & Present & Mature & Advanced & Mature & Advanced \\
\hline \multicolumn{13}{|l|}{ Chromium-Containing } \\
\hline Super alloy: & & & & 2.33 & & 0.77 & & 12.15 & 1.50 & & 1.65 & \\
\hline Stainless steel & 2.905 & 0.319 & 0 & 5.40 & 3.25 & 4.19 & 1.61 & 28.8 & 14.94 & & $30: 6$ & 4.14 \\
\hline Alloy steel & $0: 014$ & 0.014 & $<.01$ & 0.08 & 0.06 & 0.08 & 0.06 & 0.22 & 0.08 & 0.07 & 0.12 & 0.12 \\
\hline Cast iron & $0: 735$ & $0.949 b$ & 0. & 0 & 0 & 0 & 0 & 0 & 0 & 0 & 0 & 0 \\
\hline TOTAL Chromium & 3.654 & 1.282 & $<.01$ & 7.81 & 3.31 & 5.04 & 1.67 & 41.17 & 16.52 & 0.07 & 32.37 & 4.26 \\
\hline \multicolumn{13}{|l|}{ Other. } \\
\hline Ceramic & & & & 20 & 112 & 20 & 106 & 22 & 22 & 110 & - & 93 \\
\hline Aluminum & & & & & & & & 51 & 181 & 178 & & \\
\hline Cobalt & & & & 3.9 & & 0.60 & & & 2.2 & & 2.2 & \\
\hline Tungsten & & & & 0.80 & & 0.75 & & & 0.37 & & 0.27 & \\
\hline
\end{tabular}

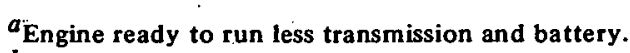

${ }^{b}$ The diesel is assumed to have head, block, and bearing caps weighing 1.35 times the Otto. Other castings are the same.

NOTE: Based-on data from:Jet Propulsion Laboratory, 1975. 
REFERENCES

Automotive Industries. "58th Engineering Specifications and Statistics Issue." Automotive Industries (April 1\%" 1976): 25,43 .

Harvey. D.G., and Menchen, W.P. A Technology Assessment of the Transition to Advanced Automotive Propulsion systems." Columbia. Marỵland: Hittman Associates, Inc.. May 1974.

Iron Age. "Ceramic Gas Turbine Has a Promising Future." Iron_Age 217 (March 1, 1976):37-9.

Jet Propulsion Laboratory: Should We Have a New Engine?. Vol. II. Pasadena: California Institute of Technology: Jet Propulsion Laboratory, 1975.

NOTES

1. J.E. LaBelle, General Motors Corporation, reports that in a December 1975 conversation. Robert Neison, Materials Engineer, General Motors Truck and Coach Division, indicated that:

Stainless and chromium usage is similar to that of a passenger car in gasoline-powered trucks, the two principle exceptions are diesel-powered heavy duty trucks and some buses. since diesel engines are much heavier and the vehicles are larger, the engine, transmission, and drive iine components are all larger and employ more ailoy iron and steel. (It is probable however that without the catalytic converter, actual chromium content, is' nearly the same). In the case of coaches. aluminum is used externaliy; however, two models employ large stainiess components. "Otherwise they would be similar to trucks in actual stainless and chromium usage. one type of coach employs Type 304 stainiess steel bumpers on both front and rear. These weigh 200 pounds each or 400 pounds per vehicle, The 200 units produced per year represent a usage of 80,000 pounds of stainless and 15.200 pounds of chromium. An additional 50 percent of production is used for replacement parts. The total is therefore 120,000 pounds of stainless containing 22,800 pounds of chromium. 
The other part is the front step well employed on 375 coaches per year. This part has a finished weight of 80 pounds and a rough weight of 120 pounds. The finished weight usage of stainless Type 304 is 30,000 pounds containing 5,700 pounds of chromium. The above is for GM truck and coach production only.

In a January 1976 conversation with J.E. LaBelle, Art sewart, Chief Metallurgist, General Motors Central Foundry Division, indicated the following for 350 cubic inch V8 automobile engines:

Cylinder Blocks and Heads

Chromium content is held to $0.28-0.32 \%$ for heads and blocks.

Approximate charge $=10,0001 \mathrm{bs}$.

$$
\begin{array}{ll}
20 \% & -0.3 \% \mathrm{Cr} \text { steel turnings } \\
28 \% & -0.3 \% \mathrm{Cr} \text { foundry returns } \\
45 \% & -0.1-0.2 \% \mathrm{Cr} \text { gray iron } \\
& \text { casting turnings } \\
\text { Balance } & - \text { pig iron }
\end{array}
$$

$60 \%$ ferrochrome is added to achieve 0.28 to $0.32 \%$; 6 to 10 pounds normally containing 3.6 to 6 pounds of chrome.

\section{Camshafts}

$$
\begin{aligned}
& \text { Olds }-1.30-1.50 \% \mathrm{Cr} \\
& \text { Pontiac }-0.90-1.10 \% \mathrm{Cr}
\end{aligned}
$$

Iittle, if any, chromium was lost in remelting chromium-containing scrap. The principle problem is that cast iron chips are not segregated by chrome content nor are scrap castings. As a result, cast iron chips containing chrome are purchásed by foundries that do not require it and vice versa.

In a January 1976 letter to J.E. LaBelle, Carl J. Casza, Research and Development Division, Fruehauf corporation, reported that:

The volume of stainless steel tankers (which are used to haul milk, acids, and various chemicals) produced by all trailer manufacturers is tabulated below. 


$$
\frac{1973}{1.450} \frac{1974}{1.410} \div \frac{1975 \text { (6 months) }}{500}
$$

Each unit uses about 5,000 1bs. of stainlss steel making a total stainless steel usage of 3,500 tons (based on 1,400 units/year).

Some bulk hopper trailers which are used to haul fertilizer and other hygroscopic materials are made of stainless steel as are some vans that are used for hauling ammunition; however, there is no industry breakdown on this, but the number of these units would probably not exceed 50 and would consume an estimated 125 tons of stainless.

The industry also uses stainless steel tubes and hangers in "meat-railers" which transport beef carcasses and other meat products. There are about 5.000 of these units produced yearly by the trailer manufacturers with about 350 pounds of stainless steel per unit; this gives an additional usage of 875 tons of stainless steel making a grand total of 4.500 tons per year. 


\section{Appenọix C CHROMIUM UTILIZATION IN THE AIRCRAFT INDUSTRY}

Eighteen major aircraft engine and airframe manufacturers were contacted by letter requesting actual chromium consumption quantities for 1975 as well as projected quantities for each subsequent year through 1980 . seven of the eight responses contained the information requested in varying detail. Two of the larger airframe and one aircraft engine manufacturers are included among the seven respondents. Generally, the chromium consumption quantities provided included metallurgical and chemical chromium that was purchased by the respective companies for the manufacture of their products, as well as the excess necessary for fabrication operations and projection. Material purchased by subcontractors is not included. Historically, significant portions of large commercial aircraft transports are fabricated by subcontractors.

Table $\mathrm{C}-1$ summarizes the aircraft chromium consumption data provided by the 7 respondents, rounded to the nearest 10 tons. The value for 1975 includes both actual data and estimates, while the values for subsequent years are the estimates made by the various companies. Projections for future chromium consumption for individual companies varied from a constant annual rate to an increased consumption rate 46 percent greater for 1980 than for 1975. The three major consumers shared 95.6 percent of both the 1975 and the 1980 totals. Data received for 1975 represent approximately 20 percent of the 1972 consumption computed for the U.S. aircraft industry.

Chromium consumption in terms of the various mill products and materials is shown in Table $\mathrm{C}-2$. The various forms are listed in the same manner that they were identified by the individual companies, but unfortunately, over 85 percent of the total consumption was not identified as to the forms involved.

Corrosion-resisting steels and superalloys account for the values shown for the mill products in Table $c-2$. Chromium contained in low-alloy steels and aluminum alloys was not determined for by those supplying data for these forms. Low chromium content, averaging approximately 0.2 percent in the high-strength aircraft-type aluminum alloys, should result in only small changes in the total consumption. Low-alloy steel chromium contents average about 1 percent and may increase the consumption total by a significant amount. Approximately 20 percent of the chromium used in fabricating a large commercial transport 
TABLE C-1 Estimated Aircraft Industry Chromium Consumption

\begin{tabular}{ll}
\hline & $\begin{array}{l}\text { Chromium } \\
\text { Consumption } \\
\text { (short tons) }\end{array}$ \\
\hline 1975 & 2,890 \\
1976 & 2,940 \\
1977 & 3,100 \\
1978 & $3,250 . \ldots$ \\
1979 & 3,250 \\
1980 & 3,370 \\
\hline
\end{tabular}

TABLE C-2 Aircraft Industry Chromium Consumption by Material Form for 1975

\begin{tabular}{lc}
\hline $\begin{array}{l}\text { Material and } \\
\text { Mill Product Form }\end{array}$ & $\begin{array}{c}\text { Chromium } \\
\text { Consumption } \\
\text { (short tons) }\end{array}$ \\
Sheet and plate & 96.9 \\
Bar & 36.6 \\
Forging & 20.0 \\
Wire & 0.9 \\
Tubing & 35.3 \\
Castings & 5.9 \\
Low alloy steels & 12.4 \\
Corrosion-resisting steels & 98.3 \\
Aluminum alloys & 7.1 \\
Paint primers & 14.2 \\
Chemicals & 62.5 \\
Unidentified. & Total
\end{tabular}


airframe was in low-alloy steels. Airframe, as used here, refers to the structure, controls, and hydraulics of the aircraft and excludes the engines.

purchased equipment (excluding engines) that is installed in aircraft generally has a very low chromium content and is presumed not counted in the submitted data. The time and effort required to develop data for this equipment would be excessive considering the weights involved.

Yield figures (flying weight versus purchased weight) were furnished by one aircraft manufacturer for each form of metallic raw material and are shown in Table c-3. Overall yield figures, identified for different models of aircraft, also were provided and varied from 48 percent to 61 percent. Yield figures are expected to improve with the maturity of the production line for each model due to less rejections. the use of die forgings, and more efficient operations.

The catastrophic consequences of failure in critical aircraft components while landing or in the air result in a cautious approach to changes in the materials involved. Aerospace use of chromium is only a small percentage of the total chromium production; yet, the effect of chromium on the life and reliability of aerospace alloys is extremely critical, and elimination or even reduction of chromium in these alloys would be particularly devastating to aircraft turbine engines.

TABLE C-3 Ratio of Chromium Contained in Completed Airframe versus that Purchased by Manufacturer

\begin{tabular}{ll}
\hline Raw Material Form & $\begin{array}{c}\text { Fly/Buy } \\
(\%)\end{array}$ \\
\hline Sheet and plate & 58 \\
Bar & 37 \\
Castings & 91 \\
Forgings & 57 \\
Tubing & 70 \\
\hline
\end{tabular}


Chromium contained in the metallic materials that are required to fabricate a large commercial transport aircraft currently can be determined only by review of all drawings released for a particular series of aircraft. The total number of drawings involved for the aircraft airframe used in this survey is estimated at over 80,000 , and includes drawings for all the models offered as well as various optional features that are available. An automated data process is being developed to list metallic materials used on the aircraft airframe (private communication with $\mathrm{J}$. $\mathrm{H}$. Adams, Boeing 1976). Drawings reviewed to date include essentially all the larger metallic components and about two-thirds of the estimated total. This list will not cover purchasea equipuent, thereby excluding the engines.

Data presented herein for the airframe were obtained from 1,280 drawings for superalloy and steel components. Chromium usage was calculated from the average alloy composition and the raw material stock size listed on the drawing or weight in the case of forgings and castings. Less than 5 percent of these drawings. primarily forgings, did not list raw material weight or stock size.

Table $\mathrm{C}-4$ indicates the chromium usage computed from available data in terms of raw material form and the type of alioy. Quantities of part numbers and individual parts also are included. Chromium usage by alloy type totals 4.001 pounds for corrosion-resisting steels, 426 pounds for superalloys, and 1,127 pounds, for low-alloy steels.

Table $\mathrm{C}-5$ contains the chromium usage results for different functional areas of the airframe as calculated from available data. A total lower than in Table C-4 results because a functional area was not listed for every item in the data lists. Essentially all of the difference is contained in corrosion-resisting steel castings.

As mentioned above, chromium usage data generally are based on stock sizes listed on the engineering drawing, but for a few sheet metal parts, the stock size was not listed and was estimated. Chromium usage totals, determined from these stock sizes, will be less than the quantity actually purchased since increases for rejections and additional allowances involved in the manufacture or fabrication of parts are not included. The latter allowance would be negligible for forgings or castings and would be the greatest for tubing or sheet where forming is used to produce complex contours.

Airframe components fabricated from each raw material form can be grouped into a limited number of general types. Bar and forgings are used for fittings (e.g.. structural, 
TABLE C-4. Chromium Usage for a Large Commercial Transport Airframe by Raw Material

\begin{tabular}{|c|c|c|c|c|}
\hline Form & Alloy Type & $\begin{array}{l}\text { Quantity } \\
\text { of Parts }\end{array}$ & $\begin{array}{l}\text { Quantity } \\
\text { Part Numbers }\end{array}$ & $\begin{array}{l}\text { Chromium } \\
\text { (pounds) }\end{array}$ \\
\hline Sheet and plate & $\begin{array}{l}\text { Corrosion-resisting steel } \\
\text { Superalloys } \\
\text { Low-alloy steel }\end{array}$ & $\begin{array}{r}20,890 \\
415 \\
222\end{array}$ & $\begin{array}{r}162 \\
64 \\
26\end{array}$ & $\begin{array}{r}356 \\
126 \\
4\end{array}$ \\
\hline Bar & $\begin{array}{l}\text { Corrosion-resisting steel } \\
\text { Superalloys } \\
\text { Low-alloy steel }\end{array}$ & $\begin{array}{r}20,700 \\
4,995 \\
2,946\end{array}$ & $\begin{array}{r}352 \\
18 \\
395\end{array}$ & $\begin{array}{r}1,847 \\
252 \\
190\end{array}$ \\
\hline Forging & $\begin{array}{l}\text { Corrosion-resisting steel } \\
\text { Superalloys } \\
\text { Low-alloy steel }\end{array}$ & $\begin{array}{r}6,959 \\
18 \\
699\end{array}$ & $\begin{array}{r}83 \\
2 \\
158\end{array}$ & $\begin{array}{r}1.185 \\
46 \\
927\end{array}$ \\
\hline Tubing & $\begin{array}{l}\text { Corrosion-resisting steel } \\
\text { Superalloys } \\
\text { Low-alloy steel }\end{array}$ & $\begin{array}{r}227 \\
45 \\
50\end{array}$ & $\begin{array}{r}20 \\
8 \\
10\end{array}$ & $\begin{array}{r}419 \\
2 \\
6\end{array}$ \\
\hline $\begin{array}{l}\text { Sasting } \\
\text { Total }\end{array}$ & Corrosion-resisting steel & $\frac{1,350}{59,516}$ & $\frac{133}{1,431}$ & $\frac{194}{5,554}$ \\
\hline
\end{tabular}


TABLE C-5 Chromium Usage for a Large Commercial Transport Airframe by Functional Area

\begin{tabular}{|c|c|c|}
\hline Functional Area & Alloy Type & $\begin{array}{l}\text { Chromium } \\
\text { (pounds) }\end{array}$ \\
\hline Body & $\begin{array}{l}\text { Corrosion-resisting steel } \\
\text { Superalloys } \\
\text { Low-alloy steel }\end{array}$ & $\begin{array}{r}488 \\
57 \\
27\end{array}$ \\
\hline Wing & $\begin{array}{l}\text { Corrosion-resisting steel } \\
\text { Superalloys } \\
\text { Low-alloy steel }\end{array}$ & $\begin{array}{r}567 \\
75 \\
596\end{array}$ \\
\hline Landing gear & $\begin{array}{l}\text { Corrosion-resisting steel } \\
\text { Superalloys } \\
\text { Low-alloy steel }\end{array}$ & $\begin{array}{l}456 \\
-- \\
405\end{array}$ \\
\hline $\begin{array}{l}\text { Propulsion } \\
\text { (excluding engines) }\end{array}$ & $\begin{array}{l}\text { Corrosion-resisting steel } \\
\text { 'Superalloys } \\
\text { Low-alloy steel }\end{array}$ & $\begin{array}{r}1,780 \\
293 \\
49\end{array}$ \\
\hline Controls & $\begin{array}{l}\text { Corrosion-resisting steel } \\
\text { Superalloys } \\
\text { Low-alloy steel }\end{array}$ & $-\frac{35}{26}$ \\
\hline Hydraulics & $\begin{array}{l}\text { Corrosion-resisting steel } \\
\text { Superalloys } \\
\text { Low-alloy steel }\end{array}$ & $\begin{array}{r}14 \\
1 \\
21\end{array}$ \\
\hline Payloads & $\begin{array}{l}\text { Corrosion-resisting steel } \\
\text { Superalloys } \\
\text { Low-alloy steel }\end{array}$ & $\begin{array}{l}456 \\
-- \\
-- \\
\end{array}$ \\
\hline Total & & 5,346 \\
\hline
\end{tabular}


hydraulic actuator, and cargo handling). Sheet and plate are used for formed parts (e.g.. brackets and duct parts). doublers, and fittings from the thicker gauges of plate. Castings are used for components of hydraulic, control, and pneumatic systems as well as on the landing gear. Tubing transmits hydraulic fluids and air, and is used as structural components on the landing gear as well as in other functional areas. Selection of a chromium-containing alloy for the above components is based on many factors.

Low-alloy steels are selected for such engineering properties as elastic modulus, hardenability, and high strength capability. Strength ranges as high as 275,000 to $300.000 \mathrm{psi}$ are not uncommon since weight is of primary concern in aircraft design. An estimated period of 10 years has been required to develop reliable use of steel at these high strengths. The techniques employed should be useful also on substitute steels; however, the industry would be reluctant to use substitute steels in critical applications without thorough evaluation of their properties as well as some accumulation of service experience in noncritical applications. Substitution of low-alloy steels containing no chromium could result in a significant reduction in the amount of chromium used in an airframe. Data presented in Tables $\mathrm{C}-3$ and $\mathrm{C}-4$ indicate that 20 percent of the metallurgical chromium used is contained in the low alloy steels.

Corrosion-resisting steels are used primarily for their corrosion resistance and the resulting low maintenance. The low maintenance is particularly attractive for parts that are subject to surface damage (e.g., parts involved in cargo handling). For less severe applications, surface corrosion can be controlled by coatings applied to substitute materials. Some coatings, however, have adverse effects on engineering properties of the material. Chromium plating reduces fatigue life of a part by as much as 25 percent (Boeing Company 1975). A coated low-alloy steel part also would not perform as well as a corrosion-resisting alloy where stress-corrosion cracking determines the service life of a component. Stress corrosion tests (private communication with S. E. Wilson, Boeing, 1976) have indicated 17-4 $\mathrm{PH}$ at a 180.000 to 200,000 psi strength level had over 4 times the stress-corrosion-cracking resistance of 4340 steel (Erdmann 1973). Penetration of the coating on a low-alloy steel component by the corrosion environment is a potential problem due to damage. coating defects. or inadequate thickness.

Titanium has been used to replace corrosion-resisting steels for some applications (e.g.. fasteners) and no doubt would be suitable for other applications. Weight savings 
associated with use of titanium alloys make them an attractive substitute even though material costs are higher.

Superalloys are chosen because of their elevated temperature properties. Substitute materials with lower chromium contents could be utilized in those airframe applications where present materials are not subjected to temperatures near their maximum, working temperature.

Chromium usage in aircraft turbine engines has been excluded from previously presented data because the engines are equipment purchased by the aircraft producer. Information provided by a major aircraft turbine engine manufacturer reveals that the engines account for the bulk of the chromium used in a jet aircraft. The total weight of chromium used in alloys purchased for a typical large aircraft turbine engine has been reported at 6,066 pounds. Considering 4 such engines as propulsion for the typical large transport aircraft discussed earlier. the engines account for approximately 81 percent of the total chromium purchased for manufacture of the aircraft:

Aircraft turbine engines use chromium principally as a constituent of superalloys in applications involving exposure to elevated temperatures. Modern designs use the high-strength alloys of approximately 10 percent chromium to near their maximum capability while relying on air-cooling systems to minimize exposure temperatures. Improvement in air-cooling efficiency is a continuing effort in engine development. Other cooling systems, such as liquid cooling. also are being investigated and developed to further improve engine performance.

Chromium contents up to 22 percent are utilized in other engine applications where oxidation or corrosion resistance, formability, and weldability are given more consideration than strength at temperature.

Design limitations imposed by the elevated temperature capability of turbine engine alloys severely restrict material substitutions if equal performance and reliability are to be maintained. The potential high loss of human life caused by engine failure dictates that new alloys be incorporated into production only after their capability has been proved through extensive development effort. 


\section{REFERENCES}

Boeing Company - D-5000 Design standards. Vol. 81. section 280.42, Figure 280.42-2. Seattle, Washington: The Boeing Company, February 17, 1975.

Erdmann. J.C. "Review of Data on Subcritical Crack Growth in 4340 stee1." In Minuteman Materials and Processes. MMMP-215. Seattle, Washington: Boeing Aerospace Company. November 21. 1973. 
Appendix $\cdot \mathbf{D}$

\section{CHROMIUM USAGE IN THE MARINE INDUSTRY}

Twenty-two large shipbuilders and ship equipment companies from a list of fifty-five were selected and requested to supply chromium consumption data. Actual consumption for 1975 was requested as well as estimates of chromium consumption for each succeeding year through 1980. Included among the four respondents who supplied data were a major company involved.in new construction and ship repair. and another that manufactures barges; vessels, and off-shore platforms. In most cases, the data supplied were identified by the sources as proprietary. Two additional shipbuilding companies and one ship. equipment company responded to the Committee's inquiry by noting that chromium consumed was contained in purchased equipment and the amount was not readily determined or that no chromium was consumed.

Table D-1 shows annual chromium consumption quantities compiled from the limited data received. The quantities shown are based on raw materials purchased by the respective companies and, consequently, do not include quantities purchased by subcontractors or contained in purchased equipment. The 1975 quantity consists of 35 tons from lowalloy high-strength steel, 132 tons from ferrochrome, 5 tons from paint, and 108 tons from corrosion-resistant steels. Data received for 1975 represent approximately 15 percent of the 1972 consumption calculated from U.S. Census statistics for ship building and repair plus boat building and repair.

TABLE D-1 Estimated Marine Industry Chromium Consumption

\begin{tabular}{ll}
\hline Year & $\begin{array}{l}\text { Chromium } \\
\text { Consumption } \\
\text { (short tons) }\end{array}$ \\
\hline 1975 & 280 \\
1976 & 180 \\
1977 & 273 \\
1978 & 345 \\
1979 & 430 \\
1980 & 475 \\
\hline
\end{tabular}


Data reported in Table $D-1$ are believed to exclude quantities of chromium that would be required to construct deep water ports or terminal facilities for crude oil and liquid natural gas (LNG) tankers. Annual consumption for these applications depends on a decision to build and the scheduling of the construction.

Chromium required to construct a deep water port to accommodate large crude oil tankers has been estimated at 2,160 short tons (Albers and Bawiec 1975):

The deep water port facilities include the berths for the tankers, any necessary booster pumping facilities, the pipelines from berth to tank farm, and the necessary intermediate tankage at the terminal. They do not include the distribution pipelines and pumping facilities from marine terminal to refineries.

An estimated 21.6 short tons (Albers and Bawiec 1975) of chromium are required to construct an LNG terminal facility:

The typical liquid natural gas (LNG) terminal contains facilities to berth a liquid natural gas (LNG) tanker, receive and store $L N G$, raise the pressure of the ING to the gas pipeline pressure, vaporize the ING. compress the boil-off gases, and deliver a daily average of 500 million cubic feet to a gas pipeline at generally not less than 40 o F and 1200 psig.

A search for detailed data on the quantity of chromium required to fabricate a typical marine vessel revealed that the data are not readily available at this time. Contacts were made with shipbuilders, Navy offices, the Maritime Aaministration, the American Bureau of Shipping, and the Society of Naval Architects in addition to reviewing marine industry periodicals.

A number of ship applications were identified as requiring alloys containing chromium. Low-temperature applications such as containers for LNG may utilize stainless steel; however, two sources indicated that current economics favored use of aluminum alloys and that currently only limited use was being made of stainless steel for shipboard LNG containers. Higher strength ship hull steel containing 0.25 percent maximum chromium is used as required by the American Bureau of Shipping rules. An estimate was received that 10 percent of hull steel is this grade. Lowalloy steel pipe conforming to ASTM A335. Grade P11, is used for steam.lines. Using an estimated 20,000 pounds of low- 
303

alloy steel per ship results in 250 pounds of contained chromium being consumed for this application. stainless steel is used for nuclear primary pipe systems, gas turbine exhaust lines, galley areas and equipment, and cladding of tail shafts. In the case of hydrofoil vessels, it is used for strut and foil material. Ship machinery also can be expected to involve use of chromium, the degree of consumption being dependent on the application and its. design requirements.

REFERENCE

Albers. J.P., and Bawiec, W. J. Demand and Supply of NonFuel Minerals and Materials for the United States Energy Industry, 1975-1990: A Preliminary Report. USGS Professional paper 1006-A,B 75-583. Washington, D.C.: U.S. Geological Survey. 1976. 


\section{Appendix E \\ CONSUMPTION OF CHROMIUM AND FERROCHROMTUM}

Table E-1 lists the annual consumption of chromium and ferrochromium, and the production allocations to stainless and alloy steels for 1968, 1970, 1972, and 1974. Tables E-2 through E-5 present the consumption of chromium additions. the general composition of the input charge, the raw steel produced, the reported home scrap generated, calculated yields, and the distribution of shipments according to mill product for stainless and alloy steels.

Table E-1 provides calculated allocations of ferrochromium and ferrochromium-silicon based on annual production of these ferroalloys and the following distribution: 67.4 percent for stainless steel, 18 percent for chromium-containing steels, and 14.6 percent for other alloys. (The relation between ferrochromium production and chromium-containing steel production is changing because an increasing fraction of ferrochromium has been imported.)

Annual raw steel production and shipments are the measures of the input and output volumes, respectively. for stee 1-mil1-product fabrication. Since a portion of the fabrication may be placed in inventory, a second measure of the mill output is the annual raw steel production minus the generated home scrap. A factor critical to chromium consumption and recovery -- net yield of steel -- is the-sum of shipments plus home scrap.

The gross yields, shipments as a percent of raw steel production, for stainless steels (Table E-2) averaged 57 percent and alloy steels (Table E-4) averaged 57 percent with relatively narrow variations. The equivalent yield for the entire steel industry is about 67 percent. The lower yields for chromium-containing steels are associated with their smaller ingot sizes, the workability of the alloys. and the efficiency of the available equipment. The corresponding net yields are 95.3 percent for raw stainless steel processed into mill products (leaving a net loss of 4.7 percent equivalent to 3 percent of total annual consumption) and 67.7 percent for chromium-containing alloy steel, resulting in an apparent loss of 32.3 percent. According to AISI data, 36.6 percent of alloy steels contain chromium, an amount equivalent to a loss of 4 percent of total annual chromium consumption: These losses, which are much greater than the losses with stainless steel, are associated with the greater variety of alloy steel chemistry. large volume of hot-rolled products, greater ingot crop length, larger scale and pickling losses, and 
TABLE E-1 Production and Allocations of Ferrochromium Alloys for Stainless Steels and Chromium-Containing steels ( 1,000 tons)

\begin{tabular}{llllll}
\hline Ferroalioy Type & 1968 & 1970 & 1972 & 1974 \\
\hline
\end{tabular}

Annual Production

\begin{tabular}{|c|c|c|c|}
\hline Ferrochromium & 253 & 275 & 295 \\
\hline Ferrochromium silicon & 129 & 165 & 112 \\
\hline Total & 382 & 440 & 407 \\
\hline
\end{tabular}

Production Allocations

Ferrochromium to stainless steel $257.5 \quad 296.6 \quad 274.3 \quad 309.4$

$\begin{array}{lllllll}\text { Ferrochromium to alloy steel } & 68.8 & 79.2 & 73.3 & 82.6\end{array}$

$\begin{array}{llllll}\text { Ferrochromium to other alloys } & 55.7 & 64.2 & 59.4 & 67.0\end{array}$

NOTE: Data from American Iron and Steel Institute 1975, and Charles River Associates, Inc. 1970 . 
TABLE E-2 Stainless Steel Production and Losses

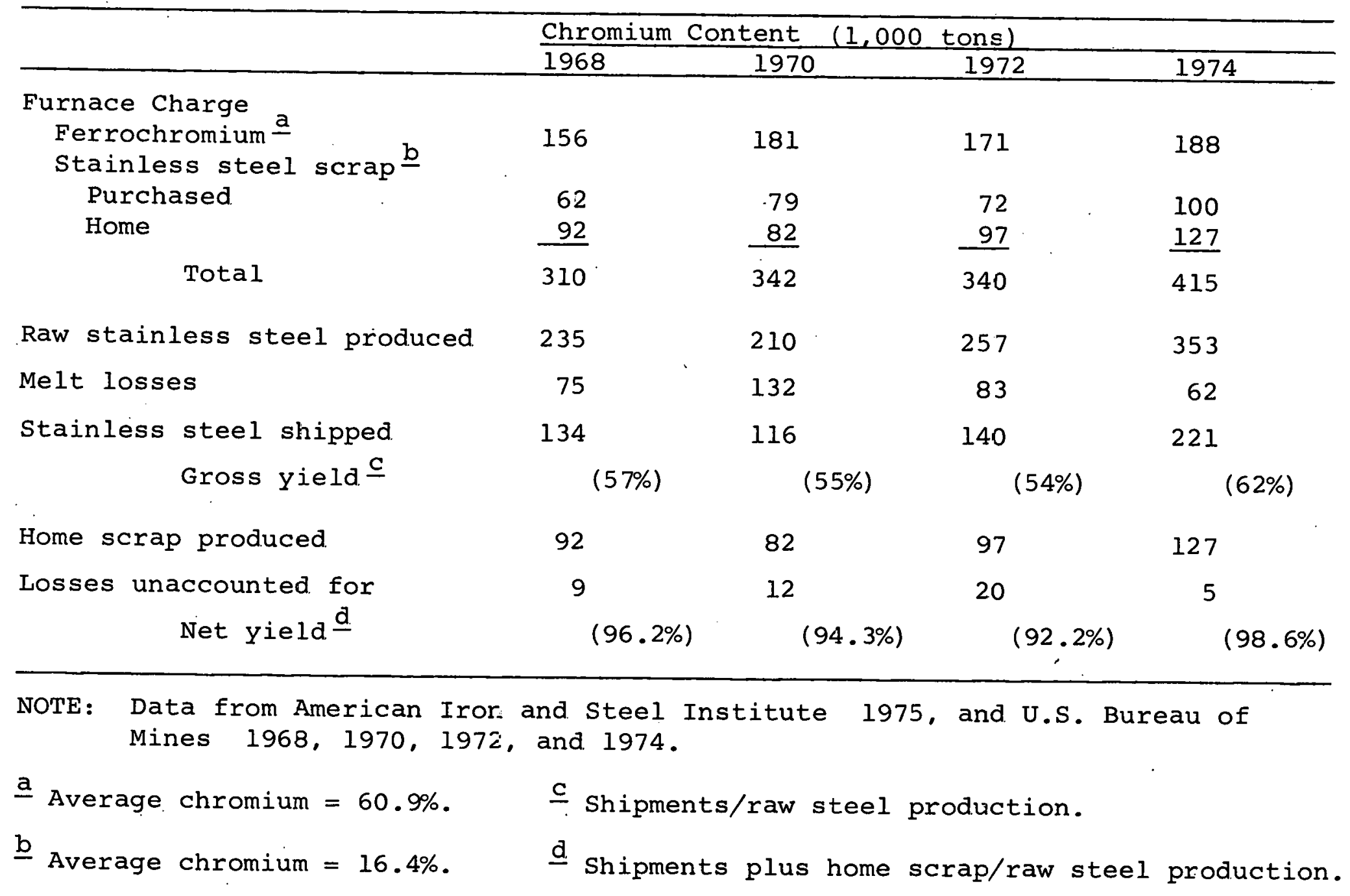


TABLE E-3 Breakdown of Stainless Steel Shipments, 1968-1974 (1,000 tons)

\begin{tabular}{|c|c|c|c|c|c|c|c|c|}
\hline Product Form & 1968 & & 1970 & & 1972 & & 1974 & \\
\hline Ingots and castings & 5.9 & $(0.7 \%) \underline{a}$ & 9.6 & $(1.4 \%)$ & 17.3 & $(2.0 \%)$ & 26.9 & $(2.0 \%)$ \\
\hline Semifinished mill products & 49.0 & $(6.0 \%)$ & 48.6 & $(6.8 \%)$ & 40.5 & $(4.7 \%)$ & 66.6 & $(5.0 \%)$ \\
\hline $\begin{array}{l}\text { Finished mill products (except } \\
\text { sheet and strip) }\end{array}$ & & & & & & & & \\
\hline Shapes and plates & 56.6 & $(6.9 \%)$ & 54.8 & $(7.7 \%)$ & 57.0 & $(6.7 \%)$ & 128.4 & $(9.6 \%)$ \\
\hline $\begin{array}{l}\text { Bars } \\
\text { Hot rolled } \\
\text { Cold drawn }\end{array}$ & $\begin{array}{l}44.6 \\
91.8\end{array}$ & $\begin{aligned}(5.4 \%) \\
(11.2 \%)\end{aligned}$ & $\begin{array}{l}42.8 \\
79.3\end{array}$ & $\begin{array}{r}(6.0 \%) \\
(11.2 \%)\end{array}$ & $\begin{array}{l}44.8 \\
70.5\end{array}$ & $\begin{array}{l}(5.2 \%) \\
(8.2 \%)\end{array}$ & $\begin{array}{r}61.0 \\
107.0\end{array}$ & $\begin{array}{l}(4.5 \%) \\
(8.0 \%)\end{array}$ \\
\hline Pipe and tubes & 26.0 & $(3.2 \%)$ & 32.1 & $(4.5 \%)$ & 28.8 & $(3.4 \%)$ & 53.1 & $(3.9 \%)$ \\
\hline Wire & 24.5 & $(3.0 \%)$ & 14.7 & $(2.1 \%)$ & 29.8 & $(3.5 \%)$ & 38.3 & $(2.8 \%)$ \\
\hline Subtotal & 243.5 & $(29.7 \%)$ & 223.7 & $(31.5 \%)$ & 230.9 & $: 27.0 \%)$ & 387.8 & $(28.8 \%)$ \\
\hline Sheet and strip & & & & & & & & . \\
\hline $\begin{array}{l}\text { Sheet } \\
\text { Hot rolled } \\
\text { Cold rolled }\end{array}$ & $\begin{array}{r}32.9 \\
182.9\end{array}$ & $\begin{array}{r}(4.0 \%) \\
(22.3 \%)\end{array}$ & $\begin{array}{r}34.2 \\
157.8\end{array}$ & $\begin{array}{r}(4.8 \%) \\
(22.3 \%)\end{array}$ & $\begin{array}{r}17.9 \\
258.7\end{array}$ & $\begin{array}{r}(2.1 \%) \\
130.3 \%)\end{array}$ & $\begin{array}{r}44.7 \\
475.5\end{array}$ & $(3.3 \%)$ \\
\hline $\begin{array}{l}\text { Strip } \\
\text { Hot rolled } \\
\text { Cold rolled }\end{array}$ & $\begin{array}{r}22.7 \\
282.1 \\
\end{array}$ & $\begin{array}{r}(2.8 \%) \\
(34.5 \%)\end{array}$ & $\begin{array}{r}23.4 \\
212.1 \\
\end{array}$ & $\begin{array}{r}(3.3 \%) \\
(29.9 \%)\end{array}$ & $\begin{array}{r}15.9 \\
273.5 \\
\end{array}$ & $\begin{array}{l}(1.9 \%) \\
(32.0 \%)\end{array}$ & $\begin{aligned} & 17.1 \\
& \vdots 26.1 \\
&\end{aligned}$ & $\begin{array}{r}(1.3 \%) \\
(24.3 \%)\end{array}$ \\
\hline Subtotal & 520.6 & $(63.6 \%)$ & 427.5 & $(60.3 \%)$ & 566.0 & $(66.3 \%)$ & $\varepsilon 63.4$ & $(64.2 \%)$ \\
\hline Total shipped & 819.0 & $(100.0 \%)$ & 709.4 & $(100.0 \%)$ & 854.7 & $(100.0 \%)$ & $1,344.7$ & $(100.0 \%$ \\
\hline
\end{tabular}

NOTE: Data from American Iron and Steel Institute, 1975.

a Numbers in parentheses indicate the percentage of total stainless steel shipped. 
TABLE E-4 Chromium-Containing Alloy Steel Production and Losses

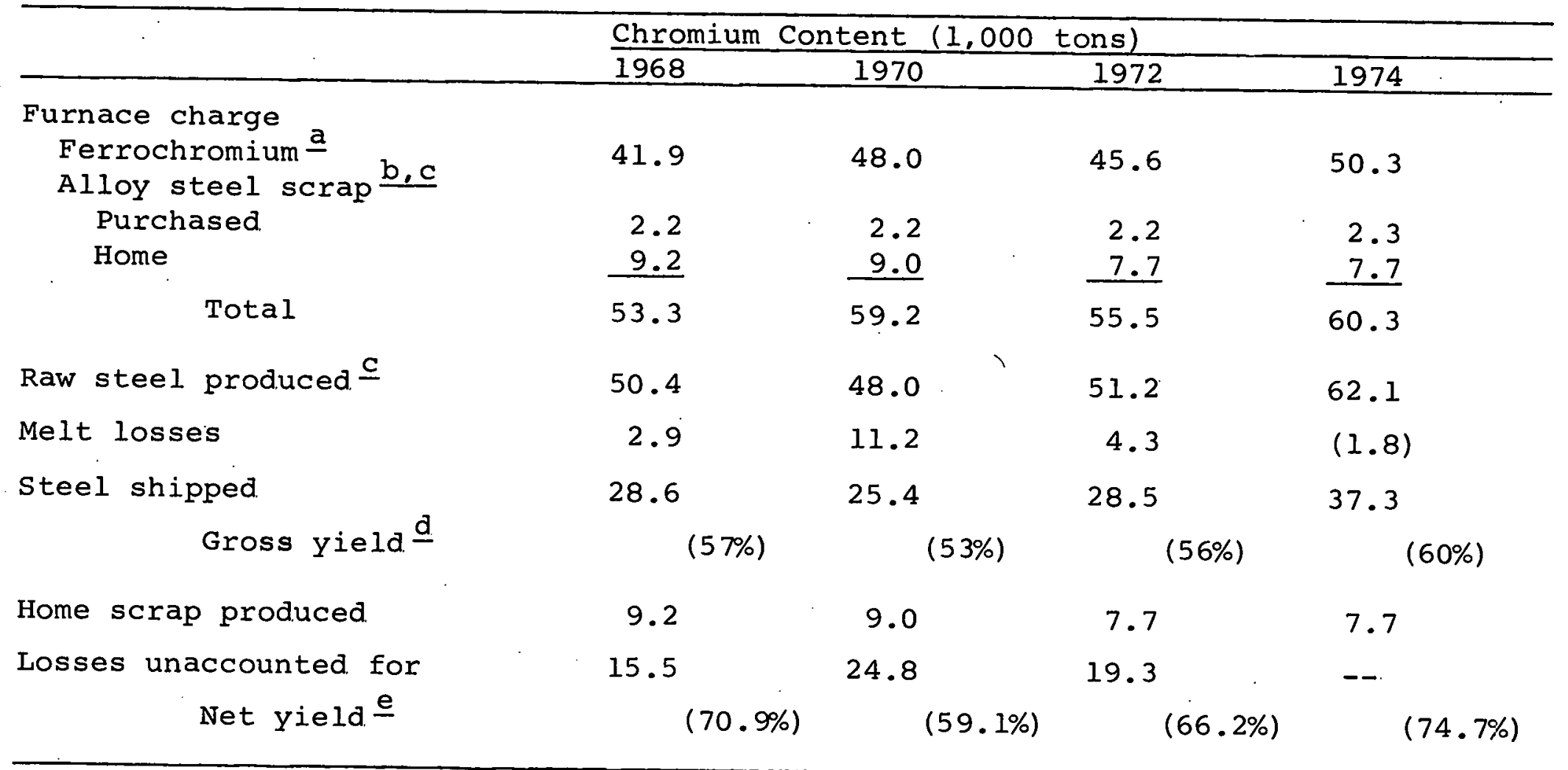
NOTE: Data from American Iron and Steel Institute 1975, and U.S. Bureau of Mines
1968, 1970, 1972, and 1974.

a Chromium average $=60.9 \%$.

$\underline{b}$ Chromium average $=1.0 \%$.

C See Table E-5 for ratio of chromium alloy to total alloy steel. d. Shipments/raw steel production.

e shipments plus home scrap/raw steel production. 
TABLE E-5 Breakdown of Chromium-Containing Alloy Steel Shipments, 1968-1974 (1,000 tons)

\begin{tabular}{|c|c|c|c|c|c|c|c|c|}
\hline Product Form & 1968 & & 1970 & & 1972 & & 1974 & \\
\hline Ingots and Castings & 64.0 & $(2.2 \%) \underline{a}$ & 96.2 & $(3.8 \%)$ & 84.6 & $(3.0 \%)$ & 158.6 & $(4.3 \%)$ \\
\hline Semifinished mill products & 197.5 & $(7.0 \%)$ & 240.9 & $(9.5 \%)$ & 263.2 & $(9.2 \%)$ & 314.0 & $(8.4 \%)$ \\
\hline Finished mill products & & & & & & & & \\
\hline Shapes and plates & 594.6 & $(20.8 \%)$ & 612.7 & $(24.1 \%)$ & 647.0 & $(22.7 \%)$ & 925.5 & $(24.8 \%)$ \\
\hline Bars - hot rolled & 847.8 & $(29.6 \%)$ & 727.3 & $(28.6 \%)$ & 889.4 & $(31.2 \%)$ & $1,148.2$ & $(30.8 \%)$ \\
\hline Tool steel & 39.6 & $(1.4 \%)$ & 32.7 & $(1.3 \%)$ & 33.4 & $(1.2 \%)$ & 40.2 & $(1.1 \%)$ \\
\hline Pipe and tubes & 709.0 & $(24.8 \%)$ & 438.2 & $(17.2 \%)$ & 507.0 & $(17.8 \%)$ & 555.3 & $(14.9 \%)$ \\
\hline Wire & 11.0 & $(0.4 \%)$ & 7.3 & $(0.3 \%)$ & 10.4 & $(0.4 \%)$ & 13.4 & $(0.4 \%)$ \\
\hline Subtotal & $2,202.0$ & $(77.0 \%)$ & $1,818.2$ & $(71.5 \%)$ & $2,087.2$ & $(73.3 \%)$ & $2 ; 582.6$ & $(72.0 \%)$ \\
\hline Strip and sheet & & & & & & & & \\
\hline Sheet - hot rolled & 139.8 & $(4.8 \%)$ & 122.0 & $(4.8 \%)$ & 147.6 & $(5.2 \%)$ & 254.4 & $(6.8 \%)$ \\
\hline Coated sheet and strip & 228.0 & $(8.0 \%)$ & 239.0 & $(9.4 \%)$ & 227.4 & $(8.0 \%)$ & 263.0 & $(7.1 \%)$ \\
\hline $\begin{array}{l}\text { Strip } \\
\text { Hot rolled } \\
\text { Cold rolled }\end{array}$ & $\begin{array}{l}15.8 \\
12.3 \\
\end{array}$ & $\begin{array}{l}(0.6 \%) \\
(0.4 \%)\end{array}$ & $\begin{array}{l}14.3 \\
10.8 \\
\end{array}$ & $\begin{array}{l}(0.6 \%) \\
(0.4 \%)\end{array}$ & $\begin{array}{l}22.6 \\
13.6 \\
\end{array}$ & $\begin{array}{l}(0.8 \%) \\
(0.5 \%)\end{array}$ & $\begin{array}{l}37.6 \\
15.4 \\
\end{array}$ & $\begin{array}{l}(1.0 \%) \\
(0.4 \%)\end{array}$ \\
\hline Subtotal & 395.9 & $(13.8 \%)$ & 386.1 & $(15.2 \%)$ & 411.2 & $(14.5 \%)$ & 570.4 & $(15.3 \%)$ \\
\hline Total shipped & 2.859 .4 & $(100.0 \%)$ & $2,541.4$ & $(.100 .0 \%)$ & $2,846.2$ & $(100.0 \%)$ & $3,725.6$ & $(100.0 \%)$ \\
\hline
\end{tabular}

NOTE: Data from American Iron and Steel Institute 1975.

a Numbers in parentheses indicate the percentage of total chromium-containing alloys shipped. 
lower material cost (and scrap value) and its effects on overall process economics. Most importantly, much alloy scrap loses its identity. which is the probable cause for its low chromium content recovery. A program for more active scrap segregation and reuse of its alloy content would reduce chromium losses. The recovery of stainless steel is excellent in mill-product fabrication and indicates that the major source of chromium consumption is in melting.

Tables E- 6 and E-7 show that about 60 percent of stainless steel production is associated with 7 different steel chemistries, whereas 60 percent of alloy steel production is associated with 4 ranges of composition, each of which includes, several specific compositions. The greater variety in the stainless steels reduces the order size and therefore increases the processing costs and lowers the efficiency of the mill employed. In general. losses from scale, pickling, and conditioning would be significantly larger for alloy than for stainless steels. These-losses are associated with the chemistries of the alloys, the product mix (Tables $E-4$ and $E-5$ ). and the available equipment. Approximately 60 percent of stainless steel shipments are cold-rolled sheet and strip with the production of sheet having increased significantly from 182,900 tons in 1968 to 475,500 tons in 1974. During this same period the alloy steel finished mill products -- hotrolled shapes, plates, and bar -- accounted for about 52 percent of the total production, an increase from 1.450 million to 2 million tons.

The continuous casting capacity for alloy and stainless steel also increased markealy between 1968 and 1972, and included at least one stainless continuous slab casting facility in the United States. Continuous casting is made economically attractive because of significant improvements in yield (and therefore costs) plus lower capital costs because the ingot and blooming/slabbing mill stages are eliminated. No actual yield figures could be obtained. 
TABLE E-6 Major Stainless Steel Grades, 1970 Production

\begin{tabular}{lc}
\hline & Percent of \\
Steel Grade & Tutal Production \\
\hline 304 & 30.0 \\
430 & 8.8 \\
301 & 6.4 \\
316 & 5.3 \\
3041 & 3.8 \\
201 & 3.5 \\
410 & 4.0 \\
All other 300 series grades & 10.3 \\
Al1 other 400 series grades & 6.1 \\
Other chromium-nickel stainless & 4.8 \\
steels & \\
501, 502, and all other high- & 2.9 \\
chromium heat-resistant steels & 14.1 \\
All other grades & \\
\end{tabular}

NOTE: Data from American Iron and Steel Institute Form AIS-7A, 1970. The principal alloy elements in the AISI 200 and 300 series are chromium and nickel, and in the AISI 400 and 500 series, chromium. 
TABLE E-7 Major Alloy Steel Grades, 1970 Production

\begin{tabular}{ll}
\hline Steel Grade & $\begin{array}{l}\text { Percent of } \\
\text { Total Production }\end{array}$ \\
\hline High-strength, low-alloy steels. & 26.5 \\
Nickel-chromium-molybdenum (Ni-Cr-Mo) & 12.2 \\
Chromium-molybdenum (Cr-Mo) & 12.0 \\
Silicon sheet steel & 10.4 \\
Chromium & 9.5 \\
Molybdenum & 6.6 \\
Manganese & 5.1 \\
Nickel-molybdenum (Ni-Mo) & 1.5 \\
Manganese-molybdenum (Mn-Mo) & 1.4 \\
Chromium-molybdenum-vanadium (Cr-Mo-V) & 1.3 \\
All other grades & 13.5 \\
\hline
\end{tabular}

NOTE: Data from American Iron and Steel Institute Form 104, 1970. 


\section{REFERENCES}

American Iron and Steel Institute, New York. Forms AIS-7A and 104 (unpublished). 1970.

American Iron and Steel Institute. Annual Statistical Report. Washington, D.C.: American Iron and Steel Institute, 1975.

Charles River Associates. Inc. Economic Analysis of the Chromium Industry- Cambridge, Mass: Charles River Associates. Inc.. 1970.

U.S. Bureau of Mines. Minerals Yearbook, Vol. I. Washington, D.C.: U.S. Bureau of Mines, 1968, 1970, 1972, 1974. 
Appendix $\mathbf{F}$

JOINING

\section{F. 1 WELDING}

The American Welding Society (AWS) summary chart of welding processes (see Figure $F-1$ ) shows 19 arc welding processes and variations, 8 solid state welding processes, 7 resistance welding processes, 3 oxyfuel gas welding processes, and 6 other welding processes.

The autogenous processes, which use no filler material, are notably resistance welding, solid state welding. electron beam welding, laser beam welding. induction welding, and pressure gas welding. Optimally. no filler is used in gas welding and certain arc processes, especially gas tungsten arc and plasma arc welding. These autogenous applications, except for flash, friction, and electron beam welding generally are limited to thin sections (i.e.. $2 \mathrm{~mm}$ thick) - Welds with filler metal addition are made by shielded metal arc welding (covered electrodes or stick welding). gas metal arc and flux cored arc welding. submerged arc welding. electroslag welding, and thermit welding; welds with hot or cold wire feed are made by gas tungsten arc, plasma arc, and oxyfuel gas welding.

Those few chromium-containing materials that are not thought of as weldable are the metal-ceramics, magnetic alloys. glass-to-metal alloys, and some coatings other than weld overlays. It is possible that even these exotic materials may still be welded by solid state processes.

The nominal compositions of all welding electrode grades containing chromium or used to join chromiumcontaining materials are listed in Tables F-1 through F-7.

Some chromium alloys are brittle and difficult to weld. The martensitic steels require care in welding since they are air-hardening and produce martensite in the weld heataffected zone. The martensitic layer is extremely hard and may crack from shrinkage stresses, especially if hydrogen is present. Preheating and postheating are almost always needed.

Distortion from shrinkage stresses is a perennial problem in welding and is expecially acute with stainless steels because of their high coefficients of expansion and their low heat conductivities. Favorable weld designs and welding sequences that minimize this problem have been developed by welding specialists. 


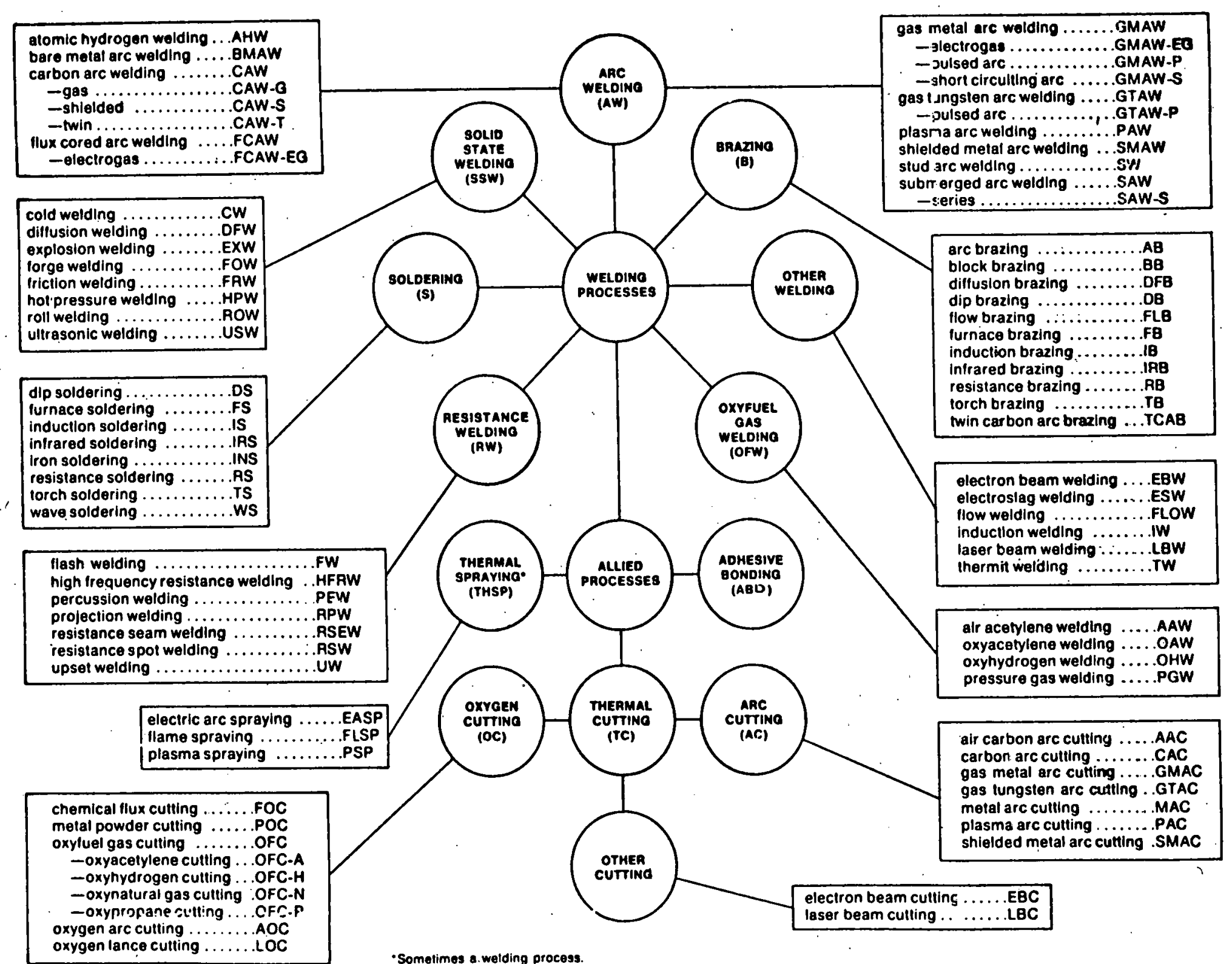

FIGURE F-1 Master Chart of Welding and Allied Processes (American Welding Society 1976) 
TABLE F-1. Nominal Compositions of Low-Alloy Steel Chromium-Bearing Welding Electrodes

\begin{tabular}{|c|c|c|c|c|c|c|}
\hline \multicolumn{7}{|c|}{ American Welding Society Classifications } \\
\hline \multirow{2}{*}{$\begin{array}{l}\text { Covered Electrodes } \\
\text { (Spec. A5.5-69) }\end{array}$} & \multirow{2}{*}{$\begin{array}{l}\text { 3are Electrodes } \\
\text { (Spec. A5.23-76) }\end{array}$} & \multicolumn{5}{|c|}{ Nominal Compositions } \\
\hline & & $\overline{C r}$ & Mo & $\mathrm{Ni}$ & $\mathrm{Mn}$ & $\mathrm{Fe}$ \\
\hline E $80 X X-B 1$ & EBI & 0.5 & 0.5 & -- & 0.6 & 98 \\
\hline-- & EB5 (0.5Si) & 0.5 & 1.0 & -- & 0.6 & 98 \\
\hline-- & EF4 & 0.5 & 0.2 & 0.5 & 0.8 & 97 \\
\hline-- & EF5 & 0.4 & 2.5 & 0.5 & 2.0 & 94 \\
\hline El2018M & -- & 1.0 & 0.5 & 2.0 & 2.0 & 94 \\
\hline $\mathrm{E} 80 \mathrm{XX}-\mathrm{B} 2, \mathrm{E} 80 \mathrm{XX}-\mathrm{B} 2 \mathrm{~L}$ & $\mathrm{~EB} 2, \mathrm{~EB} 2 \mathrm{H}(0.2 \mathrm{Va})$ & 1.2 & 0.5 & -- & 0.6 & 97 \\
\hline $\mathrm{E} 90 \mathrm{XX}-\mathrm{B} 3, \mathrm{E} 90 \mathrm{XX}-\mathrm{B} 3 \mathrm{~L}$ & EB3 & 2.4 & 1.0 & - & 0.6 & 96 \\
\hline-- & EB6, EB6H & 5.0 & 0.5 & -- & 0.6 & 93 \\
\hline
\end{tabular}

NOTE: Consult specifications for exact ranges and limitations. 
:ABLE F-2 Nominal Compositions of Stainless Steel Welding Electrodes

\begin{tabular}{|c|c|c|c|c|c|c|c|}
\hline \multicolumn{3}{|c|}{ American Welding Society Classifications } & \multirow{2}{*}{\multicolumn{2}{|c|}{ Nominal }} & \multirow{2}{*}{\multicolumn{3}{|c|}{ Compositions }} \\
\hline Covered Electrodes: & Bare Electrodes & Flux-Cored Electrodes & & & & & \\
\hline (Spec. A5.4-6.9) & (Spec. A5.9-6.9) & (Spec. A5.22-74) & $\mathrm{Cr}$ & $\mathrm{Ni}$ & Mo & Other & $\mathrm{Fe}$ \\
\hline E308, E308L. & ER308, ER308L & E308T-X, E308LT-X & 20 & 10 & -- & -- & 68 \\
\hline-- & -- & E308MoT-X, E308MoLT-X & 20 & 11 & 2.5 & -- & 66 \\
\hline E309 & ER309: & E309T-X, E30.9LT-X & 24 & 13 & -- & -- & 61 \\
\hline $\mathrm{E} 30.9 \mathrm{Cb}$ & ER30.9Cb & -- & 24 & 13 & -- & $\mathrm{lCb}$ & 60 \\
\hline E309Mo: & ER309Mo & -- & 24 & 1.3 & 2.5 & -- & 58 \\
\hline E310: & ER3 10 & -- & 26 & 22 & -- & -- & 50 \\
\hline $\mathrm{E} 310 \mathrm{Cb}$ & ER3 $10 \mathrm{Cb}$ & -- & 26. & 22 & -- & $1 \mathrm{Cb}$ & 49 \\
\hline E310Mo & ER3 10MO & -- & 26 & 22 & 2.5 & -- & 48 \\
\hline E312 & ER3 12 & -- & 30 & 9 & -- & -- & 5.9 \\
\hline E16-8-2 & -- & -- & 16 & 8 & 1.5 & -- & 72 \\
\hline E316, E316L & ER316, ER316L & E316T-X, E316LT-X & 18 & 12 & 2.5 & -- & 65 \\
\hline E317 & ER317 & -- & 20 & 13 & 3.5 & -- & 62 \\
\hline E318 & ER318 & -- & 19 & 13 & 2.2 & $0.8 \mathrm{Cb}$ & 63 \\
\hline $\mathrm{E} 320$ & ER320 & -- & 20 & 34 & $2 . .5$ & $4 \mathrm{CuCb}$ & 37 \\
\hline E330 & -- & -- & 16 & 35 & -- & D. $8 \mathrm{Cb}$ & 47 \\
\hline E347 & ER347 & E347T-X & 20 & 10 & -- & $0.8 \mathrm{Cb}$. & 67 \\
\hline$-\dot{-}$ & ER348 (no Ta) & -- & 20 & 10 & -- & $0.8 \mathrm{Cb}$ & 67 \\
\hline E349 & ER349 & -- & 20 & 9 & 0.5 & $3 \mathrm{CbW}$ & 66 \\
\hline E4 10 & ER4:10, E4 10T-X & -- & 12 & -- & -- & -- & 87 \\
\hline-- & ER420 & -- & 13 & -- & -- & -- & 86 \\
\hline E430 & ER4 30 & E430T-X & 16 & -- & -- & -- & 83 \\
\hline $\mathrm{E} 502$ & ER502 & $\mathrm{E} 502 \mathrm{~T}-\mathrm{X}$ & 5 & -- & 0.6 & -- & 93 \\
\hline E505. & -- & E505T-X & 10 & -- & 1.0 & -- & 87 \\
\hline $\mathrm{E} 7 \mathrm{Cr}$ & -- & -- & 7 & -- & 0.6 & -- & 97 \\
\hline
\end{tabular}

NOTE: Consult specifications for exact ranges and limitations. 
TABLE F-3 Nominal Compositions of Nickel Alloy Welding Electrodes Containing Chromium

\begin{tabular}{|c|c|c|c|c|c|c|c|}
\hline \multicolumn{8}{|c|}{ American Welding Society Classifications } \\
\hline \multirow{2}{*}{$\begin{array}{l}\text { Covered Electrodes } \\
\text { (Spec. A5.11-69) }\end{array}$} & \multirow{2}{*}{$\begin{array}{l}\text { Bare Wires } \\
\text { (Spec. A5.14-69) }\end{array}$} & \multicolumn{6}{|c|}{ Nominal Compositions } \\
\hline & & Cr & $\mathrm{Ni}$ & Mo & $\mathrm{Cb}$ & Other & $\mathrm{Fe}$ \\
\hline ENiCr-1 & -- & 18 & 76 & -- & 3 & -- & 2 \\
\hline-- & ERNiCr-2 & 20 & 77 & -- & -- & -- & -- \\
\hline-- & ERNiCr-3 & 20 & 72 & -- & 2.5 & $3 \mathrm{Mn}$ & -- \\
\hline ENiCrFe-l & -- & 16 & 72 & $-\infty$ & 3 & -- & 8 \\
\hline $\mathrm{ENiCr}-\mathrm{Fe}-2$ & -- & 16 & 67 & 2 & 2 & $3 \mathrm{Mn}$ & 10 \\
\hline $\mathrm{ENiCrFe-3}$ & -- & 16 & 66 & -- & 2 & $8 \mathrm{Mn}$ & 8 \\
\hline-- & PNiCrFe-4 & 16 & 75 & - & -- & -- & 8 \\
\hline- & ERNiCrFe-5 & 16 & 72 & -- & 2 & -- & 8 \\
\hline-- & ERNiCrFe-6 & 16 & 72 & -- & -- & $6 \mathrm{MnTi}$ & 5 \\
\hline-- & ERNiCrFe-7 & 16 & 72 & -- & 1 & 3TiAl & 7 \\
\hline ENiMo-3 & ERNiMo & 5 & 63 & 25 & -- & -- & 6 \\
\hline ENiMoCr-I & ERNiMo-5 & 16 & 57 & 16 & -- & $4 W$ & 6 \\
\hline-- & ERNiMo-6 & 5 & 63 & 24 & -- & -- & 6 \\
\hline
\end{tabular}

NOTE: Consult specifications for exact ranges and limitations. 
TABLE F-4 Nominal Compositions of Surfacing Electrodes Containing Chromium

\begin{tabular}{|c|c|c|c|c|c|c|c|c|c|}
\hline \multicolumn{2}{|c|}{ Classifications and ipecifications } & \multirow{2}{*}{\multicolumn{8}{|c|}{. }} \\
\hline Rods and Electrodes & $\begin{array}{l}\text { Composite Rod.s and } \\
\text { Electrodes }\end{array}$ & \multicolumn{2}{|c|}{ Nominal Compositions } & & & & & & \\
\hline (AWS A5.13-70) & (AWS A5.21-70) & $\mathrm{C}$ & $\mathrm{Cr}$ & W & Mo & $\mathrm{Va}$ & $\mathrm{Si}$ & $\mathrm{Mn}$ & $\mathrm{Fe}$ \\
\hline RFe5-A, EFe5-A & RFe5-A, EFe5-A & 0.8 & 4 & 5 & 5 & 2 & -- & -- & 82 \\
\hline RFe5-B, EFe5-B & RFe5-B, EFe5-B & 0.8 & 4 & 2 & 7 & 1 & -- & -- & 85 \\
\hline$--\quad$ EFe'5-C $^{\prime}$ & $--\quad$ EFe5-C & 0.4 & 4 & 2 & 7 & 1 & -- & -- & 85 \\
\hline $\mathrm{RFeCr}-\mathrm{Al}$ & $\mathrm{RFeCr}-\mathrm{Al}$, EFeCr-Al & 4.0 & 30 & -- & -- & 5 & 2 & 5 & 59 \\
\hline (AWS A5.13-70, cont.) & (Military R-17131B) & C & $\mathrm{Cr}$ & $\mathrm{W}$ & B & Si & $\mathrm{Fe}$ & Co & $\mathrm{Ni}$ \\
\hline RCOCr $-A$, ECoCr $-A$ & MIL-R-CoCr-A-1 & 1.0 & 30 & 4 & -- & -- & 2 & 62 & -- \\
\hline-- & MIL-R-COCr-A-3 & 1.0 & 30 & 5 & -- & 1 & 1 & 61 & -- \\
\hline $\mathrm{RCOCr}-\mathrm{B}, \mathrm{ECOCr}-\mathrm{B}$ & -- & 1.5 & 30 & 3 & -- & -- & 2. & 58 & -- \\
\hline $\mathrm{RCOC} r-\mathrm{C}, \mathrm{ECOC} r-\mathrm{C}$ & MIL-R-COCr-C-1 & 2.5 & 30 & 12 & -- & -- & 2 & 53 & -- \\
\hline $\mathrm{RNiCr}-\mathrm{A}$, ENiCr-A & -- & 0.5 & 11 & -- & 2.5 & 2 & 2 & -- & 81 \\
\hline RNiCr-B, ENiCr-B & $\mathrm{RNiCr}-\mathrm{B}-1$ & 0.6 & $13^{\circ}$ & -- & 3 & 4 & 4 & -- & 75 \\
\hline-- & $\mathrm{RNiCr}-\mathrm{B}-2$ & 0.6 & 11 & -- & 2.5 & 4 & 4 & -- & 78 \\
\hline RNiCr-C, ENiCr-C & $\mathrm{RNiCr}-\mathrm{C}-\mathrm{l}$ & 0.8 & 15 & -- & 3.5 & 5 & 5 & -- & 70 \\
\hline-- & $\mathrm{RNiCr}-\mathrm{C}-2$ & 0.8 & 15 & -- & 3.5 & 5 & -- & -- & 75 \\
\hline
\end{tabular}

NOTE: Consult specifications for exact ranges and limitations. 
TABLE F-5 Nominal Compositions of Titanium Alloy Electrodes a Containing Chromium

AWS Classification

Bare Rods and Electrodes

(Spec. A5.16-70)

Nominal Composition

ERTi-13V-11Cr-3AI Cr Ti Va

Al

ERTI-13V-11Cr-3AI

$11 \quad 72 \quad 13.5$

NOTE: Consult specification for exact ranges and limitations.

a

Welding filler metal ERTi-13V-llCr-3Al is the only commercially available all-beta alloy. The welds respond to heat treatment, but the mechanical properties in the heat-treated condition are sensitive to variations in microstructure.

In the as-welded state, joints in the beta alloy are ductile but low in strength compared to the heat-treated base metal. Heat treatment increases the strength and decreases the weld ductility. Exposure to elevated temperatures embrittles the welds. At present the full strength potential of alloy $\mathrm{Ti}-13 \mathrm{~V}-11 \mathrm{Cr}-3 \mathrm{Al}$ cannot be realized in welding applications.

As suggested by the panel on substitutability, many other alloying elements are available to strengthen titanium. Deletion of this chromiumbearing alloy and the corresponding welding electrodes and rods will save chromium with no loss in desired properties. 
TABLE F-6 Nominal Compositions of Chromium-Free Nickel-Base Welding Electrodes

\begin{tabular}{|c|c|c|c|c|c|c|c|}
\hline \multicolumn{8}{|c|}{ American Welding Society Classifications } \\
\hline \multirow{2}{*}{$\begin{array}{l}\text { Covered Electrodes } \\
\text { (Spec. A5.11-69) }\end{array}$} & \multirow{2}{*}{$\begin{array}{l}\text { Bare Rods and Electrodes } \\
\text { (Spec. A5. 14-69) }\end{array}$} & \multicolumn{2}{|c|}{ Nominal } & \multicolumn{4}{|c|}{ Compositions } \\
\hline & & $\mathrm{Ni}$ & $\mathrm{Cu}$ & $\mathrm{Mn}$ & $\mathrm{Fe}$ & $\mathrm{Ti}$ & Others \\
\hline ENi-1 & ERNi-3 & 97 & -- & -- & -- & 3 & -- \\
\hline$-\infty$ & $\mathrm{RNi}-2$ & 99 & $-\therefore$ & -- & -- & 1 & -- \\
\hline ENiCu-1, ENiCu-2 & - & 66 & 26 & 3 & 2 & 1 & $2 \mathrm{Cb}$ \\
\hline ENiCu-4 & -- & 66 & .27 & 3 & 2 & 1 & 1.21 \\
\hline-- & $\mathrm{RNiCu}-5$ & 66 & 31 & 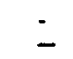 & 2 & -- & -- \\
\hline-- & RNiCu-6 & 58 & 41 & -- & -- & -- & $1 \leq i$ \\
\hline-- & ERNiCu-7 & 66 & 25 & 3 & 2 & 2 & $1 \subseteq i, 1 \mathrm{Al}$ \\
\hline ENiMO- 1 & ERNiMo-4 (0.5Va) & 66 & -- & -- & 6 & -- & 28Mo \\
\hline
\end{tabular}

NOTE: Consult specifications for exact ranges and limitations. 
TABLE F-7 Nominal Compositions of Chromium-Free Surfacing Electrodes

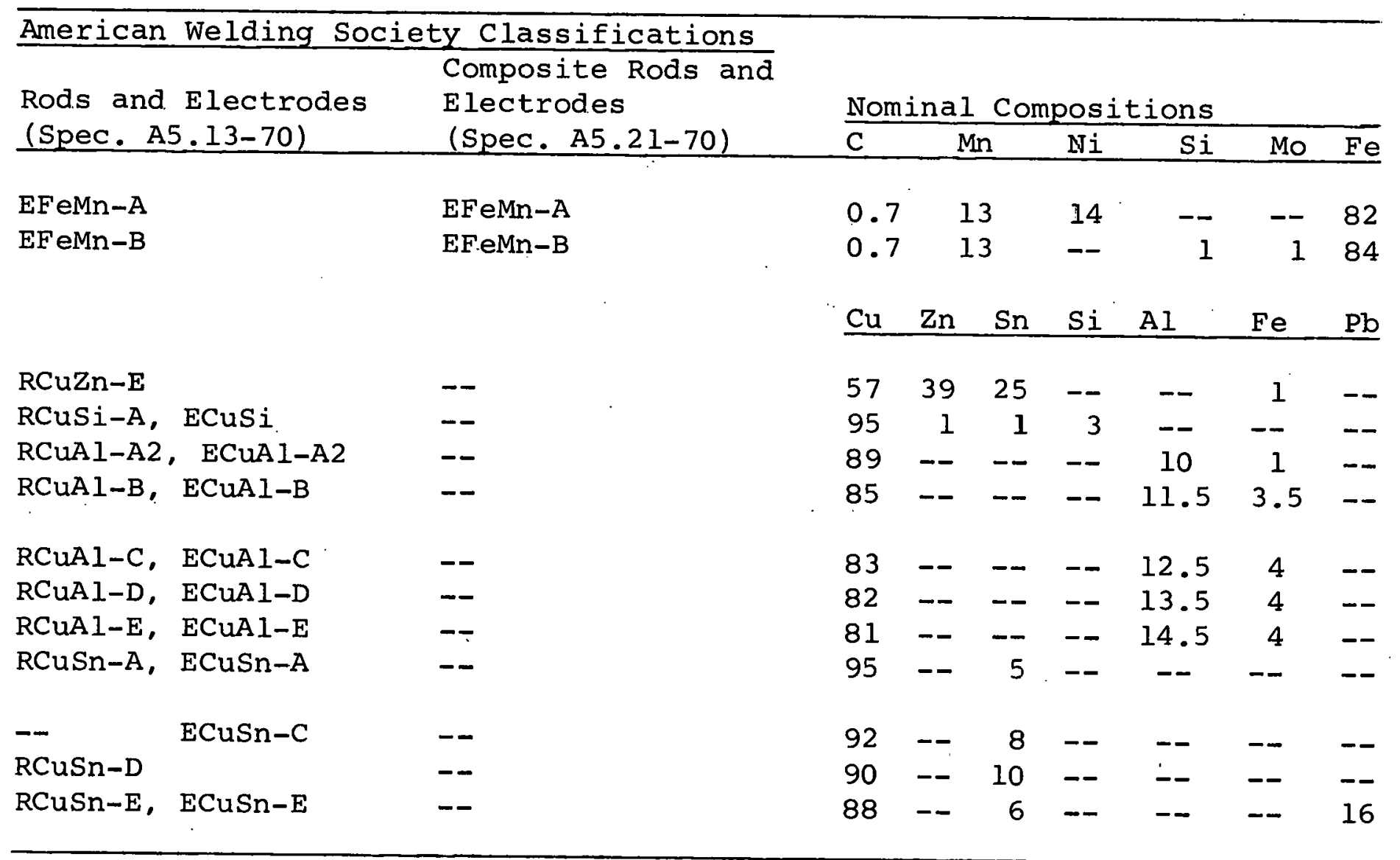

NOTE: Consult specifications for exact ranges and limitations. 
A welding technique being encouraged by the present interest in energy and materials conservation is narrow gap welding which is accomplished using several semiautomatic and automatic processes. New extensions of autogenous welding involve the joining of thick sections by electron beam welding and plasma arc welding in the keyhole mode. As power output improves, laser tealm weluing will join heavier sections. Solid state welding applications are steadily increasing in size.

Welding electrodes that currently would be required in a chromium contingency would be the chromium-free nickel and nickel-base alloys listed in Table F-6.

\section{F. 2 BRAZING AND SOLDERING}

The AWS summary chart of welding processes (see Figure $F-1)$ identifies 11 brazing processes and 8 soldering processes. Brazing may be used to join practically any of the chromium metals and alloys shown in the metallurgical list. Even a weld-deposited stainless steel overlay or hard surfacing overlay could be brazed to a die or mounting if desired. Normally, however, the overlay would be deposited in its final form ana position by welding.

Most brazing alloys do not contain chromium (Table $\mathrm{F}-8$ ). Those suitable for brazing stainless steels are found in the silver group (classification BAg), the precious metals group (BAu), the copper and zinc group (class $\mathrm{BCu} / \mathrm{BCu} \mathrm{n}$ ), and the nickel classification group (BNi). Brazing alloys in the nickel group retain their heat resistance at service temperatures up to 1800 of and higher. depending on the specific filler metal.

Brazing filler metals containing chromium are found only in the nickel and cobalt classifications (Table F-9).

The $\mathrm{BNi}-1, \mathrm{BNi}-1 \mathrm{a}$ (low carbon), $\mathrm{BNi}-2$, and $\mathrm{BNi}-5$ (nuclear grade, no boron) filler metals are used for joining turbine blades, jet engine parts. highly stressed components (including sheet metal structures), and apparatus for cryogenic service. Alloy $\mathrm{BNi}-7$ (no boron) is used for furnace brazing honeycomb structrures, thin-walled tube assemblies, and high-temperature structures including nuclear applications.

BCo-1 alloy is used for its high-temperature properties and compatibility with cobalt-base metals. Under diffusion brazing conductions, it is used in jet engine applications with service temperatures up to $1900^{\circ} \mathrm{F}$ and excursions to 2100 o $\mathrm{F}$. 
TABLE F-8 Nominal Compositions of Brazing Filler Metals without Chromium, Suitable for Brazing Chromium-Bearing Alloys

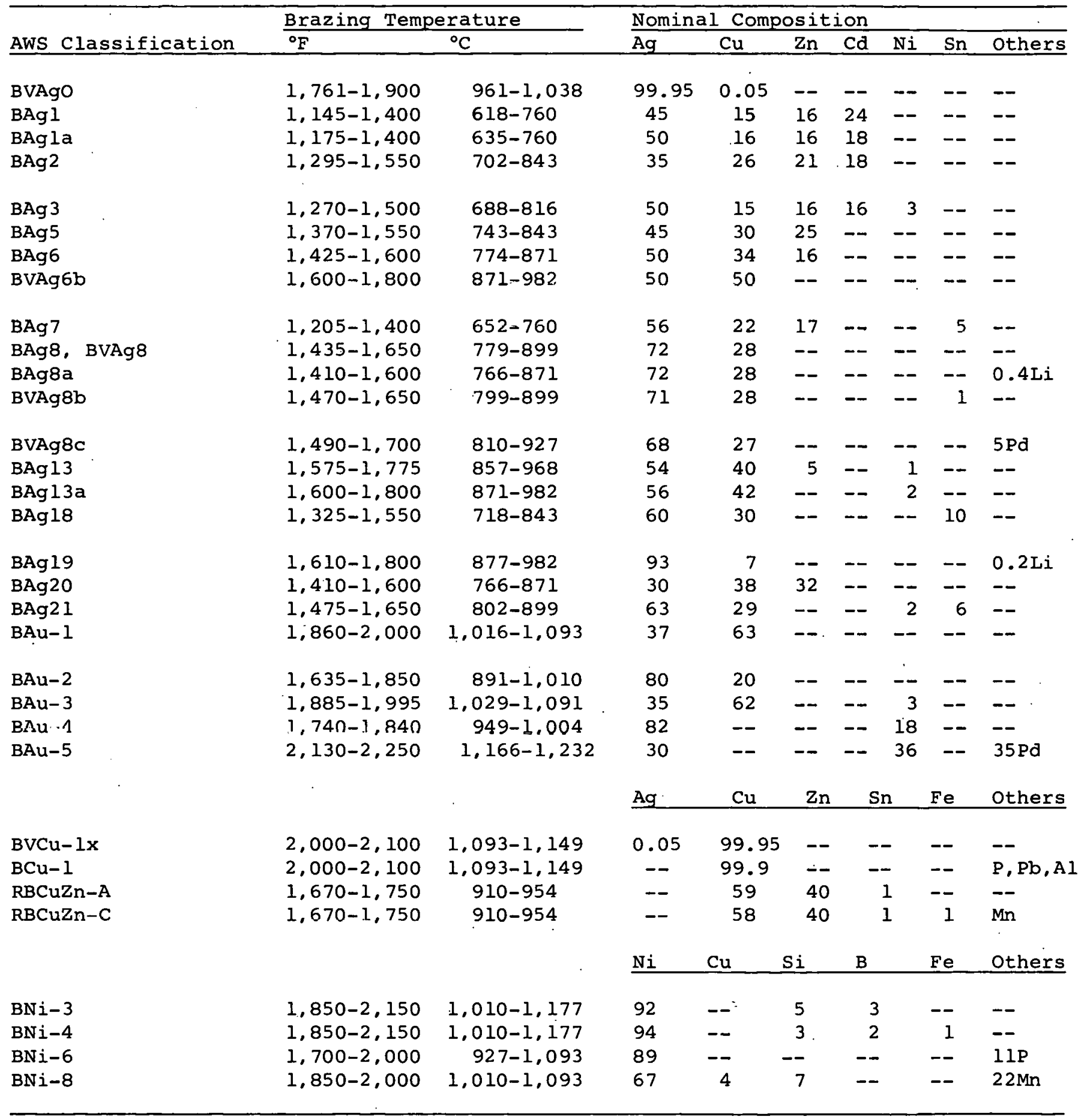

NOTE: Consult specifications for exact ranges and limitations. 
TABLE F-9 Nominal Compositions of Brazing Filler Metals Containing Chromium

\begin{tabular}{|c|c|c|c|c|c|c|c|c|}
\hline \multirow[b]{2}{*}{ AWS Classification } & \multicolumn{2}{|c|}{ Brazing Temperature } & \multicolumn{6}{|c|}{ Nominal Composition } \\
\hline & ${ }^{\circ} \mathrm{F}$ & ${ }^{\circ} \mathrm{C}$ & $\mathrm{Ni}$ & $\mathrm{Cr}$ & B & $\mathrm{Si}$ & $\mathrm{Fe}$ & Others \\
\hline $\mathrm{BCO}-1$ & $2,100-2,200$ & $1,149-1,232$ & 17 & 19 & 1 & 8 & - & $4 \bar{W}, 51 \mathrm{Co}$ \\
\hline $\mathrm{BNi}-1$ & $1,950-2,200$ & $1,066-1,204$ & 75 & 14 & 3 & 4 & 4 & $0.7 \mathrm{C}$ \\
\hline BNi-la & $1,970-2,200$ & $1,077-1,204$ & 75 & 14 & 3 & 4 & 4 & lcw $\mathrm{C}$ \\
\hline $\mathrm{BNi}-2$ & $I, 850-2,150$ & $1,010-1,177$ & 83 & 7 & 3 & 4 & 3 & - \\
\hline $\mathrm{BNi}-5$ & $2,100-2,200$ & $1,149-1,204$ & 71 & 19 & - & 10 & - & - \\
\hline $\mathrm{BNi}-7$ & $1,700-2,000$ & $927-1,093$ & 76 & 14 & - & - & - & $10 P$ \\
\hline
\end{tabular}

NOTE: Consult specifications for exact ranges and limitations. 
Commercial solders also do not contain chromium. The largest portion in use belongs to the tin-lead alloy system but solders containing tin-antimony-lead, tin-zinc, leadsilver, cadmium-silver, cadmium-zinc, zinc-aluminum, fusible alloys (or solders) containing bismuth, and Indium solders are available. Specifications for solders are ASTM B-32, "Solder Metal," ASTM B-284, "Rosin Flux Cored Solder," and Federal Specifications QQ-S-571. "Solders."

Corrosion is a problem with brazed joints. Galvanic attack is invited by the dissimilar metal joint which has been made, and crevice corrosion is always possible if the joint design creates pockets. Brazing filler metal BAg-21 seems immune to crevice corrosion on AISI type 400 series stainless steels because of its high nickel content (2 to 3 percent). which imparts a nickel-rich layer to the fillet edge.

Compatible brazing materials must be selected. Copperphosphorus fillers (not shown in Tables F-8 and F-9) should not be used on ferrous and nickel-base alloys with a nickel content in excess of 10 percent. Erosion occurs with some alloys and attacks, and dissolves iron- and nickel-base alloys. BAu fillers have a low rate of interaction with base metals.

Brazing filler metal BAg-20 is finding new applications due to its good brazing properties, its freedom from cadmium (otherwise a health hazard from brazing fumes), and its more economical silver content. The self-fluxing brazing alloys in Tables F-8 and F-9 are fillers BAg-8, BAg-8a, BAg-18, $B \Lambda g-21$, and BAu.

\section{F. 3 MECHANICAL JOINING}

Mechanical fastening is applicable to all tabulated applictions of chromium except coatings.

\section{F.4 ADHESIVE BONDING}

With adhesive bonding, thin and thick sections of any shape may readily be joined. Adhesive joints resist fatigue, and the adhesive seals the joint, insulates against electrical and thermal currents, ană dampens vibrations. The heat required for aging the thermosetting adhesives usually does not affect the strength of metal parts. Adhesive bonding is a fast and inexpensive process.

\section{F. 5 WELD OVERLAY}

Weld overlays are applied where clad steel surfaces are not available or are not reliable. Typical applications 
have been the flanges (14 inches thick) for nuclear reactors, dished heads for pressure vessels, nozzles welded into boilers and chemical retorts, and cylindrical vessels with wall thickness greater than 4 inches. These overlays provided a corrosion-resistant surface equivalent to commercially clad products.

Weld overlays also are applied for wear resistance. Electrodes are available with special properties of hardness, hot hardness, impact strength, oxidation resistance, corrosion resistance, abrasion resistance, resistance to metal-to-metal wear. mechanical properties in compression, and machinability. Methods used for overlay welding are primarily those with low dilution llow penetration) and high deposition rate.

Oxyfuel gas welding is excellent for depositing thin, undiluted overlays of the chromium-cobalt stellite compositions on wear surfaces and overlays of tungsten carbide granules. The low-temperature deposition achieved with the oxyacetylene flame leaves undissolved tungsten carbide grains dispersed in the weld deposit while arc welding tends to dissolve most of the granules in the matrix.

Shielded metal arc welding (manual deposition) is used in difficult welding positions. Submerged arc welding with series-arc (two-wire) deposition achieves rapid coverage of the surface being overlaid with about 12 percent dilution. submerged arc welding with strip electrodes achieves about the same dilution at faster deposition speeds. Gas tungsten arc welding with hot wire feed and plasma arc welding with hot wire feed achieve dilutions as low as 5 percent.

Weld cracking is a common difficulty, especially with the harder alloys. With some electrodes, peening of each bead after deposition is employed to reduce stresses. preheating and postheating schedules often are recommended. The copper-base alloys used for bearing surfaces are deposited with braze-welding techniques.

Uniform coverage of the base metal is required. Variations in penetration change the weld composition by dilution. Multiple layers often are deposited just to guarantee the required alloy content in the surface layer.

Conservation of chromium will encourage extensive use of clad steels. Welding sequences and electrode recommendations are ready now for all popular alloys. Most weldments will require only the butt-welding of clad plates, but many constructions will have nozzles and flanges that preferably will be surfaced by weld overlay techniques. 
Substitute coatings without chromium are proposed in chapter 6. Equivalent weld deposits may not be possible to develop, but studies should be initiated. Low-chromium alloys will lack the corrosion resistance of higher chromium compositions. 


\section{Appendix G}

CALCULATIONS AND ASSUMPTIONS FOR DETERMINING THE CHROMIUM USED FOR STAINLESS STEEL PRODUCTION

Table G-1 is based on data from American Iron and steel Institute (AISI) Form 104. "Ingot Production of Stainless and Heat Resisting steels -- Net Tons." for the years 1965 to 1975. The following factors were used in calculating data for 1976 and 1980-1990:

\section{Years Used}

1965 to 1975. The 1975 production calculated as twice the first half-year value.

\section{Baseline Production for Growth Calculation}

Average of years 1965 to $1975--1.52$ million tons. 1976 production assumed 1.52 million tons.

\section{Assumed Yearly Growth}

5 percent. 1980, 1985 and 1990 production calculated from 1.52 million with 5 percent per year growth. This is growth without conservation or substitution measures.

Average Chromium Content of stainless steels Calculated from 1974 AISI Production by Grade

16.4 percent. The same chromium content assumed to hold for all years.

\section{Irreversible Chromium Loss in Melting}

1965 to 1976 -- assumed 12 percent 1980 to 1990 -- assumed 7 percent The reduction in iosses is due to widespread introduction of $A O D$ melting.

\section{Source of Chromium}

Assumed 6.0 percent from scrap (own recirculating scrap plus purchased scrap): 40 percent from ferrochromium (high carbon ferrochromium, low carbon ferrochromium and chrome-silicon). From 1980 on, all ferrochromium will be mostly high carbon with the low carbon becoming practically negligible. 
TABLE G-1 Chromium Use in Stainless Steel, Based on AISI Ingot Tons

\begin{tabular}{|c|c|c|}
\hline & Contained $\mathrm{C}$ & ium (tons) \\
\hline Source of Chromium & Up to 1976 & $1980-1990$ \\
\hline Chromium in ingot & 16.4 & 16.4 \\
\hline Chromium charged & 18.6 & 17.6 \\
\hline Chromium loss in slag & 2.2 & 1.2 \\
\hline Chromium from ferrochromium & 7.44 & 7.1 \\
\hline Chromium from scrap & 11.16 & 10.5 \\
\hline $\begin{array}{l}\text { Source of scrap for } 100 \text { ton ingot } \\
\text { Total chromium from recirculating scrap } \\
\text { Total chromium from purchased scrap } \\
\text { Total chromium from scrap }\end{array}$ & $\begin{array}{r}6.56 \\
4.60 \\
11.16\end{array}$ & $\begin{array}{r}6.57 \\
3.94 \\
10.50\end{array}$ \\
\hline $\begin{array}{l}\text { Purchased chromium for } 100 \text { ton ingot } \\
\text { Chromium from ferrochromium } \\
\text { Chromium from purchased scrap } \\
\text { Total purchased chromium }\end{array}$ & $\begin{array}{r}7.44 \\
4.60 \\
12.04\end{array}$ & $\begin{array}{l}7.1 \\
3.94 \\
3.94\end{array}$ \\
\hline $\begin{array}{l}\text { Purchased chromium for } 100 \text { ton finished steel } \\
\text { (60\% yield from ingot) } \\
\text { Chromium from ferrochromium } \\
\text { Chromium from purchased scrap } \\
\text { Total purchased chromium }\end{array}$ & $\begin{array}{r}12.33 \\
7.66 \\
19.99\end{array}$ & $\begin{array}{r}11.84 \\
6.56 \\
18.40\end{array}$ \\
\hline
\end{tabular}

NOTE: Data from American Iron and Steel Institute, Form 104, 1965-1975. 
Yield from_Ingot to Shipped weight

60 percent. This assumed value was used to calculate the recirculating scrap; 41 percent of total scrap up to 1976 and 40 percent after calculation was as follows: Chromium in 100 ton ingot -16.4 tons; chromium in tinished steel mill product assuming a 60 percent yield - 9.84 tons; 16.4 tons minus 9.84 tons equals 6.56 tons of chromium recirculated. This remains constant at a constant rate of production. It is probably invalid for periods of change in production. 


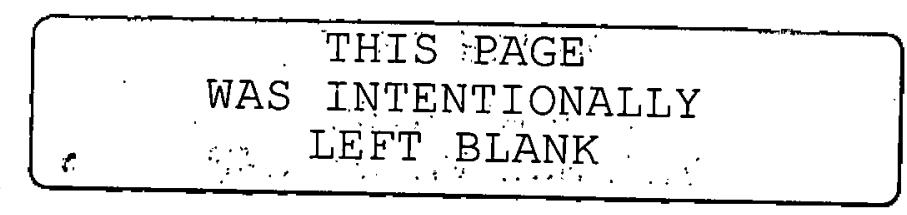




\section{Appendix H}

SUBSTITUTES FOR STAINLESS STEEL

Substitutes for stainless steel are shown in Table H-1. 
TABLE H-1 Substitutes for Stainless Steels

\begin{tabular}{|c|c|c|c|c|c|c|c|c|}
\hline $\begin{array}{l}\text { Stainless } \\
\text { Steel } \\
\text { Type } \\
\end{array}$ & $\begin{array}{l}\text { Contained } \\
\text { Chromium } \\
\end{array}$ & $\begin{array}{l}\text { Product } \\
\text { Form }\end{array}$ & Properties Needed & Material & $\begin{array}{l}\text { Contained } \\
\text { Chromium }\end{array}$ & Limitations & Research Needed & $\begin{array}{l}\text { Proba- } \\
\text { bility of } \\
\text { Success }\end{array}$ \\
\hline \multirow[t]{6}{*}{$\begin{array}{l}201,202 \\
301,302 \\
304,304 \mathrm{~L} \\
321,347\end{array}$} & 18 & $\begin{array}{l}\text { Sheet }+ \\
\text { strip }\end{array}$ & $\begin{array}{l}\text { Atmospheric and } \\
\text { mild aqueous corro- } \\
\text { sion resistance. Good } \\
\text { fabrication includ- } \\
\text { ing welding. Good } \\
\text { structural properties. } \\
\text { Broad strength range. } \\
(\sim 70-250 \mathrm{ksi})\end{array}$ & $\begin{array}{l}12-14 \mathrm{Cr} \text { austenitic steel } \mathrm{Cr} \text {, } \\
\mathrm{Ni} \text { or } \mathrm{Cr}-\mathrm{Ni}-\mathrm{Mn} \text { or } \mathrm{Cr}-\mathrm{Mn}-\mathrm{N} \\
\text { of equivalent stability of } \\
\text { austenite. }\end{array}$ & 13 & $\begin{array}{l}\text { Slightly lower corrosion resis- } \\
\text { tance which could be compen- } \\
\text { sated, when needed, by Mo } \\
\text { addition. }\end{array}$ & $\begin{array}{l}\text { Determine optimum } \\
\text { composition and } \\
\text { evaluate properties. }\end{array}$ & High \\
\hline & . & $\because$ & & $\begin{array}{l}\text { Single clad stainless steel on } \\
\text { carbon steel ( } 10 \% \text { average } \\
\text { stainless). }\end{array}$ & 1.8 & $\begin{array}{l}\text { Loss of corrosion resistance at } \\
\text { all exposed edges and welds. } \\
\text { Corrosion resistant on one side } \\
\text { only. Some formability and } \\
\text { strength limitations. }\end{array}$ & $\begin{array}{l}\text { Develop processing } \\
\text { methods and edge pro- } \\
\text { tection methods. Eval- } \\
\text { uate properties. }\end{array}$ & High \\
\hline & & & & $\begin{array}{l}\text { Double clad stainless steel- } \\
\text { carbon steel core ( } 20 \% \\
\text { avercge stainless steel) }\end{array}$ & 3.6 & $\begin{array}{l}\text { Same as single clad stainless } \\
\text { steel on carbon steel except } \\
\text { corrosion resistance arailable } \\
\text { on both sides. }\end{array}$ & $\begin{array}{l}\text { Same as single clad } \\
\text { stainless steel on } \\
\text { carbon steel. }\end{array}$ & High \\
\hline & & & & $\begin{array}{l}\text { Cr electrolytic plating on } \\
\text { carbon steel }\left(0.001^{\prime \prime} \mathrm{Cr} \text { on }\right. \\
\text { average } 0.040^{\prime \prime} \text { carbon } \\
\text { steeb. }\end{array}$ & 2.5 & $\begin{array}{l}\text { Can be applied only on finished } \\
\text { components. Size and shape limi- } \\
\text { tations. Surface damage destroys } \\
\text { corrosion resistance. Higher cost. } \\
\text { Potential ecology problems. }\end{array}$ & Existing technology. & \\
\hline & & & ` & $\begin{array}{l}\text { Cr solid state diffusion } \\
\text { (chromizing) } 0.002^{\prime \prime} \mathrm{Cr} \text { on } \\
0.050^{\prime \prime} \text { (average) carbon } \\
\text { steel, both sides }\end{array}$ & 4 & $\begin{array}{l}\text { Loss of corrosion resistance at } \\
\text { all exposed edges and welds. } \\
\text { Surface damage impairs cor- } \\
\text { rosion resistance. }\end{array}$ & Existing technology. & \\
\hline & & & & $\begin{array}{l}\text { Cr vapor deposition, ion } \\
\text { implantation, etc. }\end{array}$ & Negligible & $\begin{array}{l}\text { Damage prone surface layer will } \\
\text { lose corrosion resistance. Lim- } \\
\text { ited fabrication shape and size. }\end{array}$ & $\begin{array}{l}\text { Develop processes and } \\
\text { fabrication methods. } \\
\text { Evaluate properties. }\end{array}$ & Medium \\
\hline
\end{tabular}


Aluminum alloys

Plastics

Cryogenic application Aluminum alloys

9\% Ni steel

Atomic power

Not replaceable.

High-temperature application requiring

strength and oxida-

tion resistance.

$12-14 \mathrm{Cr}$ austenitic steels
(Cr-Ni, $\mathrm{Cr}-\mathrm{Ni}-\mathrm{Mn}$ or $\mathrm{Cr}-$
$\mathrm{Mn}-\mathrm{N}$ with $\mathrm{Al}$ to obtain
sufficient oxidation resistance).

High-temperature ap- New $\mathrm{Cr}-\mathrm{free} \mathrm{Al}, \mathrm{Ti}, \mathrm{Si}-$ plication requiring ferritic steel system.

oxidation resisțance

but not strength.

Chemical industry.

Titanium

Tantalum

Lead

Plastics
Some limitation in fabrication, especially welding, and in

structural properties.

Low strength. Limited fabrication.

Existing technology. Need to determine capacity of aluminum industry.

Develop stronger materials with better fabrication.

$-$

\section{Expected to have equivalent} properties.

Fabrication not as good as that of austenitic steels. Low strength at high temperature.

$$
\text { . }
$$

Not acceptable in certain sulfuric acid environments, hydrofluoric acid and some organic acids. Higher cost.

- $\quad$ Very expensive.

- $\quad$ Limited to some environments like sea water, buried pires and cables, sulfuric acid, nitr"c and hydrofluoric acid.

Limited to $400^{\circ} \mathrm{F}$. Strength limitations.
Develop new austenitic steels. Evaluate properties.

Develop new ferritic steels. Develof processing and fabrication methods. Evaluate properties.

Check availabiiity of $\mathrm{Ti}$ industry capacity.

Check capacity.

Existing technology. Check capacity. Poor structural properties. High density. 
TABLE H-1 Substitutes for Stainless Steels (continued)

\begin{tabular}{|c|c|c|c|c|c|c|c|c|}
\hline $\begin{array}{l}\text { Stainless } \\
\text { Steel } \\
\text { Type } \\
\end{array}$ & $\begin{array}{l}\text { Contained } \\
\text { Chromium }\end{array}$ & $\begin{array}{l}\text { Product } \\
\text { Form } \\
\end{array}$ & Properties Needed & Material & $\begin{array}{l}\text { Contained } \\
\text { Chromium } \\
\end{array}$ & Limitations & Research Needed & $\begin{array}{l}\text { Proba- } \\
\text { bility of } \\
\text { Success }\end{array}$ \\
\hline & & , & & Impervious graphite. & - & $\begin{array}{l}\text { Limited to } 335^{\circ} \mathrm{F} \text { and } 50 \mathrm{psi} \text {. } \\
\text { Brittle. }\end{array}$ & & \\
\hline & & & & $\begin{array}{l}\text { Glass (piping, tubing, } \\
\text { glass-lined vessels, dis- } \\
\text { tillaticn columns). }\end{array}$ & - & $\begin{array}{l}\text { Limited to } 550^{\circ} \mathrm{F} \text {. Limited } \\
\text { availability. }\end{array}$ & & \\
\hline \multirow[t]{3}{*}{$\begin{array}{l}201,202 \\
301,302 \\
304,304 \mathrm{~L} \\
321,347\end{array}$} & 18 & Plate & $\begin{array}{l}\text { Atmospheric and } \\
\text { mild aqueous cor- } \\
\text { rosion resistance, } \\
\text { fabrication including } \\
\text { welding structural }\end{array}$ & $\begin{array}{l}12-14 \text { Cr austenitic steel } \mathrm{Cr} \text {, } \\
\mathrm{Ni} \text { or Cr-Ni-Mn or } \mathrm{Cr}-\mathrm{Mn}-\mathrm{N} \\
\text { of equivalent stability of } \\
\text { auster.ite. }\end{array}$ & 13 & $\begin{array}{l}\text { Slightly lower corrosion resis- } \\
\text { tance which could be compen- } \\
\text { sated, when needed, by Mo } \\
\text { addition. }\end{array}$ & $\begin{array}{l}\text { Determine optimum } \\
\text { composition and } \\
\text { evaluate properties. }\end{array}$ & High \\
\hline & & & properties. & $\begin{array}{l}\text { Single clad stainless steel on } \\
\text { carbon steel ( } 10 \% \text { average } \\
\text { stainless). }\end{array}$ & 1.8 & $\begin{array}{l}\text { Loss of corrosion resistance at } \\
\text { all exposed edges and welds. } \\
\text { Corrosion resistant on one side } \\
\text { only. Some formability and } \\
\text { strength limitations. }\end{array}$ & $\begin{array}{l}\text { Develop processing } \\
\text { methods and edge pro- } \\
\text { tection methods. Eval- } \\
\text { uate properties. }\end{array}$ & High \\
\hline & . & & & $\begin{array}{l}\text { Type } 308 \text { or } 309 \text { weld over- } \\
\text { lay on carbon steel ( } 1 / 4^{\prime \prime} \text { type } \\
308 \text { an average } 2 " \text { carbon } \\
\text { steel). }\end{array}$ & 2.5 & $\begin{array}{l}\text { Economic limitations at lighter } \\
\text { gage. Some shape limitations. }\end{array}$ & Existing technology. & \\
\hline \multirow[t]{3}{*}{$\begin{array}{l}201,202 \\
301,302 \\
304,304 \mathrm{~L} \\
321,347\end{array}$} & 18 & $\begin{array}{l}\text { Billet } \\
\text { bar } \\
\text { forgings } \\
\text { wire }\end{array}$ & $\begin{array}{l}\text { Atmospheric and } \\
\text { mild aqueous cor- } \\
\text { rosion resistance. } \\
\text { Acceptable machin- } \\
\text { ability. Good me- }\end{array}$ & $\begin{array}{l}\text { 12-14 Cr austenitic steel } \mathrm{Cr} \text {, } \\
\mathrm{Ni} \text { or } \mathrm{Cr}-\mathrm{Ni}-\mathrm{Mn} \text { or } \mathrm{Cr}-\mathrm{Mn}-\mathrm{N} \\
\text { of equivalent stability of } \\
\text { austenite. }\end{array}$ & 13 & $\begin{array}{l}\text { Slightly lower corrosion resis- } \\
\text { tance which could be compen- } \\
\text { sated, when needed, by Mo } \\
\text { addition. }\end{array}$ & $\begin{array}{l}\text { Determine optimum } \\
\text { composition and } \\
\text { evaluate properties. }\end{array}$ & High \\
\hline & & & $\begin{array}{l}\text { chanical and strength } \\
\text { properties. }\end{array}$ & $\begin{array}{l}\text { Cr electrolytic plating on } \\
\text { carbon steel }\left(0.001^{\prime \prime} \mathrm{Cr} \text { on }\right. \\
\text { average } 0.040^{\prime \prime} \text { carbon } \\
\text { steel). }\end{array}$ & $\begin{array}{c}\text { Negligible } \\
\text {. }\end{array}$ & $\begin{array}{l}\text { Can be applied only on finished } \\
\text { components. Size and shape limi- } \\
\text { tations. Surface damage destroys } \\
\text { corrosion resistance. Higher cost. } \\
\text { Potential ecology problems. }\end{array}$ & Existing technology. & \\
\hline & & & & $\begin{array}{l}\text { Cr solid state diffusion } \\
\text { (chromizing) } 0.002^{\prime \prime} \mathrm{Cr} \text { on } \\
0.0 \leq 0^{\prime \prime} \text { (average) carbon } \\
\text { steel, both sides. }\end{array}$ & Negligible & $\begin{array}{l}\text { Loss of corrosion resistance at } \\
\text { all exposed edges and welds. } \\
\text { Surface damage impairs cor- } \\
\text { rosion resistance. }\end{array}$ & Existing technology & \\
\hline
\end{tabular}


Cr vapor deposition, ion implantation, etc.

316,317,
proprietary
$\mathrm{Cr}-\mathrm{Ni}-\mathrm{Mn}$,
Mo, $\mathrm{Cu}, \mathrm{N}$,
highly
corrosion
resistant
alloys

Sheet,

strip,

Corrosion resistance in chemical industry and in sea water
bar,
application.

billet,

wire

alloys

\begin{tabular}{|c|c|c|c|c|}
\hline & & & & Plastics \\
\hline & & & & Impervious graphite. \\
\hline & & & & $\begin{array}{l}\text { Glass (piping, tubing, } \\
\text { glass-lined vessels, dis- } \\
\text { tillation columns). }\end{array}$ \\
\hline & & & $\cdot$ & $\begin{array}{l}\text { Clad } 316 \text {, etc. on carbon } \\
\text { steel (average } 10 \% \text { on } 2^{\prime \prime} \\
\text { carbon steel. }\end{array}$ \\
\hline \multirow[t]{2}{*}{$\begin{array}{l}308,309 \\
310\end{array}$} & 22 & $\begin{array}{l}\text { Sheet, } \\
\text { strip, } \\
\text { bar, } \\
\text { billet, } \\
\text { wire }\end{array}$ & $\begin{array}{l}\text { High temperature } \\
\text { strength, oxida- } \\
\text { tion and corrosion } \\
\text { resistance. }\end{array}$ & Not replaceable \\
\hline & & & $\begin{array}{l}\text { Oxidation resistance } \\
\text { at high temperature. } \\
\text { No strength or cor- } \\
\text { rosion resistance. }\end{array}$ & $\begin{array}{l}\text { New Cr-free Al, Ti, Si- } \\
\text { ferritic steel system. }\end{array}$ \\
\hline
\end{tabular}

\section{Titanium}

Negligible Damage prone surface layer will Develop processes and lose corrosion resistance. Limited fabrication shape and size.

Evaluate properties.

$-$

Not accep table in certain sul-

Check availability of $\mathrm{Ti}$

furic acid environments, hydro-

industry capacity.

fluoric acid and some organic.

acids. Higher cost.

\section{Tantalum}

Lead

Very expensive.

Limited to some environments like sea water, buried jipes and cables, sulfuric acid, nitric and hydrofluoric acid.

Check capacity.

Existing tecr.nology. Check capac:ty. Poor structural properties. High density.

- $\quad$ Limited to $400^{\circ} \mathrm{F}$. Strength limitations.

Ltd. to $335^{\circ} \mathrm{F}$ \& 50 psi. Brittle.

- $\quad$ Limited to $550^{\circ} \mathrm{F}$. Linited availability.

Requires special weldirg technique. 
TABLE H-1 Substitutes for Stainless Steels (continued)

\begin{tabular}{|c|c|c|c|c|c|c|c|c|}
\hline $\begin{array}{l}\text { Stainless } \\
\text { Steel } \\
\text { Type } \\
\end{array}$ & $\begin{array}{l}\text { Contained } \\
\text { Chromium }\end{array}$ & $\begin{array}{l}\text { Product } \\
\text { Form } \\
\end{array}$ & Properties Needed & Material & $\begin{array}{l}\text { Contained } \\
\text { Chromium }\end{array}$ & Limitations & Research Needed & $\begin{array}{l}\text { Proba- } \\
\text { bility of } \\
\text { Success }\end{array}$ \\
\hline \multirow[t]{2}{*}{409} & \multirow[t]{2}{*}{11} & \multirow[t]{2}{*}{$\begin{array}{l}\text { Sheet, } \\
\text { strip, } \\
\text { plate, } \\
\text { bar, } \\
\text { wire }\end{array}$} & \multirow[t]{2}{*}{$\begin{array}{l}\text { Corrosion and oxida- } \\
\text { tion resistance for. } \\
\text { auto exhaust. }\end{array}$} & $\begin{array}{l}\text { Aluminized carbon steel or } \\
\text { low alloy steel. } \\
\text { Cr solid state diffusion } \\
\text { (chromizing) } 0.002 " \mathrm{Cr} \text { on } \\
0.050^{\prime \prime} \text { (average) carbon } \\
\text { steel, both sides. }\end{array}$ & - & $\begin{array}{l}\text { Shorter life, lower corrosion } \\
\text { resistance. }\end{array}$ & $\begin{array}{l}\text { Develop alloy system. } \\
\text { Aluminizing technology } \\
\text { available. }\end{array}$ & High \\
\hline & & & & New 5-6 Cr, $\mathrm{Al}$ alloy steel & 5 & $\begin{array}{l}\text { Oxidation resistance of new } \\
\text { alloy system should be equiv- } \\
\text { alent to } 409 \text { but the corrosion } \\
\text { resistance will be lower. }\end{array}$ & $\begin{array}{l}\text { Develop new alloy and } \\
\text { fabrication and process- } \\
\text { ing. Evaluate properties. }\end{array}$ & High \\
\hline \multirow[t]{3}{*}{$\begin{array}{l}430,434 \\
436,439\end{array}$} & \multirow[t]{3}{*}{17} & \multirow[t]{3}{*}{$\begin{array}{l}\text { Sheet, } \\
\text { strip, } \\
\text { plate, } \\
\text { bar } \\
\text { products }\end{array}$} & \multirow[t]{3}{*}{$\begin{array}{l}\text { Corrosion and oxida- } \\
\text { tion resistance. Deco- } \\
\text { rative. }\end{array}$} & $\begin{array}{l}\text { Ferritic steel with } 13-14 \% \\
\mathrm{Cr}\end{array}$ & 13 & $\begin{array}{l}\text { The slightly lower corrosion re- } \\
\text { sistance due to lower } \mathrm{Cr} \text { can be } \\
\text { compensated by Mo addition. }\end{array}$ & Existing technology. & \\
\hline & & & & $\begin{array}{l}\text { Single clad stainless steel } \\
\text { on carbon steel ( } 10 \% \\
\text { aver age stainless) but using } \\
\text { ferritic steel for clad. }\end{array}$ & 1.8 & $\begin{array}{l}\text { Loss of corrosion resistance at } \\
\text { all exposed edges and welds. } \\
\text { Corrosion resistant on one side } \\
\text { only. Some formability and } \\
\text { strength limitations. }\end{array}$ & $\begin{array}{l}\text { Develop processing } \\
\text { methods and edge pro- } \\
\text { tection methods. Eval- } \\
\text { uate properties. }\end{array}$ & High \\
\hline & & & & $\begin{array}{l}\text { Double clad stainless steel- } \\
\text { carton steel core ( } 20 \% \\
\text { average stainless steel) but } \\
\text { using ferritic stainless steel } \\
\text { for :lad. }\end{array}$ & 3.6 & $\begin{array}{l}\text { Same as single clad stainless } \\
\text { steel on carbon steel except } \\
\text { corrosion resistance available } \\
\text { on both sides. }\end{array}$ & $\begin{array}{l}\text { Same as single clad } \\
\text { stainless steel on } \\
\text { carbon steel. }\end{array}$ & High \\
\hline
\end{tabular}


Aluminum alloys

446, 26-1

26

She

strip,

plate,

bar

products

Corrosion resistance. Titanium

Bar Automotive valves.

valve steel with $12-14 \%$

$\mathrm{Cr}$ content.

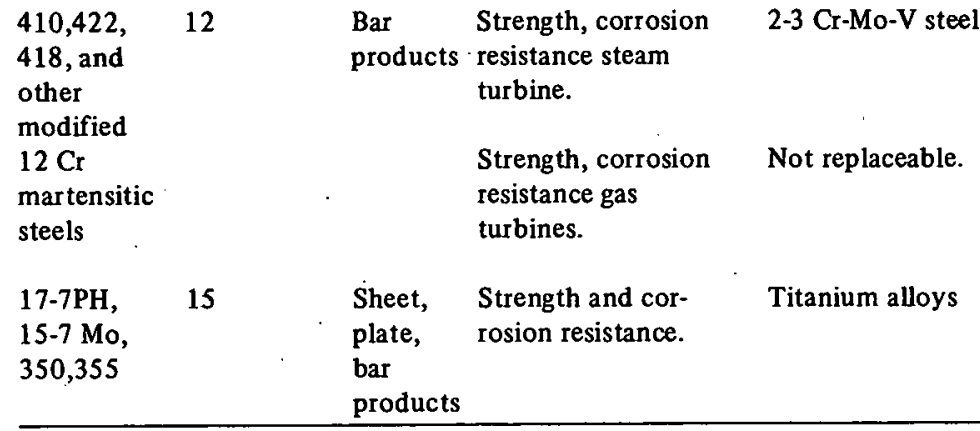

Some limitation in fabrication, Existing technology. especially welding, and in structural properties.

Need to determine

capacity of aluminum industry.

Check availability of $\mathrm{T}$ industzy capacity.

Not acceptable in certain sul-

furic acid environments, hydro-

fluoric acid and some organic

acids. Higher cost.

No major disadvantages anticipated with a lower $\mathrm{Cr}$ steel.

Develop new alloy with High

equivalent strength prop-

erties. Evaluate properties.

No major disadvantage; ex- Existing technology.

pected.
Titanium alloys are cursently Existing technology.

alternate materials for $\mathrm{PH}$

stainless steels. Cost dised- 
The following data used for the automotive industry were provided by Allegheny Ludlum Steel Corporation and represent average stainless steel use per car in 1976, which includes 22.5 pounds per car of AISI type 409 for the catalytic reactor, that was not used in 1974 .

Automotive

1976 Average: $22.51 \mathrm{~b} / \mathrm{car}$ AISI type 409 for catalytic converter, including pipes

9.5 lb/car Functionai -- various parts

$9.51 \mathrm{~b} / \mathrm{car}$ Decorative -- trim, hub caps,

$41.51 \mathrm{~b} / \mathrm{car}$ wheelcovers

Basis: $10 \mathrm{million}$ cars/year

Stainless steel Function

Decorative - $9.5 \mathrm{lb} / \mathrm{car}$

Functional -- 32 lb/car

Current steels

Decorative -- AISI types 201, 301, 430, 434, 436

Functional - AISI types 301, 201, 409, 305, 21-2N, 17-7 PH

Current Use of Stainless Steel Tons/Year for 10 million Cars

Decorative $--47,500$ tons
Functional $--\frac{160,0000 \text { tons }}{207,500 \text { tons }}$

Contained Chromium

It is assumed that:

Average for Decorative . - 17 percent

Average for Type 409 -- 11 percent

Average for Balance Function -- 18 percent

Average Irreversible Loss

in Melting -- 7 percent 
contained chromium (corrected by 7 percent for melt loss):

Decorative - 8,640 tons

Functional -- $\frac{22,33}{30,970} \frac{30 \text { tons }}{\text { tons }}$

* 13,182 tons for T409 and 9,148 tons for balance

\section{Alternative Chromium-free Materials}

Assuming a severe shortage (i.e.. all chromium imports stopped) :

- Replacement for decorative stainless -- aluminum (nil chromium content).

- Replacement for functional stainless: aluminized carbon steel or low-alloy steel (nil chromium content) for AISI type 409 in catalytic reactor: 75 percent replacement by alloys with no chromium for balance of functional stainless.

- Chromium used in decorative and functional replacements: $9.148 \times 0.25=2.287$ tons.

Chromium savings versus current usage: $30,970-2,287=$ 28.683 tons.

\section{Comments}

- Replacement of AISI type 409 by aluminized steel requires research and development.

- Other functional parts such as seat belt anchor plates, seat belt retractors, piston ring expanders, door lock springs, flex fans, bumper guard brackets, and hose clamps to be replaced by existing cuated carbon and low-alloy steel. No research and development is needed.

- Radiator tanks (trucks and buses), radiator and tank caps, and manifold gaskets to be replaced by brass. No research and development is needed.

- Valve steels (21-2N) to be replaced by new 12-15 percent chromium austenitic steel. Research for alloy development is needed.

- AISI type 305 for fasteners to be replaced by new 12-14 percent chromium austenitic stainless steel with 
342

equivalent work hardening characteristics. Research is needed.

Chromium usage is much greater after 1975 than that shown in Table 26 (chapter 5).

A substantial amount of chromium can be saved by replacing stainless steel mostly with existing materials. The only new materials are for exhaust valves and fasteners. These should be essentially lower chromium versions of the existing stainless steel grades.

It is believed that the substitutions recommended are feasible without any significant technical degradation. The life cycle of the car would, however, be decreased by the elimination of stainless steel and initial cost will be higher than for conventional vehicles. 
Appendix $\mathrm{J}$

COATINGS FOR PLASTICS

\section{J. 1 ELECTROPLATING}

This process typically involves an oxidizing acid etch, an activation step (e.g.. deposition of finely divided palladium), an electroless nickel deposit to make the surface conductive, and conventional electroplating such as duplex nickel covered by microcracked chromium. Approximately 2 grams of chromium is used per square meter of plated area. When properly applied, these electroplated coatings are durable, and they have gained general acceptance even in such demanding applications as exterior automotive trim.

\section{J. 2 VACUUM METALLIZING}

This process typically includes: a base coat that seals the plastic to prevent gassing in subsequent operations and provides a surface to which the metal film will adhere; a very thin. somewhat porous metal film; and a clear topcoat. Because of the thinness and porosity of the metal film, the adhesion of the topcoat is enhanced by penetration through this film to the base coat. The three principal deposition processes used for the metal film are filament evaporation, electron beam heating, and sputtering.

Filament evaporation generally is used for the vacuum deposition of aluminum; aluminum on tungsten is the source. Filament evaporation of refractory metals results in short filament life and relatively dark films. Alloy composition is difficult to control. There is extensive literature on this process (Holland 1956).

Electron beam heating is similar to filament evaporation except that the energy for the evaporation is delivered by an electron beam incident on the material to be evaporated. It has essentially the same limitations as filament evaporation (Modern plastics 1974).

In the case of ion sputtering, an ionized sheet of an easily ionizable gas (e.g.. argon) is confined near a cathode by a suitably shaped magnetic field. The impact of the ions on the surface of the cathode causes the surface to be eroded, and the removed material then is deposited on the workpiece. The main advantages of ion sputtering are that it is applicable to relatively refractory metals and that the composition of the material deposited on the workpiece 
is essentially the same as that of the surface of the cathode (Penfold and Thorton 1976).

J. 3 CHEMICAL VAPOR DEPOSITION

In chemical vapor deposition, the workpiece is introduced in a space containing the vapor of a volatile metal compound such as nickel carbonyl. Decomposition of the compound on the surface of the workpiece is achieved either thermally (by preheating the workpiece) or chemically

(by coating the workpiece with a substance capable of causing the decomposition of the volatile metal compound).

J. 4 PAINTING

A metallic appearance of a plastic may be produced by painting with a suitably pigmented paint such as the argent paints:

\section{J.5 ADHESIVELY BONDED METALLIC FILMS}

In the most common application, a three-part film consisting of a clear polymeric film, a thin aluminum foil, and a layer of pressure sensitive adhesive is prepared. This composite $\mathrm{film}$ then is bonded to the part to be coated so that the clear polymeric film is on the outside to provide protection. to the aluminum film, which in turn provides the bright, metallic appearance.

\section{REFERENCES}

Modern Plastics. "Restoring the Luster to Metallized Markets." Modern Plastics (1974):42-46.

Holland, L. Vacuum Deposition of Thin Films. Iondon: Chapman \& Hall, Ltd., 1956.

Penfold, A.S., and Thornton, J.A. "A Post Magnetron Sputtering System for Front Loading Chambers.." Paper presented at the Society of Vacuum Coaters 19th Annual Technical Conference, Toronto, Canada, May 11-13, 1976. 


\author{
Appendix $\mathrm{K}$ \\ ELIMINATION OF CHROMIUM FROM BRIGHT TRIM
}

Significant reduction in overall chromium use is achieved most readily by replacement of stainlesa steel compolients by anodized aluminum, painted steel, or metallized plastic. Elimination of chromium from bright. trim would require substitution of chrome-free alloy plating and metalizing or restyling to allow expanded use of anodized aluminum and painted steel trim. The issues involved are related primarily to styling although design changes would be necessary in some applications.

The chromium layer of standard nickel chromium plating is typically $0.00025 \mathrm{~mm}$ in thickness (American Society for Testing and Materials 1974), corresponding to about 2 grams of chromium per square meter of plated surface. Bumpers. bezels, and grilles (the large area chrome plated parts) thus account for only a small fraction of total chromium usage -- perhaps 10 grams of the 3.5 kilograms estimated for the average U.S. car in 1970 (Personal communication with N. Heller. Ford Mot or Company. 1976). Proposed metallizing processes based on chromium sputtering use thinner films than electroplating -- about $0.0001 \mathrm{~mm}$ or less (Product Finishing 1975): Stainless steels suitable for bright trim contain about 18 percent chromium by weight (Zapffe 1949); wheel covers alone can account for 400 grams or more chromium per car (Personal Communication with R. Dickie, Ford Motor Company, 1976).

Replacement of stainless steel by plated or painted steel or plastic or by anodized aluminum can result in major reductions in chromium usage. Elimination of chromium would require additional changes, as outlined below, for specific applications.

\title{
K. 1 BUMPERS
}

Bumpers currently are nickel-chromium electroplate. Chromium-free alternatives include:

1. Chromium-free alloy plating (e.g.. Ni-Sn); however; some sacrifice in performance (brittle and hard-to-remove rust deposits) and appearance (rosy color) would be likely (Brenner 1963)

2. Soft-face painted bumpers, but a major styling change would be involved 
3. Anodized alumi num; however, some sacrifice in performance (pitting) and appearance (yellowish color) would be involved (Hoover 1974)

K. 2 GRILLES, BEZELS, AND OUTSIDE REAR-VIEW MIRRORS

These parts currently are nickel-chromium electroplate. Alternatives include:

1. Argent paint

2. Anodized aluminum, but a design change would be needed in some cases to accommodate use of extrusions

3. Chromium-free plating or metallizing, but development work would be needed to prove feasibility and assess performance for plastic parts

\section{K. 3 WHEELCOVERS}

Stainless steel and anodized aluminum are both used currently. Some design modifications might be needed to meet strength requirements, but anodized aluminum or painted steel (currently used for trucks) could be substituted for stainless steel.

\section{K. 4 WINDSHIELD WIPER ARMS}

Stainless steel is currently used. Redesign might be needed to allow material substitution.

\section{K. 5 DOOR HANDLES}

Chrome-plated zinc die castings are used for abrasion characteristics as well as corrosion resistance and appearance. Alternatives include:

1. Anodized aluminum; however, design changes might be needed to accommodate use of extrusions

2. Chromium-free alloy plating

\section{K. 6 LETTERING AND EMBIEMS}

These usually are chrome-plated die-cast zinc, but they could be changed to:

1. Metallized plastic (possibly a second surface process as currently used for some emblems) 
2. Plastic-metal foil composite (in-mold decoration)

3. Chrome-free alloy plating

K.7 WINDOW SURROUND MOLDINGS, ROCKER PANEL MOIDINGS, BODY SIDE MOLDINGS

Some stainless steel is used, but the primary material is a nodized aluminum. Aluminum foil/plastic coextrudate has been proposed for window surround moldings.

K. 8 INTERIOR BRIGHT TRIM

Aluminum metallizing and hot stamping are used for much of the interior bright trim; door handles and dome lamp housing are chrome-plated. Alternatives include: metallized plastic, anodized aluminum, and chrome-free plating.

REFERENCES

American Society for Testing and Materials. "ASTM B456-71: Standard Specification for Electrodeposited Coatings of Nickel plus Chromium." In Annual Book of ASTM Standards. Philadelphia, Pa.: American Society for Testing and Materials, 1974.

Brenner, A., Electrodeposition of Alloys. Vol. II. New York: Academic Press, 1963.

Hoover, S., "Extruded Bumpers Score with Chevy." Metal proqress 105 (June 1974): 45 .

Product Finishing. "Vacuum Metalized Auto Grilles for 176 Models," Product_Finishing 40 (November 1975): 80 .

Zapffe, C.A., Stainless Steels. Cleveland, Ohio: American Society for Metals, 1949. 


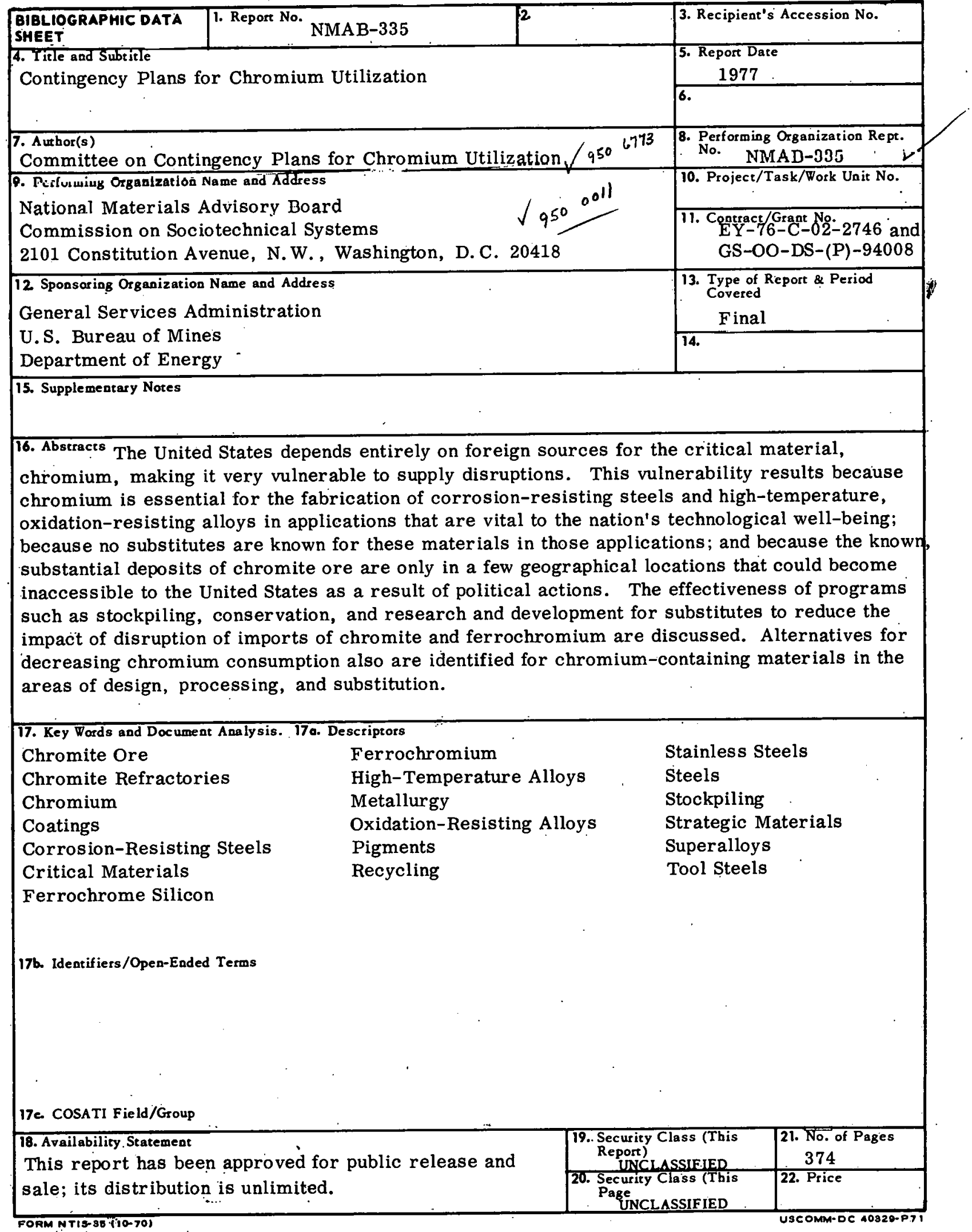

